\title{
WestVirginiaUniversity
}

THE RESEARCH REPOSITORY @ WVU

Graduate Theses, Dissertations, and Problem Reports

2016

\section{Resistance, Agency and Violence: Dalit Women's Education in Kerala, India}

\author{
Sera A. Mathew
}

Follow this and additional works at: https://researchrepository.wvu.edu/etd

\section{Recommended Citation}

Mathew, Sera A., "Resistance, Agency and Violence: Dalit Women's Education in Kerala, India" (2016). Graduate Theses, Dissertations, and Problem Reports. 6175.

https://researchrepository.wvu.edu/etd/6175

This Dissertation is protected by copyright and/or related rights. It has been brought to you by the The Research Repository @ WVU with permission from the rights-holder(s). You are free to use this Dissertation in any way that is permitted by the copyright and related rights legislation that applies to your use. For other uses you must obtain permission from the rights-holder(s) directly, unless additional rights are indicated by a Creative Commons license in the record and/ or on the work itself. This Dissertation has been accepted for inclusion in WVU Graduate Theses, Dissertations, and Problem Reports collection by an authorized administrator of The Research Repository @ WVU.

For more information, please contact researchrepository@mail.wvu.edu. 


\title{
Resistance, Agency and Violence: Dalit Women's Education in Kerala, India
}

\author{
Sera A. Mathew \\ Dissertation submitted \\ to the College of Education and Human Services \\ at West Virginia University \\ in partial fulfillment of the requirements for the degree of \\ Doctor of Philosophy in \\ Education, Interdisciplinary \\ Melissa Sherfinski, Ph.D. Co-Chair \\ Ann Oberhauser, Ph.D. Co-Chair \\ Carol Markstrom, Ph.D. \\ Sharon Hayes, Ph.D. \\ Audra Slocum, Ph.D. \\ Department of Curriculum \& Instruction \\ Morgantown, West Virginia \\ 2016
}

Keywords: Kerala, Women's Education, Dalit, Agency

Copyright 2016 Sera Mathew 


\section{ABSTRACT \\ Resistance, Agency and Violence: Dalit Women's Education in Kerala, India \\ Sera A. Mathew}

This dissertation is a critical feminist analysis of the discourses, narratives and hegemonic power structures that define Dalit women's lives in Kerala, India. It focuses on intergenerational narratives of women and girls to illuminate how Dalit communities navigate development by specifically focusing on their educational narratives. To explore Dalit narratives, I conducted fieldwork in Kerala using in-depth interviews, photovoice, and participant observation as primary data. I coupled my primary data with secondary data sources such as development reports, trend data and newspapers to document how Dalit needs are framed. This research uses postcolonial feminist theory as it applies to the Kerala context along with intersectionality of identities as a conceptual framework to understand how gender, class, caste and religion shape Dalit women's education across different generations.

The findings of this study speak to three specific themes: (1) the material and social locations held by women and girls in the Dalit communities, (2) the neoliberal forces shaping Kerala's education, and (3) the patriarchal forces in the context of marriage and gender-based violence in Dalit homes, communities and schools. This research exposes the gendered subjectivities and vulnerabilities that Dalit women navigate through resistance, agency and power. Thus, by offering a contextualized place-based study of Dalit lives in Kerala, I argue that the discourses and practices of development in Kerala have failed to attend to Dalit needs. 
To

Matty

Nandu

Chuttichayan

bahut sara pyar 


\section{Acknowledgments}

Dr. Melissa Sherfinski, thank you for being a wonderfully astute and patient advisor. Your feedback through this whole process helped expand my critical thinking about inequalities. Dr. O., thank you for your guidance, support and care through my journey as a graduate student and especially through the dissertation process. I am deeply indebted to the feminist space that you created in your classroom that helped me grapple with postcolonial contexts and theory. To the rest of my committee, Dr. Hayes, Dr. Markstrom and Dr. Slocum, thank you for your support and advice along with your enthusiasm to talk and engage with me through the development of my dissertation. The dissertation fieldwork was made possible by grants from the College of Education and Human Services at West Virginia University (WVU). Also, I would like to thank the Program Evaluation and Research Center at WVU and the Center for Women's and Gender Studies at WVU for providing me with graduate funding.

And finally, much gratitude and love to my family and friends both near and far for being an indispensable source of strength and sustenance for me. Thank you for being my village. 


\section{Table of Contents}

\section{ABSTRACT}

Table of Tables vii

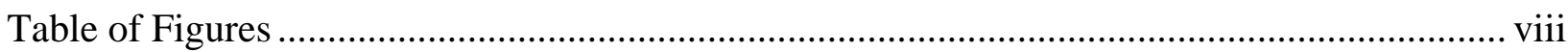

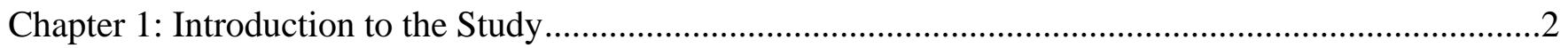

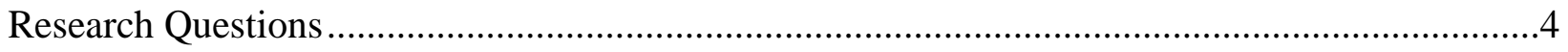

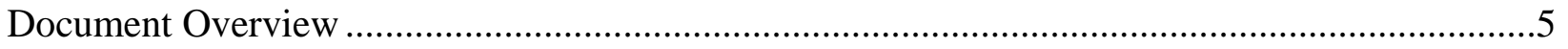

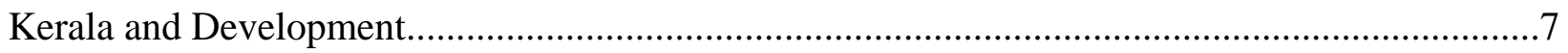

Social Context Of Kerala (Gender, Caste, Class And Religion) .............................................15

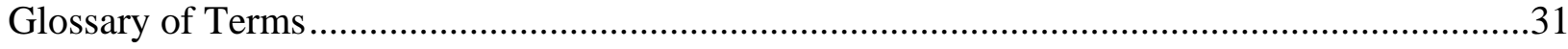

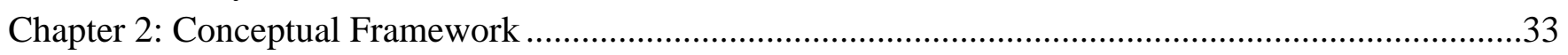

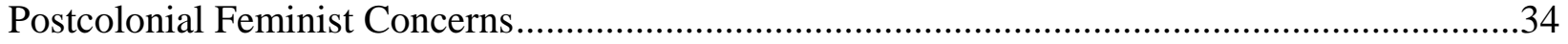

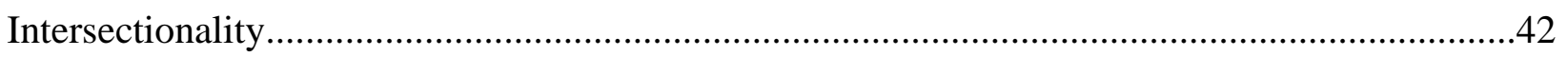

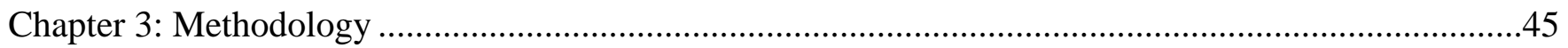

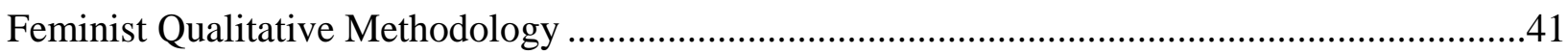

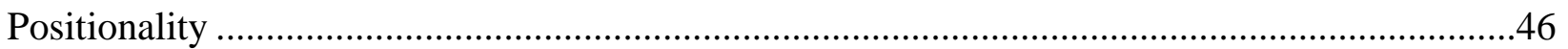

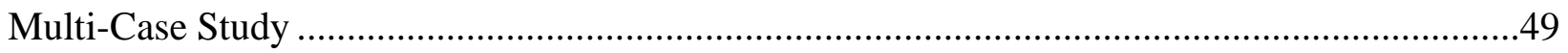

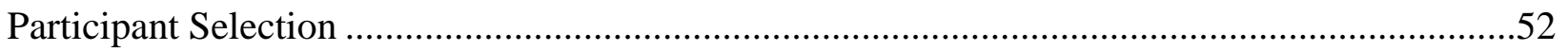

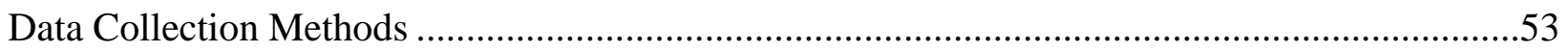

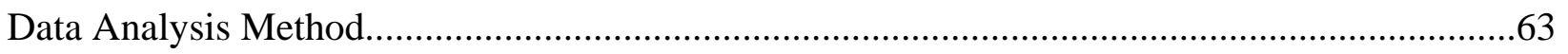

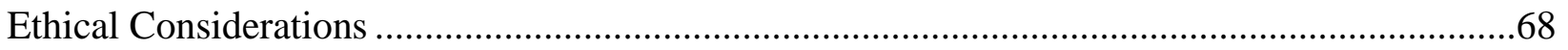

Profiles of the Women and Girls, and Family Trees ..........................................................69

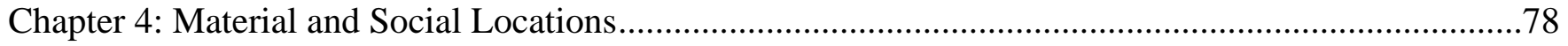

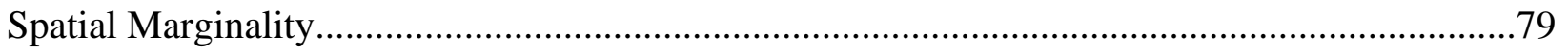

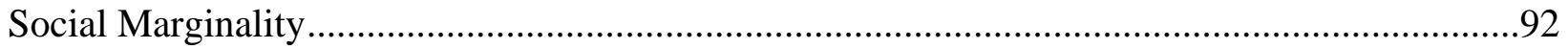

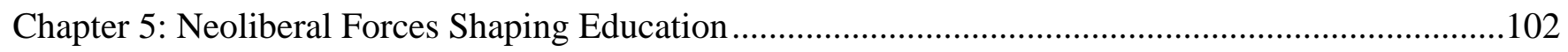

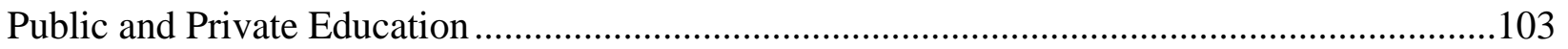

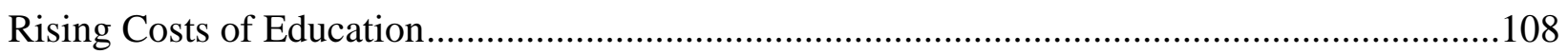

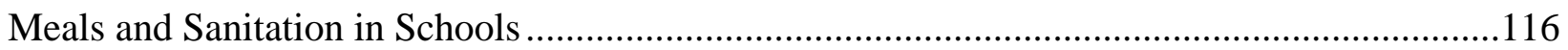

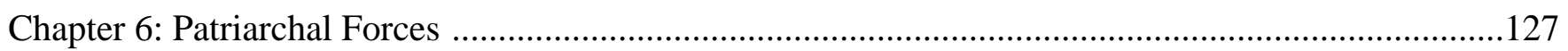

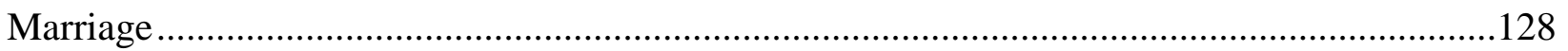

Negating Safe Spaces: Violence in Home and Community ................................................135

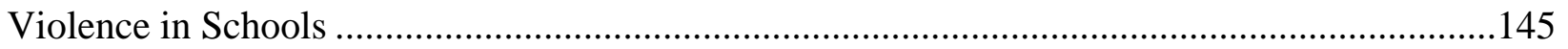

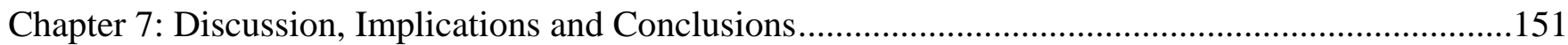

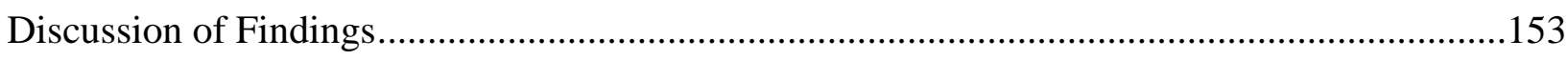

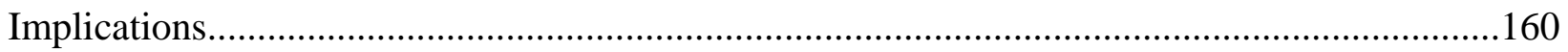

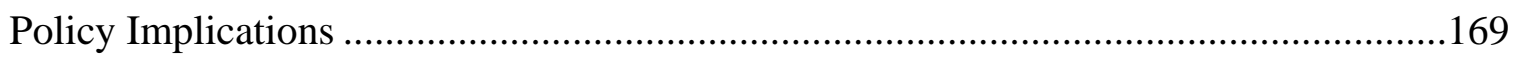

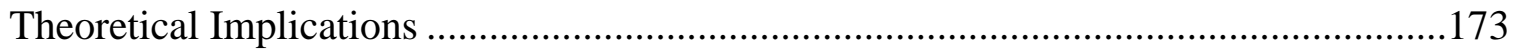

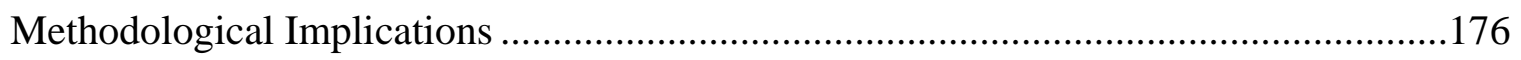




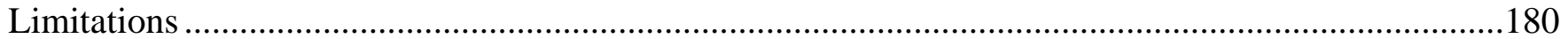

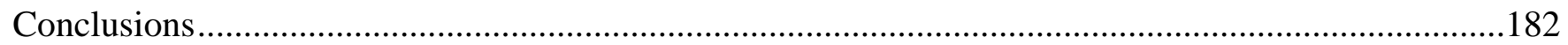

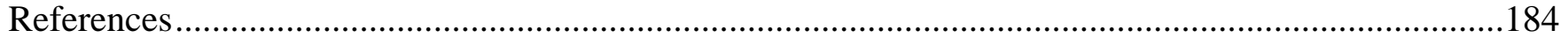

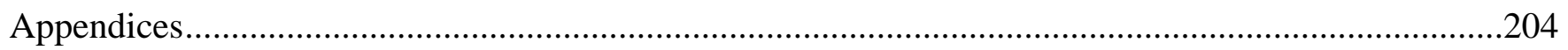




\section{Table of Tables}

Table 1: Attributes as Related to Gender......................................................................... 17

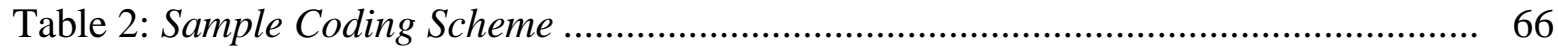

Table 3: Generic Intersectionality Template ............................................................. 67

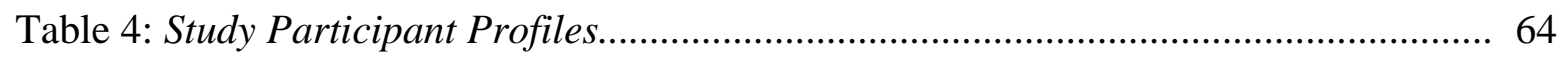

Table 5: List of Private Cost ................................................................................. 109

Table 6: Average Total Private Cost of School Education............................................. 109

Table 7: Major Reform Bills ........................................................................... 161

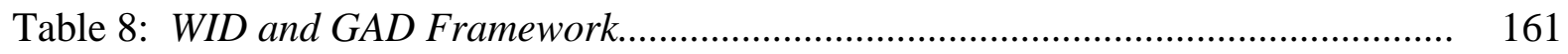

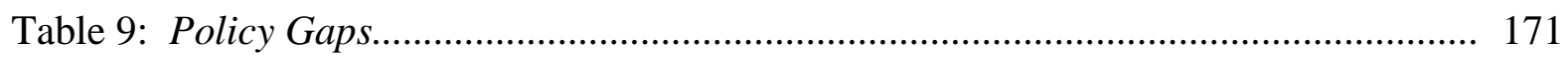




\section{Table of Figures}

Figure 1: The Indian Caste System................................................................... 19

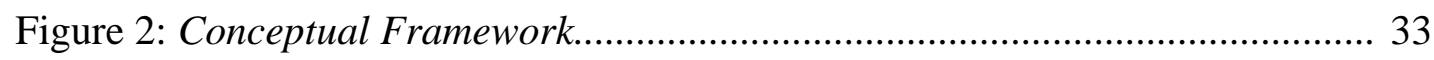

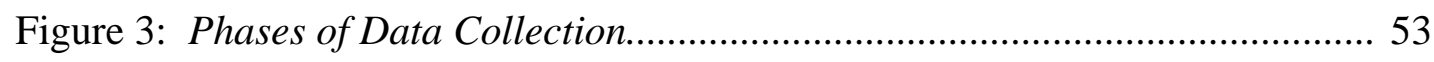

Figure 4: My Field Journal..................................................................... 59

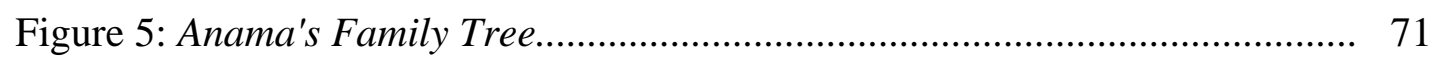

Figure 6: Lila's Family Tree ...................................................................... 72

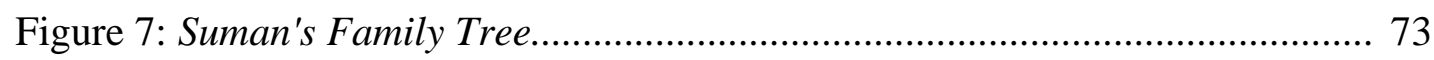

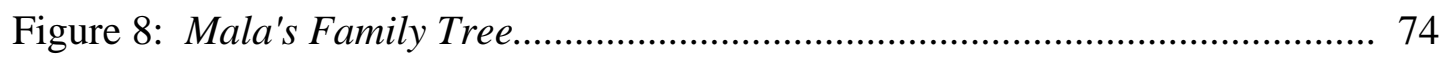

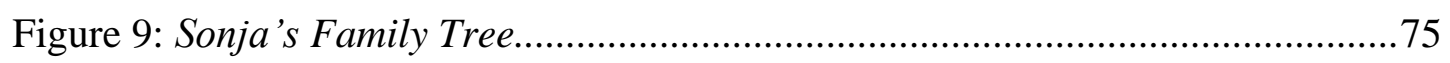

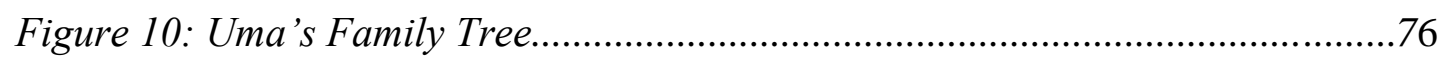

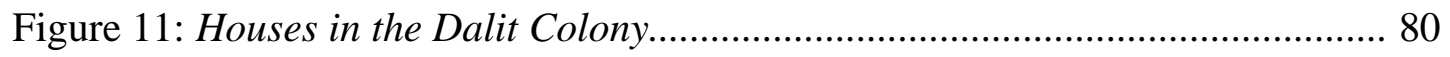

Figure 12 Newspaper Article ...................................................................... 82

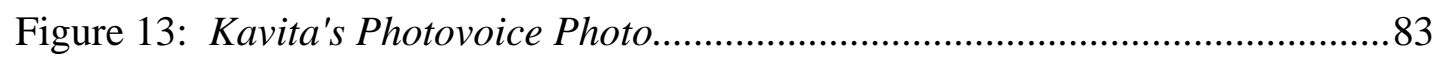

Figure 14: Kavita's Photovoice Photo.......................................................... 83

Figure 15: Kavita's Photovoice Photo............................................................ 84

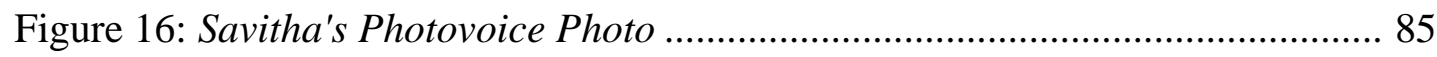

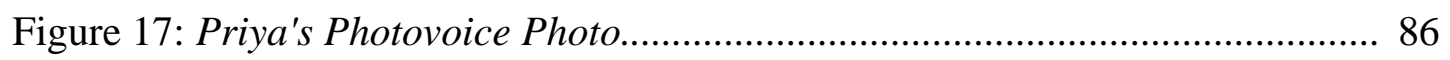

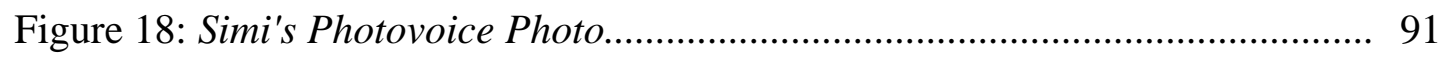

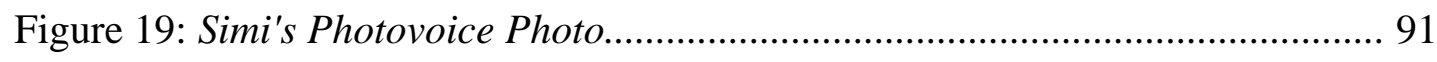

Figure 20: Type of Schools in Kerala ............................................................... 104

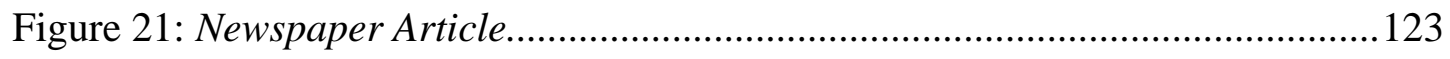

Figure 22: Matrimonial in Newspaper............................................................ 129

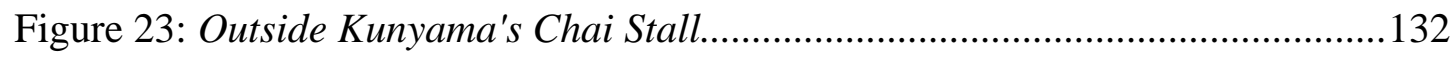

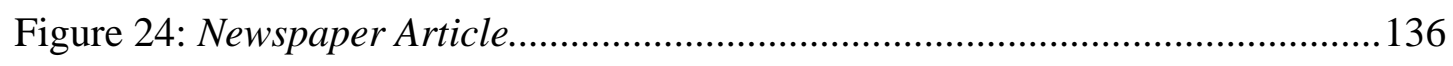

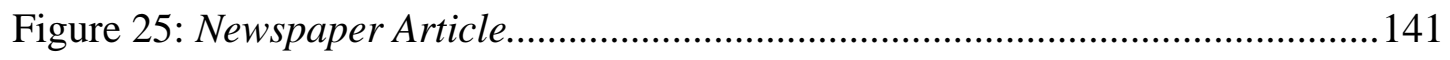




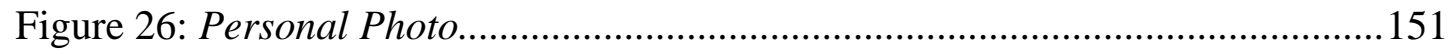

Figure 28: Framing, Limiting and Controlling .....................................................156

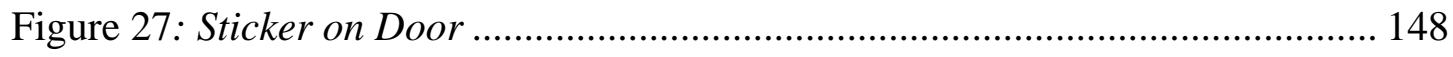

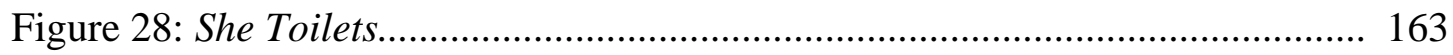




\section{With Love "Pranayapoorvam"1}

Saumini,

Didn't you say that black is beautiful

And haven't the poets sung so too

How then were Blacks disgraced?

Not we the ones who drink and drain sweat and blood

We are the ones who melt

We are not caressed

By the blazing flames of the sun

Or the blistering red-hot earth

Amme, we Blacks lack space

to hide under your wings

We are being shooed away

By Dalit poet G. Sasi Madhuraveli

1 The Oxford India Anthology of Malayalam Dalit Writing (2012). 


\section{Chapter 1}

\section{Introduction to the Study}

This dissertation examines Dalit women's educational experiences in the context of Kerala's development initiatives. It focuses on intergenerational narratives of women and girls from the Pathanamthitta District in Kerala. In Governments and Culture: How Women Made Kerala Literate, Jeffery (1987) addresses the important place that women held in early Kerala society along with their fundamental role in nation building by suggesting that "literate men have literate sons, literate women have literate children in Kerala" (p. 462). This narrative is still seen in present day Kerala with women's education being an essential element of the Kerala government's development initiatives.

Kerala's achievements have been extensively celebrated in the development literature (Dreze \& Sen, 2002; Sen, 2000). This praise has given rise to the profile of Kerala as a "Model of Development" with high indicators of development such as low birth rates, low infant and maternal mortality, high adult literacy ${ }^{2}$ and health care access higher than most countries in Asia and Africa, and comparable to those of some developed countries. However, this Model of Development has also been critiqued by many researchers for its lack of gender sensitivity and the systematic marginalization of communities such as the Dalits (Devika, 2010; Rammohan, 2008; Raj, 2013). The Dalit communities have been cited as "outliers in development" based on the poverty, exclusion from education initiatives, lack of employment, lack of social mobility and landlessness that they have experienced across generations (Devika, 2010; Padmanabhan, 2010; Rammohan, 2008; Raj, 2013). In the context of education specifically, despite having

\footnotetext{
${ }^{2}$ Refers to the definition of literacy in the Indian census, which is anyone who can read and write in any Indian language.
} 
wide-ranging state sponsored formal and non-formal educational initiatives, the Dalit communities has not profited from them (Padmanabhan, 2010). Research suggests that a failure of the state to take into account the complexity of gender, caste, and class as shaping forces in the lives of Dalit women in Kerala has contributed to this exclusion from development (Devika, 2010; Padmanabhan, 2010). This research seeks to understand educational experiences among Dalit women as they are influenced by the intersection of gender, caste, class and religion.

Furthermore, the Dalit communities in Kerala have also been framed as submissive stateaide receiving groups who have failed to utilize the initiatives that the government has created for them (Devika, 2010). However, this narrative has been challenged in the literature as Dalit women are seen as active agents in their communities and families, working tirelessly for justice and equality in a system that has often failed to include them (Raj, 2013). Seleena Parkkanam, a prominent Dalit female activist in the Dalit Human Rights Movement in Kerala, addresses the disparities faced by her people, stating that:

From childhood I have always felt deeply for my people, never have I wanted to follow the ways of those who were above us. As a child I could see, we did the hardest, most taxing work. Such hard work, the body itself became worn and weak. Our mothers slaved in other people's kitchens. And we had nothing, others seemed to have everything. They commanded, made us work, and my people took orders. True, it was for wages, but I could not see anything more than slavery there. All they lacked was the whip. (Devika, 2014, p. 41)

This dissertation seeks to illuminate how Dalit women and girls navigate development in Kerala by specifically focusing on their educational narratives. By doing so, it aims to explicate 
the actions of these women and girls as social agents working within institutional and societal structures in postcolonial Kerala. Dalit women's experiences in Kerala have been distorted and obliterated in development narratives about Kerala (Raj, 2013). As a step towards understanding Dalit women's educational experiences, this dissertation combines two conceptual and analytic tools: postcolonial feminist theory and intersectionality. Postcolonial feminist theory conceptualizes women's position and representation in developing societies. It also challenges colonist knowledge creation and helps to analyze women's experiences in the context of their social and historical positions (Mohanty, 2003). Intersectionality helps to raise questions on the multiple systems of powers that interact and interlock to shape Dalit women's narratives and experiences. In doing so, intersectionality draws attention to the way that multiple forms of power relations such as gender, caste, class and religion influence women's education in Kerala.

\section{Research Questions}

The following research questions outline how this dissertation will critically explore Dalit women's educational intergenerational experiences in the Pathanamthitta District in Kerala, India:

1. How do the intersections of gender, caste, class and religion shape Dalit women and girls' educational experiences in their families and communities?

2. What is the process of inclusion and exclusion of Dalit women and girls in state sponsored formal and non-formal education initiatives?

3. What are the implications of state-sponsored formal and non-formal education initiatives for Dalit women and girls? 
In order to answer these questions, Dalit women and girls were recruited and data collection was conducted over a two-month period using in-depth interviewing, participant observations and photovoice. This study also reviewed existing secondary data such as policy documents, trend data and Kerala newspaper articles. Feminist values and principles guided the methodology and approaches to data collection in this study.

\section{Document Overview}

This dissertation is divided into seven chapters. The second section of Chapter 1 provides an overview of the social, political and cultural factors in the past and present that shape Kerala's development. This section contextualizes and historicizes the creation of the modern state of Kerala. It focuses on the education initiatives in Kerala and specifically the gendered nature of education in the state. Furthermore, this chapter discusses the caste system in India and how caste interacts with gender, class and religion to shape Dalit lives in India and within the Kerala context. It subsequently narrows the discussion about the Dalit community's experiences in Kerala and addresses the inclusion and exclusion of Dalits in Kerala's educational system. Chapter 2 focuses on the conceptual framework of this dissertation. It provides an overview of postcolonial feminist theory as it applies to the Kerala context and explains how intersectionality serves as an appropriate conceptual framework in understanding how gender, class, caste and religion shape Dalit women's education across different generations. Chapter 3 describes the methods and how feminist qualitative methodology guides the research questions. Chapters 4, 5, and 6 present a detailed analysis of the data in this study. Chapter 4 is a discussion of social and material locations of the Dalit community in Kerala. It addresses themes about spatial and social marginality. I demonstrate how Dalit women and girls navigate conditions of poverty, lack of 
amenities and landlessness. I specifically emphasize how spatial and social marginality has severe gendered consequences for Dalit women and girls, which subsequently results in shaping their educational engagement and access. Chapter 5 is a discussion of the neoliberal forces that shape Dalit women's education. It addresses and highlights issues regarding privatization, costs and hidden equity issues in the context of Kerala's education system. It also explores the deficiencies in school amenities, for example meals and sanitation, in the school system. Chapter 6 is a discussion of the patriarchal forces shaping Dalit women's lives in Kerala. I use this sixth chapter to highlight how marriage and domestic violence in the homes and communities coupled with corporal punishment in schools negates spaces for women and girls in the Dalit community. Thus, I emphasize, that Chapters 4, 5, and 6 serve as reminders that Dalit lives in Kerala are not only shaped by their marginality but are also shaped by their agency, resistance and power. Chapter 7 explores the implications, limitations and conclusions of this study. In the context of implications, I explore policy, theoretical, and methodological implications. The policy implications revisit the larger development literature and this section explores gaps in blanket development policies that lack critical consideration of Dalit needs. The theoretical implications highlight how accounting for Dalit women's and girls' multiple identities along with the multiple systems and structures that they work within and against is essential for contextualizing Dalit lives. The methodological implications discuss reframing questions, probing memories, and accounting for silence in fieldwork. This chapter concludes with limitations that were faced during data collection and a summary of the study's findings. 


\section{Background and Literature Review}

\section{Kerala and Development: Creation of Kerala's Modernity}

Kerala is located at the Southwest tip of the Indian peninsula, a narrow strip of land along the Arabian Sea. It is often referred to as the "Land of Coconuts" and "God's own country" for its picturesque beaches, backwaters and countryside. The modern state of Kerala was created in 1956 as a result of the unification of three distinct provinces of Malabar and the princely states of Cochin and Travancore due to the reorganization of states based on their language. Malayalam is the main language of the region and the people of this region are commonly referred to as Malayalis. The prominent gender belief in the region categorizes men as the providers and women as the caretakers of the home (Hapke, 2013). There have been many community movements and reform movements that were influential in the creation of modern governable subjects (Devika, 2010). One of the earliest traditions that celebrated the position of women in Kerala society was Marumakkathayam (the matrilineal system of inheritance of property), which was a common practice among the Hindu families. However, this tradition was challenged by Hindu men who wanted to relegate this tradition to the past with the advent of colonization (Menon, 2008). This is an early example of the cultural changes, which highlighted the coming together of the influence of colonization, patriarchy and influx of Western tenets in early Kerala society (George, 2011).

In 1957, Kerala became the first state in the world to democratically elect a communist government with the Communist Party ${ }^{3}$ of India (Marxist) coming to power. Sharmila Sreekumar in her book Scripting Lives: Narratives of Dominant Women in Kerala lists the four

\footnotetext{
${ }^{3}$ Except San Marino.
} 
most commonly cited reasons for Kerala's modernity as: (a) the benevolent monarchies, (b) the Christian Missionaries, (c) the Left movements, and (d) the social reform movements of the late nineteenth and early twentieth century (p. 73). The British advised the monarchies in the region to embark on modernizing reforms and the monarchies followed suit with land reforms and the expansion of education and healthcare in the region. By way of illustration, Desai (2005) in her exploration of the legacy of welfare in this region, states:

Kerala's welfare legacy was thus contradictory_it was simultaneously modernizing but within a dependent colonial context. Its consequences, largely unintended, opened up and revealed the fault lines of a status segregated, neocolonial regime. (p. 464)

Desai highlights how early reform movements spearheaded by the monarchies in the region were also a result of the strong hand of colonization and its quest for commercialization and capitalist infiltration. Additionally, she also addresses the racist and evangelizing agenda of missionaries who focused on the poorest in the colonies (Comaroff and Comaroff, 1991 as cited by Desai, 2005). This highlights the "liminal position" held by missionaries in this region, as they campaigned for reforms in the region but under their vested interest of religious conversion. Additionally, the Left has been cited in the region as playing a key role in the creation of the Kerala Model of Development through the establishment of an extensive network of social security policies. Desai (2005) asserts that their policies included extending access to land, education, and wages to the most marginalized in Kerala society. Thus, the influence of the monarchies, missionaries, the Left and early reform movement continue to shape the modern state of Kerala and its policies. 


\section{Education in Kerala}

Education in Kerala has always been called exceptional for its achievements of access to schools in rural communities along with greater representation of women in education and higher literacy rates (Kumar \& George, 2008). Jeffery (1987) emphasizes four reasons why the education system in postcolonial Kerala was different from the rest of India. First, Kerala's educational system is based on the local old village school through and after the British rule. Second, the curriculum followed in these schools focuses on recitation instead of reading and writing as forms of literacy. Teaching the community to read and write was not the only purpose of schooling. Third, the enrollment of both girls and boys in schools signifies the freedom offered to women in Kerala. And fourth, "modern" instruction is provided to the students in vernacular local languages instead of English. Thus, even in present day Kerala, we see an extensive network of schools that continue to use Malayalam instruction.

Saradamoni (1994), addressing women's education in Kerala, states "that an average girl today may spend more time in the name of education than her mother would have and most other girls elsewhere in India" (p. 503). As a step towards furthering this dialogue, I draw on Devika and Mukherjee's (2007) feminist examination of the early roots of women's education in Kerala. Education initiatives extend beyond formal schooling in Kerala. They include initiatives by nonformal reformist movements, churches and women's organizations. The authors suggest that women's education in Malayali society was motivated by assertions of "civilizing the natives" ( $p$. 104) coupled with being a venture in "proper gendering" (p. 104). Notions of female domesticity were viewed as redemptive for society as a whole, insinuating that women reached their full gendered potential by carrying out their domestic duties. Despite the inherent nature of these skills, women were positioned as needing skill refinement through training and education. 
Devika and Mukherjee posit that this need for refinement of gendered abilities and mindsets was an essential motivating factor for the spread of women's education in Kerala. Additionally, the idea that women could expedite the running of modern society through social management also gained momentum. This led to the creation of jobs in which women used their intrinsic capacity as caring, loving disciplinarians in schools and hospitals along with reputed persuasion skills that were found useful in political realms in Kerala. Along with the gendered division of labor as a direct consequence of women's education in Kerala, Devika and Mukherjee (2007) state that a matter of urgent consideration is the "double expectation" on women in contemporary Kerala. Women are required now to do as well as boys in school along with conforming to societies' feminine ideas of domesticity. This pressure was also addressed in Mitra and Singh's (2006) study which revealed the major cause of female suicides in Kerala according to the State's Crime Record's Bureau as poor academic performance in examinations followed by unhappy relationships, damaged social reputation, illegitimate pregnancy and dowry disputes.

In Kerala, families and society as a whole monitor women's schooling and work decisions as a way to ensure marriage prospects for women (Eapen \& Kodoth, 2002). The patrifocal family's interests are prominent in this context. Therefore, the goal is to enhance women's abilities as wives and mothers, and to contribute to the financial security while fortifying the patrifocal system (Eapen \& Kodoth, 2002). This draws attention to the hegemonic tendencies of the State and the manifold patriarchies that shape women's identities and subjectivities in Kerala.

Kerala has an extensive formal and non-formal education system. This dissertation uses Comb, Prosser, and Ahmed's (1973) definitions for formal and non-formal education. In the context of this research, formal education is defined as "institutionalized chronologically graded 
and hierarchically structured educational system, spanning lower primary school and the upper reaches of the university" (Comb, Prosser, \& Ahmed, p. 8). Non-formal education is defined as "any organized, systematic, educational activity carried on outside the framework of the formal schooling system to provide selected types of learning to particular subgroups in the population" (Comb, Prosser, \& Ahmed, p. 8).

Kerala's formal education system follows a $10+2+3$ system, in which ten years of basic education includes four years of lower primary (classes ${ }^{4}$ one to four), three years of upper primary (classes five to seven) and three years of lower secondary education (classes eight to ten). Following which there are two years of upper secondary and three years of higher education (Mukundan \& Bray, 2004, p. 229). Additionally, educational institutions across Kerala are divided into government, government aided (private schools aided by government funds) and private (unaided by government) designations. The medium of instruction in most private schools is English while government schools have both English and Malayalam as medium of instruction.

According to the Directorate of Public Instruction (2006) there has been a drop in enrollment in government and government aided schools across Kerala over the years (Retnakumar \& Arokiasamy, 2006). There is a lack of consensus among researchers about why this decline has occurred. Despite there being a decrease in enrollment in government and government unaided schools, there has only been a very small increase in enrollment numbers in private schools in Kerala (Retnakumar \& Arokiasamy, 2006). Some researchers have also attributed this change in enrollment across Kerala to demographic shifts, i.e. the drop in fertility

\footnotetext{
${ }^{4}$ Classes or grades.
} 
across the state and the subsequent drop in numbers of school aged children (Retnakumar \& Arokiasamy, 2006).

According to the Kerala State Planning Board, mostly all government schools in Kerala are in pucca ${ }^{5}$ buildings. However, there are disparities reported in school infrastructure and teacher quality between government schools and private schools across Kerala (Retnakumar \& Arokiasamy, 2006). Often government schools are praised for having even basic infrastructure. It was reported that according to the data available in 2011 from the Kerala State Planning Board, 98.4\% of government schools have access to drinking water and $99.49 \%$ of government schools have proper sanitation. There is a lack of documentation about quality of teaching, qualification and retention of teachers, skills attained by students, student participation, etc. in government schools or government aided schools in Kerala, as the conversation often stops at the provision of drinking water and sanitation. This is despite Kerala's extensive education budget. A 2013 article from one of India's Leading News Magazines, India Today, states "Kerala remains the country's best state in the field of education." The article praised Kerala's budget for education:

No state except Kerala has earmarked as much as 40 percent of its annual budget for education. The results: Full literacy, near-full enrolment, highest ratio of educational institutions and teachers to population, lowest dropout rate, pucca buildings for all schools. Most remarkably, all these achievements cut across class, religion, caste, gender and rural-urban divides. (Radhakrishnan, 2013)

However, this praise has been challenged in the literature. For example, Kumar and George (2009) address present day Kerala's education system, explaining its transition from an

\footnotetext{
${ }^{5}$ Concrete buildings.
} 
inclusive system to an exclusive one that hosts a plethora of hidden equity issues. The inclusive factors of Kerala's schools include features like the widespread access to education in rural communities. This, along with a versatile and widespread transportation system in Kerala, allows for easier access to school for rural students if they choose to travel to other parts of the region for education. Another aspect of the widespread government-owned and funded schools is that there are no fees at any of the levels in schools. However, the authors also highlight exclusionary trends in the education system, which have been revealed by numerous micro-level studies. These include how the lack of school fees does not necessarily translate into low costs incurred by students. For example, the cost faced by students include special fees, examination costs, school supplies, clothing, travel, personal tuition, and donations to parent-teacher associations to list a few of many. Another key exclusionary trend seen in the propagation of private agencies was unaided schools, which are not government aided, which has resulted in the commercialization of education in the region. There are also non-financial entry barriers for students from Malayalam medium ${ }^{6}$ schools; government and rural schools struggle to be represented in professional courses with high fees and entrance exams, which require expensive tutoring classes and are often in English. The authors also highlight the lack of inclusivity to “disadvantaged groups" such as scheduled castes and scheduled tribes, which are groups of historically disenfranchised groups as recognized by the Indian Constitution. Kumar and George (2009) thus highlight the "commercialization, communalization and politicization" (p. 60) of the education system in Kerala.

Besides formal education initiatives, Kerala also has an extensive network of non-formal education. According to Abraham (2010), Kerala's non-formal education system started around

\footnotetext{
${ }^{6}$ Malayalam as the medium of instruction.
} 
the temples as early as the $18^{\text {th }}$ century. Abraham attributes the roots of this non-formal education system focused on educating women to the matriarchal system among the Nayar caste ${ }^{7}$ in Kerala. Abraham states, "The status of women in the family was raised and they were given the opportunity to learn in the native local "Kudippallikkudoms" (schools) run by the Asans (masters) (p .61). This provided women in the Nayar community access to non-formal education. However, the non-formal education system spread across other castes under the Kerala Granthasala Sangham ${ }^{8}$ in 1945, which advocated for adult education for individuals who dropped out, or for elderly members of society who wanted to learn (Abraham, 2010).

In the context of present day non-formal education, the Kerala State Literacy Mission Authority (KSLMA) under the Government of Kerala has an extensive network of literacy and equivalency programs. According to the KSLMA, equivalency programs cater to neo-literates ${ }^{9}$ who were unable to complete their education in the formal education system and want to continue their education. There are three phases of equivalency that have been implemented: standards four, seven and ten. Starting in January of 2014, the state government has implemented standard ${ }^{10}$ twelve equivalency programs. A 2008 newspaper article in India's leading newspaper, The Hindustan Times, entitled "With age no bar, non-formal education a hit in Kerala" highlights the story of M. M. Jameela, a 50-year-old woman who hopes to complete her 10-standard equivalency. Jameela, sharing her story, states, "I had to discontinue my schooling after class seven. I got married when I was fifteen. Now I am grandmother. But I want to study 'til my death." The article described how Jameela attended equivalency classes that start at 9 a.m. and

\footnotetext{
${ }^{7}$ The caste system is extensively described later in this chapter. Nayar is one of the upper castes in Kerala.

${ }^{8}$ Kerala State Library Council.

${ }^{9}$ According to the UNICEF, "neo literates" are adults or adolescents who have not been able to make use of educational opportunities and at a later stage seek to gain education through either formal or non-formal education.

${ }^{10}$ Standard means grade or class.
} 
run until 5 p.m. on the second Saturday and Sunday of every month. Individuals that complete the various levels of equivalency qualify for further education and promotions in government jobs.

Other programs under KSLMA include income-generating programs that link literacy to employment. KSLMA has programs such as umbrella making, basket weaving, soap making, tailoring, etc. Another set of programs under KSLMA is the Quality of Life Improvement programs which address community health and outreach and focus on nutrition, sanitation etc. However, despite the extensive network of governmental initiatives in Kerala, non-governmental agencies spearhead the non-formal educational efforts (Abraham, 2010).

\section{Social Context of Kerala's Development}

\section{Gender Concerns in Kerala}

Women in Kerala have been hailed as enjoying high status based on conventional gender development indicators such as female literacy and health status indicators (Mukhopadhyay, 2007). However, studies have also shown that women in Kerala fared poorly in non-conventional indicators, which attempted to capture issues surrounding power, mobility and decision making (Rajan \& Sreerupa, 2007).

The framing of women's development in Kerala using only conventional indicators has been challenged in the literature. Mukhopadhyay (2007) addresses these limitations in her analysis of the Kerala woman where women can work but often have no power over finances, and secluded widowhood in Kerala may be guised as longevity for women. She also discusses the maxim from Hindu sacred writing, Manusmitri, which gives women the guidance to be subservient to their fathers as children, their husbands as adults and their sons when they age. 
Messages of women's subordination such as these problematize gender indicators that fail to account for women's subjectivities in patriarchal societies such as Kerala. She highlights the need to address context and women's agency while using indicators such as literacy, longevity and participation in the labor market as measures of women's progress. Thus, there is a growing unrest in the feminist and development narratives about Kerala (Devika \& Mukerjee, 2007; George, 2011; Hapke, 2013; Mukhopadhyay, 2007). This unrest has been caused by an emergent body of research on how Kerala is the land of gender paradoxes with one of the lowest female labor force participation rates in the country along with high discrimination against educated women in a gendered labor market (Mitra \& Singh, 2006). Furthermore, the rising rates of suicide, female depression and violence against women in the state have become a matter of grave concern in the region (Mitra \& Singh, 2006).

Hapke (2013) states that to comprehend this gender paradox, one must turn to theorizing patriarchy in Kerala. She suggests that the deeply engrained patriarchal system governs social programs and incentives. These, in turn, facilitate the process of creating modern gendered citizens. Along the same lines, Devika (2010) also argues that to be able to truly understand hegemonic discourses of development and social progress, it is imperative to understand how the state's mission of welfarism aims to create ideal gendered subjects. Devika highlights how the primary mandate of social reform is the creation and restoration of individuals to their true gendered selves which increased gender division and inequalities: "Women, therefore have been directed towards womanly capacities, usually implicated in the domestic domain or low pay and low skill, heavy workloads outside" (p. 276). Devika (2010) states that women are able to acquire full agency only after they had undergone self-transformation. Until then, they were under the reformers' protection and instruction. The modernization of people in the region has 
been focused on creating a desexualized and fertile ideal of womanhood. Devika contends that this ideal woman is the center and driving power of the modern home in Kerala.

However, gender does not work in isolation as demonstrated by Linderg (2001). Linderg, in her intergenerational analysis of class consciousness and identity in female cashew workers from the 1930's to the present decade in Kerala, asserts the interplay of gender, class and caste. She states "People have multiple identities which fluctuate, overlap and are fragmented, dynamic, ambiguous and sometimes conflicting. It may, for example, conflict to be a high caste and yet be a member of the working class, to be woman and a worker, or to be mother and a trade union leader. Identities are historicized and culturally formed” (p. 162). Further demonstrating this, Linderg suggests that the women that she studied underwent a process she calls effeminization, which is attributing feminine qualities to women. Linderg lists various dichotomous attributes related to gender that she observed in her work in the Kerala context (Table 1).

Table 1

Attributes as Related to Gender in the Kerala Context

\begin{tabular}{ll}
\hline Femininity & Masculinity \\
\hline Bodily attributes (work -related) & \\
\hline Weakness & Strength \\
\hline Dexterity & Awkwardness \\
\hline Untechnical & Technically-minded \\
\hline Mental attributes (connected to relations) & \\
\hline Patient & Impatient \\
\hline Docile & Unruly \\
\hline
\end{tabular}




\begin{tabular}{ll}
\hline Loyal & Rebellious/ Faithless \\
\hline Home-orientated & Outgoing \\
\hline Timid & Fearless \\
\hline Resultant attributes (connected to way of living) \\
\hline Dependent & Supportive (breadwinner) \\
\hline Helpless & Protecting \\
\hline Nurturing/emotional & Political/Radical \\
\hline
\end{tabular}

Note: Lindberg (2001), p. 180

Linderg's (2001) work with the cashew workers is seminal in the context of gender, class and caste analysis in Kerala as it demonstrates how the process of effeminization has resulted in women being seen as outsiders of the working class and taking on primary roles as housewives. Caste complicated women's representation and action; for example, Linderg suggests that lower caste women workers are also influenced by the process of effeminization that has limited class identity and the potential for action in the factories that they work in. Caste identity continues to be a powerful force among the three generations of women that Linderg interviews. She asserts that caste division of labor continues among men and women in the factories but states that "differences in wages are only seen along gender lines, showing the primacy of gendered division of labor" (p. 178).

Thus, it is essential to be mindful of tendencies to analyze gender, class and caste in the Kerala context as simple individual categories that act independently of each other. To be able to conduct a worthwhile analysis, it is imperative that we see that these are interconnected and interlocking identities. 


\section{Caste System: India and Kerala.}

The term caste comes from the Latin word "castas" which indicates something unmixed (Kapoor, 2007). The Hindu caste system in India is severe and ranked (Figure 1), the Brahmins are placed highest in the caste system and the Dalits are outside this system, thus making them "outcastes" and below all the other castes in India (Majid, 2012). The caste system places individuals in various castes based on their karma (deeds of a past life) and thus necessitates them to fulfill their dharma (duties) in order to maintain the Hindu directives. Yadav (2006), addressing the role of caste in Indian society, states:

Invisibility of caste is a fallacy. The caste system is very much a part of modern Indian society and politics. Its interaction with gender, religion and other variables make it a defining factor in many social and economic processes and its effects on these processes must be considered in any accurate analysis of the Indian polity. (p. 1)

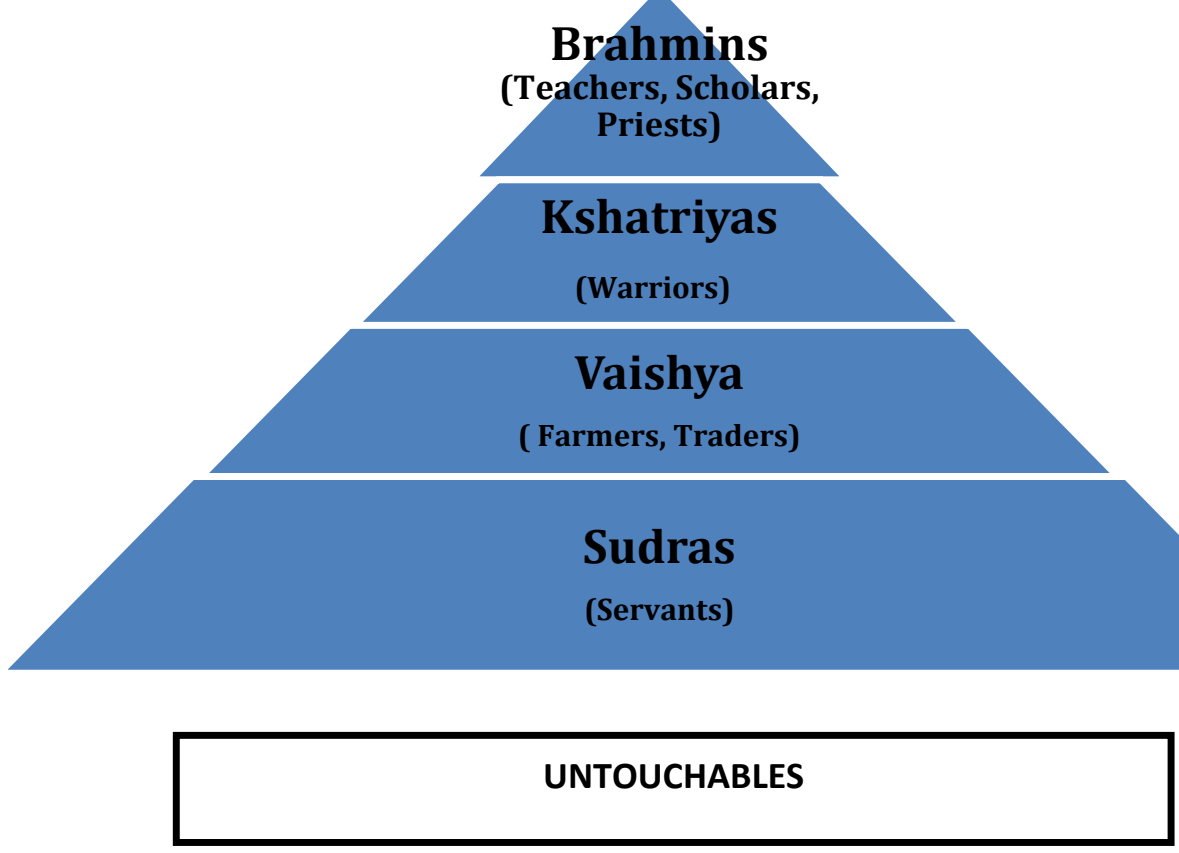

Figure 1. The Indian caste system with the untouchables (Dalits) as outside the system (Majid, 2012, p. 268). 


\section{Dalits and the Caste System}

Dalits ${ }^{11}$ in India have been a historically marginalized community (Majid, 2012). Dalit is a Marathi ${ }^{12}$ word, which means downtrodden and these communities have also been called "untouchables". There has been a resurgence of the term Dalit as a highly politicized term in the face of caste-based political and social movements in India (Majid, 2012; Still, 2008). Some of the other terms used to describe the Dalit communities include Harijan, which translated to "children of god" has been coined by Mahatma Gandhi as a way framing the Dalits as tolerable to the rest of society by evoking religious protection.

The position in the caste system is based on birth and those who are upper caste are known to aggressively discriminate against the lower castes in India (Majid, 2012). The Dalits are considered "impure to the touch" and presumed to have been born impure (Still, 2008). Additionally, with the stigma of being born impure, Dalit communities are often associated with "dirty" occupations in the community such as dealing with corpses and human waste, and working with leather (Still, 2008). This combination of the stigma of birth along with the stigma associated with these jobs makes these communities outcastes even in modern India. However, it is important to note here that being Dalit is based on caste and not class, despite the double discrimination that is brought upon these communities based on both birth and occupation. The Indian Constitution abolished untouchability after independence in 1950 and promoted equal citizenship by passing the Untouchability Offences Act (Majid, 2012; Karade, 2008). Furthermore, according to the Government of India, Article 46 of the Indian Constitution states:

\footnotetext{
${ }^{11}$ The Government of India officially uses the term "scheduled caste ${ }^{11}$ " to identify the Dalit communities.

${ }^{12}$ Regional language of the state of Maharashtra, India.
} 
The State shall promote with special care the educational and economic interests of the weaker sections of the people, and, in particular, of the Scheduled Castes and the Scheduled Tribes, and shall protect them from social injustice and all forms of exploitation.

Despite these protections, the lack of development of scheduled castes is indicative of low rates of employment, access to agriculture land, lack of access to education and social segregation (Karade, 2008). In villages, when families that are dependent on agricultural land do not own land, they become dependent on landlords and moneylenders that are often from upper castes (Still, 2008). This creates a cycle of dependence in these families, as they are often debt ridden and struggle to feed, clothe and protect themselves. Thus, the scheduled castes also suffer from poor living conditions, high rates of undernourishment and diseases such as tuberculosis, leprosy and malaria (Karade, 2008). The National Campaign for Dalit Human Rights (NCDHR) cites various examples of the deep injustices that are faced by Dalits across India. For example, Dalits are not allowed to eat with members of other castes, marry members of other castes, and they need to follow the two tumbler systems at tea shops, which means having separate glasses for Dalit and non-Dalit castes. In addition, there is required separate seating at public events, Dalits are not allowed to enter places of worship like temples, are not allowed to contest in elections, and they receive reduced and subpar wages for jobs, among many other forms of marginalization.

To counter these deep disparities, the Government of India has implemented reservations ${ }^{13}$ as specific safeguards to ensure greater access and equality. The policy of protective discrimination provides scheduled castes and scheduled tribes with three forms of

\footnotetext{
${ }^{13}$ Reservations are quotas based affirmative action. Seats (positions or vacancies) are allocated in schools, colleges and for jobs for scheduled caste individuals.
} 
reservations: 1) Reservations of seats for these groups in the parliament/state legislatures; 2) Reservations of jobs in government and semi-government services; and 3) Reservations in educational institutions specifically in colleges and universities (Xaxa, 2001). However, the reservation safeguards have been challenged because of their discriminatory practices against non-Hindu Dalits on the basis of religion. Paragraph 3 of the Indian Constitution (Scheduled Caste of 1950) states that, "no person who professes a religion different from Hinduism, Sikkim and Buddhism shall be deemed be a member of a scheduled caste" (Robinson, 2014, p. 82). Thus, Dalit Christians and Muslims are excluded from these safeguards. Some Dalits converted to Christianity hoping for it to be a solution to the discrimination, however Majid (2008) states that their religious conversion did not solve their deep-rooted discrimination. Dalit Christians have been organizing across India for equal constitutional rights. Louis (2007) addresses how the social condition of Dalits has not changed despite conversion; they are still in debt, poor and landless. These communities thus face the double discrimination in their quest for an "emancipatory identity" through conversion with neither the church nor the government providing the much-needed support.

Still (2008) suggests that despite greater access to education, women have not gained from these incentives and policies like their male counterparts have in Dalit communities. Even in cases where Dalit communities have access to education, their participation in the educational process is hampered by widespread discrimination in schools and other educational settings. This difference in access is seen in households, where young Dalit men do gain access to education while their sisters do not have the same access (Still, 2008). Education for women is a step towards gaining social mobility through marriage; if the girls are well educated then they can 
marry well-educated boys. Thus, the goal of education for these women is marriage and not employment or independence.

Thus, in the Dalit communities the stories of Dalit women and girls warrant attention as their lives are complicated by the combined interventions of gender, caste and class, as these factors serve as a 'triple disadvantage' in their lives (Still, 2008). The lives of some Dalit communities have improved post-independence but the gender gap is still far from remediated (Still, 2008). Balagopalan and Subramanian (2003) studied the educational inclusion of Dalit children in formal schooling. They indicate how both urban and rural Dalit girls want to study but their educational aspirations can be constrained by marriage and their need to work in the domestic sphere. Balagopalan and Subramanian clarify that Dalit women's work is restricted to the domestic sphere not just as a product of society's norms about women's work but also due to a lack of employment possibilities for Dalit women outside of this sphere. Dalit women are often employed as domestic cleaners and workers. Addressing the lack of focus on Dalit women's education, Balagopalan and Subramanian state that, "The relative neglect of the schooling of girls beyond primary school is part of the wider concern that the gender gap within the wider caste gap is becoming larger" (p. 51).

Further, addressing the role of Dalit women in their families, Sujatha (2014) indicates that in the Indian southern states of Telangana and Andra Pradesh, compared to women from higher castes, Dalit women work outside the home as agricultural laborers in rural communities. Their work is imperative for the family's sustenance as their husbands spend money on themselves and may become alcoholics. On the other hand in urban settings, Dalit women work as domestic help, construction workers or menial laborers (Sujatha, 2014). Furthermore, Dalit women are also exposed to higher levels of domestic violence by their husbands and their 
families, which deepen the levels of discrimination that they face. Although Dalit women support their families financially, they are treated as inferior members of the family in a patriarchal setting, which allows for a lack of decision making (Sujatha, 2014). Even government development programs serve to reinforce the cycle of exploitation. Indicating this cycle, Sujatha (2014) states:

Even state-sponsored development programs that aim at women's empowerment lead to overburdening and self-exploitation. The income generating microcredit-based programs that are intended to create the space and means to empower women often result in tremendous pressure on them to take loans not for themselves but for the benefit of their husbands and in-laws. Any refusal of this score from her results in violence. (p. 21) However, despite functioning in a complex patriarchal system that controls and tailors their lives, it is essential to recognize the strength and agency that Dalit women possess and enact. Sujatha (2014) asserts the need for this recognition in any analysis of Dalit women. In doing so, she states:

Dalit women's capacities to recognize, reflect and reorganize for effective and purposive action, both as individuals and as a part of a larger community, cannot be understood within the binary of enactment or subverting norms, or within the confines of liberalism. (p. 8)

The stories about Dalit women in India often address poverty, neglect and exclusion but there are also stories that need to be highlighted about Dalit women's agency, power and activism in their communities. Thus, Sujatha's (2014) consideration about Dalit women's agency and their strategies is an important consideration in this work. 


\section{Caste in Kerala: Dalits}

In the Kerala context, to be able to address caste it is first essential to understand the religious diversity that exists across the state. Kerala has three major religious groups: Hindus, Muslims, and Christians. The Hindus are divided into a number of different castes; the major ones among them include Brahmins, Nayars, Ezhazas and the Harijans. On the other hand, the Christians include the Syrians, Latins and Backward Class while the Muslims include Tangals who trace their birth to the Prophet, and Malabaris and Pusalars who belong to the fisher folk. The fisher folk are considered to be a lower status group in Kerala (Kurein, 2002).

Kurien also indicates the distinction between the caste system in Kerala and the system across the rest of India. The system (Figure 1) discussed above is the pan-Indian system (Brahmins, Kshatriya, Vaisya, Sudra), however in Kerala this caste system is different with the Kshatriyas (warriors) and Vaisyas (business persons) being negligible in the caste system. Instead, Kurein states, “The Nayar caste took the place of Kshatriyas, but they were regarded as Sudras by the local Brahmins. The Ezhavas came below the Nayars, followed by the slave castes" (p. 45). Regardless of being Sudra caste, the Nayars were upper-caste and married. Namboodiri Brahmins and Ezhavas, who did Sudra tasks, were still categorized as untouchable (Kurein, 2003).

The Dalit and Adivasis (tribals), together with the Dalit Christians, constitute about 65 to 75 lakh $^{14}$ in a total population of 333.87 lakh (Kerala Census, 2011). Furthermore, they account of $80 \%$ of Kerala's population without agricultural land. This degree of landlessness despite land reform is reported as higher than India's national average (Sreerekha, 2012, p. 21). Despite the lack of land over the years, the Left in Kerala has categorized the Dalit communities as

\footnotetext{
${ }^{14} 1$ lakh=One hundred thousand.
} 
agricultural workers and laborers (Sreerekha, 2012). Furthermore, Devika (2010) asserts that there was a "fear; that if children of the ex-slave communities received modern education, few would be left to labor in the fields" (p. 273). This narrative shaped the Dalit communities and their skills were often deemed as being only agricultural.

Thus, Devika (2010) suggests that the "state's historical non recognition of the preexisting dispositions of these communities has cost them dear" (p. 274). The state has provided basic provisions in education for these communities such as free primary school education and free middle school education but has failed to recognize the specific needs and history of disparity that faced these communities over the years (Devika, 2010). This indicates that the state has often found quick fix solutions for these communities and has failed to truly situate interventions and initiatives in deep understandings of their needs. Dalit progress in the state is also often reported in the context of conventional indicators such as school enrollment and literacy rates. In 2011, according to the Kerala State Planning Board, scheduled caste students represented $11.4 \%$ of the total number of students in the state. Scheduled caste students are mostly enrolled in government schools at $13.82 \%$, government aided schools at $10.73 \%$, and private unaided have the lowest number of scheduled caste students at 3.73\%. The Dalits in Kerala had higher enrolment in school when compared to the rest of India, however given a closer look at this progress; we see a lack of upward mobility (Padmanadhan, 2010). Furthermore, comparing the SSLC (Secondary School Leaving Certificate) ${ }^{15}$, Dalit students' scores were lower than those of non-Dalit students. Padmanadhan (2010) asserts that Dalit students are less prepared for state level examinations compared to other communities with

\footnotetext{
${ }^{15}$ Certificate obtained at the end of secondary schooling.
} 
better resources and access, such that "no substantial gains have been made by Dalits in creating educational community assets in the post-independence period" (p. 109)

Padmanabhan (2010) conducted an in-depth case study in a Dalit colony in the suburbs of Thiruvanthapuram (Kerala's state capital). She observed the poverty and the lack of opportunities that face this community. Padmanabhan expressed concern about the social situation of the Dalit colony, which included conditions of the home and neighborhood, which were cramped, incomplete houses or dilapidated huts, some even without electricity and proper sanitation.

Padmanabhan noted that most of the parents worked as domestic workers or construction workers and some of the children also have domestic responsibilities after school like sweeping, cleaning, washing and cooking. On the other hand, some children watched TV when they came home from school if there was electricity in their homes. They were not supervised or required to do school work. Padmanabhan also observed that her participants struggled in numeracy and English language skills that are a part of the school curriculum. She indicated that even those students who had completed primary education and were in middle school did not show skills in writing, reading, comprehension and numeracy that were required for primary school students. Some of her participants even struggled to read and write Malayalam as they had been advised to take Sanskrit instead of Malayalam by their teachers. Padmanabhan asserts that the reason that students were taking Sanskrit instead of Malayalam was because the schools were trying to save Sanskrit teachers' jobs. Some Dalit students did not have parents that could advocate for them in a school setting and get placed in Sanskrit classes instead. Padmanabhan states, "How many families should grope in the dark to save a Sanskrit teacher's post?" (p. 114). Furthermore, Dalit teachers in the Kerala educational system are also underrepresented. Despite 
job reservations for Dalit teachers in government schools, Padmanabhan asserted that the number of Dalit teachers in government aided schools were limited as government aided schools were often dominated by teachers from other communities. This lack of representation has contributed to the deepening of caste disparities in Kerala communities.

Another factor, according to Padmanabhan, that has further deepened caste disparities is the changing face of Malayali society as a whole. Malayalis have been migrating internationally (specifically Middle Eastern migration) for many generations now. Kurein (2003) in her discussion of Kerala's migration patterns states, "Economically Kerala has been largely agricultural and agro-processing based, with a negligible industrial sector. However, due to tremendous population density of the state, land has been scarce, resulting in high rates of unemployment" (p. 62). Thus, Padmanabhan (2010) asserts that this changing job market has increased the demand for English medium education and a growth of English medium schools that target students who hope to migrate for better jobs. This has resulted in not only the changing face of the job market in Kerala but has also subsequently attributed to changes in the education system (Padmanabhan, 2010). However, Dalit communities have not been able to take advantage for the changing work market in Kerala and globally.

A similar sentiment is also powerfully resonated in a recent interview (Devika, 2014) of Dalit female leader Seelena Prakkanam. When asked about Dalit women's experience with education, she said that families often do not know how to send their children to college, navigate through the education system and make an informed decision about what their children must study. The major issues include not only the lack of parental guidance but also a lack of college preparation and English fluency. Dalit students feel inadequately prepared for college, as 
other students in the class are more comfortable in English. Furthermore, teachers do not provide the required attention and help. Seelena Prakkanam asserts that,

Being Dalit, you are always treated a second class, and on top of these you have these inadequacies. And perhaps more important is how education is generally understood. People treat it as mere means to a job. Just get a job, some job, stand on your own feet. The country needs more though. It needs well-educated citizens. Instead education serves to insert people into different status levels. It is no surprise that Dalit girls hesitate to enter public forums boldly. (p. 41)

Devika (2010), who is a prominent Malayali feminist, charges that the Left was deliberate about the marginalization of the Dalit communities in the region with their confinement into governmental categories. Devika describes the framing of the subaltern in Kerala as passive and welfare receiving social groups. The handing out of welfare in the region does not indicate a demise of caste struggle that the Left emphasized in its mission, nor does it indicate a true acknowledgment of subaltern concerns. Devika (2010) highlights how the technique of "rendering the oppressed passive" (p. 805) has been a strategic practice used in Kerala politics. Social reforms have a long history of being disguised as benevolent patriarchy in the region (Devika, 2009). This has resulted in the lack of gender egalitarianism and justice for Dalit communities across Kerala.

This section highlights the structure of the caste system in Kerala and speaks to how Kerala's caste system differs from the pan-Indian system. It further addresses how Dalits in Kerala continue to struggle in the face of landlessness and a lack of social and economic mobility. The Dalit struggle for education (Padmanabhan, 2010) is deeply impacted by their poverty and the subsequent lack of opportunity that they face in present day Kerala. Thus, Dalit 
women's struggle for education and jobs is shaped by an education system that fails to understand and attend to their marginalization.

\section{Conclusion}

This chapter describes the private and public forces that frame women's lives in Kerala and specifically Dalit women's lives. Women's education is one the cornerstones of Kerala's Model of Development with an extensive network of educational initiatives and policies. However, in the changing face of Kerala society, it is vital to take into consideration the role of gender, caste, class and religion to be able to understand Dalit women's educational needs. Thus, by exploring the social context of Kerala development, we can unpack how a deeply entrenched social structure is created and maintained in contemporary Kerala society. And subsequently further engage with how these multiple social structures shapes the Dalit community's accessibility, mobility and educational outcomes. 


\section{Glossary of Terms ${ }^{16}$}

Adivasis: Tribal or indigenous people in India.

ASHA: Accredited social health activists or community health workers.

Dalit: Literally means" broken people" or scheduled caste, the lowest group in the caste system.

Class (Educational System): In the context of schools in India, class means grade (for example 5th class, 6th class etc.).

Cheramar: Caste in Kerala, the name adopted by the Pulayas. It means "children of the soil."

Jati: An endogamous social unit in the caste system within which one must marry, and whose membership is determined by descent and traditional occupation. The caste system consists of many Jatis.

Malayalam: Regional language of Kerala.

Malayali: People of Kerala.

Mahatma Gandhi National Rural Employment Guarantee Act: Livelihood security for rural areas, which ensures 100 days of wage employment in a fiscal year to each family whose adult members volunteer to do unskilled manual work.

Janasree: A development plan of the Government of Kerala concerning poor and low-income communities.

${ }^{16}$ Standard Definitions taken from Kerala government websites/ and from the glossary of Mangubhai, J. P., \& Lee, J. G. (2012). Dalit women speak out: Caste, class and gender violence in India. Zubaan. 
Kudumbashree: Female-oriented, poverty reduction project of the Government of Kerala.

Other Eligible Communities (OEC): Christian convert Dalits in this study fall under the government category of OEC (Other Eligible Communities). Religious conversion to Christianity moved Dalits into the Other Eligible Communities category from the Scheduled Caste (SC) category government reservations. Being SC has greater reservation benefits than OEC.

Private tuitions: Supplementary teaching outside the school system, which is privately owned and was created to fulfill gaps in local education systems. They are expensive and increase the cost of education for families.

Pulaya: The untouchable caste in Kerala.

Reservations: Quotas for Dalits for improved representation in education, government jobs, and political participation.

Scheduled Castes (SCs): A list of socially deprived ("untouchable") castes. The schedule of castes was proposed to augment representation of scheduled-caste members in the legislature, in government employment, and in university placement. The term is also used in the constitution and various laws. 


\section{Chapter 2: Conceptual Framework}

In the context of this study, feminist qualitative research is guided by postcolonial feminism and intersectionality. This framework is well suited to this study because of the gendered nature of Dalit women's experiences and the history of deliberate marginalization and treatment of Dalit women based on their caste and class in Kerala (Devika, 2010). Colonization in Kerala further strengthened these patriarchal forces that surround women's lives in Kerala by the infiltration of western values and standards (George, 2008). George (2008) further asserts that, "traditions are dictated and interpreted through male dominance with the support of colonial-postcolonial patriarchal norms" (p. 304). Given this backdrop of oppression that highlights the hegemonic tendencies of the state and the manifold patriarchies that shape women's subjectivities, postcolonial feminist theory along with an intersectional framework (Figure 2) is relevant for understanding the lives of women in Kerala.

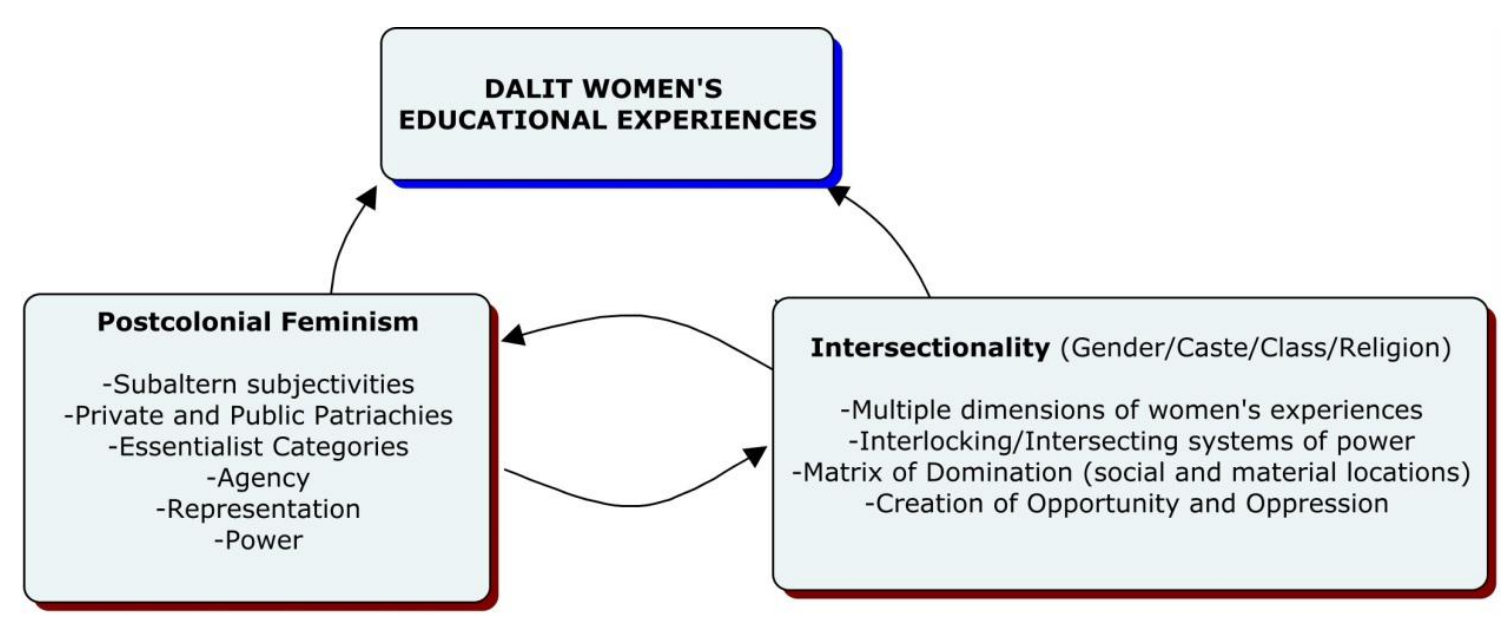

Figure 2. Conceptual framework 


\section{Postcolonial Feminism}

The following section addresses some of the key perspectives that inform a critique of the colonialist discourses of development in postcolonial Kerala. It is impossible to ponder contemporary movements without a thorough analysis of the effect of colonialism on the making of nation states and modern day subjects. For this nuanced understanding, postcolonial feminism and related scholarship provides a critical lens for the examination of women's issues in global and local development. An essential goal of postcolonial feminism is to draw attention to women's subjectivities, identities and agency in the context of contemporary social and political issues in the developing world (Figure 2). It utilizes "theories of colonial underdevelopment and post-colonial development coupled with socialist feminism to investigate the women's position in the global economy and pays special attention to newly industrialized countries" (Lorber, 2001, p. 87).

Conversations about gender issues in Kerala often address progress purely in the context of social indicators of development such as high literacy, and low maternal and infant mortality (Kerala Development Report, 2008). This leads to two misplaced assumptions about women in Kerala. First, it is widely held that women in Kerala are less marginalized by the Indian patriarchal system than women across the country because they fare better on social indicators. And second, women in Kerala have greater agency and hold a higher social status compared to other Indian women (Devika, 2006). Thus, a feminist inquiry into Kerala's Model of Development helps to highlight these problematic assumptions that link women's agency with social indicators of development (Devika, 2006). Extending this conversation to Dalit women specifically, Rao (2014) states that it is essential to understand Dalit women's agency within their individual structure of marginalization and "contingencies that structure their responses to the 
world" (Reader 2007, p. 604 as cited by Rao, 2014). These authors urge us to move beyond the simplistic view of restriction and autonomy while understanding Dalit women's experiences (Rao, 2014). Raj (2013) frames Dalit women in Kerala as political agents rather than voiceless postcolonial victims of subjugation. Raj states, “Articulating Dalit women's experiences by exposing the operations of history by which their struggles were co-opted, subsumed, misrepresented or sometimes erased by mainstream debates and tracing the survival strategies by which these women have held out against political suppression and social isolation becomes crucial in contemporary Dalit feminist struggles in Kerala" (p. 62). Thus, a feminist exploration of Kerala's Model of Development will help to reevaluate and highlight the narratives of those who have been left out of the rhetoric about Kerala.

By drawing on postcolonial feminist conceptions of power, representation and agency, this framework is centered on the subaltern Dalit subject in Kerala. Spivak (1988) in "Can the Subaltern Speak?" raises concerns about the representation of those who are at the periphery of society. She is concerned with "subalterns" who have been systematically marginalized by colonialist discourses. Spivak raises questions about the subjectivities and depiction of the subaltern in development as lacking power and voice. As discussed earlier, this holds specific relevance in the Kerala context as the Dalit communities have been framed as passive welfarereceiving groups (Devika, 2010). Thus, the awareness of how cultural reductionism and recolonization ensues through knowledge construction is a vital perspective for a postcolonial analysis of women's lives. Mohanty (2003) addresses the imperatives of postcolonial feminist analysis:

Any discussion of the intellectual and political construction of "Third World Feminism" must address itself to two simultaneous projects: the internal critique of hegemonic 
"Western" feminisms and the formulation of autonomous feminist concerns and strategies that are geographically, historically and culturally grounded. (p. 17)

Mohanty's call for the decolonization of feminism and development is deeply rooted in the representation of a singular, monolithic Third World who is powerless, victimized and dependent. Thus, "women" as a category of analysis lumps all Third World women's experiences into one homogenous group (Mohanty, 2003). The essentialist representation of women's issues without cultural or historic specificity is highly problematic and perpetuates the colonizers' control in the Global South (Mohanty, 2003).

Like Mohanty, Narayan (1998) also addresses the homogenizing conceptions of culture as she warns against colonial modes of representation, in her criticism of Mary Daly's discussion of Third-World cultural practices such as sati. Daly's representation of sati failed to address how not all Indians practiced sati and it also did not account for the movements and uprisings against sati within the Indian communities. Thus, in her omissions of these imperative considerations, Daly produced an essentialised account of sati ${ }^{17}$ in India. Narayan states that it is vital that western feminists are careful of such historically inappropriate representations.

Narayan also draws attention to the representation of dowry deaths by western feminists who frame them as "death by cultures." She problematizes the cultural explanation that is often launched in response to these violent acts; she says that the notion of "death by cultures" depicts Third World women as "victims of their cultures" (p. 62). While addressing violence against women in the West, a cultural explanation is often excluded. Thus, to be able to understand the

\footnotetext{
${ }^{17}$ Sati is a funeral ceremony wherein widows self- immolate themselves at their husbands' funeral pyres.
} 
experiences of Third World women, Alexander and Mohanty (1997) advocate that, "we must pay attention to the specificities of their/our common and different histories" (p. 28).

Further, in considering issues of representation, postcolonial feminist theory also has a clear stand on addressing issues of difference. Lorde (1981) in her anti-racist political writing addresses the examination of difference while thinking about women's representation. Pointing out the limitation of a global sisterhood, she asserts that women do not experience the same oppression just because they are women, and states that the failure to recognize this is to ignore the tools of patriarchy (Lorde, 1981). Furthermore, Lorde (1984) addresses the importance of making difference a strength when we seek to understand the conditions and lives of women. She draws attention to the "institutionalized rejection of difference" and how difference is misused and misnamed because as women we have been trained to disregard our differences. These concerns similarly shape Dalit women's representation and experiences. Indeed, "Dalit women" as a category are not homogenous but instead it is multiple and heterogeneous (Rege, 1998). This dissertation seeks to extend this argument to the treatment of difference and representation in the context of Dalit women's lives in Kerala by drawing on Rao (2003), who states:

The demands by Dalit and other lower caste women are not merely for inclusion, but for an analysis of gender relations as they are infected by the multiple and overlapping patriarchies of caste communities that produce forms of vulnerability that require analysis. (p. 5)

Dalit women's experiences have been homogenized across India and Kerala, and their vulnerabilities and subjectivities have been portrayed as widespread and inert (Rao, 2014). Thus, 
this analysis seeks to understand Dalit voices and their navigation of development in Kerala within their individual material and cultural milieu (Rao, 2014).

Colonization, according to Mohanty (2003), can be seen as an "exploitative economic exchange" or as described by feminist women of color in the West as "appropriation of their experiences" (p.18). Thus, the politics of representation informs not only the representation of women but also of the movements that seek to shape women's issues in the developing world. Postcolonial feminists have been vocal about the decolonization of both development and Western feminism by challenging the imperial European roots that shape the representation of women in the Global South. Escobar (1997) addresses the construction of the Third World in development discourse and the rooting of development initiatives in Western economic practices. He calls development policies mechanisms of control that sell modernization as a way to eliminate "archaic superstitions and relations at whatever social, cultural and political cost" (p. 86). Thus, leading to the representation of nations as Third World or underdeveloped, results in their handling as lesser in the global power dynamics of development. Furthermore, this handling also reinforces systems of patriarchy and supports the gendered division of labor under the confines of either production or reproduction.

A postcolonial feminist exploration also links the private-public domains and recognizes the subsequent exploitation of women that follows when we fail to do so. The private patriarchy interacts with the public patriarchy, thus creating another tier of domination and oppression. The work of Beneria and Sen (1981) is integral here. They highlight how the narrow focus on commodity production is an insufficient way to visualize women's work. They suggest that the problem is not with the lack of incorporation of women in the development process but instead in how they are included. Further, they state that women are often included at "the bottom of an 
inherently hierarchical and contradictory structure of production and accumulation" (Beneria \& Sen, 1982, p.161).

Similarly, Mies (1982) in her classic work with the lace makers of Narspur, India, explores the development of the household lace industry in India and the representation of women as "non-working housewives" (p. 21). This representation conceals women's productive work for capital accrual and supports their exploitation. In their book Women: The Last Colony, Mies and her colleagues (1988) provided a valuable model for feminist research on women in the developing world. They addressed the "housewifization" of labor, asserting that patriarchal capitalist practices have colonized women by confining women to the domestic sphere and not valuing the work that they do in that sphere. Thus, the gendered division of labor roles creates a social structure that values men's work over women's labor. Women's roles tend to focus on their reproductive role centered around their children and families, while men's roles tend to be focused on productive work that focuses on paid work.

In the context of Kerala's Model, the gender paradox highlights this unbalanced development, where the state is praised for high female literacy and life expectancy while having the lowest participation in the labor force in the country (Hapke, 2013). According to the 2001 census, Kerala placed 32nd of 35 state and union territories in women's participation in the labor force. Hapke (2013) explores these opposing trends in Kerala and suggests that regardless of Kerala boasting a high rate of university enrollment in women, enrollment is mostly seen by women in more stereotypically "feminine" jobs such as nursing, education and social work, while men have enrollment in engineering and skill building in technical colleges. Despite low female employment numbers, women in Kerala rank higher in the country for seeking jobs (Hapke, 2013). This may indicate two major concerns, first workforce prejudice against women 
while they job seek and second a failure of the market in Kerala to keep up with the employment needs. To understand the complexity of the gender paradox in Kerala, Hapke (2013) challenges the assumption "that education of women leads to their liberation" in Kerala and asserts that "despite the importance of material factors in shaping gender relations, understanding the apparent persistence of gender inequality requires a serious consideration of cultural ideologies and the ways in which they intersect with political economy" (p. 11).

Thus, a post-colonial feminist perspective is well suited for this exploration as it seeks to inform present-day movements by including questions of difference/distance and critically accounting for them while interrogating hegemonic tendencies both in nationalist and transnational approaches. Grewal and Kaplan (1994) describe women's multiple subjectivities as “scattered hegemonies" (p. 7). They problematize the conceptualization of women's issues, asking us to keep in mind the historicized manifold patriarchies that affect women's lives. According to the authors, "to articulate the relationship of gender to scattered hegemonies such as global economic structures, patriarchal nationalism, 'authentic' forms of tradition, local structures of domination, and legal-juridical oppression on multiple levels" (Grewal \& Kaplan, p. 17). This attention to place, connections, and differences gives rise to the exploration of counter narratives.

Dalit women's narratives in Kerala require special consideration in the exploration of Kerala's Model of Development. Addressing the lack of attention given to Dalit narratives thus far, Raman (2010) states, "the dominant discourse on the Kerala Model continues to miss the major concerns of the minorities and the marginalized; and through this silence, the unheard and the unsaid is further marginalized, in terms of both material and non-material concerns" (p. 3). Raman (2010) further cites three major challenges that face present day Kerala which include the 
rising economic and social disparity across communities, an imbalance of power among historically marginalized communities like the Dalit and the challenges that marginalized communities face in the modern age of globalization and fast-paced development.

This work seeks to transgress the "universalization of discourses" and instead works towards uncovering those obscured subjectivities of Dalit women that have been hidden by hegemonic discourses (Kim-Puri, 2005, p.151). Kim-Puri (2005) asserts that, "the creation of hegemony occurs, as we know through the repression and exclusion of subjects that dominant groups perceive as troubling or undesirable" (p. 151). Cognizant of these concerns, this dissertation seeks to systematically analyze and reveal the diversity of resistances and struggles among Dalit women in Kerala. Kerala has a network of Dalit Women's Federations that serve as networks of solidarity and fight for the Dalit cause in Kerala. The Dalit collectives in Kerala work to address issues of violence and work towards forwarding gender concerns in government policies. Bhaskaran (2011), addressing the backlash against Dalit women's solidarity in Kerala, states, "In a political climate where compromises and mediations have been the mechanisms of the exercise of power over women, this independent resistance to violence has faced hostility from families, political parties and politicians at all levels" (p. 80). To be able to understand Dalit women's experiences in Kerala, it is imperative that this work draws from this rich history of mobilization and collective action that shapes Dalit experiences in Kerala. Furthermore, this work also seeks to analyze Dalit women's daily resistance to oppressive practices and exclusions by exploring how they navigate development. And finally, in doing so it explores the boundaries and extent of Dalit women's agency in the Kerala context.

Thus, under the guise of nation building, local and global discourses of development reinforce colonialist agendas when they fail to account for issues concerning representation, 
difference and location. Post-colonial feminist analysis provides the tools to challenge the linear process of development. In addition, it also helps to make room for alternative forms of solidarities and changing frontiers of nation states in the face of neoliberal globalization.

\section{Intersectionality}

Additionally, the conceptual framework of this study draws on the theoretical and analytic contributions of intersectionality. It helps to provide a deeper understanding of postcolonial feminism concerns addressed above by examining the many intersecting and interlocking systems that shape women's experiences. Crenshaw (1991) first coined the term "intersectionality" to address how race and gender dimensions interact to shape Black women's lived experiences. Crenshaw suggests that, "Intersectionality might be broadly useful as a way of mediating the tensions between assertions of multiple identities and the ongoing necessity of group politics" (p. 1296). Thus, intersectionality draws attention to material and social locations as essential decisive forces shaping women's experiences.

These intersecting/ interlocking systems, identities and locations create subjugation and opportunity for disadvantaged groups (Zinn \& Dill, 2009). Thus, individuals occupy positions of subjugation in some areas and opportunity in others. However, Weber (1998) warns that oppressions cannot be added up and that there is no mathematical formula to capture the intricacy of these interacting systems. Weber states, "we cannot say that disadvantage on any two dimensions is the same as on any other two" (p. 25). Black feminists (hooks 1984; Collins 1991) further rallied for the role of social location in the lives of women. Collins (1991) referred to intersecting oppressions in the context of the matrix of domination. She asserts that, "intersectional paradigms remind us that oppression cannot be reduced to one fundamental type, 
and that oppressions work together in producing injustice" (p. 18). Thus, intersecting oppressions focus attention on the connections between different forms of women's subjugation and include the experiences of those who have been left out of feminist examinations (Yuval-Davis, 2006).

In the Indian context, the matrix of domination helps us to understand the intersectionality of gender, caste, class and religion. Dalit scholars have used this framework to understand how the matrix of caste, class, and religion along with gender interact in postcolonial contexts (Paik, 2014). Paik suggests, "Although gender seemed to be the fundamental basis for women's oppression, its entanglement with caste created severe problems for lower-caste women" (p. 151). Thus, intersectionality helps to include narratives of marginalized people by considering how systems of inequalities work in conjunction with each other instead of in isolation (Choo \& Feree, 2010).

Intersectionality is a suitable framework of analysis for exploring how gender, class, caste and religion shape Dalit women's educational experiences in Kerala. It provides a deeper understanding of Dalit women's resistance and agency by challenging the dichotomous understanding of freedom and subordination, which often frames Dalit experiences. By bringing together intersectionality and postcolonial feminist theory, this study serves as a critical feminist exploration of the discourses, narratives and hegemonic power structures that define Dalit women's inclusion and exclusion in Kerala's Model of Development. A postcolonial feminist critique of Kerala's Model of Development addresses the hegemonic discourses of modernity and development in Kerala. Cheryl McEwan (2001) states, "Postcolonial feminisms seek to disrupt the power to name, represent and theorize by challenging western arrogance and ethnocentrism, and incorporating the voices of marginalized peoples" (p. 100). Postcolonial feminist theory also warns against the risk of not acknowledging the role of power in knowledge 
construction. It helps to include conversations about representation by raising the question of whose interests development initiatives truly represent. Thus, postcolonial feminist theory challenges the notion of the "universal sisterhood" and helps draw attention to the function of difference and how working with difference in women's movements helps to draw awareness to the myriad conditions and lives of women across the world. Furthermore, suggesting that a true examination of difference begins by critically reflecting on one's own social position and addressing women's subjectivities in the context of both private and public power structures.

Thus, postcolonial feminist perspectives along with an intersectional framework inform our understanding of women's lives in developing countries by contextualizing women's identities and agency in the multiple contexts that shape and govern their lives. 


\section{Chapter 3: Methodology}

Chapter 3 outlines the research methodology, data collection methods and data analysis procedures. This chapter begins with explaining why feminist qualitative methodology is well suited for this study and addresses researcher positionality. The second part of this chapter lays out the data collection methods and data analysis procedures.

\section{Feminist Qualitative Methodology}

Feminist methodology argues that conventional methodology is ingrained in positivist empiricism, is focused on the quest for universal truths through value-free research and is aligned with an androcentric point of view (McDowell, 1992b). Feminist research challenges this conventional methodology and "addresses power relationships between the researcher and the researched, objectivity/subjectivity and found versus constructed worlds" (Lather, 1992, p. 92) in the research process. The lived experiences of women are recognized and are central to uncovering subjugated knowledges. Thus, by placing participants in a position of privilege, feminist research works to move women's experiences from the margins to the center (HeeseBiber, 2007). Moving away from scientific objectivity and value free research makes room in the research process for feminist objectivity. Haraway (1988) defines feminist objectivity as a lens in which subjects "situated knowledge require that the object of knowledge be pictured as an actor and agent, not as a screen or a ground or as a resource, never finally as a slave to the master that closes off the dialectic in his unique agency and his authorship of 'objective' knowledge” (p. 592). Feminist qualitative research thus acknowledges individuals as active agents instead of submissive research objects by unmasking the power relationships in the research process. 
In the context of this study, feminist qualitative research is guided by postcolonial feminist concerns and intersectionality. This framework is well suited to my study because of the gendered nature of Dalit women's educational experiences and the history of deliberate marginalization with the treatment of women as passive welfare recipients based on their caste and class (Devika, 2010). Given this backdrop of oppression that highlights the hegemonic tendencies of the State and the manifold patriarchies shaping women's subjectivities, postcolonial feminist theory is relevant to understanding the lives of Dalit women and the colonizing processes that shape their lives. Thus, the methods used in this research help "to convey the inner life and texture of the diverse social enclaves and personal circumstances of societies" (Jackson, 1985, p. 157 as cited by England, 1994). In the tradition of feminist methodology, I practiced reflexivity by engaging in sensitive and critical deliberation of myself as a researcher (England, 1994). Reflexivity thus works to expose the power inequalities throughout the research process and begins before entering the field as a way of aiding the researcher in understanding her own social position (Hesse-Biber \& Piatelli, 2007).

\section{Reflections on Positionality}

Positionality has an essential role in feminist research. Thus, it is imperative for me to consider who I am and how my multiple identities and privileges shape my research. Reflecting on issues of ethics, power, and intersubjectivity through the different phases of research helps one to understand how your research is socially conditioned (Dowling, 2000).

As I look back at my academic and personal journey, I have come to realize that my interest in gender, class and caste draws from all aspects of my own life. Questions of identity, privilege and power have intrigued me even as a young girl in India. I was born in the South, in 
Kottayam, Kerala, but grew up in the North, in New Delhi. Kerala has always been important to me as my family is ancestrally from Kerala. I spent all of my holidays from school at my maternal grandfather's rubber plantation and farm in Kerala. The coconut trees, lush green vegetation, vibrant red Marxist flags with hammers and sickles and street art of Che Guevara were some of the images of Kerala that are deeply ingrained in my mind. My family spoke highly of Kerala's development, my grandfather was proud of the active unions and the clean streets around the state. He always talked about how good the state was for women, as they were well educated and had good healthcare. However, every once in a while these stories of greatness were interspersed with stories about the lack of progress of the Dalit and Adivasi ${ }^{18}$ communities in the state. I always heard of them being addressed as "backward" regarding their lack of progress despite government schemes.

My positionality has been constantly moving between insider and outsider, and each shift of positionality has come with its own insights and privileges. Drawing on Fine's (1994) conception of "working the hyphen," I extend the margins of insider-outsider positionality and challenge the dichotomy of insider-outsider. Fine (1994) suggests that working the hyphens, or negotiating insider-outsider and subject-object, leads to the creation of a hybrid identity, one that is in flux. These are important considerations in my work with Dalit women, as I am a Malayali woman.

I have always navigated two ethnic identities: one of a Malayali woman or a Mallu ${ }^{19}$ and the other of a Delhite ${ }^{20}$. I always stood out in my community in Kerala and continue to do so to

\footnotetext{
18 Tribal communities

${ }^{19}$ Mallu is shortened version of "Malayali," the word used to refer to people from the state of Kerala in India.

${ }^{20}$ Someone who resides, or has been brought up in the city of Delhi.
} 
this day because I come from north India, because I sound different and act differently, like a "city girl." Going to school in New Delhi, I was always more fluent in Hindi ${ }^{21}$ than in Malayalam. Hindi is the national language of India, while Malayalam is the regional language of Kerala. I learned Malayalam from my mother and from my summers in Kerala, but I always sounded different. I was told I had a "northern accent." Since I started graduate school in the United States, I have found that every time I have gone back to Kerala this navigation has become even more complex. Now, I do not come from New Delhi anymore but now I am introduced by my family as being from America and married to an American man.

Furthermore, I am always struck by the gendered nature of work and education in my household. Education was very important in my house, but ensuring that I was a good wife and took care of my home and family was just as important. Devika and Mukherjee (2007) state that a matter of urgent consideration is the "double expectation" placed on women in contemporary Kerala. Women are required now to do as well as boys in school along with conforming to society's feminine ideals of domesticity. In the context of social class, I was read as privileged by my grandfather's neighbors and friends in Kerala as I lived in Delhi, the big capital city. My parents had good jobs, and now I am married to a man with a good job and I read English books. I considered myself upper middle class growing up, as my mother was school administrator and my father worked as an engineer. Being from a Christian family, as a young girl I was told that issues of caste do not affect us, it is the Hindus that practice the caste system. My family is very active in the church, and we are considered to be Syrian Christians. My family is deeply embedded in the community in Kerala and they claim that they do not see caste and class. However, the realities of how gender, caste and class shape people's lives and experiences have

\footnotetext{
${ }^{21}$ India's national language
} 
always been around me in the form of a culture that supports domestic servitude. The female domestic helpers that cooked and cleaned in the households, the male barber that came home to cut my grandfather's hair, the washer woman that came to wash our clothes, the male coconut tree climber, the man that took care of the cows and many more, these were the people who inadvertently taught me about power from the time I was young. These experiences and narratives about gender, caste and class and the ways in which they intersect and interlock to create people's experiences in Kerala are important considerations in my work. Thus, it would be essential to reflect on my own positionality in my research as a feminist researcher. How does who I am and where I stand in relation to others affect my questions and my research? In using this approach to inquiry I must navigate my positions and power relationships as an outsiderinsider researcher and Malayali woman. Thus, attending to the feminist commitments of exploring and challenging my own positionality (England, 1994; Hesse-Biber, 2007) was an essential component of my research process.

\section{Multi-Case Study}

Case study, according to Yin (2003), is "an empirical inquiry that investigates a contemporary phenomenon within its real-life context, when the boundaries between phenomenon and context are not clearly evident" (p. 13). A case study is considered as fitting when: (1) the study question is in the form of "how, why," (2) the researcher cannot control the behavior of the participants, and (3) the study is examining current events (Yin, 2003). Furthermore, case study research can also align with the tenets of feminist research. Reinharz (1992) suggests that feminist researchers conduct case studies for the same reasons that nonfeminist researchers do. She indicates reasons such as illustrating an idea, explaining the process of development over time, exploring uncharted issues by starting with a limited case, and posing 
provocative questions. Finally, Reinharz suggests that the root of feminist interest in case studies is to correct the research that has been marred by misogyny and androcentric theorizing.

Case studies help people to understand complicated social phenomena (Yin, 2003). Defining the case helps the researcher narrow their research questions and avoid the research process from being too broad with multiple objectives (Baxter \& Jack, 2008). As noted above, the central phenomenon being explored is the intergenerational complexities of Dalit women's educational experiences in Pathanamthitta District, Kerala. The case in this study, the unit of analysis, is Dalit mother and daughter dyads or triads in the Pathanamthitta District. Case studies can be single or multiple-case studies (Merriam, 1998). This study involves collecting and analyzing data from multiple cases, i.e. mother-daughter dyads or triads (Merriam, 1998). The dyads or triads of women and girls will provide an intergenerational understanding of women's education in Kerala.

Miles and Huberman (1994) propose that using multiple cases can "strengthen the precision, the validity and the stability of the findings" (p. 29). There are several reasons to utilize the case study method to examine the educational experiences of various Dalit women in Pathanamthitta. First, Dalit women's educational experiences have been primarily documented in the literature in the context of conventional indicators such as adult literacy, school enrollment and school attendance (Kerala Development Report, 2008) and a detailed study specifically of the educational experiences of Dalit women in Pathanamthitta district is lacking in the literature. For this reason, a detailed rich description of Dalit women's educational experience will be gained using a case study methodology. Second, because of the inherent heterogeneity of Dalit women's experiences in the region due to difference in caste and class, case study methods will be helpful in gaining a detailed understanding of the context of a particular community. Thus, a 
feminist qualitative case study is appropriate as it is an intensive investigation of women's educational experiences studied in a natural context. Furthermore, this study aims to be richly descriptive and to use multiple sources of information such as interviews, photovoice and observations along with secondary data sources like development policy documents and trend data to uncover the contexts within which Dalit women's educational experiences are shaped in Pathanamthitta District, Kerala.

The district of Pathanamthitta has been selected as a site for this research for several reasons. First, according to the Panchayath ${ }^{22}$ Level Statistics (2011) from the Department of Economics and Statistics, Kerala, Pathanamthitta district ranked first in literacy rate ${ }^{23}$ in the 2011 census. It would be beneficial to conduct a micro level exploration of a district, which has reported high literacy levels over the years. There are no micro level studies addressing Dalit women's education in the district.

Second, Pathanamthitta also has a large scheduled caste population. The Dalit communities are counted under scheduled caste in the Indian census and other government demographic surveys. According to the Kerala Development Report (2008), the literacy rates of scheduled caste remain behind the rest of the population in Kerala. However, there are numerous mentions of these disparities that face the Dalit communities in the development report however there are no in-depth explorations of these disparities and violations that face Dalit communities in Kerala. This feminist qualitative study will contribute to this gap in the literature by focusing on the lives of those who have been silenced in public discourse and challenging conventional assumptions that shape social policy (Hesse-Biber \& Piatelli, 2007).

\footnotetext{
${ }^{22}$ Local governance.

${ }^{23}$ Literacy rate is the percentage of literates to total population aged seven years and above.
} 


\section{Participant Selection}

Merriam (1998) suggests purposeful sampling for a case study to ensure in-depth learning about the cases. Potential mother-daughter dyads or triads were selected based on the following selection criteria, which reflect the purpose and research questions. Participation in this study was voluntary. The study recruited Dalit mothers daughters dyads and in some cases triads to gain a deeper understanding of intergenerational educational experiences of women in a Dalit household. Families were nuclear, extended or joint. Thus if the families were joint or extended and have nieces/grandmothers/mother in laws living with them, I recruited them too. The Dalit women were adult women (18 years and above) and the girls were of age nine years and above. I recruited women and girls from six families for this study.

Bala Chayan, my uncle served as a key informant for this study and provided research assistance. Bala Chayan has worked in the area as an advocate and ally for Dalit families. Due to this his work with the Dalit community for many years he has a deep understanding of the region and the people. Additionally, I have visited with several of the Dalit families on my prior visits to Kerala and they are familiar with me. I have spent time in some of the homes talking with the families, playing games with the children and eating meals with them.

Thus, on my arrival in Kerala, Bala Chayan and I sat down and started discussing possibilities about conducting fieldwork in the area. Working with Bala Chayan gave me entree into Dalit women's homes. I was unable to employ a female research assistant as I had originally planned because of scheduling conflicts, so he came with me for the initial informal visits and assisted me with preliminary interviews. The first step was identifying families that we could approach to participate in the study. Bala Chayan suggested some families with daughters in the 
Dalit colony that he has recently worked with, and approached them for me. We also identified families with multiple generations living together, such as families with grandmothers or mother in laws. He called them on their mobile phones and asked if we could come visit, or if they wanted to come to his house to talk. Thus, I started the process of approaching participants and setting up times to visit.

\section{Data Collection Methods}

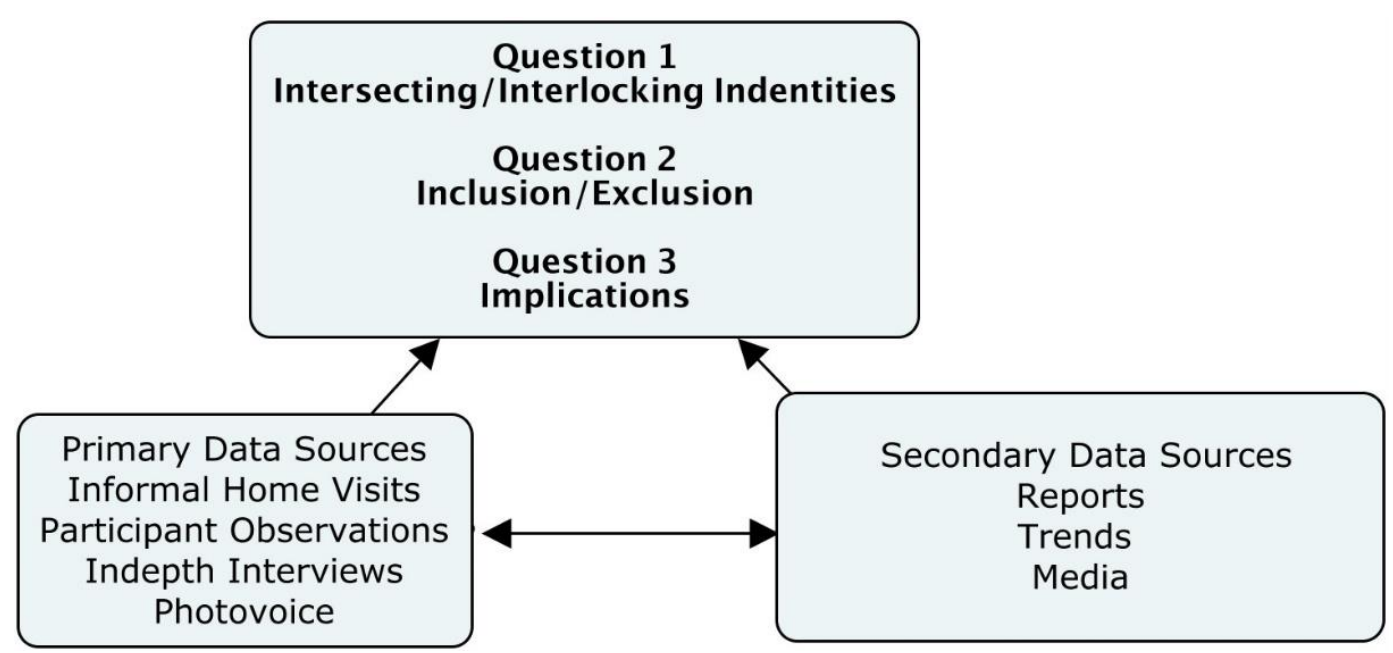

Figure 3. Phases of data collection

Figure 3 displays the various data collection methods that are utilized in this study and how the methods work together to address the research questions. Thus, to place the lives and experiences of Dalit women at the center of this inquiry and to achieve a deep understanding of their educational experiences, I used several data collection methods including participant observations, in-depth interviews, photovoice, and secondary document/data analysis. Feminist commitments have a role in all phases of the research process as they bring epistemology, methodology and methods together (Hesse-Biber, 2007). Thus, "to engage in feminist praxis and 
theory means to challenge knowledge that excludes while seeming to include" (Hesse-Biber, 2007, p. 3).

\section{Participant Observations}

Participant observation is fundamental in fieldwork as it provides the opportunity for a researcher to observe and to some extent participate in the lives of the participants (Lichterman, 2001). Participant observation was a continuous process during my fieldwork through many informal interactions such as casual spontaneous conversations and home visits and later in the form of more prescribed formal interviews. The daily spaces that the participants occupied and their willingness to share those spaces with me was integral in shaping my research. I wrote extensive field notes documenting my time in the field. According to Lichterman (2002) "The participant observer's prime source of evidence about a site is field notes. Field notes are detailed accounts of people, places, interactions, and events that the researcher experiences as a participant-observer" (p. 121)

A jotting from my field notes written after my first informal visit to Suman's house is seen below:

I went to Suman's house today for a quick chat. Suman lives on top of a steep mountain and her family needs to climb about 250 steps to reach their home. I went with Balan Chayan to their house as it was starting to get dark and I was not familiar with the area. We were greeting by children and were given sweetened black coffee. We sat on a wooden cot. Their house had two rooms and a small kitchen with posters of Che Guevara and Jesus, it was dimly lit, and they had electricity. We began chatting about the day; children came in and out of the room. Eventually everyone gathered around listening to 
us talk and chiming in about things like the heat and how he or she were waiting for the rain.... Suman said she had a busy day today, cooking, getting water for her family. Suman's husband's brother lives in the adjacent house, so his children (one daughter and two sons) were over. They spend most of their time at Suman's house because their mother left and their father drinks. Suman's mother-in-law came home from her chai stall when we were leaving. We did not talk for long as it was starting to get dark. The children walked us back to the car, Suman gave them strict directions to wait for me... they used flashlights to show us the way back to the car, they jumped from step to step in the dark, telling me to be careful, concerned about me falling, asking me if I wanted a boy or girl, how long I was staying for....when I will be back. I am going back tomorrow afternoon at 3 p.m. for my first interview with Suman. (DON'T FORGET FLASHLIGHT AND TO PEE BEFORE YOU LEAVE)

(Field note journal jottings about informal visit, $12 \mathrm{Feb}, 2015$ )

I was in the field for about two months. I arrived in Kerala around four months pregnant and was advised by my midwife that I needed to return to the U.S. before my third trimester started, which limited my time in Kerala. I was excited and nervous, and I felt like the clock was ticking. I began with a round of informal visits, which gave me an opportunity to talk to the women and introduce my work and myself. The informal visits to the women's homes were foundational to my fieldwork. The visits allowed for casual chatter, giggling and games with the children. The women asked me questions about my life and where I lived. This method helped me introduce the research to the participants and inquire about their readiness to participate in the study. I worked with the women to figure out what times worked best for them to talk to me or have me in their homes. I am aware that gaining access to women's lives in their homes is not 
the same as gaining trust. Feminist research suggests that if feminist researchers do not have the trust of the participants, they have failed as both researchers and feminists (Reinharz, 1992).

The informal visits also offered me space to begin grappling and revisiting my narratives about positionality which are fundamental in feminist qualitative work (Haraway, 1988). Haraway reminds us to consider feminist objectivity and to reflect on one's own limited location in constructing knowledge. Bhavani and Talcott (2012), expanding on Haraway, argue, "for research to be feminist, the researcher, aware of what this limited location implies, has to analyze the micro-politics of the research situation - that is, feminist researchers must explore, in public, what power dynamics come into play and when, how they shift, and what their consequences might be in the many different parts of their research" (p. 141).

I navigated and confronted issues of identity, difference, and power in exploring these said micropolitics in the field in the following ways. It was apparent very early from my informal visits in the field that I was not native but instead occupied a more transient space between multiple overlapping, shifting identities (Narayan, 1993). Firstly, as a diasporic Malayali woman who belonged to a higher caste and class position in Kerala society, I conducted research on a historically marginalized lower caste-class community. This power differential manifested itself in many small but significant gestures during my informal visits. At Uma's house, for example, she constantly apologized for her house, asking me to sit on the "good chair" or at Rinu's house where she took out her good chai glasses for me and asking me if would prefer boiled water instead of the water they drank. There was a vast distance between my interlocutors and me at some moments, but in others this distance seemed condensed. 
During my informal visits, my pregnancy became an icebreaker of sorts. The women asked me many questions about how I felt, offered me suggestions of herbal remedies for pregnancy-related aches and pains, and asked me if I wanted a boy or a girl baby. These moments filled with chatter about pregnancy; it felt like we shared a familiar human experience despite our vastly different social realities and positions. But my pregnancy also served as a reminder of gendered norms regarding motherhood in Kerala society. As a Malayali woman who has been questioned about my intentions about motherhood by my own family during my prior visits, I am acutely aware of the power it holds over women's lives. Riessman (2000) in her work on childless women in Kerala states, "The normative social biography for an Indian woman mandates childbearing after marriage. Motherhood is her scared duty—a value enshrined in religious law for Hindus, Muslims, Sikhs and Christians alike" (p.112). I knew that my conformity to marriage and childbearing served to endow me with the privilege of social acceptance. Thus, drawing on the early reflexive insights about identity, power and representation gleaned from my informal visits to the families, I began setting up more formal visits and interviews.

\section{Interviews}

Feminist research using interviews must be conducted relationally and reflexively (DeVault \& Gross, 2007). Thus it is essential to maintain that interviews are not just encounters but are embedded and crafted by "cultural considerations of similarity, difference and significance" (DeVault \& Gross, 2007, p. 181). Semi constructed and open-ended questions are in line with feminist research (DeVault \& Gross, 2007). This helped me gain access to the participants by exploring the greater social context and discourses that shape participants' responses (Appendix A). 
During my initial fieldwork, Bala Chayan accompanied me. I am fluent in spoken Malayalam but do not read or write the language, he ensured that subtle, contextual aspects of the research are properly relayed to the participants. He helped facilitate oral consent and assent processes for the study. I visited each family a few times per week based on their availability so that I can begin to build a relationship with them and they became more comfortable with me. However, some of the concerns in the field included being unable to talk to the women of the house without male members being present, especially during home visits. I believe that the conversations were more guarded based on who else is present in the home. I navigated and altered questions based on emerging situations.

I often met with the older generation of women first, and asked them to decide when it would be best for me to talk to the younger girls in the study. There was a diverse range of participants in this study with the youngest being 10 years (Kavita) and the oldest being 68 years (Kunyama). The women were kind and welcoming, offering their time to speak with me, despite their hectic schedules of going to work and taking care of their families. Speaking with the younger girls often began with chats about movies or actors or why my hair was cut so short or probing about my white American husband who they had seen me with during previous trips to the area. They were curious and funny, which made interview time friendly. Thus, working towards proximity and openness while working against distance (McDowell, 1992; England, 1994), I also observed how deeply introspective the young girls were about their complicated realities and the insufficiency of amenities they faced every day.

I conducted either two-three rounds of semi-structured in-depth interviews with recruited families based on their availability. I conducted individual interviews, but based on access and availability I also sometimes conducted interviews of mother-daughters dyads together. 
Additionally, in the case of minor daughters, I ensured that parental consent was gained first and parents were present for the interview if required. I informed the participants that the interviews would take at least 2 hours. Each interview began with a clarification about the purpose of the study and addressed issues of consent and confidentiality. The interviews were open-ended. All interviews were audio recorded if participants were comfortable with recording their voices. If participants are not comfortable, I took preliminary notes during the interview and wrote extensive notes (Figure 4) after each interview. I also took notes immediately after my visits so that I did not make my participants uncomfortable by constant scribbling in a notebook in a language that they are not familiar with. The interview used a semi-structured interview guide. (Appendix A)

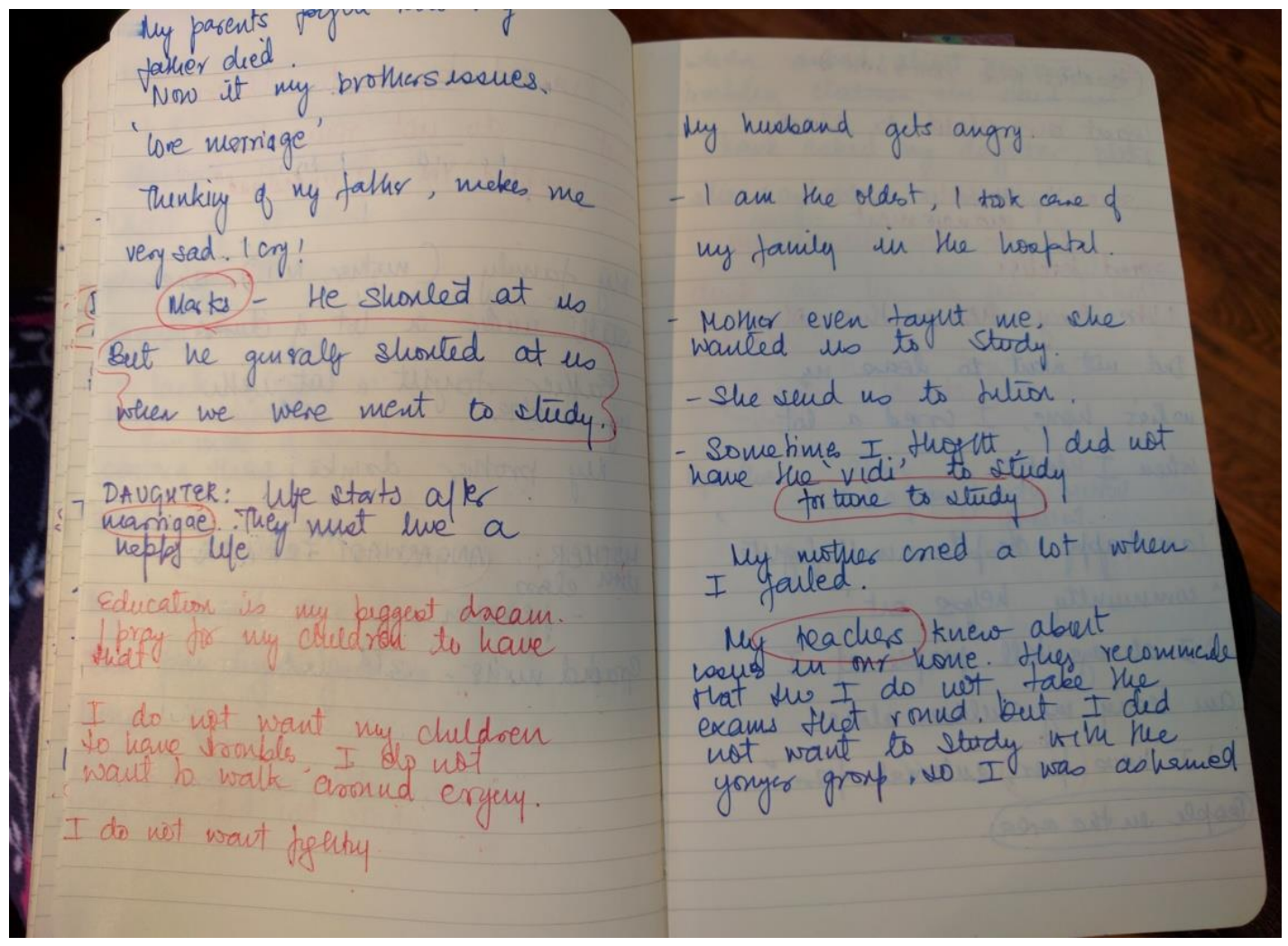

Figure 4. Personal photos. My field journal 
As I conducted the interviews, I spent time listening to interview recordings and making extensive notes about each encounter and conversation. This helped me prepare for the next round of interviews. I also had the opportunity to clarify and/or confirm my reading into the data in the next round of interviews. But I found this cyclic process through memoing (Rossman \& Rallis, 2003) of describing, analyzing and interpreting the data during fieldwork very helpful later as I approached formal translation and transcription.

The in-depth interviews were aimed at understanding their home and community lives and how gender, caste and class have shaped their educational opportunities, life chances and attitudes. Oberhauser (1997) argues that interviewing women in their homes gives the researcher the chance to learn about their lives and be a part of their surroundings. Further, she addresses the need "not to just observe, question, and leave, but to engage with them on their own terms, in their own space" (Oberhauser, 1997, p. 172). However, I was also flexible if the women did not want to speak in their homes, I asked them to suggest an alternative venue where they can speak freely. Some women chose to come to my uncle's house, so that we could speak privately.

\section{Photovoice}

Hall (1992) defines participatory research as a "social action process that is biased in the favor of dominated, exploited, poor or otherwise ignored women and men and groups" (p. 16). She suggests that the concern with power and democracy are vital for participatory research. Photovoice is an emancipatory participatory action research method that provides communities the opportunity to deliberate and reflect upon their strengths and concerns and helps to facilitate critical dialogue via discussions of photos (Wang \& Burris, 1997). Photovoice aligns with the tenants of feminist research as communities tell their stories and participants take on the role of 
co-researchers (Lykes \& Coquillion, 2007). Participatory research methods are considered culturally appropriate as they make room for the recognition of local and indigenous knowledges (Moffit \& Vollman, 2004). Thus, it privileges the voices and experiences of communities by shifting the power from the researcher to the participants.

Photovoice was conducted in conjunction with the interviews in this study. I issued disposable cameras to the girls in each household based on their willingness to participate at the end of the first round of interviews. I showed them how to use the cameras and provided instructions about taking photos ethically (Appendix C). The girls were asked to capture strengths and assets in their Dalit communities and homes (Wang \& Burris, 1997). I collected the cameras from them during the second round of interviews, developed the photos, printed them, and discussed the photos during the third round of interviews. An important aspect of using photovoice was to provide the participants with the chance to share their stories, ideas and explanations. Participants contextualized photographs using the SHOWeD Method (Wang \& Burris, 1997; Wang, 2006):

- What do you $\underline{\text { See }}$ here?

- What is $\underline{\text { Happening here? }}$

- How does this relate to $\underline{\text { Our lives}}$ ?

- Why does this situation, concern or strength exist?

- What can we $\underline{\boldsymbol{D} \boldsymbol{o}}$ to improve the situation, or to enhance these strengths?

I decided to include only the younger generation in the photovoice research as many of the women in the older generations said they did not have time to take photos during the day. Apart from going over general instructions about using cameras, I also spent time discussing 
how the girls must ensure their own safety at all times while taking photos. Wang and RedwoodJones (2001) assert that the safety of the participants must supersede the naturalness or impulsiveness of a photograph in photovoice. I followed the considerations of ethics and privacy that Wang and Redwood-Jones recommend, by addressing issues of private spaces and private lives with the photovoice participants. This often was a complicated conversation in a community where families are entitled to little private space in their homes and where the most private acts often took place in rather public settings. Thus, talking through examples of private acts was helpful in facilitating a dialogue about the privacy and ethics of photovoice.

The girls were very enthusiastic about taking photos and they took it very seriously. Lila, during her final interview, shared with me how her daughter Kavita had made her take a long walk around the area, chattering excitedly about having a camera and eagerly waiting to talk to me about the photos she took. The young girls took on the role of co-researchers by documenting and contemplating their community's assets and strengths. Thus, they worked towards deepening the conversation about their community and providing a platform for exploring gendered voices and concerns (Lykes \& Hershberg, 2012).

\section{Secondary Data Sources: Document Analysis.}

Public records are "ongoing, continuing records of society" (Webb and other, 1981, p. 78 as cited by Merriam, 1998). I also conducted a document analysis of government reports and public records, documents such Kerala Development Report from the Planning Commission. Furthermore, I also analyzed educational and socioeconomic trend information from government documents. These are publicly available government documents that are already translated into English. I analyzed documents that are available online on government websites. The rationale 
behind document analysis was to explore how the educational concerns and issues of Dalit communities are represented and addressed in government documents and in newspaper articles.

Another source of data in my study was the newspaper articles that I collected during fieldwork although I had initially not intended to add those as data sources. But the newspaper is an essential part of an Indian household across class and caste. I remember with much nostalgia how every morning, my family sat around the newspaper reading, talking and drinking our morning chai. Similarly, I began every morning of my fieldwork reading the English edition of the local newspaper. I took photos of articles and issues that were being discussed about gender, caste, class and religion. The articles provided me with a greater context of some of the local and national tensions that were relevant to my work. Thinking through some of the discourses of power and representation in the popular media helped to provide great insight into whose voices are represented and how in Kerala society. This idea is noted by Cole and Stewart (2012) when they state that "the habit of reflexivity—of continually revisiting and reframing questions in light of knowledge produced or insight gained - may support an iterative rather than a linear process" (p. 371). Thus, engaging in reflexity in the small acts of fieldwork like reading the morning newspaper served to provide great richness to the research process.

\section{Data Analysis Procedures}

I remember being told by a friend who has done extensive fieldwork back home in India that more than anything else I must be prepared for uncertainty and ambiguity. She said that often we set out with long lists and robust protocols but when you reach the field, one's willingness to be spontaneous and adaptive is just as important. Fieldwork for me was an oscillation between preparing with lists and protocols and engaging an experiment in 
spontaneity. I returned to Morgantown, U.S.A. armed with my data, a stirred conscience, and renewed motivation to contribute to civil and academic discourse about Dalit lives in Kerala. I had much work ahead of me, transcribing, translation, analysis and above all making sense of what it means in the context of my research questions.

The primary data sources include interviews, photovoice narratives, informal conversations and participant observations. The secondary sources include development policy documents and education and socioeconomic trend data. The secondary data helped in highlighting how current and past educational practices and policies have translated into patterns of inequality and access in modern day Kerala with respect to gender, caste, class and religion. The primary data was translated from Malayalam to English. Audiotapes were transcribed and any references to identifying information will be removed from the transcripts and replaced with pseudonyms. The transcripts were compared to the original audio files and notes for accuracy and reliability.

\section{Coding and Memos}

Data collection and analysis is a constant and iterative process in qualitative research, thus throughout the study I described, analyzed and interpreted the data, learned as I conducted my research (Rossman \& Rallis, 2003, p. 271). While dealing with large volumes of data such these, it is important to organize and manage the data. Thus, I began the analysis with an inventory of my data to ensure that the data translation and transcription was complete and accurate (Patton, 2001). I began data analysis by immersing myself in the data and by deeply reviewing the data, which includes the transcripts, my field, notes from observation and my document analysis notes. Following this, I wrote analytic memos and organized/sorted the data 
using line-by-line open coding. Rossman and Rallis (2003) suggest, "in-process analytic memos should be written in an exploratory, open ended narrative style" (p. 292). This form of inductive analysis, according to Patton (2001), helps the researcher find patterns, themes and categories in the data. The above-mentioned steps helped me manage, organize and begin the analysis process by helping me gain insight into my data.

Next, in the second cycle of coding I used NVIVO 10 student version software as a tool to aid my coding and categorize themes within the data. I deductively coded the data using analytic frameworks that integrate postcolonial feminist concerns and intersectionality to better capture and explain the complexity of Dalit women's experiences in Kerala. Coding schemes were developed to facilitate the analysis of data. Postcolonial feminist theory and intersectionality (Figure 2) served as both theoretical and analytic frameworks in this study as discussed in the previous chapter and presented again below in Figure 2, for my readers convenience.

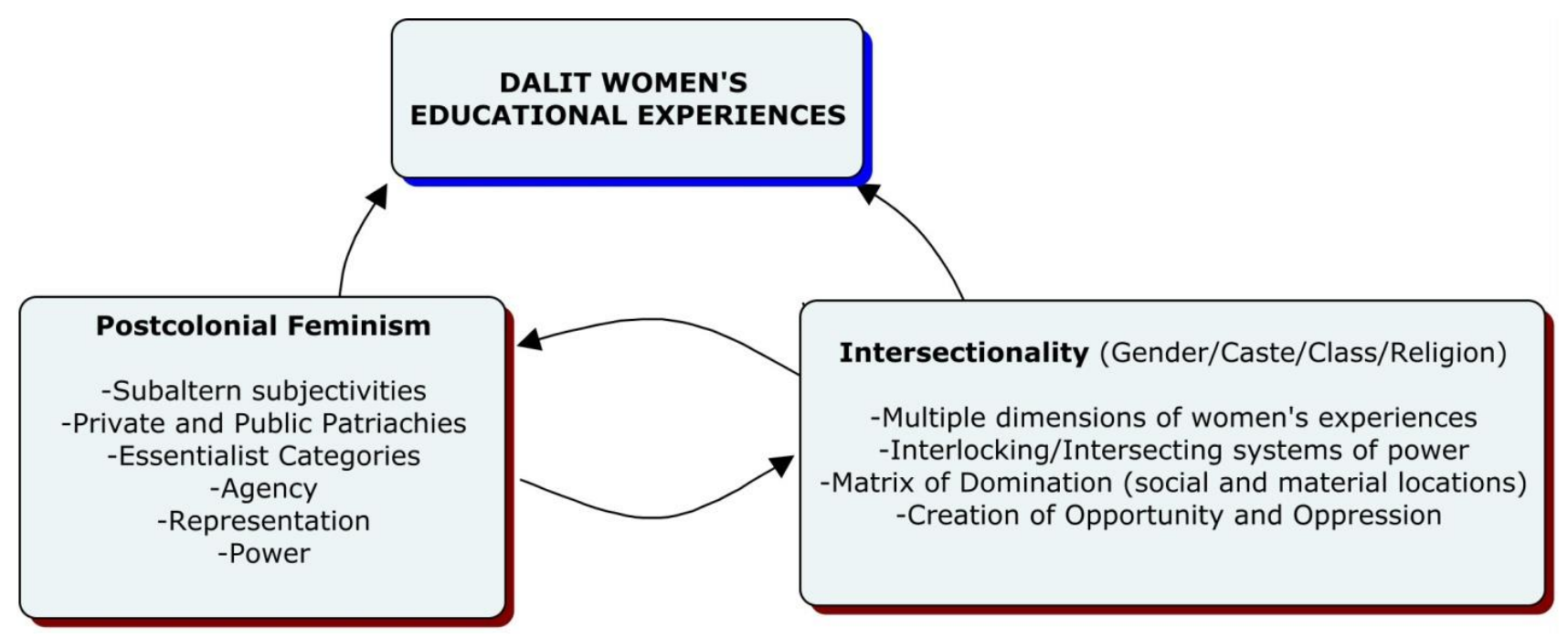

Figure 2. Conceptual framework 
For example, in the context of postcolonial feminist concerns, the data was deductively coded for themes such as private and public patriarchies in the context of women's lives (Table 2). This highlighted how educational experiences are shaped by both the private and public domains of their lives. Following which each account was analyzed using the intersectional framework to provide a deeper understanding of the data.

Table 2

Sample Coding Scheme for Postcolonial Feminist Concerns

\begin{tabular}{lcll}
\hline & Coding Theme & Sub Theme & $\begin{array}{l}\text { Example from } \\
\text { Participants }\end{array}$ \\
\hline Mother & Patriarchies & $\begin{array}{l}\text { Public } \\
\text { Private }\end{array}$ & \\
\hline Daughter & Patriarchies & $\begin{array}{l}\text { Public } \\
\text { Private }\end{array}$ & \\
& & & \\
\hline
\end{tabular}

According to McCall (2005), "Many feminists who are trained in social science methods and who are interested in intersectionality use the case study method to identify a new or invisible group — at the intersection of multiple categories — and proceed to uncover the differences and complexities of experience embodied in that location" (p. 1782). The intersectionality approach (Collin, 1991) helps to understand how women's lives are shaped by their multiple social and material realities. Thus, these intersecting/ interlocking systems, identities and locations create subjugation and opportunity for disadvantaged groups (Zinn \& Dill, 2009).

This dissertation used the Generic Intersectionality Template (adapted from Bilge, 2009, p. 7 as cited in Hunter, 2014) as a starting point for my intersectional analysis. Bilge (2009) advocates for a two-step approach. The first one is to do open and axial coding to identify 
emergent themes and patterns. The second step is deductively reinterpreting the data using the analytic template (Table 3).

Table 3

Generic Intersectionality Template

\begin{tabular}{|c|c|c|}
\hline Social categories & $\begin{array}{l}\text { Discrete considerations } \\
\text { (1st Step) }\end{array}$ & $\begin{array}{l}\text { Intersectional considerations } \\
\text { (2nd Step) }\end{array}$ \\
\hline Gender & $\begin{array}{l}\text { How gender informs this } \\
\text { individual account? }\end{array}$ & $\begin{array}{l}\text { How gender } \\
\text { interacts/interacts with other } \\
\text { social categories in this } \\
\text { individual account? } \\
\text { Or which dimensions of the } \\
\text { experience are interacting } \\
\text { with gender? }\end{array}$ \\
\hline Class & $\begin{array}{l}\text { How class informs this } \\
\text { individual account? }\end{array}$ & $\begin{array}{l}\text { How class interacts/interacts } \\
\text { with other social categories in } \\
\text { this individual account? } \\
\text { Or which dimensions of the } \\
\text { experience are interacting } \\
\text { with class? }\end{array}$ \\
\hline Caste & $\begin{array}{l}\text { How caste informs this } \\
\text { individual account? }\end{array}$ & $\begin{array}{l}\text { How caste interacts/intersects } \\
\text { with other social categories in } \\
\text { this individual account? } \\
\text { Or which dimensions of the } \\
\text { experience are interacting } \\
\text { with caste? }\end{array}$ \\
\hline Religion & $\begin{array}{l}\text { How religion informs this } \\
\text { Individual account? }\end{array}$ & $\begin{array}{l}\text { How religion } \\
\text { interacts/intersects with other } \\
\text { social categories in this } \\
\text { individual account? Or which } \\
\text { dimensions of the experience } \\
\text { are interacting with religion? }\end{array}$ \\
\hline
\end{tabular}

Note: Adapted from Bilge, 2009, p. 7

The coming together of the patriarchy and colonialism complicates the discrimination faced by women in nation states such as India along the lines of race, class and gender (Grewal, 
1996). Through integrating intersectionality and postcolonial feminist concerns (Figure 2), this research explores the multiplicity and complexity of Dalit women's lives in Kerala.

\section{Ethical Considerations}

Feminist research substitutes detachment with intimacy in the research process. According to Preissle (2007), "distance and intimacy create their own problems" (p. 527). Thus, it was essential that I made ethical decisions driven by justice throughout the research process that situates the women and their needs at the center of my work. Furthermore, I worked towards recreating unequal power relationships through the research process by continually questioning and reflecting on my motivations and research decisions. I also fulfilled the required university ethics requirements. I gained proper consent from the mothers and followed the process of assent for the daughters. I also clearly informed participants about the purpose of the study and the study expectations. 


\section{Profiles of the Women and Girls}

This section provides short profiles of the women and girls participating in this study along with a diagrammatic representation of each family.

Table 4

Study Participant Profiles

\begin{tabular}{llllll}
\hline NAME & PSEUDONYM & EDUCATION & OCCUPATION & AGE & RELIGION \\
\hline $\begin{array}{l}\text { Family } \\
\mathbf{1}\end{array}$ & Rinu & $\begin{array}{l}12^{\text {th }} \text { class } \\
\text { Computer Lab }\end{array}$ & Homemaker & 30 & $\begin{array}{l}\text { Cheramar } \\
\text { Christian }\end{array}$ \\
& $\begin{array}{l}\text { Certification } \\
\text { (Daughter-in- }\end{array}$ & $\begin{array}{l} \\
\text { law) }\end{array}$ & & & \\
& Anama & $5^{\text {th }}$ class & $\begin{array}{l}\text { Domestic } \\
\text { Worker until she }\end{array}$ & 59 & \\
& (Mother-in- & & got sick & & \\
& law) & & Employment & 38 & Cheramar \\
Family & Lila & $9^{\text {th }}$ class & Guarantee & & Christian \\
$\mathbf{2}$ & (Mother) & & Scheme & &
\end{tabular}

Kudumbashree

Janashree

\begin{tabular}{|c|c|c|c|c|c|}
\hline & $\begin{array}{l}\text { Kavita } \\
\text { (Daughter) }\end{array}$ & $5^{\text {th }}$ class & Student & 10 & \\
\hline \multirow[t]{3}{*}{$\begin{array}{l}\text { Family } \\
3\end{array}$} & $\begin{array}{l}\text { Suman } \\
\text { (Mother/ Aunt) }\end{array}$ & $\begin{array}{l}\text { Predegree } \\
\text { Nursing course }\end{array}$ & Homemaker & 43 & $\begin{array}{l}\text { Cheramar } \\
\text { Christian }\end{array}$ \\
\hline & $\begin{array}{l}\text { Savitha } \\
\text { (Daughter) }\end{array}$ & $\mathrm{BBA}^{24}$ & Student & 19 & \\
\hline & $\begin{array}{l}\text { Priya } \\
\text { (Niece) }\end{array}$ & $9^{\text {th }}$ class & Student & 14 & \\
\hline
\end{tabular}

${ }^{24}$ Bachelors in Business Administration 


\begin{tabular}{|c|c|c|c|c|c|}
\hline & $\begin{array}{l}\text { Kunyama } \\
\text { (Mother-in- } \\
\text { law) }\end{array}$ & $4^{\text {th }}$ Class & $\begin{array}{l}\text { Owns a chai } \\
\text { stall }\end{array}$ & 68 & \\
\hline $\begin{array}{l}\text { Family } \\
4\end{array}$ & $\begin{array}{l}\text { Mala } \\
\text { (Mother) }\end{array}$ & $10^{\text {th }}$ class & $\begin{array}{l}\text { Domestic } \\
\text { Worker } \\
\text { Community } \\
\text { Health Worker }\end{array}$ & 40 & $\begin{array}{l}\text { Cheramar } \\
\text { Christian }\end{array}$ \\
\hline & $\begin{array}{l}\text { Janu } \\
\text { (Daughter) }\end{array}$ & $9^{\text {th }}$ class & Student & 14 & \\
\hline
\end{tabular}

\begin{tabular}{|c|c|c|c|c|c|}
\hline \multirow[t]{4}{*}{$\begin{array}{l}\text { Family } \\
5\end{array}$} & $\begin{array}{l}\text { Sonja } \\
\text { (Mother) }\end{array}$ & $6^{\text {th }}$ class & $\begin{array}{l}\text { Employment } \\
\text { Guarantee } \\
\text { Scheme/ } \\
\text { Domestic } \\
\text { Worker }\end{array}$ & 40 & $\begin{array}{l}\text { Cheramar } \\
\text { Christian }\end{array}$ \\
\hline & $\begin{array}{l}\text { Devika } \\
\text { (Daughter) }\end{array}$ & $12^{\text {th }}$ class & Student & 17 & \\
\hline & $\begin{array}{l}\text { Lata } \\
\text { (Daughter) }\end{array}$ & $10^{\text {th }}$ class & Student & 15 & \\
\hline & $\begin{array}{l}\text { Ammachi } \\
\text { (Mother-in- } \\
\text { law) }\end{array}$ & $6^{\text {th }}$ class & $\begin{array}{l}\text { Domestic } \\
\text { Worker }\end{array}$ & 60 & \\
\hline $\begin{array}{l}\text { Family } \\
6\end{array}$ & Uma & $\begin{array}{l}\text { Predegree } \\
\text { Junior Diploma } \\
\text { course }\end{array}$ & $\begin{array}{l}\text { Lottery Ticket } \\
\text { Seller }\end{array}$ & 45 & $\begin{array}{l}\text { Pulaya } \\
\text { Hindu/ } \\
\text { Husband } \\
\text { Cheramar } \\
\text { Christian }\end{array}$ \\
\hline & $\begin{array}{l}\text { Simi } \\
\text { (Daughter) }\end{array}$ & $7^{\text {th }}$ class & Student & 13 & \\
\hline
\end{tabular}




\section{Family 1: Anama's Family}

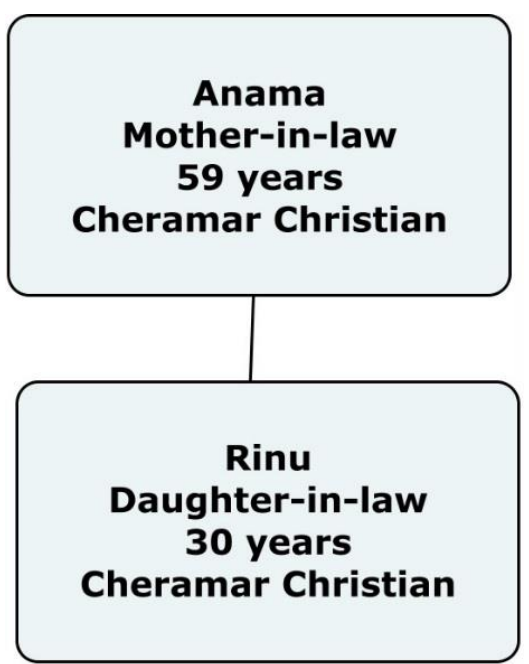

Figure 5. Anama's family tree

Anama cannot walk; she sits on a chair at the corner of her living room with her feet resting on a small wooden stool. Her home has posters of Jesus in it and she reads the bible in Malayalam every day. She lives with her husband, daughter-in-law, Rinu, and her granddaughter. Rinu is the primary caretaker of her in laws and daughter, as her husband works abroad. She studied until the $12^{\text {th }}$ class and did a computer lab certification. Rinu's favorite subject in school was history, as she likes reading about great people's lives. Rinu is computer literate and said that she recently found her friends on Facebook. 


\section{Family 2: Lila's Family}

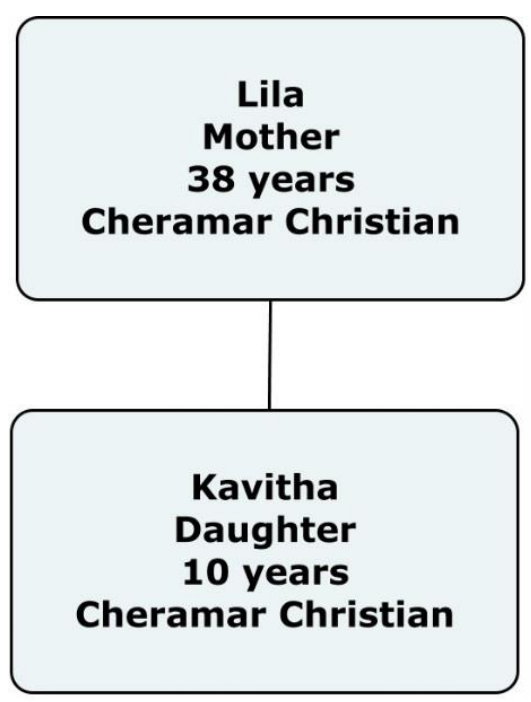

Figure 6. Lila's family tree

Lila studied until the 9th class and her non-formal education includes learning how to make soap to sell. She learned how to make soap on her own, using pamphlets as a guide. Lila is the primary provider for her family; her husband does not have regular employment. Lila participates in various government sponsored livelihood measures such as the Mahatma Gandhi National Rural Employment Guarantee Act (MGNREGA) ${ }^{25}$. Lila does manual labor for 100 days each year through the MGNREGA. She also participates in Kudumbashree and Janasree, which are female driven micro credit schemes of the Kerala government. She lives with her husband, father-in-law and her 10 year old daughter, Kavita. Kavita studies in the 5th class and her

\footnotetext{
${ }^{25}$ Mahatma Gandhi National Rural Employment Guarantee Act: Livelihood security for rural areas, which ensures 100 days of wage employment in a fiscal year to each family whose adult members volunteer to do unskilled manual work.
} 
favorite subjects in school are Malayalam and Math. Kavita loves school; she said that her teachers like her because she listens to them.

\section{Family 3: Suman's Family}

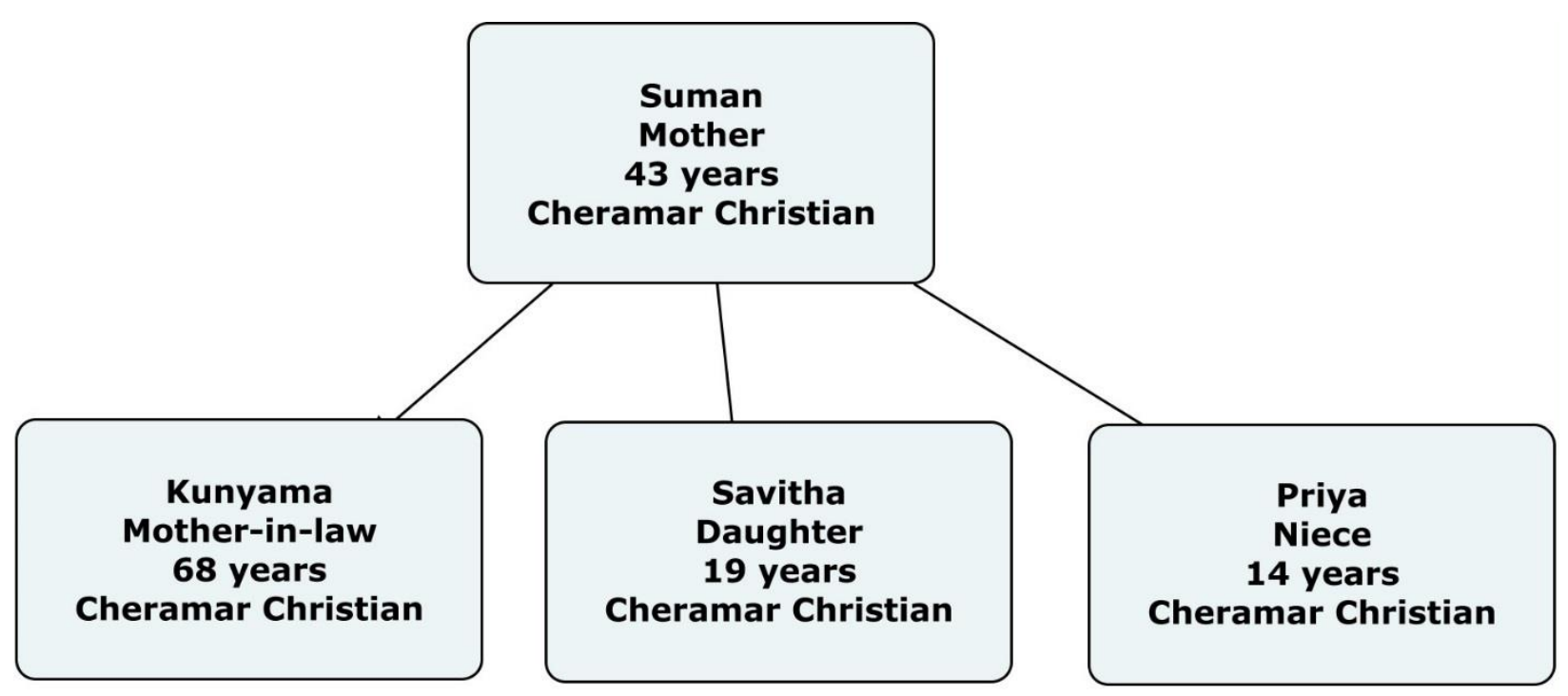

Figure 7. Suman's family tree

Suman studied until her pre degree ${ }^{26}$ but did not complete it. However, she went on to complete a nursing course and worked as a nurse for a few years. Suman stopped working after marriage. Suman lives with husband, daughter Savitha, and her son. Savitha is 19 years old and in college. She is working toward her Bachelors of Business Administration degree. Suman and Savitha live next to Priya and Kunyama. Priya's father is Suman's husband. Kunyama is Suman's mother-inlaw. Priya is 14 years old and studies in the 9th class. Priya is the primary caretaker of the house; she cooks and cleans for her family. Priya's mother left when she was little and her father

\footnotetext{
${ }^{26}$ An intermediate course of two years' duration and known as " $10+2$ ", conducted by state education institutions or boards in India.
} 
works as a mason. Kunyama lives with Priya. Kunyama is 68 years old and owns a roadside chai stall. Kunyama studied until the $4^{\text {th }}$ class and stopped studying when she got married.

\section{Family 4: Mala's Family}

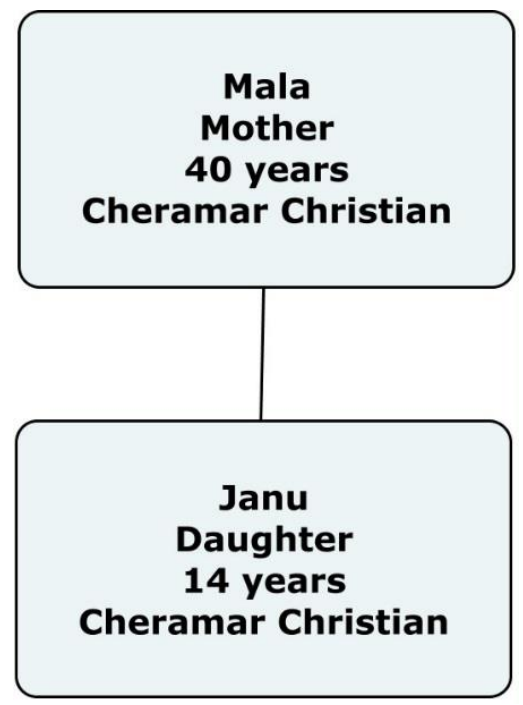

Figure 8. Mala's family tree

Mala studied until the $10^{\text {th }}$ class and her favorite subject in school was Biology. Mala spoke often of how she failed her 10th class twice and is deeply saddened about not finishing school. Mala works as a domestic worker in various houses and also works as an Accredited Social Health Activist (ASHA). Mala loves her work as a community health worker because she likes working with people. She worries about the health issues in the Dalit colony. She is very determined to provide prenatal care to pregnant mothers in the area. Mala's husband works in the "Gulf" ${ }^{27}$ as a laborer and sends money home. Mala lives with her daughter Janu and her son. Janu is 14 years old and studies in the $9^{\text {th }}$ class and her favorite subjects in school are Social Science and Hindi. After completing school, Janu wants to go to college to study the Humanities.

\footnotetext{
${ }^{27}$ Gulf in Kerala refers to the Middle East.
} 
Family 5: Sonja's Family

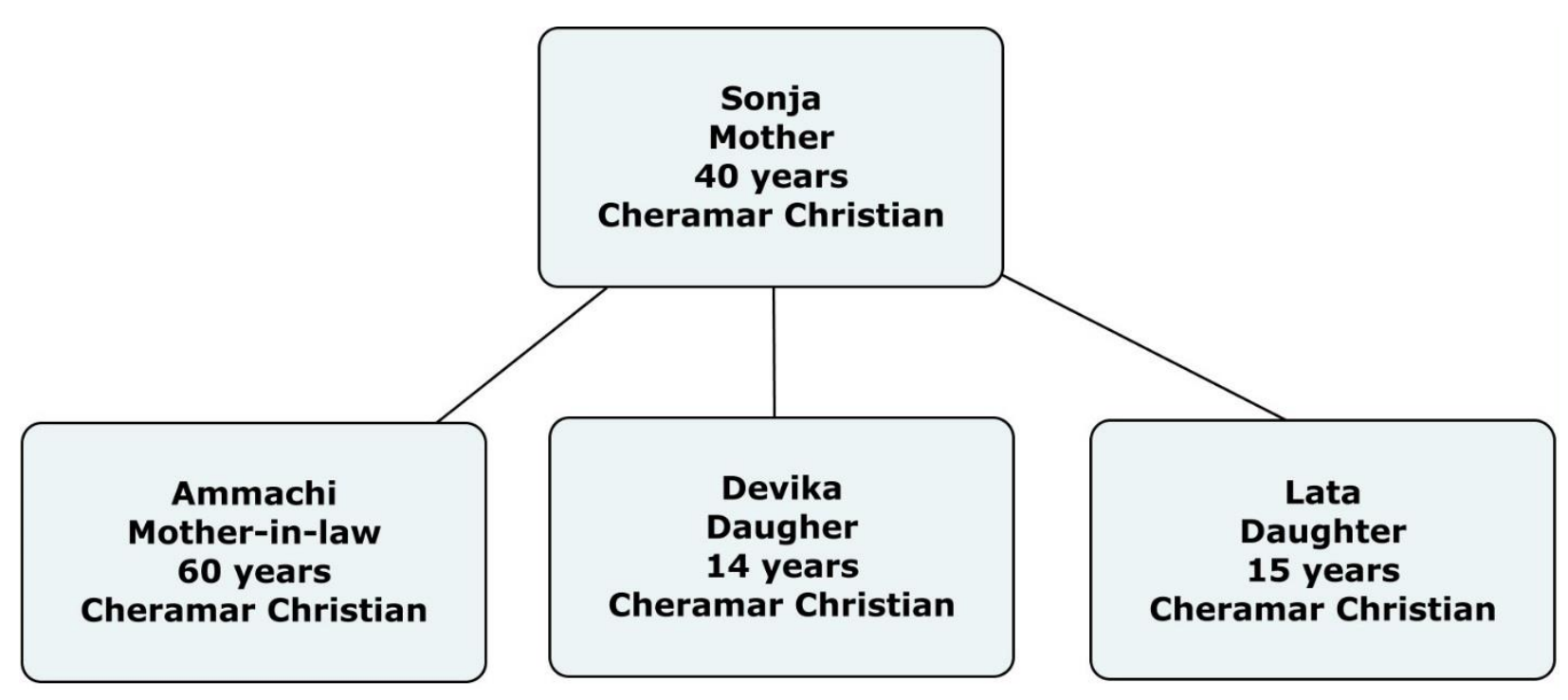

Figure 9: Sonja's family tree

Sonja studied until the $6^{\text {th }}$ class but did not continue her education, as she was struggling to clear her classes. She works as a domestic worker and also participates in various government sponsored livelihood measures such as the Mahatma Gandhi National Rural Employment Guarantee Act (MGNREGA). Sonja lives with her husband, two daughters, mother- in-law and father-in-law. Her older daughter Devika wants to study psychology in college. Sonja's younger daughter wants to study humanities in college. Both of her daughters study in government aided schools. Sonja's mother in law Ammachi is 60 years old and also studied until the $6^{\text {th }}$ class. She has worked as a domestic worker for many years. Ammachi said she loved learning Malayalam in school. 


\section{Family 6 Uma's Family}

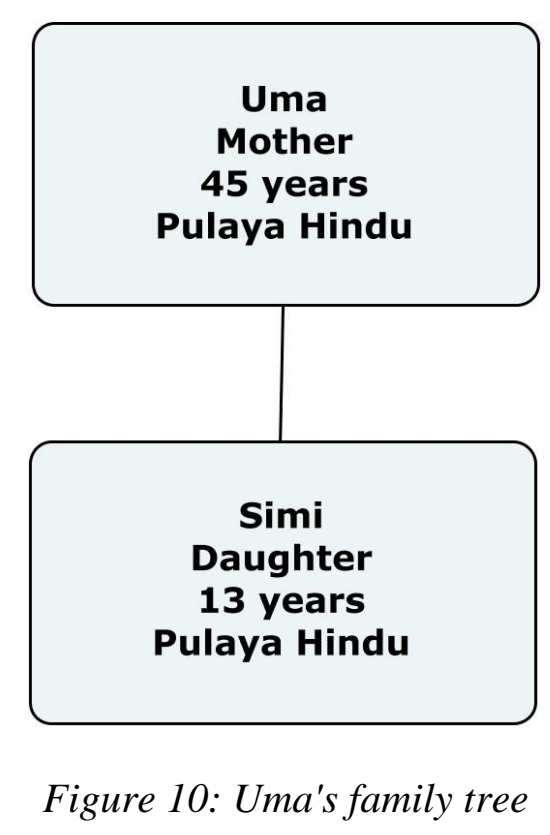

Uma studied up until the Pre degree level and also completed a junior diploma course ${ }^{28}$. She also learned how to make soap and body lotions through a community soap-making workshop. She sells soaps sometimes when she has time to make it. Uma and her husband sell lottery tickets at the local bus stand to support their family. She loves reading the newspaper and learning about Kerala politics. Uma lives with her husband and two daughters. Her older daughter Simi wants to either become a doctor or a police officer when she grows up.

${ }^{28} 10$ month course in technical education. 


\section{By Pottan Pulayan ${ }^{29}$}

Isn't it blood that oozes when you are wounded, Brahmin

Isn't it blood that oozes when I am wounded, Brahmin

Then why ask about my caste

${ }^{29}$ The questioning of a Brahmin (upper caste) by an "untouchable" about the irrationality of the caste system. The Oxford India Anthology of Malayalam Dalit Writing (2012). 


\section{Chapter 4: Material and Social Locations}

This chapter is a discussion of the material and social locations held by women and girls in the Dalit communities in Kerala. I explore this in the context of marginality (William, Vira \& Chopra, 2011) first in terms of spatial dimensions of marginality which establish subaltern communities in a state of physical separation, and second in terms of social marginality, which refers to how social structures such as caste maintain subaltern communities in a state of economic and resource inaccessibility. Thus, the spatial and social interact to establish and maintain subaltern marginality (William, Vira \& Chopra, 2011). Thus, this chapter is organized into two dominant themes.

Firstly, I attend to the theme of spatial marginality. This theme describes the material conditions and deficiencies of the Dalit communities in Kerala. Drawing on interview data, photovoice data and fieldwork observations, it seeks to contextualize Dalit lives as they occupy marginal spaces in Kerala society. But this theme seeks to move beyond documenting these said material realities as it seeks to emphasize how the material realities are sites of everyday acts of subaltern negotiation and resistance. Secondly, I attend to social marginality, which surveys the conditions of poverty that are established by multiple and overlapping patriarchies in Dalit lives. I draw specific attention to how caste based occupations such as low paying waged labor exacerbates their deprivation. Furthermore, I demonstrate how exploring gendered consequences of labor for Dalit women in the colonies helps to draw attention to a more nuanced consideration of Dalit women's agency and power. 


\section{Spatial Marginality Vellam Ella ${ }^{30}$}

Dalit colonies in Kerala are pockets of poverty nested in rural and urban landscapes. They are systematically excluded and spatially separated from the mainstream community. Early writing about the Dalits (Iye, 1909 as cited by Alexander, 1968) described their clothing and homes:

The bark (spathe) of the areca palm furnished, some places, the whole of their clothing, which at best never exceeds a bit of cloth merely sufficient for purpose of decency. Their hair is allowed to grow wild and forms an immense matted filthy mass. Their houses called madam (hut) was devoid of any furniture and was extremely dirty and filthy. (p.1071)

Thus, their bodies were described as unclean, dirty and often lacking hygiene, as in a slave community. Their homes were described as madam or huts speaking to the dismal temporary housing, which lacks amenities and access. This narrative can be seen even in contemporary Kerala where the physicality of the Dalit home is symbolic of physical exclusion and also of a deeper social exclusion based on caste in Kerala society. Devika (2015), addressing pockets of poverty in Kerala, asserts that "the state uses the strategy of marginalization by abjection where people facing abjection are thus not just marginal; they form the constitutive outside of the exclusionary order" (p. 6). Thus, communities such as the Dalits are maintained in a state of abjection, material deprivation and spatialized inequalities in Kerala. However, Indian subaltern scholars remind us to consider how marginal spaces such as colonies and slums in India despite being seen as spaces of deprivation, also constitute spaces of power and identity (Chatterjee,

\footnotetext{
${ }^{30}$ Meaning "no water" in Malayalam.
} 
2004; Appadurai, 2001). Thus, this theme attends to both the abjection and negotiation of power in the context of Dalit lives in present day Kerala.

The Dalit colonies that are included in this dissertation are located in a valley surrounded by mountains and dense greenery or on top of a mountain. The Dalit colonies or settlements are a cluster of homes, some with permanent roofing and others without, some with doors and some with sarees hanging as cover, as seen in the pictures taken during fieldwork (see Figure 11). The homes in the colonies are not only structurally inadequate but also lack running water, sanitation and electricity.

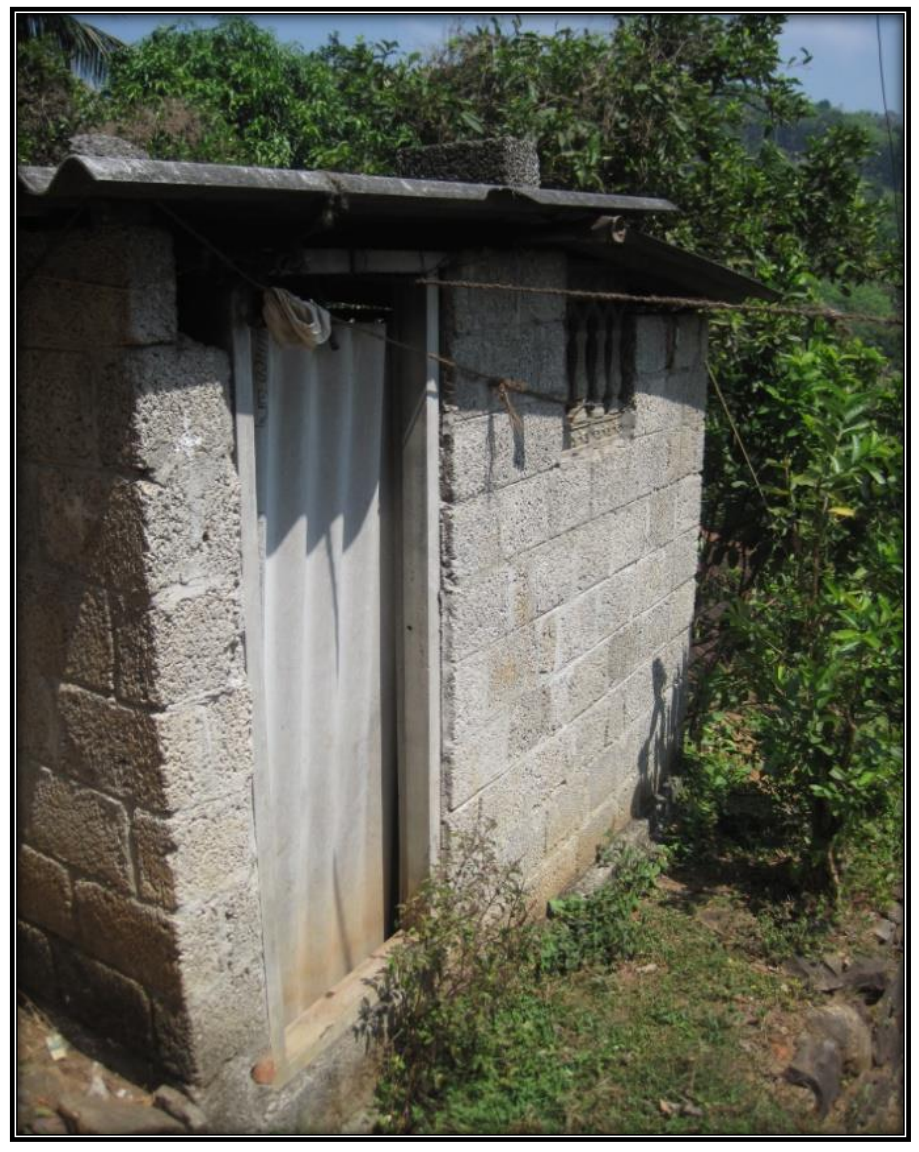

Figure 11. Houses in the Dalit colony (left and below) Personal pictures taken during fieldwork 


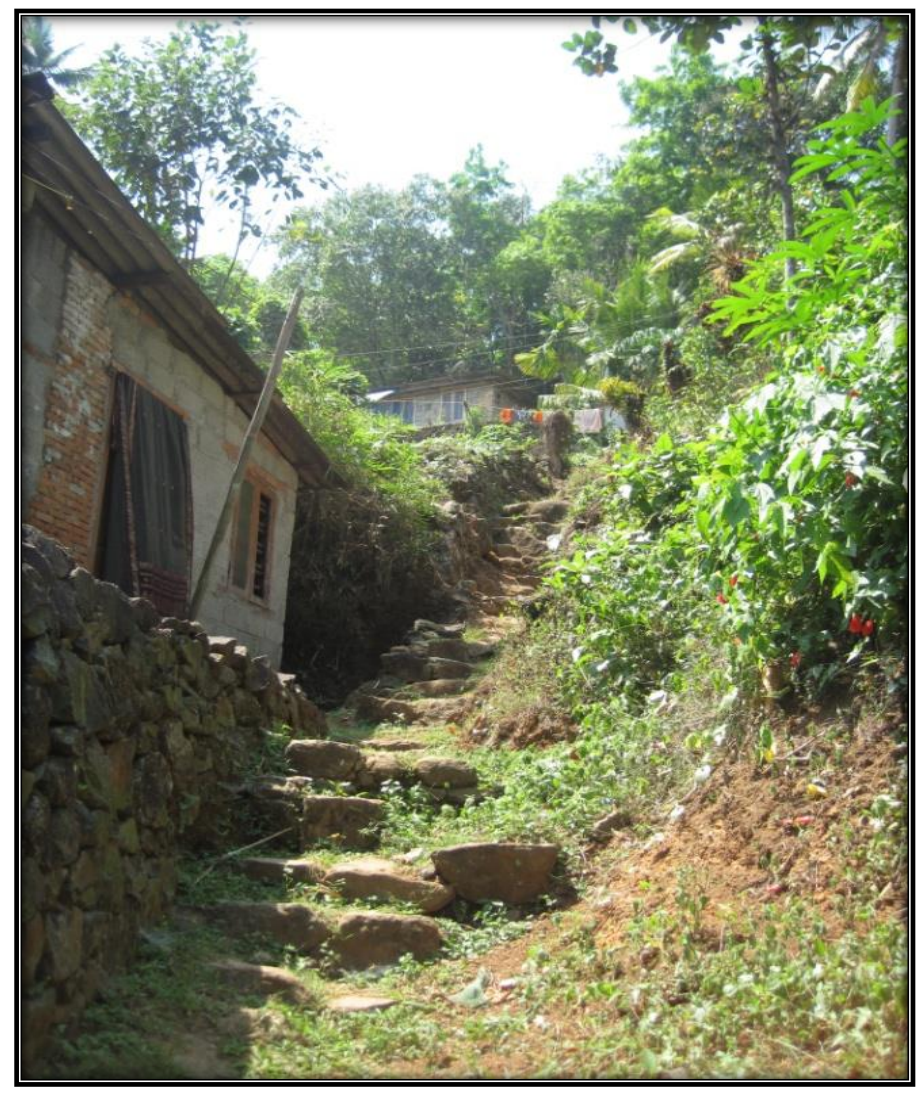

RESISTANCE \& AGENCY 81

I also observed these conversations of insufficiencies in Dalit colonies in the local newspapers when I was in Kerala for fieldwork. The newspaper article below from the Kerala Times of India ${ }^{31}$ (Figure 12) addresses drinking water issues in residential scheduled caste colonies. The author explains how the colonies are occupied by the "financially backward" and he champions the efforts of the police in providing "free" water to the colonies. This newspaper article exposes two vital concerns. First, the depictions of the Dalit communities were represented as lacking, deficient and struggling without a lack of exploration of why the Dalit communities in Kerala continue to struggle without water across generations. Secondly, there is the problematic championing of the help that the police give to the Dalit community in the form of "free water." The police are instruments of the state and this redeems the state from having any public accountability in the water crisis faced by the Dalits. This is a prime example of the

\footnotetext{
${ }^{31}$ Newspaper articles used in this chapter are from the English edition of The Times of India, Kerala.
} 
disconnection between Kerala's public dialogue and the state's failure to promulgate a true understanding of Dalit needs (Devika, 2010).

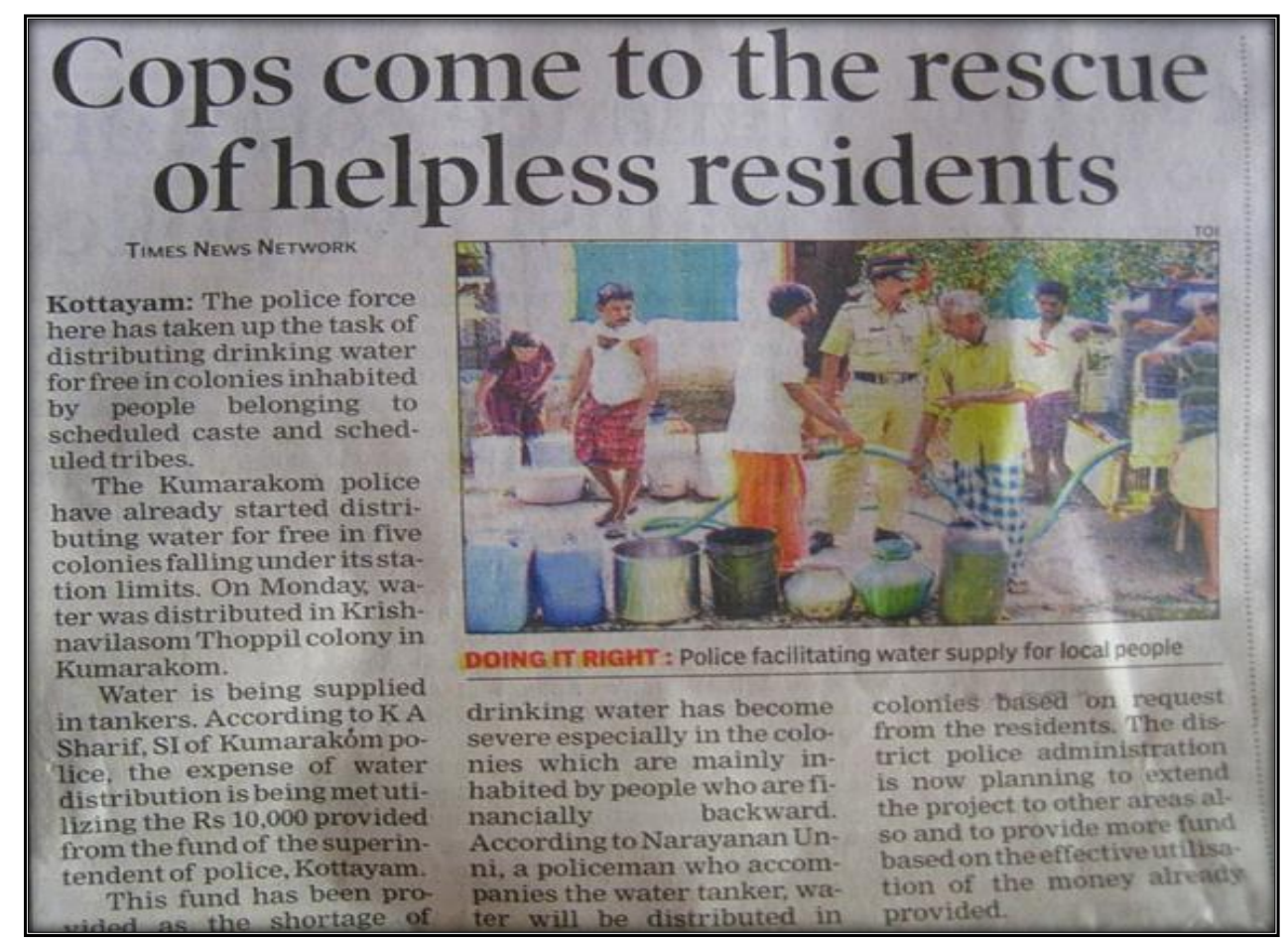

Figure 12. Newspaper article. Times of India, Kerala edition, March 2015.

Study participants experienced this politics of location in personal ways in their everyday lives. Few participants spoke of the colony as indispensable to their identity despite the problems that they faced, giving them a sense of community and belonging by being surrounded by friends and family. Others, however, spoke of the colony in terms of their struggle for lack of basic amenities like water, electricity and sanitation. Lila and her family ${ }^{32}$ live in the Dalit colony in the valley (Figure 13). Lila's 10-year-old daughter, Kavita, took photos of her house in the colony and of another house of a higher class and caste family that she passes on her way home from school (Figure 14). Kavita said that she loves her house because her family lives in it together. She likes having her chickens and the neighbor's dog to play with. However, Kavita

\footnotetext{
${ }^{32}$ See Study Participants, Table 4 and Family Tree, Figure 6.
} 
was worried about the cracks in the walls in her house and she said it can be dark in the evenings. She thought things would be better for her family if they lived in the white house because it is equipped with water and electricity. Her daily actions, like walking by this white house, reinforce her subaltern location in Kerala society.

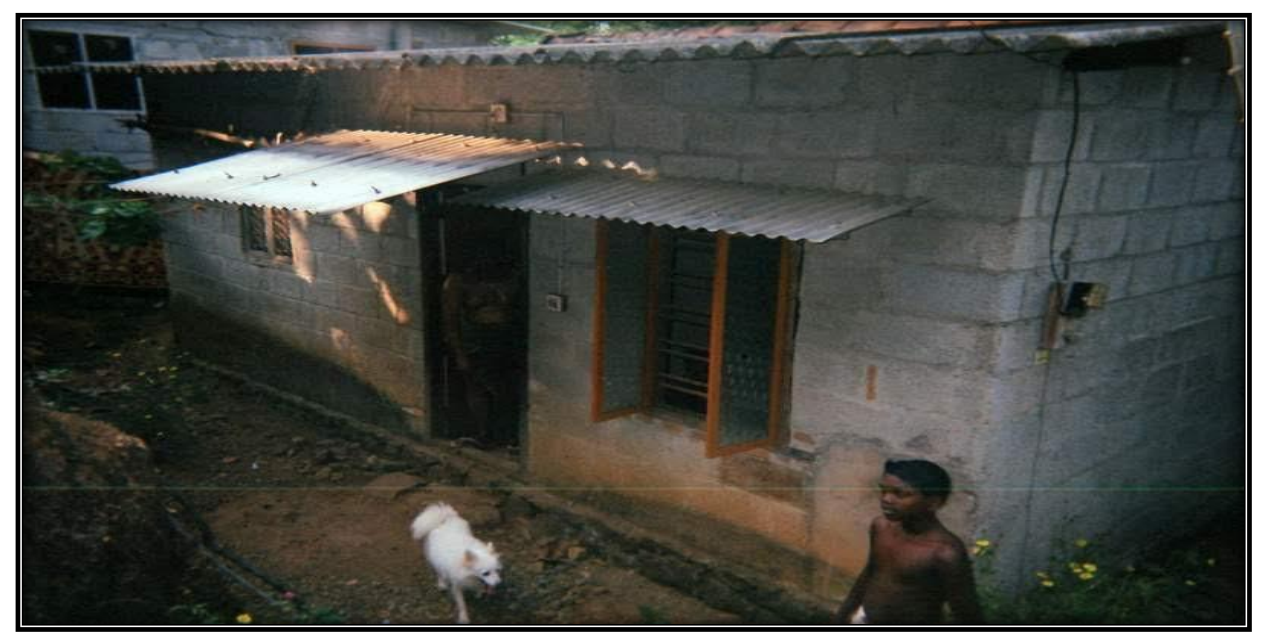

Figure 13. Kavita's photovoice photo: Kavita's home.

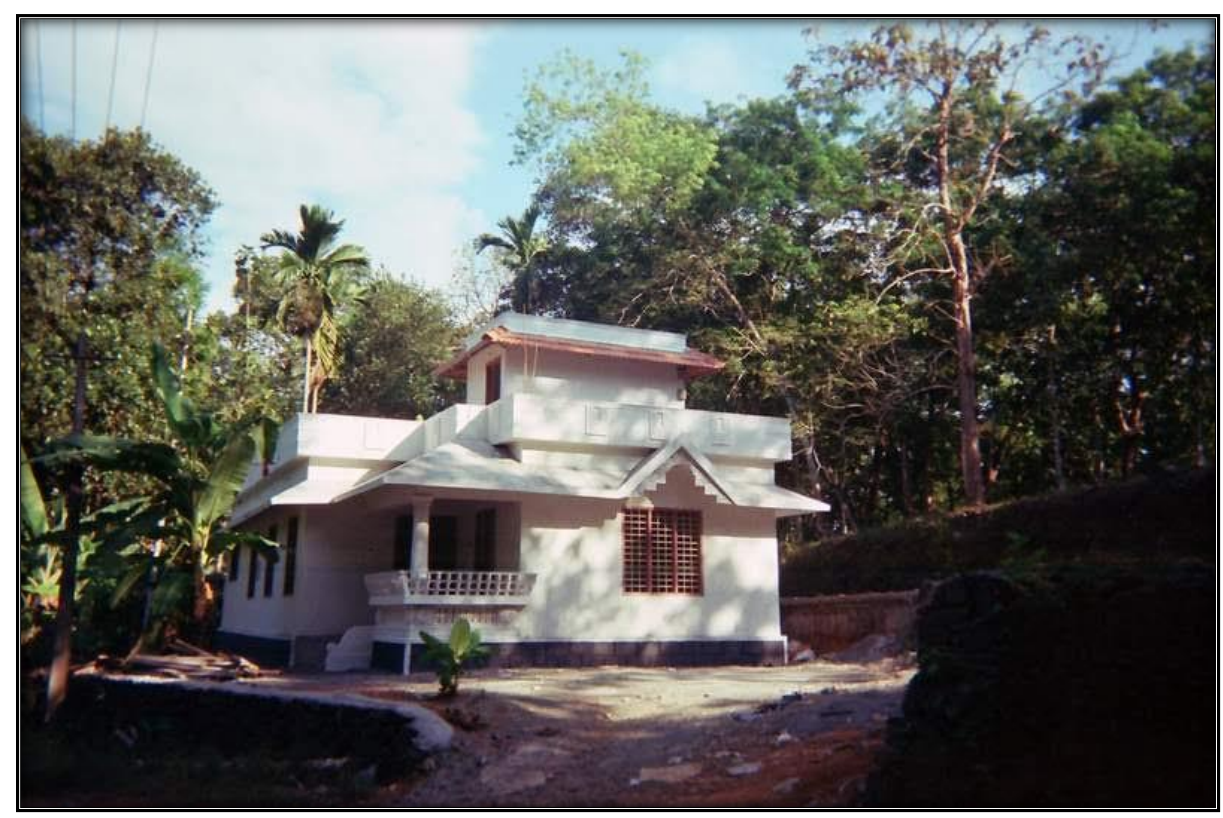

Figure 14. Kavita's photovoice photo: The white house that Kavita passes on her way home. 


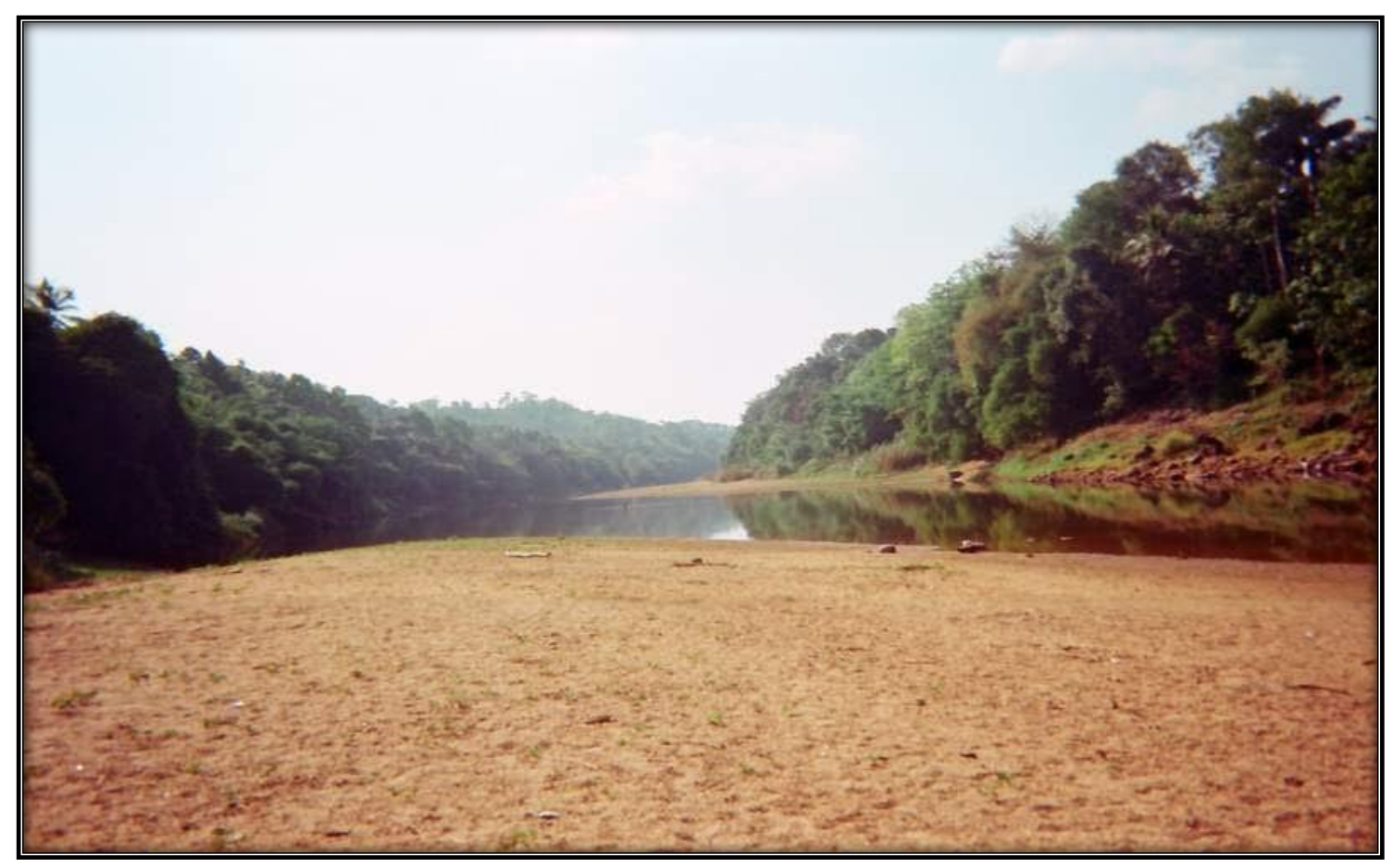

Figure 15. Kavita's photovoice photo: The river that Kavita bathes in.

Lila's family, like others in the colony, struggle perpetually with a lack of water.

Speaking about the lack of water in the colony, Lila (Mother, 38 years) said, "We do not have running water, we collect water and keep it in pots from the river. We get water for six months, the government tanks do not work." Ten out of fifteen photos that Lila's daughter Kavita (10 years) took about community assets and strengths were about the river. At age 10, Kavita was well aware of her social and material locations. Kavita spoke of the river as elemental (Figure 14) to their lives, however she also articulated concerns about the pollution in the water. She said that she sees plastic bottles and other garbage often floating through the water.

For women and girls in the colony the river is not only symbolic of a water source, it also represents a source of domestic labor, where the physical burden of carrying water is placed on them by their position as women in a household. Thus, it is essential to draw attention to how "women and men, colonized and colonizer, negotiate their positions in space through an 
interrogation with their respective social positions" (Mills, 2003, p. 694). Suman's (Mother, 43 years ${ }^{33}$ ) family lives in the colony on top of the mountain. She spoke of how her family has to climb over 250 steps to access water. Both Savitha (Suman's daughter, 19) and Priya (Suman's Niece, 14) also took photos of water sources as community assets (Figures 16 and 17). When asked about their photos, Savitha spoke about the significance of the water tap for her family. She said, "If that tap does not have water, we have to wait on the water tanker to come. It does not always come." Priya said that the steps not only gave her family access to water but without the steps, she would not be able to make her way easily to school or church. These are harsh circumstances. Climbing steep steps with pots of water, sometimes in the dark, is a grueling process. Suman said that the families in the colonies have repeatedly asked local government officials to address their water problems but nothing has been done so far. Thus, these everyday acts of subaltern negotiation are acts of resistance in the face of hegemonic power structures (Chandra, 2015).

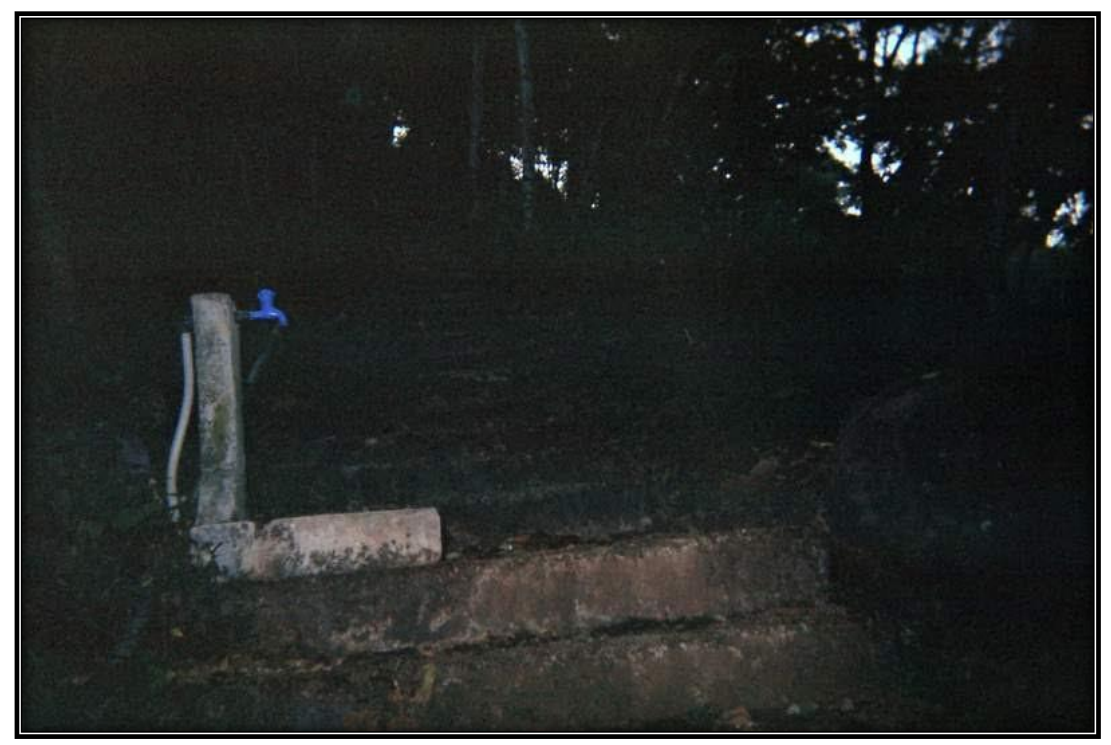

Figure 16. Savitha's photovoice photo. The water tap on the steps to Savitha's house.

${ }^{33}$ See Study Participants, Table 4 and Family Tree, Figure 7. 


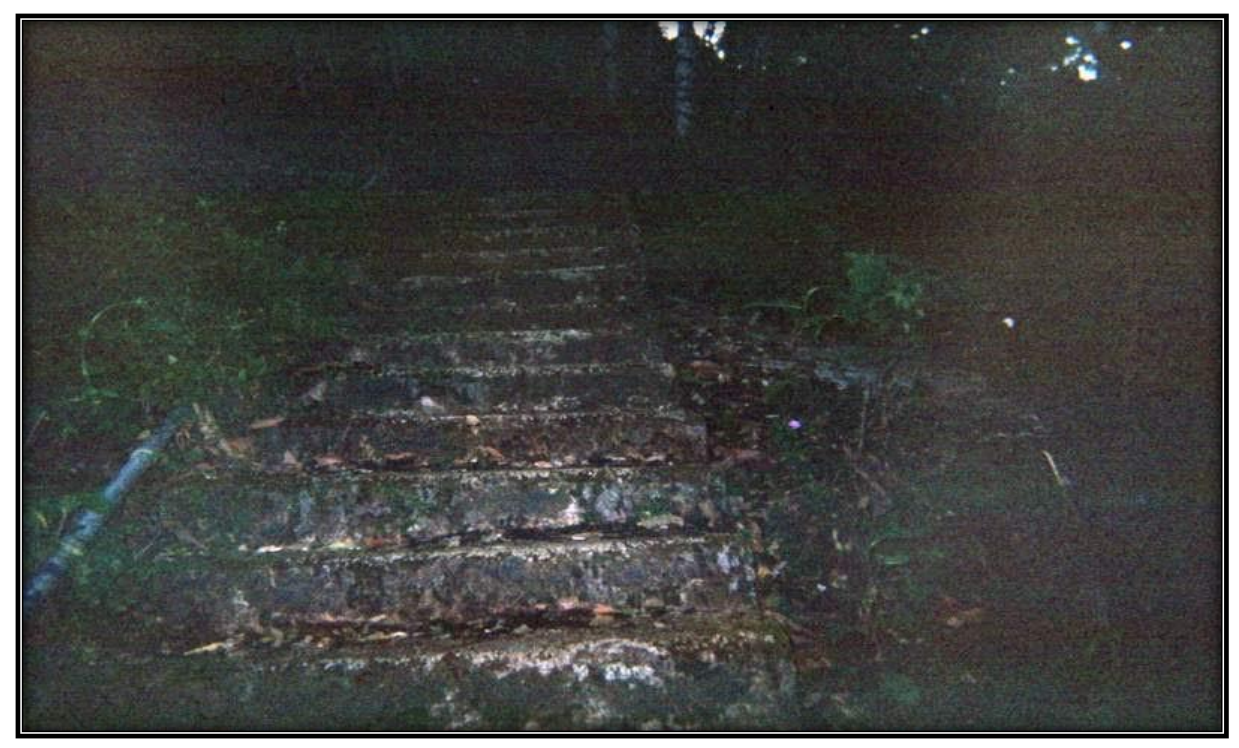

Figure 16. Priya's photovoice photo. The 250 steps that lead to Priya's house

A Dalit woman's life is often spoken of as bearing the triple burden of caste, class and gender (Still, 2011). Gender adds another dimension to these acts of everyday negotiation and resistance. It is important to note when the state fails in the provision of amenities, the responsibility of catering to the family's needs fall on the woman. Dalit men in the colony often do not carry the load of domestic work such as collecting water. There is "housewifization" of labor (Mies, Bennholdt-Thomsen \& von Werlhof, 1988), which confines women's work to the domestic sphere and does not value the work that they do in that sphere. Dalit men and boys in the colony are privileged because they do not carry this burden of domestic work. Dalit girls and women in this study spoke of how this lack of basic amenities translates into an exacerbation of gendered burden, which subsequently affects their engagement with education. Suman's family's intergenerational narratives of constraints and possibilities reveal how their location shapes their education. Suman wants her 19-year-old daughter Savitha to study instead of doing household chores like spending the evening bringing water to the home. Suman tells her daughter, "Study study, and don't be like your parents. Do not stay on the mountain." She sees 
education as redemptive from a life of struggle in the Dalit colony. Suman spoke of how her own mother encouraged her to study and take part in school activities. However, Suman struggled to study. She said, "We did not really have space in our house to study, we had a bed and some chairs. We sat outside, there were rocks nearby, and we would sit on them and study. When it was dark, we would take a lamp, a kerosene lamp. If it was windy, the smoke would get into our eyes."

Things are different for Suman's daughter. Savitha is in college and is studying for her degree in Business Administration. Savitha lives in a small cramped house like her mother but has the benefit of electricity in her house, something that her mother did not have. Also, Suman does not ask her daughter to do domestic work, but instead asks her to focus on her education, giving Savitha time after she returns home from college to focus on her studies. However, Suman's niece, 14-year-old Priya, lives in the adjacent house. Unlike her cousin, she does not have electricity in her home. Along with a lack of electricity, Priya carries the responsibility of cooking, cleaning, and carrying water for her brothers and father because her mother left because of domestic violence in the home.

Priya (Suman's Niece, 14 years), speaking of how home responsibilities coupled with a lack of electricity impedes her education, said: "I get up at 4a.m., cook, get fire wood, wash clothes and then go to school. The canal is $15 \mathrm{~km}$ down the road. My biggest burden is house issues, the burden is too much. I study in the evenings if I can, or during breaks at school. I do not have time to study at home." Priya navigates a very different social reality than her cousin Savitha who lives next door. A lack of parental support, a lack of basic amenities, domestic chores create a home environment that limits Priya. She said she studies when she can, such as in 
school during lunch breaks or between classes. Priya navigates her education in an environment that fails to cultivate and support her education.

This intergenerational account from Suman's family shows the intricacy of Dalit women's lives and how it shapes their engagement with education. Gender interacts with class and caste to shape and create opportunities. Thus, it is crucial to consider the cost of gendered labor in communities that live in poverty (Lewis \& Lockheed, 2006; Stromquist, 2001). This attention to gender specific needs such as accounting for the burden of domestic work must be an important consideration in educational policy (Aikman \& Unterhalter, 2007). Furthermore, understanding Dalit lives in the context of intersecting and interlocking hierarchies of identities (Collins, 1991) helps draw attention to how oppression and opportunity is created in their lives. This reconceptualizing of oppression and privilege helps us to also consider those who are not able bodied or the elderly who live in the colony, and their continued struggle to access basic amenities.

Both of the examples (Lila and Suman) highlighted in this theme thus far have been Dalit Christians (Christian converts). Uma's family ${ }^{34}$ is Dalit Hindu and they are the only Dalit Hindu family in this dissertation. This intergenerational narrative about a struggle with basic amenities was also seen in Uma's (Mother, 45 years) family. Uma's family does not live in the colony but in a rented home. Also her family is the only family among the participants that resides outside the colony. When I inquired as to why they lived outside the colony, Uma indicated that living outside the colony would be better for her children and provide better access to water and electricity. Uma spoke of how Dalits bring discrimination on themselves because they are not clean. Discussing this, she states: "If people in the community do not bathe, people will look

\footnotetext{
${ }^{34}$ See Study Participants, Table 4 and Family Tree, Figure 10.
} 
down on them, they spoil the name of the Jati ${ }^{35}$. I always bathe." Uma is better positioned to access water because her family has a well in their yard. Uma spoke often about her attention to her home, her family's hygiene and how she was not like the rest of her community. She was determined to pass as having characteristics often associated with upper caste and class communities such as being clean and well groomed. Uma deliberately avoids caste marking as a way to position herself as upper caste (Lukose, 2006).

Uma's desire to project herself as a well-groomed, clean Dalit woman is indicative not just of her own personal agentic motivation for hygiene. It also speaks to how she strives to set herself apart from the rest of the community. However, Uma's actions are not simple actions. They speak to the intricacy of caste in Kerala society. Lukose (2006) addressing this navigation of caste in Kerala society states, "passing focuses out attention on the actual dynamic and politics of traversing caste geographies. In particular, the formulation of passing helps to focus our attention on the secular modern as a space of a highly ambiguous caste erasure that is negotiated differently by upper and lower castes" (p. 50). This negotiation of caste for lower caste Dalit women is a way of surviving in the society that does not offer the same amenities and opportunities to all citizens.

Uma also reminisced during her interviews about her own education and how a struggle for basic amenities shaped her educational engagement. In one of her accounts she said: My mother encouraged me to study, she got up at 4 a.m., gave us black coffee and called us to study. We did not have electricity, so we would blow out the lamp and go back to sleep. I was very smart, never thought I would sell lottery tickets. I wish I had studied

\footnotetext{
${ }^{35}$ Refers to caste.
} 
some more, listened to my mother. I wish I had not blown out that lamp, and that I had studied.

Uma's statement above highlights her own negotiation of life as a young Dalit girl as she reflects with some remorse on her own desires and voices confidence in her abilities while speaking to the material constraints that limited her education. This illuminates that "voice is often assumed to reflect both consciousness of one's interests and an expression of agency" (Ardener 1975 as cited by Rao, 2014, p. 8). Thus, Uma's voicing of her own desire and decisions speaks to her agency.

Furthermore, Uma is determined to ensure that her daughter Simi does not face some of the restraints that she did, which is one of the reasons why she chooses to live outside the Dalit colony. Uma's daughter Simi (13) took photos of water and electricity as community assets (see Figures 18 and 19). During her interviews Simi spoke of how having a well in her yard and a toilet along with an electric connection saves her family time. Simi spoke of how she does not have to spend time getting water, which helps her focus on her homework in the evenings. Also most evenings, by the time Simi and her sister get home it gets dark as they often go to their parents lottery stand after school. The electricity in their home enables her to do school work at night before she goes to bed. These narratives speak to a young Dalit girl's navigation of education and how having basic amenities in the home contributes greatly towards increased educational engagement. 


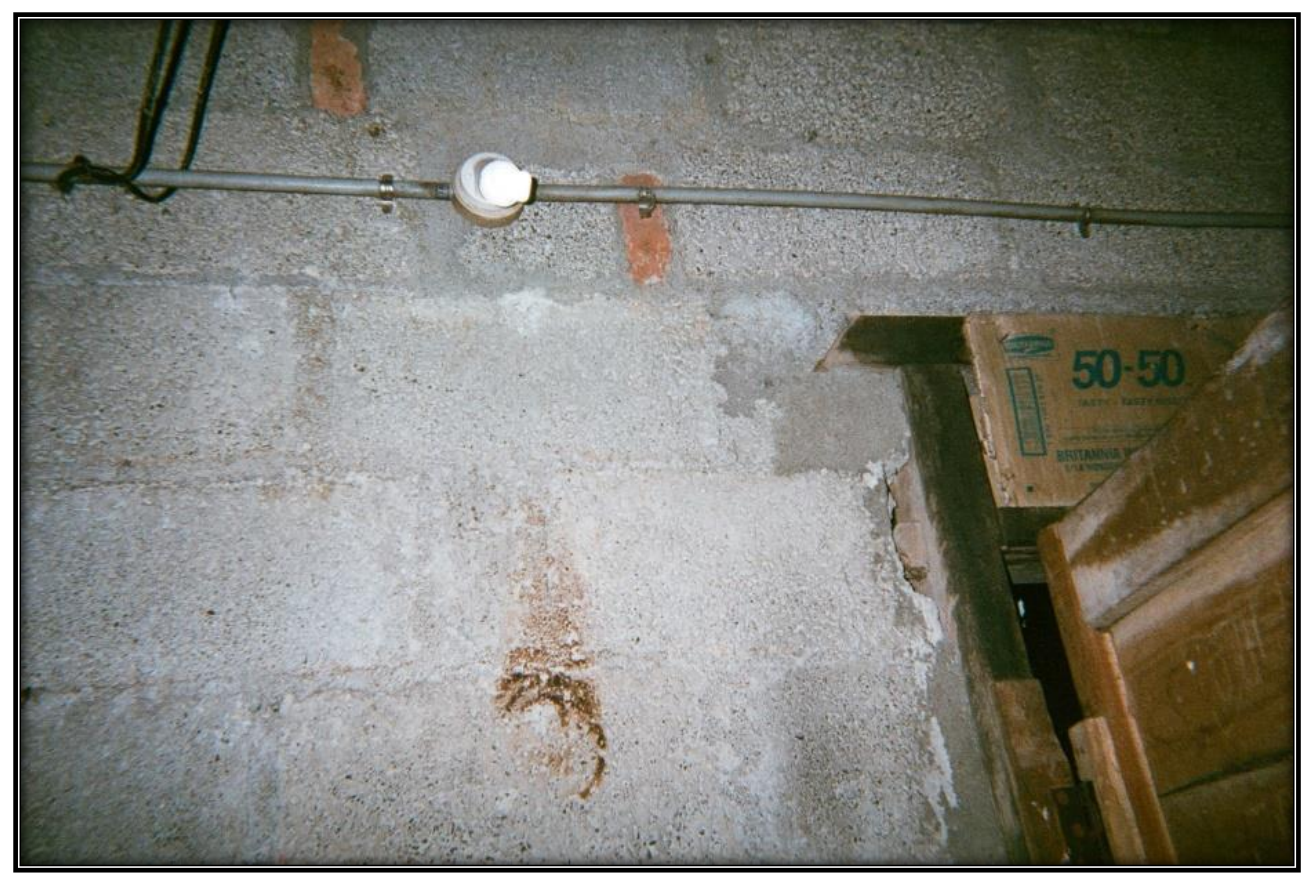

Figure 18: Simi's photovoice photo. Electricity connection in Simi's house.

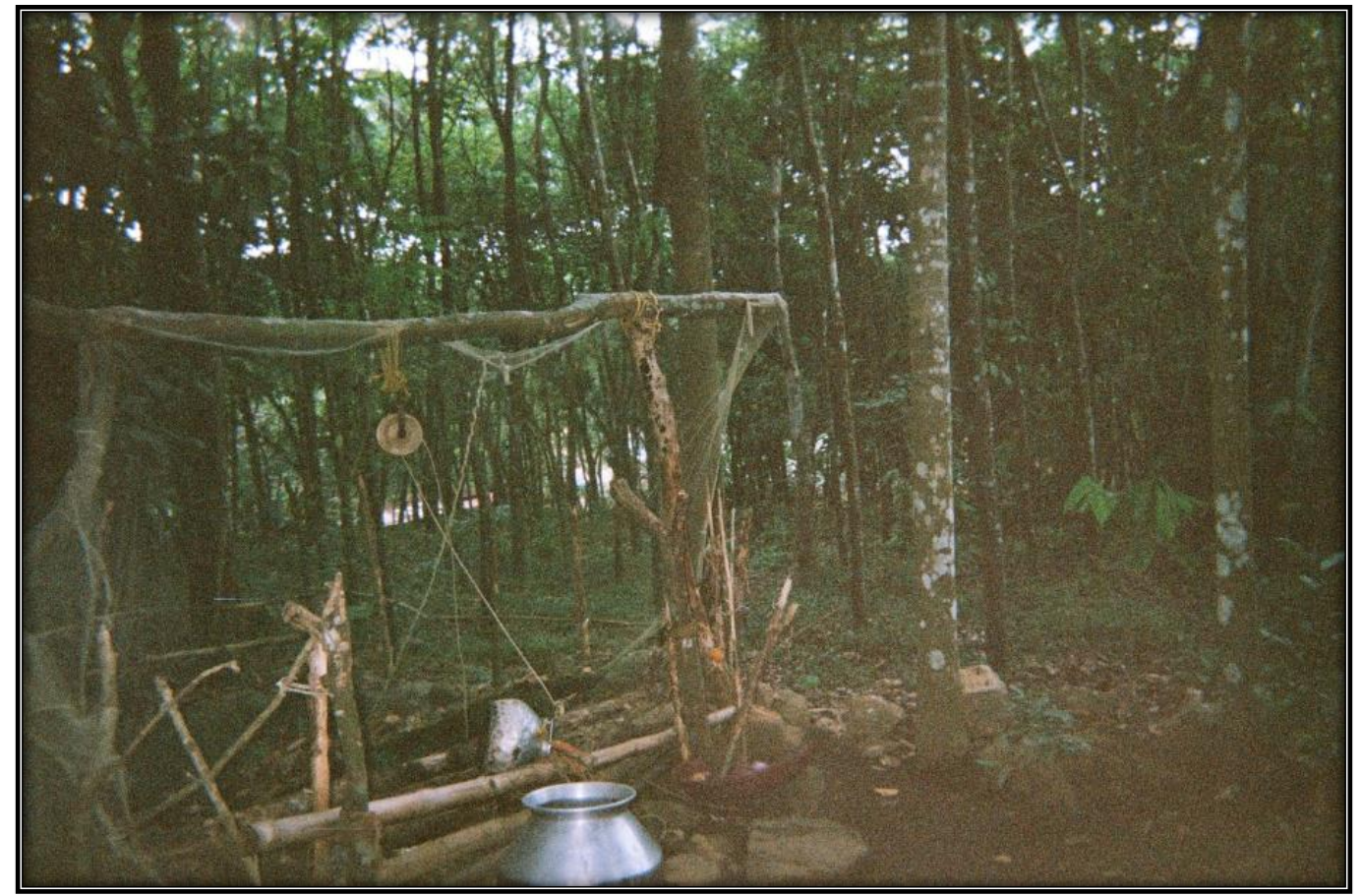

Figure 19. Simi's photovoice photo. The well in Simi's yard. 
Thus, life in the colony and in Uma's case outside the colony is shaped by spatial and material limitations. Dalit women's and girls' survival is an act of coping, negotiating and resisting. These everyday narratives of Dalit women and girls indicate how space is clearly more than a physical unit; it is social construct (Massey, 1994; Escobar, 2001). The inadequacies of the spaces that they inhabit in their daily lives subsequently shape their labor, education, and access, increasingly reinforcing their subaltern position in Kerala society.

\section{Social Marginality "Paisa ellad endo cheyam"36}

Walking around the colonies, one observes houses of different types and on inquiring about how some houses are more structurally sound than others, the conversation always came back to a lack of jobs and money, "Avark Echarude Paisa Endo"37, Avark Jole Endu ${ }^{38}$." Parpart (1993) in her critique of mainstream development, wrote, "Development was seen as a linear process, in which a nation or people proceeded from underdevelopment, which was characterized as backward/traditional/primitive, to full development, which was identified as modern/rational/industrialized" (p. 447). This is the form of development promoted by the state in Kerala, which reinforces the gendered division of labor under the confines of either production or reproduction. This definition of women's place in society that is defined on the basis of their contribution to maternity is symptomatic of a patriarchal structure (Lorde, 1984). This linear understanding of development fails to place the needs of Dalit women. Lorde (1984) warns us about this form of linear thinking. She asserts, "Advocating the mere tolerance of difference between women is the grossest reformism" (p. 25). This is the form of reformism that the state in Kerala has undertaken, which has resulted in subaltern communities in Kerala still waiting at the

\footnotetext{
36 "What can you do without money" in Malayalam, Lila's interview.

37 "They have a little more money" in Malayalam.

38 "They have jobs" in Malayalam.
} 
margins to gain from Kerala's Model of Development. Their subaltern marginality is exposed through social dimensions such as economic and resource inaccessibility which maintains them in a state of poverty (William, Vira, \& Chopra, 2011).

Dalit communities tend to be poorer than other communities in India, and their conditions of poverty have been well established in the literature (Thorat \& Newman, 2007, 2012; Still, 2014). These conditions of poverty are a consequence of how caste interacts with class in Indian society. Dalits often continue doing caste-based occupations, which are low-income jobs such as domestic work and waged labor. Even if they do gain from education with college degrees, they struggle to get jobs. Thorat and Newman (2009), in their important work Blocked by Caste; Economic Discrimination in India, highlight the discrimination that Dalits face in the whitecollar job market. They assert that caste hinders Dalits from gaining entry into the job market. They investigated the number of callbacks from job applications of Dalits and high caste Hindus with the same educational qualifications and concluded that Dalit candidates were far more likely not to receive a callback for a job than higher caste Hindu candidates. Research such as this addresses the tenuous everyday social terrain that Dalits have to navigate in Indian society, where caste maintains them at the bottom of the social hierarchy. Thus, this research indicates how Dalits are maintained in a state of deprivation and poverty across generations.

Furthermore, it is important to consider poverty as a compound multidimensional concept that has consequences beyond economic dimensions. It has severe gendered consequences especially in the way that labor, provisions and the rest are divided in a household (Razavi, 1999). These gendered consequences are exacerbated in subaltern communities that already live under the duress of poverty. The women and girls in this study spoke at length about how they 
struggle with poverty and disenfranchisement every day and how their struggles with poverty subsequently complicated their educational processes.

As seen in Anama's (Mother-in-Law, 59) narratives about growing up poor in a family with six siblings, Anama's formal education stopped in the $5^{\text {th }}$ class. Her family wanted her to study but she was unable to pass her classes and had to drop out of school. Addressing why she could not study, Anama said: "I failed because of the conditions in my house. I had six siblings and I was mother to my siblings. My parents left for work in the morning, it was hard to make money. I made sure they were fed and made sure they were able to go to school. My mind was tired but would have liked to study." Anama as the oldest sister grew up raising her siblings while her parents went for daily wage work, which speaks to how gender shapes the experience of poverty.

Anama's struggle continued after she was married. She struggled to feed and educate her own children. Her husband did not work and was an alcoholic. This placed her in a position where the burden to care for the home and her children was placed on her instead of her husband. She disrupts the gendered construction of women in Kerala society that places them only in the home. Anama carried the double burden of home and work as she struggled to provide for her family. Anama raised her children while doing domestic work. Speaking of her struggle to provide for her children she said, "I did domestic work in a Syrian Christian lady's house. She did not always pay me. She gave me coconuts and clothes. She did not give money sometimes. I never asked because I was scared. I raised my children without money. We lived in a temporary house. Now we have a cement house in the colony." Anama highlights not only the material positions of her life but also the class- and caste-based positions that she inhabits, working in the house of a Syrian Christian woman. The Syrian Christian community is an upper- caste 
community in Kerala with considerable social and political power. Her work as a domestic worker shows the persistence of caste-based occupations for Anama, as a Dalit woman who serves as a domestic worker in a Syrian Christian's home.

The roots of caste-based occupations in Kerala go back to the history of the Dalits in Kerala as slaves to higher caste groups. When slavery was abolished the Dalits became indentured servants without land or economic independence. Caste-based occupations are also linked to how caste, physical appearance and labor are closely linked in Kerala society. Dalit communities have been described in earlier writing as "slave" and "unclean" (Alexander, 1968). Upper caste women are often described as being fair with black straight hair while lower caste women are described as being devoid of those traits (Philips, 2004). Syrian Christians with their high caste status in Kerala society are described as being highly focused on being fair-skinned and thus do not engage in manual labor in the sun. Eapen (2001) described this division across social groups with Pulayas having dark skin and doing manual work while Syrian Christians are described as being fair-skinned and doing non-manual or deskwork. Thus, women from wealthier homes such as upper caste Syrian Christians are averse to taking low-paying manual work but are liable to take on work that would give them social status, such as jobs in the government sector (Eapen, 2001). Also, Anama's hesitation to confront an upper caste woman for wages shows the power that the Syrian Christian community holds over the Dalit community. Anama's acquiescence cannot be seen as passivity. It is also strategic in their navigation of her social position as a Dalit woman who knows that jobs are limited for her. With the burden of providing for her family, solely resting on her, Anama chooses not to confront. This displays her everyday negotiation of life on the margins as a Dalit woman. 
Anama's position also influenced how she helped her children study when they were younger. She states: "Children went to school from the place I worked. They came back there after school and waited for me. Then we all came home together. The children would come home around 6 p.m. and studied under the kerosene lamp. I supervised their studies the little I knew. I could only help them as much as I could." Neither of Anama's children completed school; Anama's struggle to educate herself and then to educate her children shows how Dalit lives are vulnerable to intergenerational poverty. It also speaks to how her life as a Dalit woman is shaped by multiple and overlapping patriarchies, which maintain their position with Kerala's caste ridden social hierarchy.

Furthermore, Anama also spoke of how she lived in a temporary home while she raised her children. Her family now lives in a cement home, which is more permanent. Anama's son works in the United Arab Emirates ${ }^{39}$ as a kitchen staff and sends money home. Kerala has a long history of worker migration to the Middle East due to a lack of jobs in Kerala. However, migrant workers often work as unskilled or semiskilled workers (Kurien, 2002). Her son makes better money as a hotel staff in the UAE than he would make in Kerala. This places Anama's family in a minimally higher-class position than that of many other families in the Dalit colony. Anama lives with her daughter-in-law Rinu, her granddaughter (4 years), and her husband who continues to drink. Anama hopes that things are better for her granddaughter because her son has a regular income.

Like Anama, Lila's story illustrates how caste, class and gender serve as intersecting inequalities to maintain the social position held by Dalit women in Kerala society. I introduced Lila (Mother, 38) and her youngest daughter Kavita (10) earlier in this chapter. Their

\footnotetext{
${ }^{39}$ Currency difference between the UAE and India (One Dirham equals 18.12 Indian Rupees).
} 
commentaries and photos illustrated the importance of resources as well as social class issues in the community. Lila was unable to continue her education after the $9^{\text {th }}$ class. She has an uncorrected, degenerative optic nerve problem and because of this she struggled in school.

Lila has two daughters. Rani (14 years) studies in a church boarding school and Kavita attends a government-aided school. Rani will receive free education, food and board at the church school until the 10th class. Lila is worried about her daughters' education, especially that of her younger daughter, Kavita (10 years). Although Kavita took the brilliant photos displayed at the beginning of this chapter, like her mother she has congenital problems with her eyes and limited eyesight. On the day of the interview with Kavita her glasses were broken and she struggled to see at school. When asked about school, Kavita said: "I like school. Teachers like me because I listen to them. My favorite subjects are Malayalam and Math. I sit in front in school, I can see big letters but cannot see small letters. I can see close but cannot see at a distance." Lila said that her daughter struggles to study because of her eyes, but she does not know what to do about it. Lila has taken Kavita to the doctor but is worried about the out of pocket cost, despite government run hospitals claiming to offer free services.

The Kerala Development Report (2008) acknowledges the complexity of the healthcare system in Kerala with an influx of private institutions in the past few decades, which has altered the landscape of the healthcare system in Kerala. The health care system in Kerala has been referred to as a "private-public mix" (p. 310). Kerala has the highest medical expenditure per person in India. Lila's choices are limited in a healthcare system that does not ensure egalitarian development for women and marginalized populations (Thresia, 2014). 
Lila, like Anama ${ }^{40}$, is the primary provider in her home. Lila's husband does not have a regular job and is an alcoholic. Lila works for the Mahatma Gandhi National Rural Employment Generation Scheme (MGNREGS), which guarantees 100 days of employment per year. Lila does manual labor building compost pits, doing road construction, and planting trees. Along with MGNREGS she also participates in Kudumbashree, which is a government-run microcredit program focused on poverty alleviation. However, despite her participation in government sponsored income generation programs, Lila struggles to feed to her family. Talking about feeding her family she says, "We have rice, our chicken gives us eggs. I want to give my daughter milk but we cannot afford it." Lila struggles with debt. She pawns and sells her belongings when she needs to buy medicine for herself and her family. Struggling with debt was a consistent theme in the women's narratives. Lila and others spoke of how they borrow money from local money lenders because of their everyday struggle to survive and provide for their families. Lila elaborates, "I was worried about debt, I always pay it off. My husband left because of all the debt but came back when my daughter was 1.5 years old. It was too much. I am very particular about paying back my debt. I will not give this stress to my husband." Lila speaks of how her husband abandoned them because of the burden of poverty and his own addictions and inability to provide for them. He felt around when Kavita was born and returned when Kavita was 1.5 years old. Lila knows that duty of ensuring that her family is taken care of is on her shoulders; she cannot count on her husband to provide or contribute. On the other hand, she is also protective of her conjugal home. She worries that if she burdens her husband he will leave again. For Lila, shielding her conjugal home is her way of protecting herself and her children, as being without a husband often has deeper social consequences for a woman in a patriarchal

\footnotetext{
${ }^{40}$ See Study Participants Table 4, and Family Tree Figure 5.
} 
society than having a squandering, unsupportive and abusive husband. This resembles Kandiyoti's (1988) assertion that in a patriarchal system, women's "passive resistance takes the form of claiming their half of this particular patriarchal bargain-protection in exchange for submissiveness and propriety" (p. 283).

Another example of stress over debt was heard from Uma (45). Speaking of her debt, she said: "I am epileptic, when I think of my debt I get stressed and get episodes." Uma said that money is her biggest concern. Uma sells lottery tickets at the local bus stand and takes care of herself, her husband and her two daughters. Uma's husband helps her at the lottery stand but Uma is the one who manages the finances of the house. Uma shared that the family manages with whatever money they make selling lottery tickets. Her family is very frugal and only buys the bare necessities. Uma spoke of how smart her two daughters (Simi, 13 years and Reshy, 5 years) were and how they never complain even when things are hard for their family. Uma also shares her pride in being able to provide for herself and her family. She says that despite hoping for a better job, she has no shame in selling lottery tickets at the bus stand. Uma is determined to provide her daughters with the opportunity to study and succeed. Speaking about participating in her daughter's school Uma said, "I wear a nice saree and always go to their school at least twice a month." She is aware of her need to present herself as a responsible parent who is invested in her daughters' education. She said that she must look clean and wear a nice saree, noting here the discrimination that poor Dalit parents often face when participating and advocating for their children if they present themselves as messy or unclean. This hostility that lower caste communities face is rooted in teachers failing to relate to the lives of students and their parents in India's class and caste ridden society. Vasavi (2003) asserts that "teachers are contemptuous of parents, especially those from laboring, non-literate and low ranked caste groups and their ability 
to supervise their children's homework, ensure that their children attend school regularly and keep themselves and their children clean and near or to provide their school supplies" (p. 73). This evidence indicates how education systems in India often fail to account for how social disparity is created and maintained in the school system. Uma's strategies to position herself as a clean parent speak to her individual acts of resistance in the face of a system that places her at the margins.

Anama, Lila and Uma speak to their strategic navigation of the private and public patriarchies that shape their lives of material and structural deprivation. Their narratives expose the need for further contextual and local analysis of the sexual division of labor (Mohanty, 2003), which reveals a more nuanced understanding of how women steer their social positions under conditions of resource scarcity. It is vital to note that along with narratives of struggles there are also narratives of shuffling gendered responsibilities and processes that displace common assertions and generalizations that recognize women only as contributors to the domestic sphere. Similarly, Rao's (2015) work among Dalit women in southern India explores their agency and navigation of their multiple identities inside and outside the home. Rao asserts that Dalit women "draw out the ambiguities in their personal lives, the small, everyday actions undertaken to expand the spaces available to them, demonstrating that they have not necessarily assimilated their devaluation and submission to male kinsmen or, indeed, upper-caste employers in their conceptions of selfhood (p.19). Likewise, the women and girls in this study worked towards optimizing spaces, relationships and opportunities by providing for and nurturing their families while working multiple low paying jobs, paying off family debt, and protecting their conjugal spaces by taking on family burdens. Nagar, Lawson, McDowell, and Hanson (2002) emphasize that to truly understand how capitalism shapes marginalized communities, it is 
imperative that we understand that "globalized capitalisms are historically and culturally contingent and engage with people in places to generate diverse and contradictory outcomes" (p. 263). Thus, by locating narratives of women's subjectivity, agency, resistance, and power allows for a more situated analysis of women's experiences instead of generalizing notions of universal victimhood (Loomba, 2003; Mohanty, 2003; Minh-ha, 1989; Rich, 1984).

\section{Conclusion}

In this chapter, I explored the intergenerational social and material locations of Dalit women and girls in Kerala society. Dalit colonies are islands of poverty created by state sponsored development that have failed to critically understand Dalit needs based on caste, class and gender. Addressing these islands of poverty in Kerala, Abraham and Devika (2014) state, "Development in Kerala, while it was largely inclusive in nature, had left behind spatial pockets of poverty owing to their specific historical paths and relations with the rest of the society" (p. 26). These spatial pockets of poverty with resource limitation such as a lack of electricity, income, and nutrition coupled with gendered consequences like the exacerbation of domestic labor affects Dalit women's and girls' educational engagement. Thus, it is evident from the narratives and the photos how subaltern spaces in Kerala are defined and maintained intergenerationally by the hegemonic tendencies of the state and the manifold patriarchies that shape Dalit women's lives. 


\section{Chapter 5: Neoliberal Forces Shaping Education}

This chapter is an examination of the neoliberal forces shaping Kerala's education. It draws attention to the subjectivities and vulnerabilities of the subaltern subject in Kerala. Drawing on interview narratives, development documents, and newspaper articles collected during fieldwork, this chapter is organized into three themes. Firstly, the chapter addresses private and public education, centering on the rise of private management in Kerala's education system. This has specific manifestations for the Dalit communities, as a majority of Dalit children attend private management schools because government schools have failed to provide quality education. The rise of private management exposes hidden equity issues that emerge when higher caste and class communities own and manage schools in the region. Secondly, the rising cost of education is indicative of how Dalit communities continue to struggle in an education system that is touted as free and accessible. Thirdly, addressing the school system's deficiencies in meals and sanitation shows how the educational system continues to struggle with inadequate infrastructure and poor sanitation, which has specific consequences for Dalit girls.

Thus, this chapter grapples with how inclusion-exclusion and private-public shape Dalit education experiences within Kerala's increasingly globalized education system. I assert that to understand Kerala's education for the Dalit community, Kerala's educational narrative must be situated in the broader context, as Mohanty and Alexander (2013) challenge us to "work towards grounding analyses in particular, local feminist praxis as necessary. We also need to understand the local in relation to larger, cross national processes" (Mohanty \& Alexander, 2013, p. 292). 


\section{Public and Private Education}

The rise in privatization in Kerala is a manifestation of the material and discursive practices of neoliberal development. Mohanty (2013) addressing neoliberalism states, "Neoliberal states facilitate mobility and cosmopolitanism (travel across borders) for some economically privileged communities, it is at the expense of the criminalization and incarceration (the holding in place) of impoverished communities" (p. 970). In the context of Kerala, upper caste and class communities own and manage educational institutions across the state, thus facilitating mobility and representation for their own communities. Meanwhile, lower caste and class communities such as the Dalits' are being held in place in Kerala's neoliberal climate. Kerala has a widespread system of government, private aided and private unaided schools (Figure 20). Government schools and private aided schools receive government subsidy; government schools are fully managed by the government, while private aided schools have private management of school infrastructure and teacher recruitment (Retnakumar \& Arokiasamy, 2006). Private unaided schools do not receive government funding and are completely under private management (Retnakumar \& Arokiasamy, 2006).

According to the Kerala Development Report (2008) the rise in private management schools is noteworthy, with numbers of privately managed schools being the highest in Kerala compared to the rest of the country. The division of schools in Kerala is that $44 \%$ are government schools and the rest are private schools. The public-private divide is significant for the Dalit communities in Kerala because of the caste gap between attendance in private aided and government schools. 


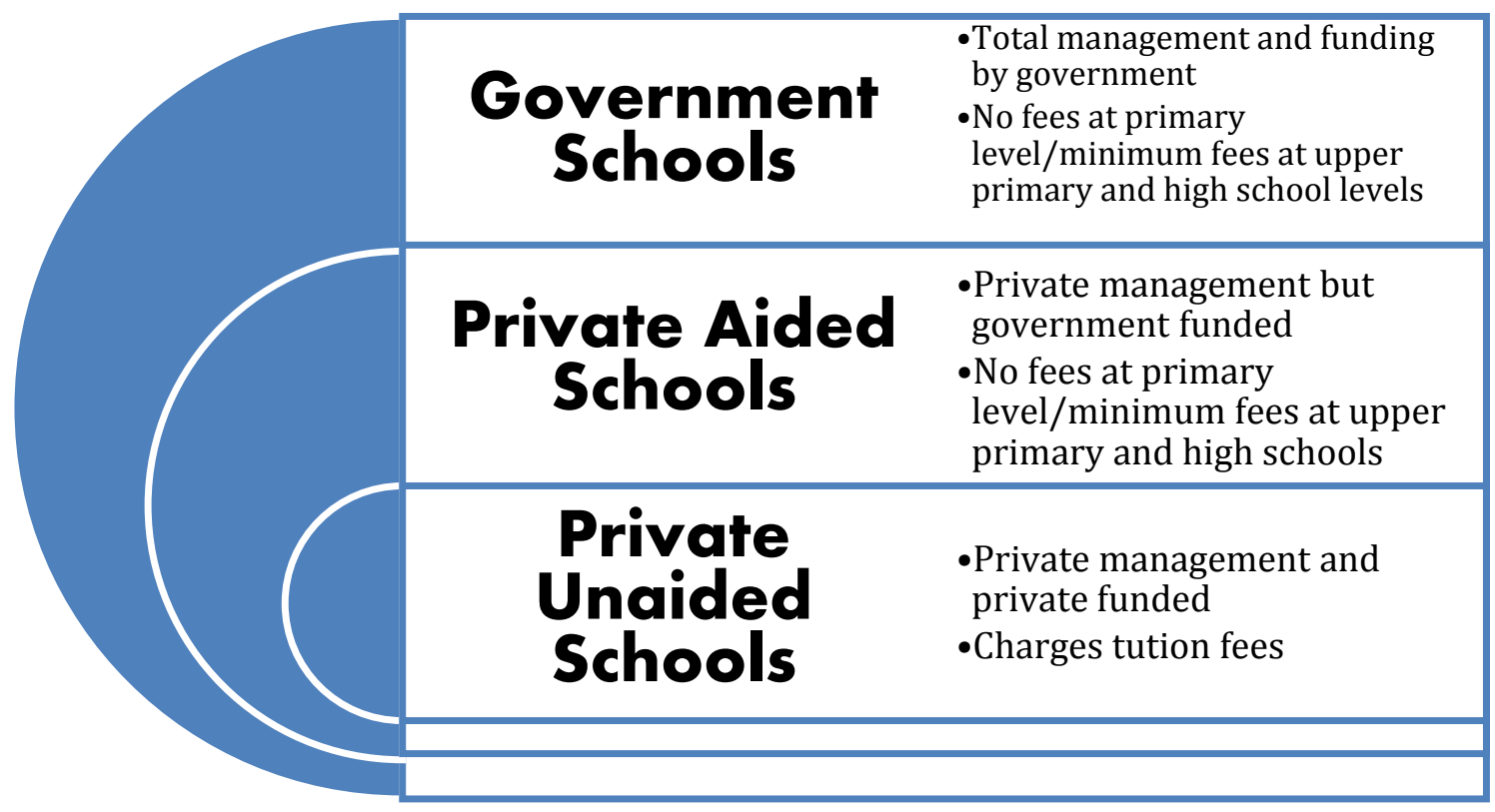

Figure 20. Type of schools in Kerala. Adapted from Retnakumar \& Arokiasamy, 2006

Padmanabhan (2010) draws attention to this caste gap between private aided schools and government schools based on data from 2003, with $57.33 \%$ of scheduled castes reported as being in private aided schools, $41.24 \%$ being in government schools, and $1.42 \%$ being in unaided private schools. This shows how students from the Dalit community rely on private aided schools over government schools in Kerala. This preference for private aided schools over government schools was also noted in the interview narratives. Rinu's ${ }^{41}$ (30 years, Mother, Anama's daughter-in-law) is the only family in this dissertation whose daughter (5 years) goes to a private unaided school. As discussed earlier, Rinu's husband works abroad and sends money home. This regular overseas income places Rinu's family in a better position to pay for their daughter's education. When asked why she sends her daughter to private school over government school, she indicated that the quality of teaching is better in private schools. Rinu was very

${ }^{41}{ }^{41}$ See Study Participants Table 4 and Family Tree Figure 5 
insistent about the need for her daughter to get a good education. Similarly Uma (45 years, Mother) sends her daughter to private aided schools instead of government school. Explaining why her daughter goes to private aided schools, Uma said: "Government schools... there is no education going on. Not at all. Government school children have no supervision, I think they teach a little better in management." ${ }^{\prime 42}$ This narrative was consistently heard across Dalit families who sent their children to private aided schools instead of government schools ${ }^{43}$.

These narratives have implications at both the individual and structural levels. At an individual level they highlight how Dalit families navigate school choice in Kerala's educational marketplace. They challenge the conventional ideas that portray lower class and caste families as being passive, and lacking agency and participation in the educational process (Vasavi, 2003). Families spoke of the value of educating their children, and I did not observe a difference in family support for education between sons and daughters. There was a burgeoning narrative among mothers and grandmothers that views modern education as redemptive from poverty and protective of the younger generation. This perspective in which lower caste communities' families in India are hopeful about education being redemptive in the form of better jobs and marriage prospects for their young was also observed in the literature (Jeffery, 2005; Jeffery et al., 2008; Page, 2005).

Mothers and grandmothers in this study spoke of the value of educating their daughters so that they could get good jobs but there was an acknowledgement of how marriage is what truly shapes women's educational and employment futures. When I inquired what jobs were considered as good for the girls in this study, the older generation commonly indicated that these

\footnotetext{
${ }^{42}$ Private schools, both aided and unaided, are referred to as "management" in local Kerala vernacular.
} 
were jobs such as being a nurse or a teacher. This narrative speaks to how women's education continues to prepare women to cater to gendered abilities and mindsets that frame women as caring labor such as teaching the young and helping the sick (Devika, 2006). Thus, it goes back to the gender belief in the region categorizing men as the providers and women as the caretakers of the home (Hapke, 2013). Marriage as a shaping force in Dalit women's lives is explored in the following chapter.

At a structural level, local circumstances speak to two critical educational shifts in Kerala, first a preference for private aided schools over government schools and second the disgruntlement with teaching and management in government schools across Kerala. These trends are also noted in terms of school enrollment, with a drop in enrollment in government schools and a rise in enrolment in private unaided schools at all stages (Kerala Development Report, 2008). The drop in enrollment in the government schools has also been attributed to the lack of teaching and infrastructure there. Retnakumar and Arokiasamy (2006) cited the following elements as being better in private unaided schools than in public settings:

- Teaching plans

- Assigning homework

- Qualification and number of teachers

- Student skill attainment in language, science and numbers

All the younger generation girls in this dissertation attended private-aided schools and spoke of a stronger preference for private management over government management schools in terms of quality of teaching and school infrastructure. This preference for private aided schools is problematic in the context of marginalized communities such as the Dalits in Kerala. Firstly, it 
is a problem because of concerns about private aided schools misusing government funds and practicing preferential hiring (George \& Sunaina, 2005). The motivation behind these preferential hiring practices is addressed in terms of "building patronage networks and strengthening the economic and political clout of communities which run these institutions" (George \& Sunaina, 2005, p. 2). For example, the Syrian Christian community in Kerala has invested heavily in education compared to the limited resources of the Dalit community (Padmanabhan, 2010). This has resulted in a greater number of Syrian Christian teachers in private aided schools who are considered upper class and caste compared to a paucity of Dalit teachers in schools. These caste and class inequalities between teachers and students has resulted in concerns about the quality of education received by Dalit students in privately managed schools who depend on private aided schools since the government schools have failed them (Padmanabhan, 2010).

Secondly, when government owned and managed schools are dysfunctional; they fail to fulfill their own constitutional obligation to provide free and compulsory education. This has resulted in poorer communities such as the Dalits in Kerala in search of an education for their children turning to private aided schools. Unfortunately, private costs are higher in these schools and hidden equity issues remain unmonitored by the government. This dilemma draws attention to how neoliberalism muddies the water by clouding responsibility for the inequalities arising in Kerala's education system. Armstrong (2010), addressing neoliberalism in action states, "The privatization of public assets and institutions further blurs the line between private and public sectors. With public/ private partnerships it is hard to know who is in charge or where to lay blame" (p. 193). I argue that the failure of government schools coupled with the rise of privatepublic education partnerships in Kerala in the form of public funded -privately managed schools 
has blurred the lines of responsibility for educational disparities in the region. There is a lack of both public and private accountability for the systematic marginalization of subaltern communities in the region.

\section{Rising Costs of Education}

One of the central government policies that support free education for children in India is the Right to Education Act (2009). The Right to Education Act aims at ensuring free and compulsory education to children of the ages 6-14 years. One of the essential contributions of this act is that it mandates that children do not have to pay school fees or indirect fees such as those that cover books and uniforms. This act covers all government schools and private aided schools, while private unaided schools are required to ensure that $25 \%$ of school admissions be given to children from poorer communities and the government refunds the cost of fees for these children to the institutions. Despite Kerala boasting of free education, education is not free for the people (Kerala Development Report, 2008). This observation is consistent with the literature about Kerala's education system such as in Kumar and George (2009), who write about the rise in private costs in Kerala's education system.

The private costs of education are the expenses that parents pay for out of pocket for their children's education (Table 5). Nampoothiri (2004) divides the private cost into academic and incidental expenses. Academic expenses include school tuition fees, the cost of supplementary private tuition classes, and the cost of books and stationary while incidental expenses include donations to Parent Teacher Association, travel, clothing, special fees in school (Nampoothiri, 2004). The rising private cost has serious implications for communities such as the Dalits, who receive government subsidies for their children's education. Kumar and George (2009) note that 
the subsidies provided by the government often cover only school tuition fees but fail to cover other private costs of education such as those listed below.

Table 5

List of private cost incurred by parents for school going children

Purchase Of Reading And Writing Material (Other Than Those, If Any Provided By The School)

Clothing (Other Than Those Uniforms If Any Provided By The School)

Cost Of Living Of The Children

Daily Travelling Cost

Costs Of Study Tour

Donations To Parent Teacher Associations

Special Fees for Computer Literacy

Examination Fees

Private Tuition Classes

Source: Kerala Development Report (2008,) p. 271.

In terms of specific numbers, the Kerala Development Report (2008) lays out the distinction between the cost of education in government, private aided, and private unaided schools. The report estimated the following numbers (Table 6). It can be observed that there is a clear distinction in the cost across government, government aided and private schools with private schools being the most expensive in terms of private costs. However, the private costs of government and aided schools are problematic in a system that mandates free education.

Table 6

Average Total Private Cost of School ${ }^{44}$ Education

\begin{tabular}{ll}
\hline Government Schools & Lower Primary (Classes 1-4): Rs. $2313^{45}$ \\
& Upper Primary (Classes 5-7): Rs. 2991 \\
& Secondary (Classes 8-10): Rs. 4676 \\
\hline Private Aided Schools & Lower Primary: Rs. 3019 \\
\hline
\end{tabular}

${ }^{45}$ Conversion to dollars $\$ 34.44$

${ }^{46}$ Conversion to $\$ 44.95$ 
Upper Primary: Rs. 3019

Secondary: Rs. 4421

Unaided Schools Lower Primary: Rs. $9100^{47}$

Upper Primary: Rs. 9281

Secondary: Rs. 10608

Source: Kerala Development Report (2008), p. 271

The burden of private fees was spoken about repeatedly in the interviews. The women spoke about how the schools are always increasing private fees and finding ways to get families to pay more. For example, Lila (38 years, Mother) has two daughters; the older daughter is in the $10^{\text {th }}$ class in a church run boarding school where she receives free education and boarding while her younger daughter (Kavita, 10 years) attends a private aided school, where she receives $\mathrm{Rs}^{48}$ 400 annually from the government for school-based expenses which barely cover all the private costs such as PTA costs, books, clothes, school trips, etc. Being Dalit Christian excludes Lila's family from qualifying for additional government grants that help with Dalit children's education.

On the other hand, Uma, who is Dalit Hindu, said that government grants and support for her daughter's education was a major motivator for their family choosing to identify as Hindu despite her husband being from a Dalit Christian family. She worried about the rising private cost of education in Kerala and did not want to be excluded from governmental grants because she was Dalit Christian. The politics of exclusion play out at the intersection of religion, caste, and class in this community. As Uma's case illustrates, government reservations in the form of stipends and grants are for the more marginalized religious group. The Hindus are considered to be more marginalized than Christians within the Dalit group. Government reservations are stipends provided to families based on identity factors, in this case religious background and

\footnotetext{
${ }^{47}$ Conversion to $\$ 135.49$.

${ }^{48}$ The Indian currency is the Rupee (Rs).
} 
caste. Kim-Puri (2005), addressing how nation states position discourses such as neoliberalism to hide lack of access and inequality state, " "The universalization of discourses, such as globalization, human rights, modernity, and tradition, among others, not only means that certain subjectivities are obscured by hegemonic discourses but also material inequalities are produced who is considered a subject and therefore has access to social resources, who is made invisible and therefore denied, who is seen as a victim and therefore in need of rescue" (p. 151). It is evident in Kerala that the forces of neoliberalism coupled with the stratifying forces of caste and religion dictate social agendas and access created by the powerful (of higher caste and class status) who decide who needs rescuing more than others. Dalit communities, both Hindus and Christians, continue to struggle to survive and continue to serve as low income domestic, agricultural or manual laborers, even in present day Kerala.

One of the major private costs identified by Uma and many other women was the fees for private tuition classes held outside of regular school. Private tuition is defined as fee-based tutoring that provides supplementary instruction to children in academic subjects they study in the mainstream education system (Dang \& Rogers, 2008). Private tuition has been identified as a major educational cost incurred by parents in Kerala (Kerala Development Report, 2008). The women and girls drew attention not just to the need for tuition but also the financial burden and the fear of students not succeeding in school if they did not attend tuition classes. Uma (Mother, 45 years) speaking of her families' struggles with private tuition said, "Tuition is a big problem, and it is expensive. I just want them to study. I want to help them in whatever way possible. I want them to learn." Uma's daughter does not go for tuition class because their family cannot afford the cost. She said she worries every day about her daughter falling behind in school. Uma's daughter Simi (13 years) also spoke of how most of the children in her class attend private 
tuition centers. When I inquired why students needed tutoring outside of school, she indicated it was because of the lack of adequate teaching in schools, and that students need to pay for private tuitions outside the school. She said that when the regular school teachers are often absent or do not explain lessons, it results in students falling behind and private tuitions are a catch-up mechanism.

A similar narrative was seen in Mala's ${ }^{49}$ (Mother, 40 years) conversation about her daughter's education. Mala spoke of how acquiring good enough education is challenging without private tuitions. Mala is a domestic worker and sends both her son and daughter to private tuition classes because she feels that the teachers do not teach in school. Drawing comparisons with her own education, she said:

When I was in school, there were like 40 students in each class, nowadays there are 20-24 students. The students are less, the teachers can sit down and explain things to students but teachers do not pay attention. Teachers just expect students to learn. Money is a big problem, I want them to study. Tuitions are required, without it is difficult. Teachers just do not teach, I send my children to tuitions. They explain things well.

Mala was upset with the lack of quality teaching in schools, and she also worries that if her children do not receive tuitions they will not succeed. These concerns about the quality of teaching and lack of personal attention in the schools were also noted by Priya, Suman's niece (14 years). Priya's family struggles financially because of her father's alcohol use and his lack of a steady job. Priya had tuitions earlier but she had to stop going to them, as her family did not have the money for it. Priya, like Mala, pointed out how a lack of teaching in schools forces students to resort to private tuitions. Priya, speaking about this said, "Because they do not

\footnotetext{
${ }^{49}$ See Study Participants, Table 4 and Family Tree, Figure 8.
} 
explain in the school, children go to tuitions. Even if you don't understand, no one really explains anything. At the tuition center, they explain well.” It was evident from the narratives about private tuitions that tuitions serve to fill gaps in regular school-based instruction.

Furthermore, Uma (45 years, Mother) also drew significant connections regarding how the medium of instruction in schools exacerbates the need for private tuitions. Uma said that she could help her children with their homework if the medium of instruction in schools is Malayalam, as she herself went to school where the medium of instruction was Malayalam. She is unable to help them if they go to English medium schools because she does not read, write or speak English. Kerala has an extensive network of Malayalam and English medium schools. The medium of instruction is also connected to the boards of education that create and oversee implementation of the syllabi used in the schools. For example, at government or private-aided schools that follow state boards, such as Kerala's State Council of Educational Research and Training, the medium of instruction is generally Malayalam, other than if it is clearly indicated that it is an English medium school (Retnakumar \& Arokiasamy, 2006). But private unaided schools that follow non-state school boards, like the Central Board for Secondary Education (CBSE), operate in English (Retnakumar \& Arokiasamy, 2006).

It has been reported that Kerala has a parental preference for English medium instruction and thus a greater demand for private unaided schools despite the high costs of these schools (Nair, 2004). This preference for the English medium of instruction is often linked to how success in the neoliberal job market and higher education in Kerala is connected to being proficient in English. This belief about the importance of English was observed consistently across the interviews. The older generation women discussed that when they were in school, English did not have such a prominent role in the job market or higher education, but that in 
present times children must know English to succeed. To the women, success meant getting high paying jobs and providing for families. This highlights how forces of globalization shape parental preferences for English language instruction for children in present day Kerala. The preference for English education over vernacular education is rooted in the upper caste and class viewpoint that links English to upward mobility in postcolonial Kerala. Faust and Nagar (2003) in their examination of English medium education in postcolonial India state, "English-medium education in India plays a central role in shaping the discourses around modern social institutional structure and existing class inequalities, while also widening and deepening social gulfs between the privileged elite and the common people to an unprecedented degree" (p. 2882). Faust and Nagar speak to how English medium instruction in postcolonial India is seen as a force of modernity as well as a symptom of imperialism that further establishes and maintains disenfranchisement. This creates an illusion of upward mobility for lower caste and class communities and then forces them to conform to the crippling, rising costs of sending their children to English medium private schools in an effort to give their children an opportunity for success and mobility.

While aspects of caste include community involvement in government policies such as school-based grants, religion coupled with caste excludes communities like the Dalits Christians in Kerala from government funding. Padmanabhan (2010), addressing the educational inequalities faced by the Dalit community in Kerala states, “The child's caste, gender and community now defines which school is attended thus giving rise to a new trend of hierarchies of $\operatorname{access}^{50 "}$ (p.115). The neoliberal forces cause greater privatization and capitalistic infiltration resulting in the commodification of Kerala's education system. This further complicates these

\footnotetext{
${ }^{50}$ The term "hierarchies of access" is taken from Ramachandran (2004).
} 
hierarchies of access. Hierarchies of access in Kerala significantly affect family investment in women's education, as there is a greater focus on women's roles in the domestic realm, with families often monitoring education to fulfill societal priorities and pressures brought on by marriage and dowry.

The rising private cost of education in Kerala challenges the government's claim of a free education system and Kerala's "Model of Development" that calls equitable education one of its cornerstones. A failure of the state to provide quality education is indicated in the mass exodus of students from government schools towards private management in Kerala. Thus, this examination of the rise of neoliberal forces in Kerala highlights how globalization seeks the reemergence of "colonial and neocolonial relations" (Swarr \& Nagar, 2010, p. 7). It is imperative that we pay close attention to how gender, class, caste and religion work together to define women's access to education in Kerala's neoliberal era of development. Globalization is often addressed as being void of gendered consequences, however as Joan Acker reminds us, "gendering' the discourse of globalization exposes the discontinuities between the realities of women's and men's lives and mainstream scholarly writing about global process" (Acker, 2004, p. 20). I argue that Dalit girls in contemporary Kerala struggle with the double expectation that they must do as well as boys in school and conform to society's ideas of domesticity and femininity. Dalit families support their education, often taking on debt and sending them to private management schools. In Dalits' lives, caste is a major stratifying, hegemonic force, which holds class in place and defines material inequalities, educational access and engagement. Thus, Dalit women are required to work against the confines of a gender and caste system in the pursuit of a modern education. These neoliberal forces in Kerala complicate Dalit women's access to education by coupling a complex patriarchal system in the home and community that 
controls and tailors their lives within a capitalistic system that excludes them further by applying higher costs and using inequitable practices.

\section{Meals and Sanitation in Schools}

As I grapple with the educational consequences of the rising forces of neoliberalism in Kerala, it becomes reasonable to conclude that the Kerala government is distracted by quantity in terms of the embracing the relatively high numbers of schools with higher literacy scores than the rest of the nation. These gross measures, however, deflect from the fact of low educational quality. One of the problems with this distraction is that educational institutions then continue to fail to provide adequate school amenities. I explore amenities in schools in this section specifically in the context of school meals (also called "feeding programs") and school sanitation. One of the characteristics of neoliberalism is a neglect of social welfare responsibilities (Jaggar, 2001), which results in budgetary cuts along with a lack of critical consideration for shaping and providing amenities such as school meal programs and adequate sanitation facilities. This neglect is a consequence of the masculine motivations of neoliberalism that ignore gendered consequences of this process (Beneria, 2003; Runyan \& Marchand, 2000). Thus, by exploring gaps in meals and sanitation, this section serves as an entry point to expose caste, class and gendered concerns that result from gaps in meals and sanitation in schools.

\section{Schools Meals}

Mid-day meals are one of the most touted achievements in Kerala schools. In 1961, the Kerala government implemented this feeding program in both government and governmentaided schools (Kerala Development Report, 2008). The execution of the feeding program in government and government-aided schools was strategic as those schools cater to poorer 
communities such as the Dalits (Kerala Development Report, 2008). Compared to the rest of India, Kerala was ahead in mid-day meal implementation. It was only in 2001 that the Supreme Court decreed that all states across India must provide mid-day meals to every child in government and private aided primary schools across India (Department of School Education \& Literacy, Government of India, 2001). The 2001 Indian Supreme Court ruling said that the State government must implement the mid-day meal scheme by providing every child in every government and government assisted primary school with a prepared mid-day meal to include a minimum of 300 calories and 8-12 grams of protein each day of school for a minimum of 200 days per year. In 2007, the scheme was extended to the upper primaries (classes 6-8). Higher calorie levels were required in economically backwards blocks ${ }^{51}$ across the country, and subsequently extended to all areas throughout the country (Department of School Education \& Literacy, Government of India, 2001). Many states across India failed to comply with this, while Kerala was well ahead of this ruling in its implementation of mid-day meals in schools. Despite the early enactment of the mid-day meal schemes in Kerala, there was a narrative among the students of "meals as entitlement," which I will explain in this section. Also troublesome is the fact that in some cases no meals were actually provided in the schools when they were promised.

The Kerala Development Report (2008) identified the school feeding program as the "most comprehensive food support programme to children ages 5-12 years" (p. 332). However, there have been recent media reports about lapses in government funding for mid-day meals. For example a recent article entitled Kerala's Mid-Day Meals Are a Success: Except Teachers Are Funding Them (Koshy, 2016) on the news website NDTV ${ }^{52}$ exposed the paucity of government

\footnotetext{
${ }^{51}$ Economically backward blocks are identified on the basis of low female literacy.

${ }^{52}$ New Delhi Television Limited, an Indian commercial broadcasting television network.
} 
funding to ensure meals for children. It addressed how this lack of funding results in schools being unable to buy allocated food such as dal ${ }^{53}$, vegetables, and milk for the children. Due to the lack of real government funding, the teachers in the schools contributed money towards buying food for the children (Koshy, 2016). This unfunded mandate has implications for poorer communities such as the Dalits across Kerala whose children are often dependent on the schoolfeeding program.

Apart from serving as a nutritional intervention for school children, mid-day meals in India address equity issues such as discrimination based on class, caste and gender (Dreze \& Goyal, 2003). In the context of caste and class, mid-day meals encourage children to sit together. However, there have also been instances reported where it has been a platform for discrimination such as when upper caste students refuse to sit with lower caste children, or parents of upper caste children do not want lower caste cooks to prepare food for their children (Dreze \& Goyal, 2003). Additionally, mid-day meals have been reported to encourage female school attendance with free school incentives reducing the private cost of education for parents who hesitate to send their daughters to schools because of the high cost and societal preference for male education (Dreze \& Goyal, 2003; Khera, 2006). In the general Indian context, free school programs such as meals serve as incentives for lower income parents to send girls to school as parents face additional societal pressure to save money for their daughters' marriage and dowry. Regarding boys, families will presumably receive a dowry from girls' families and education often serves to prepare them to be providers in the home.

\footnotetext{
${ }^{53}$ Lentils.
} 
The school-going girls in this study spoke about how they preferred taking meals from home instead of eating at school. Mala (40 years, Mother), speaking of her daughter's mid-day meals, said that her daughter does not want to eat at school, while her son (10 years) does eat at school. She said that girls are ashamed to eat meals at school. Girls in classes 8, 9, and 10 do not ever eat meals at her daughter's school. Mala suggested that girls do not go to eat, as they do not want to be the only ones going to eat the free meals. When asked what girls do if they did not have food at home, Mala said that parents often scramble and send food for their children, as they refuse to eat the school food. When I asked her daughter Janu (14 years) about not eating in school, she was hesitant to talk about it and indicated that she did not find the food tasty.

This narrative of girls being ashamed to eat was also noted in Uma's (45 years, mother) daughter's narrative about mid-day meals in her schools. Simi (13 years) spoke of how she does not eat mid-day meals that are provided at school and would rather take food from home that her mother makes for her. Simi shared how she, like Mala's daughter, was shy about eating school provided mid-day meals. Simi indicated that she does not go to the school canteen to eat because her friends do not go to these meals. On pressing Simi for reasons behind her hesitation to eat school meals, she indicated that she did not want to be singled out.

I extrapolate that there are three probable explanations for this hesitation among girls, one related to social class where girls do not want to be seen as coming from homes that do not have food; to be seen eating school-provided food by peers and teachers is to be "outed" as needy. Second, caste adds an additional level of social stratification in schools for Dalit children. Some of the girls when asked if they have ever experienced any caste-based discrimination in schools from other students or teachers or staff, said that people in school do not say anything to their faces, but that does not mean they are not thinking of them as lower caste. Thus, the younger 
generation indicated an awareness of their subaltern positions in Kerala's deeply classed and caste-ridden society. There is a silence about caste in Kerala society. Dasan (2012) indicates that this silence was a strategic move by upper caste communities in Kerala. Expounding on this, Dasan (2012) says that caste was made a nonissue by narratives that indicated that Kerala society was beyond the bounds of caste, and instead class was projected as the main issue. Thus, by projecting class as the real concern holding communities back, upper castes were able to usher in development initiatives that focused on class without addressing the historical burden brought on communities by caste. This was a strategic move on the part of the upper castes to keep hidden the privilege they gain based on their caste status.

Thirdly, it is also a manifestation of gendered social expectations about bodily attractiveness due to which girls monitor themselves in Kerala society (Osella \& Osella, 1996). This is particularly important in contemporary Kerala, where the global market shapes young people. I argue that young Dalit girls are also participants of this globalized culture, which was evident from our many informal conversations in the field. The girls in this study were very articulate about their consumer identities based on their excitement about popular media such as movies, TV shows and their favorite actresses. Lukose (2005) writing about youth as a gendered category of consumption in post-colonial Kerala asserts that Western standards of beauty regarding thinness and fair skin are morphing "indigenous" standards of beauty. But Lukose challenges us to contemplate these norms in the context of caste politics and warns us against assuming that globalization is a homogenous experience for all communities across Kerala. Thus, it is essential to consider how young Dalit women navigate the gendered expectations placed on them as women in a global patriarchal system coupled with a silent recognition of the 
historical discrimination that runs through Kerala society that holds Dalit girls in their social position demarcated by gender, caste, class and religion.

\section{Sanitation in Schools}

Secondly, I explore gaps in sanitation in schools in contemporary Kerala. Sanitation in schools is a key contributing factor to educational participation for girls. The presence of sex specific latrines in schools lessens gender disparities for pubescent age girls by providing greater privacy and safety while unisex latrines worsen gender disparities (Adukia, 2014). It is important to address the gendered burden of a lack of sanitation in schools as it has stronger consequences in terms of school enrollment and attendance for girls over boys (Adukia, 2014). Brewster et al. (2006) addressing this gendered burden with regards to inadequate water and sanitation facilities notes, "Women often have no voice in decisions about the kind of services they receive. This is unfortunate, because women bear the greatest burden when it comes to inappropriate technologies or inadequate access to safe water and adequate sanitation" (p.1).

Concerns about inadequate sanitation in schools are rampant even in present day Kerala, with $74 \%$ of schools having common toilets ${ }^{54}$ and $40 \%$ of schools having toilets specifically for girls compared to the national averages of $34 \%$ common toilets and $22 \%$ girls' toilets (Kerala Development Report, 2008, p. 266). Although in comparison to national numbers Kerala is doing better with sanitation, the lack of sanitation in schools across Kerala remains an issue that requires examination. The Union Ministry of Human Resources and Development, Government of India conducts a sanitation rating for $\mathrm{CBSE}^{55}$ schools across India. This initiative is part of the

\footnotetext{
${ }^{54}$ Multiple urinals.

${ }^{55}$ CBSE stands for Central Board of Secondary Education, which is the Board of Education for public/private schools. The Government of India oversees it.
} 
National School Sanitation Initiative called Swachh Bharat, Swachh Vidyala. ${ }^{56}$ The initiative promotes policies regarding adequate sanitation facilities and privacy in schools. The initiative requires one toilet for every forty girls and one female teacher. Furthermore, it requires one urinal with partitions for every twenty girls, and mandates a two-minute maximum waiting/ queuing time during peak hours of toilet use. It has been reported that 70\% of the CBSE schools in Kerala fall under the organization's "red" category, which indicates poor sanitation requiring immediate attention. This statistic may underestimate the problem, as many schools in Kerala have not completed the government required rating survey despite being warned that it was a part of the School Quality Assessment and Accreditation scheme. Kerala as of 2015 had 1,360 schools under CBSE and only 151 schools completed the rating survey (Krishnakumar, 2015).

One of the direct consequences of inadequate sanitation in schools is seen in children's health as in the newspaper article shown below (Times of India Newspaper, 2015). The article addresses the rise in urinary infection in schoolgirls in Kerala (see Figure 21) along with a lack of resources for girls in schools across the state during menstruation. This article discusses how girls who have clean toilets at home do not want to use the dirty toilets at school. Furthermore, it indicates how girls struggle during menstruation because of the lack of bolts on doors and dearth of receptacles for napkin disposal. The Kerala media draws attention to the concerns of middleclass families because the journalists who select and disseminate the news stories are middleclass themselves and wish to address concerns relevant to themselves and their families. Often, journalists fail to reflect on their social positions in their writing. Additionally, public dialogue created by the media in India produces a range of images, which portrays the urban middle classes as the main benefactors of reform in the nation (Fernandes, 2000). Thus, the media fails

\footnotetext{
${ }^{56}$ Translates in Hindi to "Clean India, Clean Schools."
} 
to expose the plight of lower class and caste communities where women and girls do not have sanitation at home or at school.

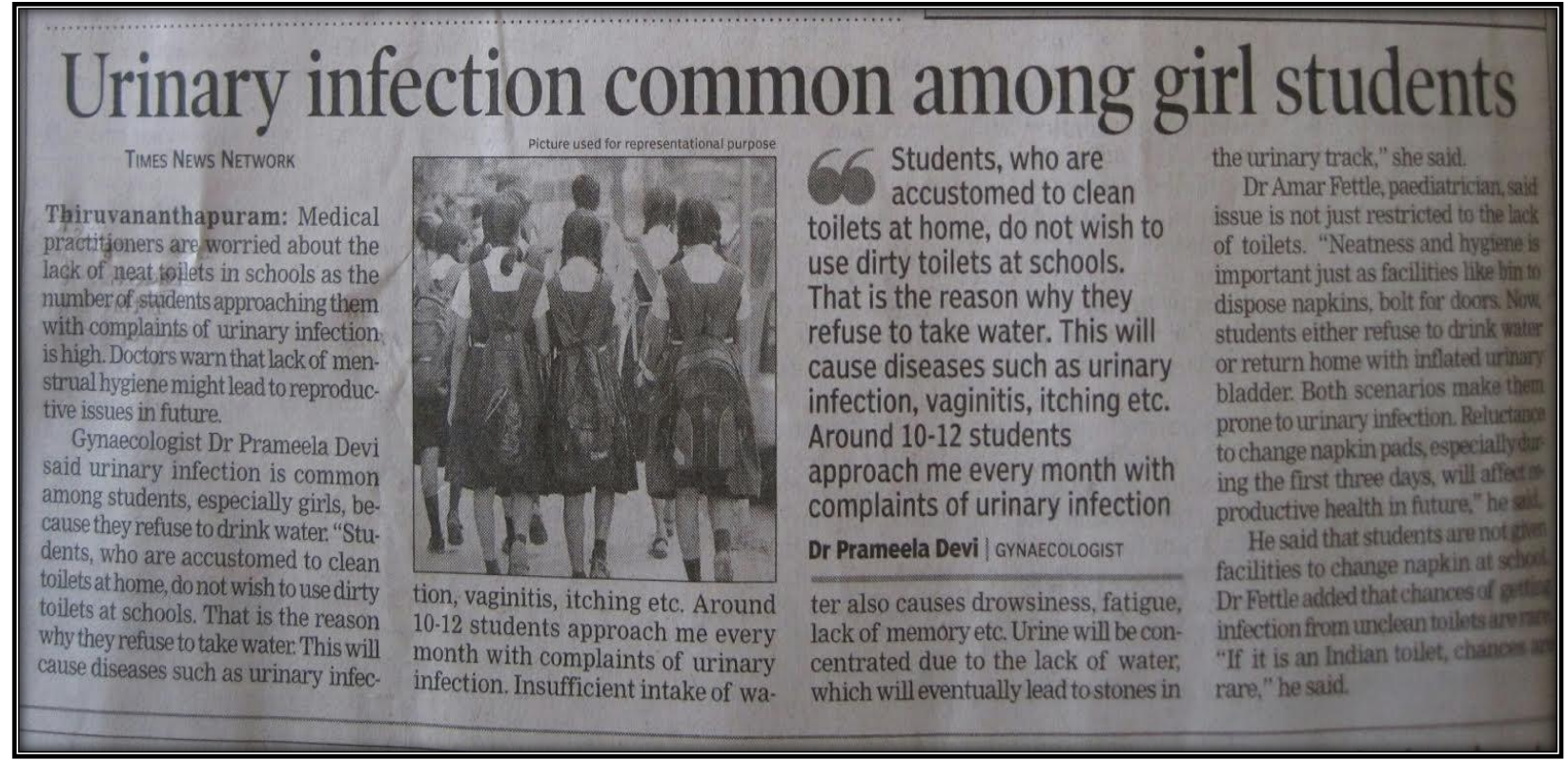

Figure 21. Newspaper article. Times of India, Kerala edition, March 2015.

This omission of subaltern voices and their needs in the mainstream seeks to "reinscribe the gendered subaltern's invisibility and inability to speak for herself' (Abraham, 2007, p.119). The voices of these women are absent from mainstream voices being raised about sanitation issues, which are then overlooked and unaddressed in Kerala's Model of Development, a model that prides itself in educating women but fails to provide them with the basic human right to clean sanitation.

This sanitation burden is exacerbated in the content of Dalit women and girls who struggle with a profound lack of basic amenities both at home and school. The older generation spoke about open urination and defecation while they were in school. Open urination and defecation deprives women and girls of privacy and makes them vulnerable to violence (United Nations, 2014). This issue was noted by Sonja (40 years, Mother), Suman (43 years, Mother) and 
Uma (45 years, Mother) who spoke of how they did not have toilets at home or at school when they were young. They went into the woods surrounding their homes and schools. The teachers had toilets at school, but the students did not have proper toilets. However, in their daughters' cases there has been a change in sanitation facilities with schools now often having toilets. However, the sanitation infrastructure continued to be dismal a generation later with a limited number of toilets, a lack of clean toilets, and a lack of menstrual pad disposal provisions. Uma's daughter Simi (13 years), speaking of toilets in schools said:

We have nine bathrooms in the school. There are many sections ${ }^{57}$ in each class and many students. The bathrooms are shared, like classes 8 and 9 share one bathroom. Because I study in management school now, there are more bathrooms. But in my previous school where there were fewer children, but it was from classes 1-10 that we only had two bathrooms for all the girls. The boys' bathroom in the government school did not even have a sheet or a door; the girl's bathroom had a door.

Her mother (Uma, 45 years) chimed in here about how Simi's younger sister ( 8 years) goes to a government school and they have three toilets for the school, one each for boys and girls and one for the teachers. Uma said that things get harder when girls start menstruating. The prepubescent girls like her younger daughter can manage with fewer toilets but most of the trouble starts when the girls get older and have their periods. Uma and Simi note some key issues in their observations about schools in Kerala. Firstly, Simi initially studied in a government school where the number of students was low and thus the numbers of toilets was fewer. Simi also observes the lack of privacy for boys, with bathrooms not having a proper door while the girls'

\footnotetext{
${ }^{57}$ Sections or divisions of classes, students of each class are divided into sections.
} 
bathrooms had doors. Secondly, Simi observes how private-aided school had more children and minimally better bathroom facilities. Through this observation she highlights the distinction between private-aided schools and government schools in terms of student enrollment and school amenities such as sanitation. Thirdly, she points to the gendered burden of inadequate sanitation for pubescent girls who struggle with a lack of privacy, menstrual supplies, and hygienic disposal of used napkins.

Thus, the provision of school meals and sanitation can be seen as improved for Dalit women if one views improvement as moving from no access to toilets and meals in schools for the older generation to inadequate access in terms of poor quality food or fewer toilets than needed in schools for the younger generation. It is evident that forces of neoliberalism and the intensifying focus on capital accumulation have hidden these inadequacies in Kerala's education system. The younger generation faces a new set of challenges in the neoliberal era of Kerala's development.

\section{Conclusion}

Kerala's education has been recognized as an integral contributor to development in the region. Addressing the reach and potential of the education system in Kerala, the Human Development Report (2005) praises the education system for "spreading across the breadth and length of Kerala, to the poor and the non-poor, to all castes, including former outcastes, and not only to men but also women" (Human Development Report, 2005, p.7). This statement draws attention to how Kerala, compared to the rest of the country, has created a system that transcends caste, class and gender in development circles. However, as indicated by the rising rhetoric in both the media and academic circles about how Kerala's education system is morphing under the 
forces of neoliberalism and globalization, a contradictory message is indicated (Kumar \& George, 2009; Devika, 2010; Rammohan, 2008; Raj, 2013). A recent article in the national political magazine Frontline covered the "Congress on Kerala Studies" held on January 9-10, 2016 where experts on Kerala and people from across the State congregated to discuss the state of the "Model of Development." A prominent Kerala scholar present at the Congress, Dr. Tharakan, discussed the unequal and problematic development trends when he stated: In education Kerala has the numbers; it is way ahead of the Indian average in terms of graduates per square kilometer, total literacy, and so on. But the quality of education is not up to the mark, and secondly, an appropriate education system that could transmit democratic and development values seems to be missing. This is because a restructuring, in terms of development, educational and democratic values, has not been consciously introduced into the educational system. So the State is slipping in that sector. As a result, we tend to become a group of people who are not bothered about the fact that marginalization within education is on the increase. This kind of distancing is on the increase, and Kerala is not bothered enough because the people who benefit from it are those who are in the business of implementing the new policies. (Krishnakumar, Feb 5, 2016)

Dr. Tharakan's argument about a rise in marginalization in education highlights the neoliberal forces that are shaping the "business" of education in present day Kerala. The Kerala education system has been monopolized by private management and has responded to the forces of globalization by adopting a business model. Thus, this examination of the neoliberal forces shaping Kerala's education draws attention to the subjectivities and vulnerabilities of subaltern 
subjects as they navigate the educational marketplace with its greater gender, caste and class inequalities. 


\section{Chapter 6: Patriarchal Forces}

This chapter addresses the patriarchal forces shaping Dalit women's lives and is organized into two major themes. First, it addresses marriage as a prevailing force in their lives, one that shapes duties, roles, choices, access and labor. It serves to demonstrate how Dalit women navigate their multiple identities both inside and outside the home, often as a way to protect the conjugal home. Secondly, this chapter addresses gender-based violence in the home, community and school. In doing so it exposes the underlying patriarchal structure as it pertains to each of those areas. It also considers counter narratives of resistance and agency.

Women's high status has been challenged in the feminist and development literature with a counter argument that highlights how women's lives are monitored by a complex, ingrained patriarchal system in Kerala society (Devika \& Mukerjee, 2007; George, 2011; Hapke, 2013; Mukhopadhyay, 2007). I draw on Mohanty's (1999) reminder about addressing violence against women in which she cautions us that "defining women as archetypal victims freezes them into 'objects-who-defend-themselves', 'men into subjects-who-perpetrate-violence' and every society into a simple opposition between the powerless (read: women) and the powerful (read: men) groups of people" (p. 67). The reminder helps to move the analysis towards a more nuanced understanding of a patriarchal system that perpetuates and supports violence against women instead of analysis that is just focused on powerless female victimhood. In this chapter, I argue that violence in the home, school and community in Kerala shapes women's educational futures by stripping women of the right to a secure and productive environment that supports educational engagement and advancement. Furthermore, I examine how societal institutions such as marriage shape education and how marriage is viewed as protective for women in a patriarchal system where a lack of compliance to these institutions is reprimanded and discouraged. 


\section{Marriage}

Marriage is an established, influential force in women's lives in Kerala, as in the rest of India. Marriage is vital and being unmarried is not socially acceptable. Saradomi (1994), addressing the importance of marriage in Kerala society states "the message that is given to a girl growing up is to see marriage as the most important and essential act in life" (p. 505). Marriage is a socially regulated. It follows the stringent rules of endogamy and is often arranged by families after careful deliberation of compatibility of caste, class, physical appearance, and education as indicated by the newspaper advertisements shown above (Figure 22). Matrimonial advertisements in daily newspapers are a common way to facilitate marriage in Indian society. They are platforms for the promulgation of heteronormative androcentrism that privilege narratives such as considerate homemaker (read: gentle, kind, submissive, pretty, fair, slim) and aggressive breadwinner (read: agentic, strong and ambitious) (Pandey, 2004; Ramasubramanian, 2008). Marriage in Kerala society likewise monitors and reinforces gender identities and gender roles in the home and outside it. The centrality of marriage results in the establishment of a “conjugal patriarchy” in Kerala, which frames women's roles, and abilities as centered on the home (Hapke, 2013; Kodoth, 2006). In the context of education, women are not openly dissuaded from education but there are many obstacles such as marriage that restrict educational access (Saradomi, 1994). There is an underlying belief that marriage offers greater social protection and privilege in Kerala society than education alone for women. This belief often complicates women's educational futures and opportunities. 


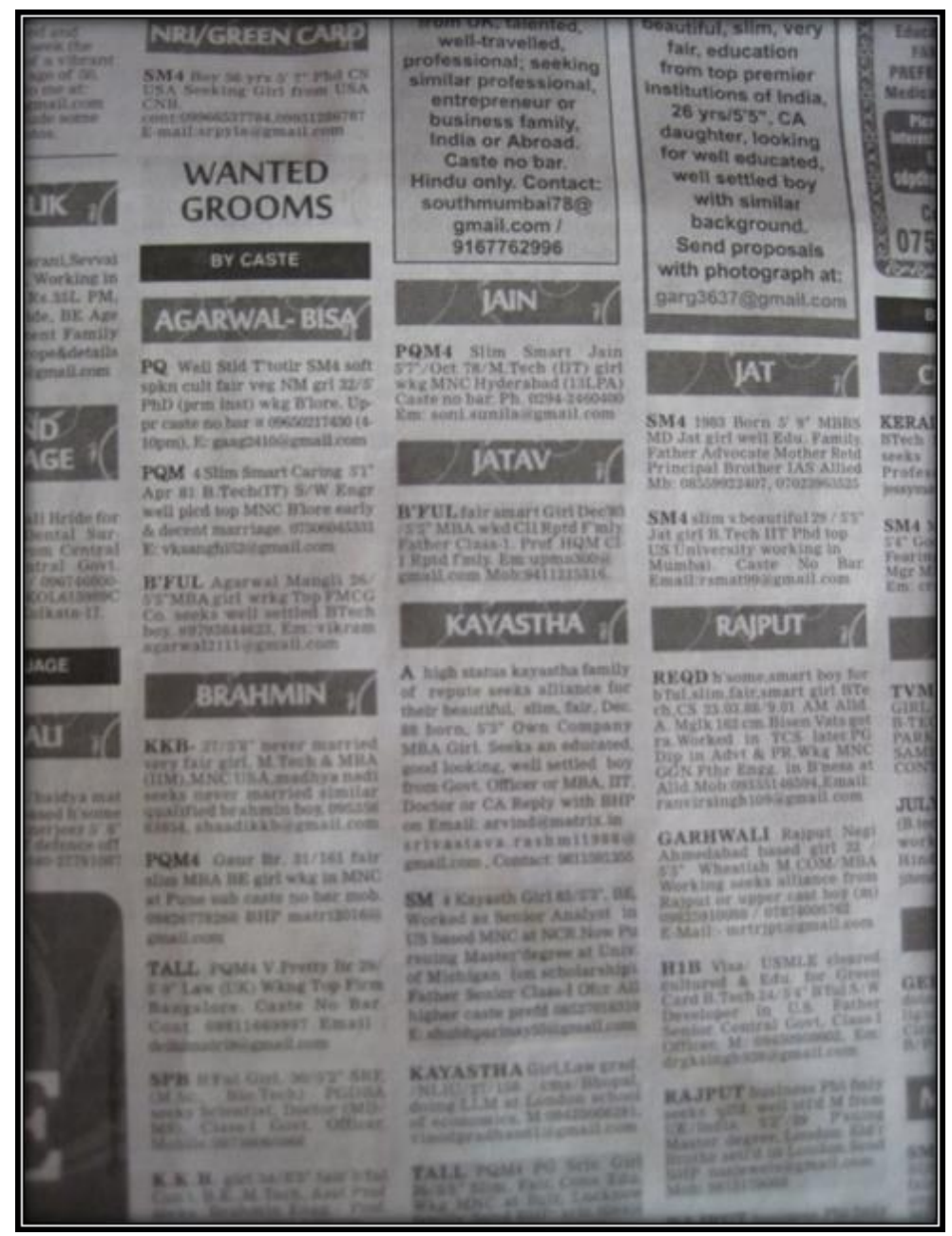

Figure 22. Matrimonial in newspaper. Times of India, Kerala edition, March 2015.

Education for women in Kerala has not altered beliefs of female domesticity (Devika \& Mukherjee, 2007). It supports the widespread gender philosophy in Kerala that places women in the domestic sphere while men are outside the domestic sphere as providers. However, in many lower caste families such as the Dalits, women often work outside the home to financially provide for the family and ensure their survival (Rege, 2013; Rao, 2015). This disrupts the gendered dichotomy in lower caste and class families in which women are both home makers and providers in the home. 
Still (2011) studied the marriage and education narratives of a Dalit community in rural Andhra Pradesh ${ }^{58}$, India. In addressing Dalit motivations about marriage, she said, "While education for employment is unheard of among Dalit women, education as a means to marriage is a recognized part of the pursuit of respectability, class standing and self-improvement" (Still, 2011, p. 1145). This draws consideration to the larger social context of why families choose marriage for their daughters over education, by addressing how Dalits' family honor and hope for upward mobility is attached to daughters' marriages. Still draws on Patricia Jeffery's (2000) writing titled Frogs in a Well: Indian Women in Purdah which explores the lives and motivations of women who live in strict purdah ${ }^{59}$ in Delhi, India. Jeffery reminds feminist writers to place a woman's decision to favorably partake in social institutions and practices considered restraining or objectionable to the feminist eye in a larger social and economic milieu. Likewise, in this dissertation women and girls spoke of marriage as an uncontestable norm that is required for social acceptance for themselves and their families. They also spoke of how life outside of marriage is often undesirable or achievable for them and how the family unit was an essential defining force in their lives. They shared stories of personal agency and their strategies of resistance as they navigated power structures such as marriage that monitor their lives, jobs and education, as in this narrative about marriage:

My family loved me, my father cared for us. I was married when I was 14 years old and then I stopped studying and moved to my husband's house, I was in the 6th class. At that time it was common to get married early. That is how it was. My older sister-in-law

\footnotetext{
${ }^{58}$ Located on the southeastern coast of India.

${ }^{59}$ Purdah translates to "curtain" in Urdu. Purdah is a seclusion practice among Muslim communities in South Asia.
} 
taught me all the housework. I did not know anything when I was married. (Kunyama, 68 years, Suman's Mother-in-Law)

Kunyama spoke of how she had an arranged marriage and how once she was married she stopped her formal education. She spoke to the normalcy of early marriage for girls when she was young, unable to negotiate or challenge the inevitability of arranged marriage. As a young 14-year-old child, Kunyama showed great resilience and spoke of how her female relationships were crucial for her domestic education in her new home. Kunyama's agency as a young Dalit girl is integral here to consider, as Rao (2014) indicated specifically in the context of Dalit women. Rao, speaking about Dalit women, characterized their agency as "a complex mix of subjection, conformity, and resistance, in response to the ongoing gender politics within an often homogenized group" (p. 3).

Kunyama strategically nurtured the relationships around her, particularly the women in her conjugal home as a way to gain knowledge of the requirements for her new life as a child bride. She described her husband as a kind man who always provided for her; it was hard for her to speak of her husband's death. Kunyama struggled financially after her husband's death but she took over the roadside chai stall (Figure 23) that they owned and she is determined to provide for herself. She sells hot chai and cigarettes. 


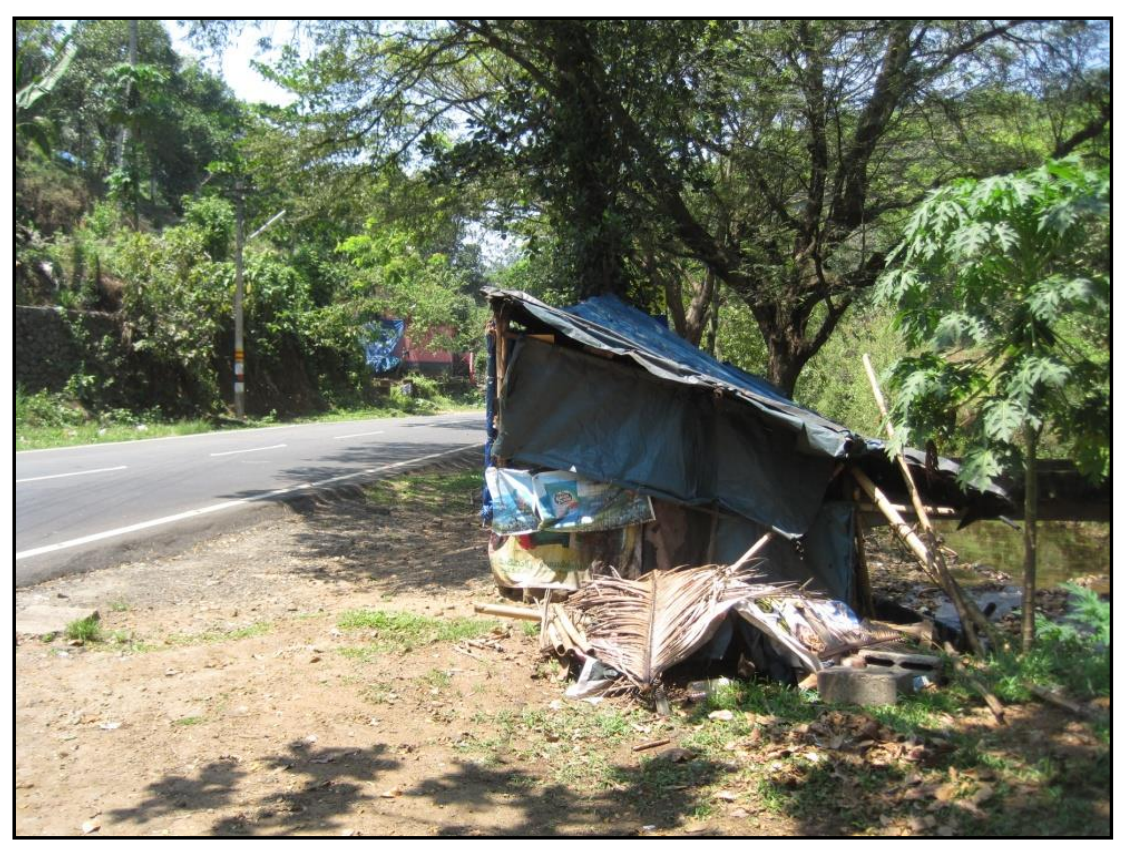

Figure 23. Outside Kunyama's chai stall. Personal photo.

On the other hand, Sonja (Mother, 40 years) spoke of how her marriage was selfarranged; she called it a "love marriage". Sonja and her husband both grew up in the Dalit colony. Her family disapproved of her choice of a husband so they eloped and went to live with her aunt. Rao (2012) indicates that the disapproval of love marriages comes from a disapproval of the couple's defiance of the patriarchal control that seeks to control choices in marriage. Sonja's love marriage was a fierce act of defiance. The couple eventually returned to their families after much coaxing. Sonja stopped studying in the 6th class and was not studying when she got married. At the time of this study, Sonja has been married for 25 years.

Sonja wants her daughters (15 years and17 years, respectively) to study and not worry about marriage. She wants them to get good jobs and be able to work. However, she repeatedly spoke of how life starts after marriage and hinted at how she sometimes wonders if investing in their education had actual value. Despite speaking of how deeply invested she is in her daughters' education, Sonja wonders if her daughters will be permitted to work outside the home 
or if they will be able to use their education after marriage. Kandiyoti (1988) reminds us that "women's strategies are always played out in the context of identifiable patriarchal bargains that act as implicit scripts that define, limit, and inflect their market and domestic options" (p. 285). Her subtle questioning of the value of education in their lives shows her consciousness of stringent patriarchal structures that scrutinize women's lives through marriage. It is her own patriarchal bargaining, where she works hard inside and outside the home to ensure that her daughters get an education but also save for their marriage, which she knows is vital for her daughters. Thus, Sonja works within and against patriarchal systems, identities and locations (Zinn \& Dill, 2009) to create opportunity for herself and her family.

However, her neighbor Rinu (30 years, Anama's daughter-in-law) does not work outside the home. Rinu completed her education until the 12th class and was certified to work in a computer lab. Rinu worked in Bangalore until her marriage. After marriage, Rinu is responsible for taking care of her ailing mother-in-law. Rinu washes, bathes and cleans her mother-in-law, who is confined to a chair in their living room. She is a full-time care provider; along with caring for her mother-in-law, Rinu also does all the household domestic chores and cares for her fiveyear-old daughter. Rinu's husband works in the Middle East as a hotel staff member. He sends money home, placing Rinu's family at a marginally higher class position than the others in the colony. When I inquired about her desire to work, she indicated that it depends on what her husband and in-laws allow her to do, and that she still wants to work someday. At the end of the interview Rinu said, "Don't think I do not like my life, I do whatever is needed of me with joy. This is my life now. I do not mind the work, what makes me sad is the drinking and the fighting." Rinu notes that in this statement her silent recognition of her gendered labor as a daughter-in-law, she does not want anyone to think that her endurance of the harsh realities 
negates her sense of agency. Rinu speaks boldly about how she fulfills her responsibilities while navigating a hard home situation caused by her father-in-law's drinking and fighting. Reader (2007) draws on Das's writing Life and Words (2007) about violence against women in India in her argument for why endurance must be framed in the context of women's agency. She says: Women here have a practical knowledge of how to manifest life between violence and the things they love. Their endurance absorbs the violence, as a harbor wall absorbs the forces of the sea. Das's study suggests that many victims believe that far from demanding to be spoken, the knowledge that informs this aspect of endurance demands silence, so that ordinary life can continue, or begin again, amid the rubble that violence has created. (p. 598)

Rinu loves her daughter and wants to be whatever is needed to provide a life for herself and her daughter. Rinu's case is also indicative of how participating in domesticity supersedes women's participation in labor outside the home. This vignette indicates how in Rinu's life, patrifocal monitoring resulted in shaping her labor inside and outside the home. Her conjugal home is a site for bargaining, conformity and resistance.

Another example of patrifocal monitoring in Dalit women's lives was seen in Mala's case. Mala spoke candidly about her aspiration to study through Kerala's non-formal education program as a 40-year-old mother. She spoke about how she had bought textbooks and had inquired about the state-sponsored equivalency programs ${ }^{60}$ that offer adult education in her district. But Mala has not been able to attend classes in the evening. She said that her husband would find the idea of her attending school shameful. Mala has spoken about shame often in the

\footnotetext{
${ }^{60}$ Equivalency programs cater to adults who were unable to complete their education in the formal education system and want to continue their education.
} 
context of her education. As a young girl, she experienced the shame of repeating failed classes. This eventually led to her dropping out of school. Now she is a wife who cannot shame her husband by going back to study as an adult. Shame is used to regulate women's gendered expectations in both the personal and public domains, as seen in Mala's life. Feldman (2010) in her writing addresses shame and honor as socially constituted sites of contested meanings which women negotiate based on their understandings of social practices and the expectations that frame their lives. Feldman challenges us to consider what women's lives would look like if they confronted and broke away from gendered expectations. Mala's is a strategic decision to ensure her own welfare and the security of her conjugal home.

Spivak (1988) reminds us to be cautious about representing the subjectivities of the subaltern in development as lacking power and voice. Dalit women should be seen as social agents that navigate a society where they are placed at the margins. Their daily acts of resistance and agency highlight the need to frame Dalit women as more than submissive welfare-receiving victims in Kerala. Women shared stories of strength as they faced married life as child brides, defied marital norms by challenging an arranged marriage and choosing conformity in the face of patriarchal control. Conformity is not a demonstration of victimhood, as seen in many narratives in this study. It is also an expression of women's agentic negotiation of gendered expectations such as those seen in the narratives of the Dalit women in this dissertation.

\section{Negating Safe Spaces: Violence in Home and Community}

Violence in the home has been universally described as one of the most insidious and prevalent human rights concerns (UNICEF, 2006). Kerala has been reported as having some of the highest rates in India of violence against women in terms of rape, molestation, and domestic violence (Irudaya \& Sreerup, 2007). Furthermore, crimes against women increased by $41.5 \%$ 
between 2007 and 2011 according to the Kerala Police as reported in the newspaper article below addressing the rise in marital violence in Kerala (Figure 24).

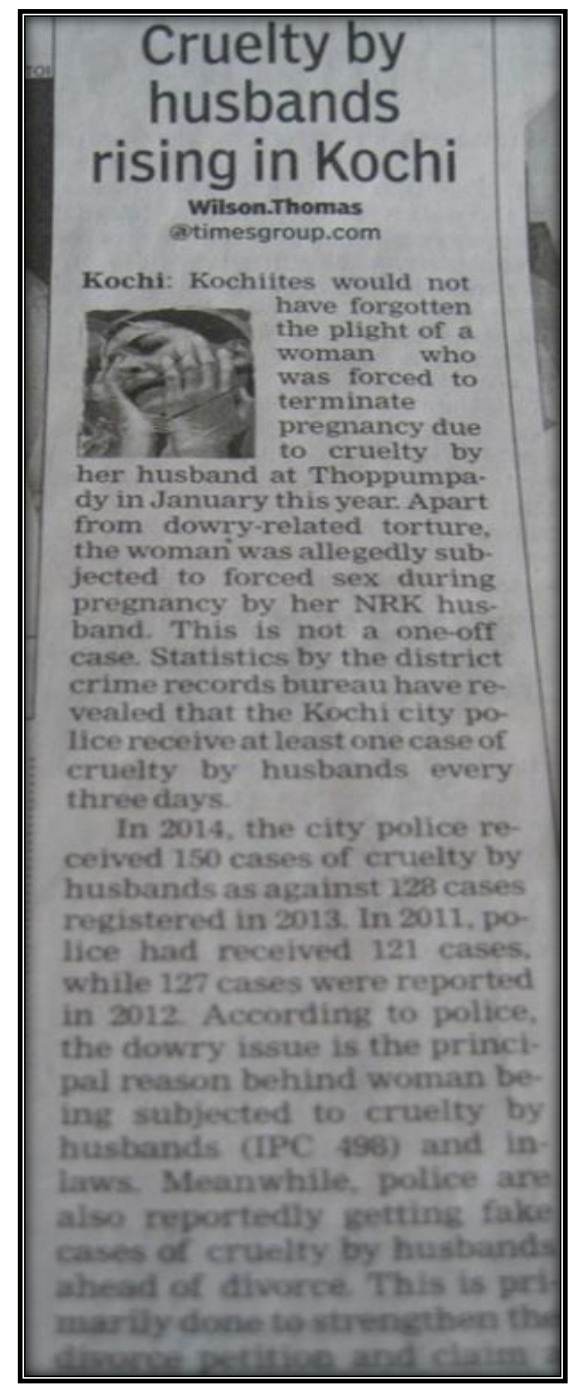

Figure 24. Newspaper article. Times of India, Kerala edition, March 2015.

The escalating rates of violence against women in Kerala is a matter of serious concern as it highlights the paradoxical location held by women in a society that boasts of high female literacy rates as one of its greater achievements (Devika \& Mukerjee, 2007; George, 2011; Hapke, 2013; Mitra \& Singh, 2006; Mukhopadhyay, 2007). Research has suggested that violence 
against women has been neglected because the government has failed to look beyond positive oratory about women's high literacy rates in Kerala (Sakhi, 2004). Thus, this indicates the need to examine the underlying social structures that frame women's live in Kerala. I assert that to contextualize this systematic rising violence in Kerala society one must turn to understanding how the patriarchy shapes narratives about violence and control in women's lives. Kodoth and Eapen (2005) addressing violence against women in Kerala state, "Patriarchal structures are associated with systematic legitimation of violence against women. However, if patriarchy sanctions violence, it is also known that resistance to patriarchal norms is one of the key triggers of violence" (p. 3283). Their observation of how patriarchal control operates in Kerala society draws attentions to how patriarchal conditioning and policing has a tight grip on women's lives. This is seen in the institutions of marriage and dowry, which justify and normalize using violence against women. According to the Human Development Report (2008), which notes a significant number of women in Kerala who have experienced marital violence in the home, justified it under the guise of marital norms. These societal norms clearly designate women as inferior and men as superior, thus leading to the legitimation of marital violence.

Violence in the home is often seen as a private matter that is not candidly discussed in the public realm. Panda (2004) who extensively surveyed rural and urban households in Thiruvananthapuram District of Kerala reported that $35.7 \%$ of women experienced being slapped, hit, kicked or beaten in their married lives, while $64.9 \%$ reported having experienced physiological violence at least once in their married life. Another factor that links violence and marriage is alcohol consumption in the home. Panda (2004) reported that $61 \%$ of the women who reported that their husbands were intoxicated at least once a week also reported physical violence such as being hit, kicked, slapped or beaten by them. 
Marital physical violence in the home is criminalized under the Indian Constitution. However, marital sexual violence is sadly allowed by the Government of India, which has failed to criminalize marital rape despite repeated demands by women's activists in the country. Section 376 of the Indian Penal Code, which addresses punishment for rape, has a marital rape exception. Agnes (2015) observes how a government official justified marital rape by saying, "Marriage in India is perceived as a sacred union, marital rape cannot be brought within the purview of the law on rape" (p. 12). This indicates how men are offered state sponsored freedom to violate women's bodies and how the state clearly turns a blind eye to violence in private spaces. The protection offered to men in marital relationships by the state is a manifestation of the safeguard of patriarchal interests (Menon, 1999; Sinha, 2003).

However, this violence is also regularly observed in public spaces that women traverse daily such as the streets, public transportation and educational institutions in Kerala. A hierarchy exists in Kerala society that supports the standpoint that men are authoritative while women are submissive (Osella \& Osella, 1998). This hierarchy manifests in public spaces in the form of physical and verbal harassment of women by men. Kerala's society responds to this explicit public harassment by creating gendered spaces that serve as protection for women. Some of these gendered spaces where men and women are spatially separated are girls-only educational institutions and separate sections in public transportation for men and women (Mukhopadhyay, 2007; Osella \& Osella, 1998). Another response to this public harassment is monitoring women's mobility in public spaces, which is viewed as a spatial manifestation of patriarchy (Valentine, 1989).

An example of women's mobility being curtailed in educational spaces was seen when the College of Engineering Thiruvananthapuram (CET) enforced a 6:30 p.m. curfew for women 
to return to the women's college hostel ${ }^{61}$ while the college library and computer labs remained open until 8:00 p.m. and 9:30 p.m., respectively. While men can stay on campus and complete assignments in the library and labs, women must guarantee that they return to the hostel on time or else pay a monetary fine. As seen in the newspaper article below titled "CET Girls Raise Voice to Break Curfew", the basis for this curfew imposed on women was ensuring women's security on campus (Figure 25). In response to this discriminatory and regressive rule, the women on CET's campus organized and launched a movement called "Break the Curfew" as a call for equal rights for men and women on campus. This movement resulted in the removal of the fines for missing the curfew; however, the curfew is still enforced. Break the Curfew was one of many examples of how women in Kerala gathered to raise their voices through strong social mobilization in the face of patriarchal politics. Kerala society is an oppositional civil society with a rich history of social movements and grassroots initiatives that challenges mainstream political discourse and development narrative (Center for Development Studies, 2008).

Prominent Malayali feminist activist J. Devika, responding to how curbing women's mobility disguised as concern for women's safety is a blatant violation of women's rights on CET's campus wrote an open letter on the dissent blog Kafila. Devika (2015) states:

These are places in which the violation of Constitutional rights and freedoms pass off as 'security measures' and 'moral considerations'. These 'moral considerations' apparently deserve more weight when they come into conflict with Constitutional rights and reduce woefully the academic competence and personal capacities of students! (para. 3).

\footnotetext{
${ }^{61}$ Hostels are dormitories in Indian colleges.
} 


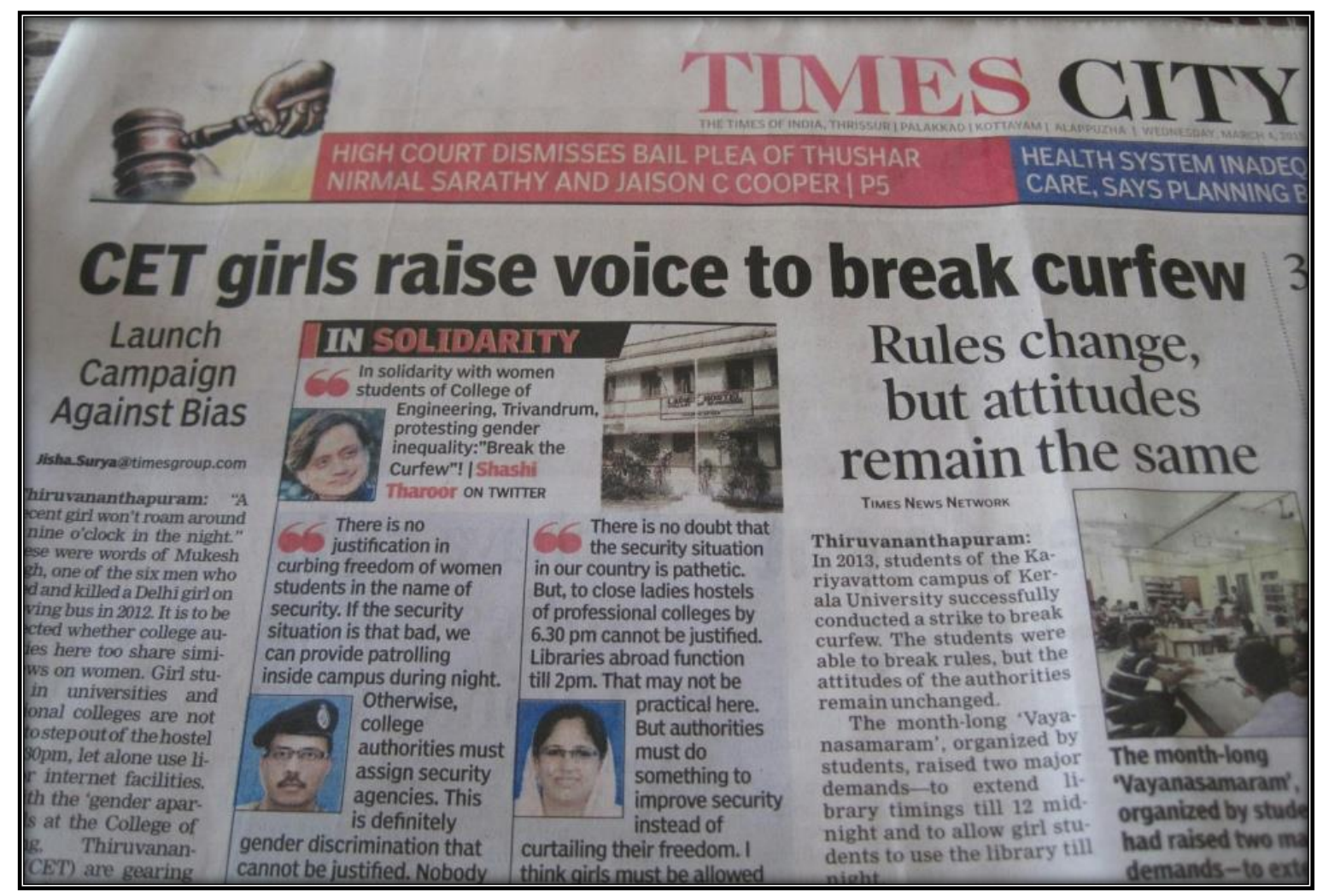

Figure 25. Newspaper article. Times of India, Kerala edition, March 2015.

Devika highlights how moral policing in Kerala society is used to monitor women in public spaces. This has grave educational consequences for women who are often denied the same access to resources such as the library and technology as men on campus. Thus, representing how violence against women is used as a political tool to control women's mobility and uphold gendered hierarchies in Kerala society.

In India's stratified society, violence against women cannot be seen as purely connected to caste, class, and gender in isolation. Being lower caste and lower class exacerbates gendered vulnerability to violence in the home and in the community and further negates safe spaces for women. Thus, exposing how "violence has emerged as the linchpin around which both the experience and enforcement of gendered and caste identities revolve" (Brueck, 2012). This was 
evident in the recent highly publicized brutal rape, torture and murder of a Dalit female law student, Jishamol, in Kerala (April 28, 2016). Jishamol lived with her mother and sister in a shed without proper security, as they were landless Dalits. According to her sister, Jishamol was studying to be a lawyer so she could fight against the injustices that the Dalit community faces in Kerala. The family reported incidents of harassment by neighbors but the police did not take their complaints seriously because Jishamol was a single Dalit woman raising two daughters alone.

Addressing the systematic discrimination that Jishamol's family faced, Amnesty International reported how the family faced isolation and separation from the rest of the community who were upper caste, and how they were not permitted to get water from their neighbors' wells. The family was not silent, and intrepidly challenged this discrimination, which further ostracized them. Their revolt in the face of abjection speaks to their resistance and agency and disrupts the victim discourse that surrounds Dalit women as historically marginalized communities. This heinous act of mutilation, overt public discrimination and a lack of prompt attention and justice from the police revealed how Dalit women's lives are far from secure in present day Kerala. It also stirred public consciousness towards the plight of how being landless and a lack of secure housing exposes Dalit families to violence. Furthermore, it draws attention to how the Kerala government continues to fail to address the complexities of Dalit lives. S. Irudaya Rajan (2016) (Senior Scholar, Center for Development Studies, Kerala) speaking about Jisha in an online news article, said:

Jisha was educated but also socially disadvantaged. That's what Kerala's prized model of development doesn't take into account. For all the great progress for women in the state, poor, lower caste women are still falling through the cracks. Women are literate, there's 
no question about that, and I never said women are not literate. But it has not transformed their lives. (McCarthy, 2016)

Rajan draws attention to how the Kerala government often cites education as a panacea for the systematic marginalization of the Dalit community and fails to move the narrative towards a true acknowledgement of their several other needs. It is evident that the state has failed to present a deep consideration of why Dalit women across generations continue to live on the fringes of society as seen in Jisha's tragic story.

This limited government understanding of Dalit needs was also seen in the articulations of women and girls in this dissertation. They assert that violence against women, a lack of security, and the effects of landlessness are everyday realities in their lives. When I inquired about pressing problems that women faced in this community, women across the generations unanimously spoke of how violence and alcohol use among men were two of the foremost concerns that needed to be addressed.

Uma (Mother, 45 years), speaking about the pervasiveness of alcohol use in her community said, "Men drink alcohol for entertainment, while women watch serials ${ }^{62}$ for entertainment. Then, men drink and then come and fight with their families. Some men work to drink." Uma speaks to the burden of a community that struggles with alcohol use and how their relationship with alcohol is aggravated in the face of poverty and a lack of social mobility.

Likewise, speaking about violence in her community, Rinu (30 years, Mother) noted: "Recently in a house near us a man got drunk and forced himself on a woman. The woman's house does not have a door. He hit her with a stick because she did not allow him. Men drink and harass the women." Rinu draws consideration to how a lack of secure housing coupled with

\footnotetext{
${ }^{62} \mathrm{TV}$ shows are called serials.
} 
alcohol use in the colony exposes women and girls to violence in the community. She also comments on how women's resistance to male advances aggravated assault on women. Mukhopadhyay (2007), addressing violence against women in Kerala society, writes about the underlying patriarchal structure that gives men an unequivocal right over the female body. If women challenge this right or attempt to resist, then men have societal permission to discipline them. Thus, a culture that supports male dominance hothouses an environment in which violence thrives. Specifically in the context of domestic violence in Kerala, Mukhopadhyay notes:

"Domestic violence is different from other forms of violence against women in that it is bred and nurtured on a one-to-one basis, within the four walls of the home, perpetuated by individuals on whom depends the very identity of the woman" (p.13).

Likewise Priya (14 years) who spoke of how her inebriated father battered her mother and how the violence impacted her family's life, said:

I did not have any issues in my life. I had a good childhood. Things got difficult after the 5th class, after my mother left. My father drank a lot and hit her so she left us. I am angry that she left us. She left and the workload of the house is on me, I study when I can. I do not mind the work but my father fights. Priya has little choice in the matter of housework, as her brothers do not contribute towards labor in the home. Priya's words highlight how domestic violence coupled with the gendered labor in her home have placed her in a position where the burden of responsibilities falls on her. She said she studies when she can, such as in school during lunch breaks or between classes. Priya navigates her education in an environment that fails to cultivate and support her education. She speaks, however, to her survival strategies, resistance, and agency in the face of the everyday violence in her life. 
A similar narrative was shared by Mala (40 years, Mother) about her childhood. Mala failed the tenth class twice. Her parents fought every day and the fighting caused her much anguish. Mala was the oldest of her siblings so she had to help her mother. She said by the time everything at home was done, she did not have the attention left to study. On inquiring how the school system responded to her troubled home life, Mala said: "My teachers knew about the issues in my home. They recommended that I do not take the exams the round that I failed but I did not want to study with a younger group, I was ashamed." Mala failed the tenth class twice and having her repeat a class was clearly not the support that she needed. The shame of failure was too much and she dropped out of school. Mala's case is visibly indicative of how a lack of understanding exists in the school system about helping children who witness and experience violence in their homes and communities.

These narratives of domestic violence in which families navigate strenuous violent home lives were a recurrent theme in this dissertation. The women and girls in this dissertation articulated how a thread of violence often ran through their lives often erasing opportunities for true engagement with their education. Exposure to violence in the home has serious consequences for children such as behavioral, social and academic problems (Kernic et al., 2003; Kernic et al., 2002). Vasavi (2003), addressing the gaps in teachers' training in India, states that most of the training that teachers are given focuses on filling pedagogical gaps but little attention is paid to helping teachers understand the complexities of marginalized communities that they teach. Thus, this is a systematic failure of the education system in Kerala when students slip through the cracks because of the education system's apathy to violence and a lack of judicious educational interventions at various levels, which include teachers, administrators, and management as a whole. It is vital for the education system in Kerala to recognize the individual 
and cultural milieu (Rao, 2014) that Dalit women and girls navigate to gain an education and to recontextualize educational structures, resources, and knowledge to meet their needs.

\section{Violence in School}

Another space where violence exists is the schools in Kerala. Morrell (2001) explains corporal punishment as "the purposeful and frequent infliction of pain by those in authority in a formal and ritualized way in an institutional setting" (p. 140). In 1986 (modified in 1992), corporal punishment was outlawed at the national level by the National Policy on Education in India. The National Policy on Education states that corporal punishment will be firmly excluded from the educational systems. Furthermore, the Right to Education Act (2010), a more recent act, made corporal punishment a punishable offense. The provisions under the act read as follows: Prohibition of physical punishment and mental harassment to the child - (1) No child shall be subjected to physical punishment or mental harassment. (2) Whoever contravenes the provisions of sub-section (1) shall be liable to disciplinary action under the service rules applicable to such person. (Guidelines for Eliminating Corporal Punishment in Schools, National Commission for protection of Child Rights, 2010, p. 11) Bajaj (2016) addresses the use of corporal punishment in schools as a paradox of child protection. Bajaj highlights the disconnection between what the law lays out as protection and what is in fact occurring in schools. The onus of ensuring that these acts are imposed lies with the local government and authorities, though many states across India fail to comply with and suitably enforce child protection laws (Bajaj, 2016).

Corporal punishment is a widespread disciplinary practice in most Indian schools. It is crucial to recognize the fundamental social order that supports this practice. This is deeply rooted 
in the Indian understanding of Guru-Shishy $a^{63}$ where teachers have undeniable authority and are free to use violence to control students. There is a normalizing of violence as a disciplinary practice to preserve this deeply entrenched social order. Addressing violence in the classroom, Proctor (2015) draws consideration to the role of the family structure in India. She states:

Women and children rank low in these authority systems, and as such, are expected to be obedient to those above them. This demand for obedience is a central aspect of the assertion of age and gender hierarchies in Indian society. Violence is a common means of enforcing such hierarchies in India, and schools are no expectation. (p. 6)

Thus, Proctor returns the narrative to how hierarchies must be maintained in the classroom and how patriarchy is manifested in educational spaces as domination and the free passage to use violence to discipline those who transgress. Furthermore, in the narrative about corporal punishment in Kerala, one must also attend to the role of caste and class in maintaining power hierarchies in the classroom. The majorities of teachers in the schools in Kerala are upper caste (Padmanadhan, 2010), and are clearly placed in a position of power. This is not only because of the teacher-pupil hierarchy and age discrepancy but also because of being upper caste. Corporal punishment in schools in Kerala exposes many axes that intersect and interlock to maintain power differentials. It reveals how the upper caste can discipline the lower caste, the rich can discipline the poor and the elder can discipline the younger. Thus, to understand corporal punishment in schools, we must draw attention to intersectional paradigms (Collins, 1991).

Mala (40 years, Mother) spoke of how corporal punishment was a widespread disciplinary practice in her school. The indiscretion that sparked violence in her classroom was not knowing the answers to questions posed by the teacher. I assert that this is a manifestation of

${ }^{63}$ Translates to Teacher- Disciple 
benevolent patriarchy where lower caste, lower class, young students require the supervision from a person in authority at all costs. Thus, this exposes the patriarchal perception that there is benevolence in subjugation (Tichy, Becker \& Sisco, 2009). Mala spoke of how she managed to get through classes through rote memorization; she said that she did not really comprehend subjects like English, Math, Physics and Chemistry. Her favorite subject in school was Biology; she liked reading about it and understood a few topics in Biology class. When I asked if she felt she could ask questions in class if she did not understand something, Mala said:

Teachers always explained, I never understood Chemistry and what they taught. I got so bored in the Chemistry Sir's ${ }^{64}$ class, I never paid attention. The Chemistry teacher would cane the children. While he taught he would ask you questions, and if you did not know he would hit you. Everyone would get beaten if they did not know.

Along with corporal punishment, according to Mala the teachers also gave the students "impositions" (punishments) if they got questions incorrect when asked by the teacher. Impositions included writing the correct answer one hundred times so that the student would not forget the correct answer. Mala said that she received impositions but she had to write them when the teacher was teaching, so she often missed out on the lesson. There were two important factors that influenced Mala's school difficulties: a pedantic atmosphere, and a fear of corporal punishment and other harsh punishments for poor performance. These issues contributed to an unsettling environment.

Similarly, Sonja (Mother, 40 years) also spoke of the practice of corporal punishment in her school when she was young. When asked what she disliked about school she said that she detested the teachers that hit students if they did not study. Devika and Lata (Sonja's Daughters

\footnotetext{
${ }^{64}$ Referring to male teachers as Sir, Female teachers as madam
} 
17 and 15 years) also spoke of how they have corporal punishment in their schools in present day Kerala. They both said that often children study because they do not want to be hit in school and some students study out of fear. When asked if boys and girls both were hit, they said that boys generally get hit more than girls. In addition, on asking where they were hit, Devika and Lata said that the girls get hit on their hands and the boys get hit on their thighs. Teachers would stay as far as possible from the genitals and breasts of girls when disciplining to avoid accusations of indecency and uphold their moral position as fighting for intellectual and moral discipline. Additionally, boys are hit more than girls also because of the patriarchal norms that connect masculinity with being able to bear greater aggression and violence. Boys are thought to be insubordinate and to require harsher punishments while girls are deemed subordinate and requiring more lenient punishments. Furthermore, there were evidently no penalties for teachers who hit their students in spite of legal consequences for teachers and safeguards for children. Thus, it is essential to note that patriarchy and violence do not have a one-dimensional relationship where one leads to the other. In Kerala, like the rest of Indian society, it is crucial to position violence in the larger intersectional framework that draws consideration to the various systems that sustain violence in the home, community and schools. Dalit lives are susceptible to greater violence due to their social position below all others in India's hierarchical society (Irudayam, Mangubhai, \& Lee 2011). However, it is also necessary to remember here that Dalit women are not merely defined by the violence in their marriages, homes and communities.

\section{Conclusion}

Marriage is a decisive structure in India and is deeply ingrained in its patriarchal structure. It was evident from the narratives in this study that Dalit families wanted to educate their daughters but there was also a widespread acceptance that marriage was a stronger influence than education in Dalits' lives. Furthermore, Dalit women challenge conventional 
notions of provider-homemaker in marriage by working outside the home and providing for their husbands and children. Despite the violence in their marriages, Dalit women in this study know that they need to protect their conjugal home as a step towards protecting themselves and their children. Thus, they enact patriarchal bargains (Kandiyoti, 1988) in which they endure violence to protect and educate their children. It is evident from the narratives seen in this chapter that in a state which boasts of its educational initiatives for women, violence against women is robbing them of safe spaces for educational engagement and access. 


\title{
Poem by Poikayil Appachan ${ }^{65}$
}

\author{
About my race... \\ I see no alphabet \\ about my race \\ I see histories \\ of many races \\ The world's histories \\ Think each one \\ as two races \\ I see no alphabet about my race \\ Oh, that there was no one \\ in the ancient world \\ to write the story of my race! \\ When I think of it, regret begins \\ within me \\ let me add something \\ in my own melody. \\ the story of how \\ a people who lived from times long ago \\ in Keralam \\ came to be lowly on earth.
}

${ }^{65}$ Dalit Poet from Kerala, writing addresses Dalit erasure from history. The Oxford India Anthology of Malayalam Dalit Writing (2012). 


\section{Chapter 7: Discussion, Implications and Conclusion}

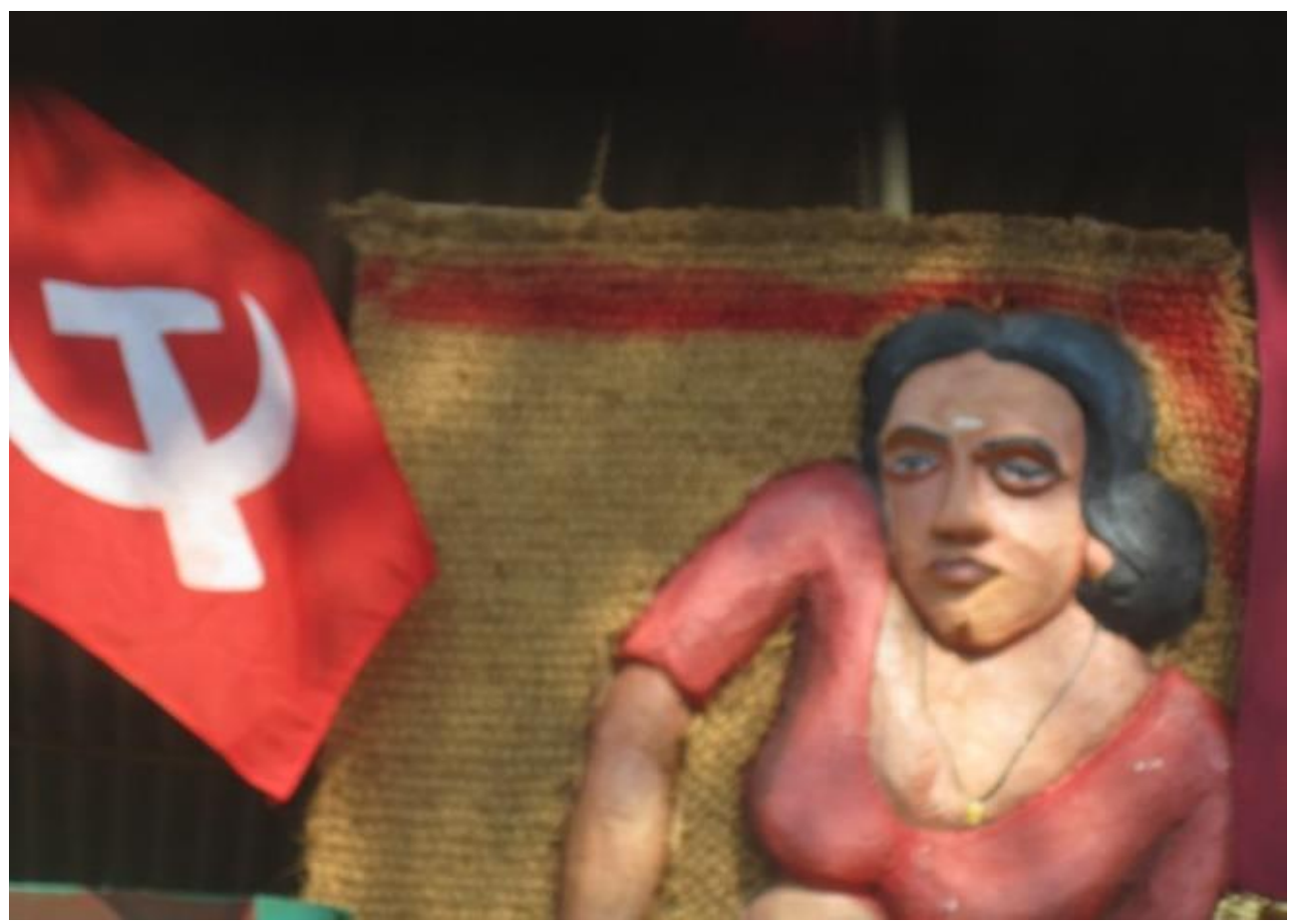

Figure 26. Personal photo. The Dissent

This image serves as a reminder of the centrality of women in the development discourse in Kerala's social, cultural and political arenas. This photo was taken during fieldwork at the site of a political protest for worker rights in Thiruvananthapuram, Kerala. Women in Kerala are articulated as the foundation of Kerala's development but Dalit women in this region are considered to be outliers to development. I was drawn to these conflicting yet widespread governmental narratives that were observed in development documents and in the literature about Kerala. I began thinking and raising questions such as: Why are Dalit women called outliers? Who is at the margins and who is at the center? Are Dalit women's relegated positions at the margins of Kerala society the state's strategy to establish and maintain them as the "Other"? This feminist qualitative study seeks to offer contextualized place-based narrative 
accounts of Dalit women's subjectivities as a step towards exploring how Dalit women traverse and negotiate state sponsored development in Kerala. The main questions of the research project are:

1. How do the intersections of gender, caste, class and religion shape Dalit women and girls' educational experiences in their families and communities?

2. What is the process of inclusion and exclusion of Dalit women and their daughters in state-sponsored formal and non-formal education initiatives?

3. What are the implications of state-sponsored formal and non-formal education initiatives for Dalit women and their daughters?

Using in-depth intergenerational interviews, photovoice, development documents and field observations this dissertation explores the intersectional nature of Dalit lived experiences and in particular their educational experiences. This research draws on postcolonial feminist conceptions of power, representation and agency and is centered on the subaltern Dalit subject in Kerala. Drawing on Mohanty's (1988) reminder in Under Western Eyes, "It is only by understanding the contradictions inherent in women's locations within various structures that effective political action and challenges can be devised" (p. 56).

These contradictions challenge the deployment of binary discourses, such as power/ powerlessness in development. They seek to contravene universal notions of Dalit women's subjugation that frame them as only victims of their individual and collective oppression. Thus, I argue that the state has failed to recognize these contradictions, which has resulted in failed and often limited policies targeting Dalit lives. 


\section{Discussion of Findings}

The Model of Development in Kerala has invested heavily in education and has been celebrated as one of the first states in India to achieve universal literacy (Kumar \&George, 2009). However, there is a growing unrest in the literature about Kerala's education system with its disregard for historically disadvantaged groups like the Dalits (Devika, 2014; Kumar \& George, 2009; Padmanabhan, 2010). Thus, this study presents how Dalit communities in contemporary Kerala navigate Kerala's Model of Development. Their stories demonstrate the many dimensions of subaltern subjectivities in the face of material and discursive neoliberal development and patriarchy. Furthermore, the intersecting/ interlocking identities, systems and locations of caste, class, gender and religion that Dalit women navigate exemplify how inequity is maintained by hegemonic power structures such as the state in Kerala. To understand how Dalit women engage with state-sponsored educational initiatives in particular it is imperative to use a comprehensive approach. This approach must not only draw consideration to the historicized manifold patriarchies but also provide space for a Dalit woman's individual reframing and counter-narratives as a response to these patriarchies.

This discussion of findings is divided into two sections as indicated by the diagram below (Figure 27), each section speaks to how Kerala society frames, limits and controls the subaltern subject but also attends to the agentic enactments of Dalit women. In the context of framing, it attends to the depiction of the subaltern in development as lacking power and voice by colonist discourses of development. While in the context of limiting/controlling it attends to how Dalit communities are maintained in a state of subjugation because of lack of amenities, access and equity. It is essential to note the cyclical character of this approach; it speaks to how 
framing, limiting and controlling the subaltern subject work individually but also in conjugation with each other.

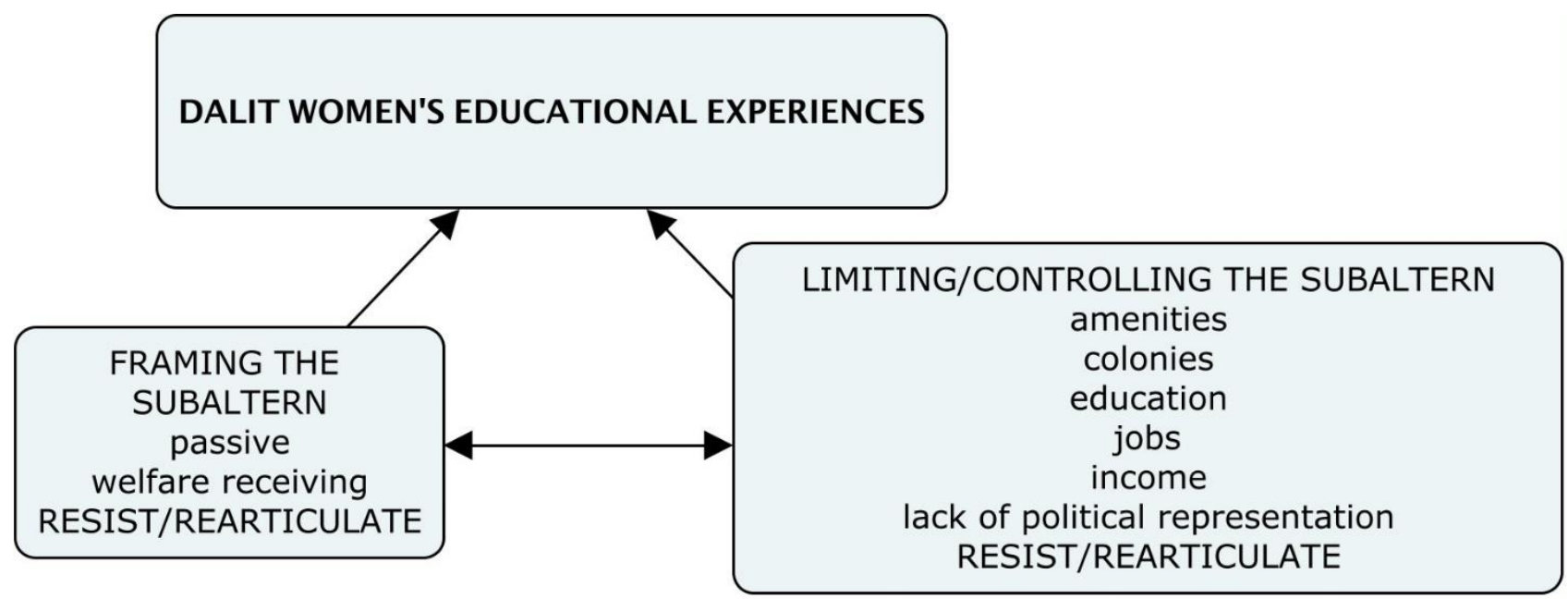

Figure 27: Framing, Limiting and Controlling Dalit Lives

\section{Framing the Subaltern Subject}

It is vital to contemplate the historical and ideological representation and framing of the subaltern subject in Kerala. The term Dalit appeared around the 1980's in this region. Dasan (2012) attributes this late appearance of the word Dalit to suppressing and misrepresentation of Dalit needs in Kerala. During this period, Dalit communities started to challenge their systematic exclusion from government agendas (Dasan, 2012) that was enabled with the rhetoric about Kerala's development, which was based on a society that projected an image of being beyond the confines of caste. Speaking to this projected image, Dasan (2012) states:

It was fashionable to say that one did not practice casteism. Caste was a non-issue; class and class enmities were the main issues. Thus, by masking caste in the public realm through 'progressive' discourse based on class, the upper caste made sure that cultural, 
symbolic, social capitals which their elite caste status had conferred on them was not visible. (p. xv)

However, in response to Dalit assertions for inclusion in government agendas the state framed Dalits as submissive essentialist government categories, which resulted in policies, which framed them as outliers, limited, voiceless and subjugated (Devika, 2010; Raj, 2013). In response to this mode of framing used by the state, many Dalits in Kerala moved towards new modes of reframing caste not as collective subjugation but in terms of their vibrant history and culture (Raj, 2013). This reframing has resulted in many Dalit not only in Kerala, but also across the country, distancing themselves from the umbrella term 'Dalit'. The Dalit has many names; Still (2014) notes how some Dalits use Jati (caste) associated names and do not use the singular homogenous identity of Dalit. Some align with Harijan, which means children of god, while many Dalits reject this term as they consider it disparaging and condescending to their cause.

The women in this study did not identify as Dalit, they either identified as Cheramar Christian or Pulaya Hindu, which are their Jati names. Their distancing themselves from the Dalit identity is a form of reframing that distances them from the historical marginalization and the untouchability of their community. A majority of the women in this study converted from Hinduism to Christianity often as a way to escape caste-based discrimination. Such was seen in this image below of a sticker on the door in the Dalit colony (Figure 28), which embodied the sentiment "Freedom from Caste, Jesus Christ" that drives Dalit communities converting to Christianity in Kerala. However, the systematic marginalization of the Dalit community has not been reversed by religious conversion (Indian Institute of Dalit Studies, 2012). 


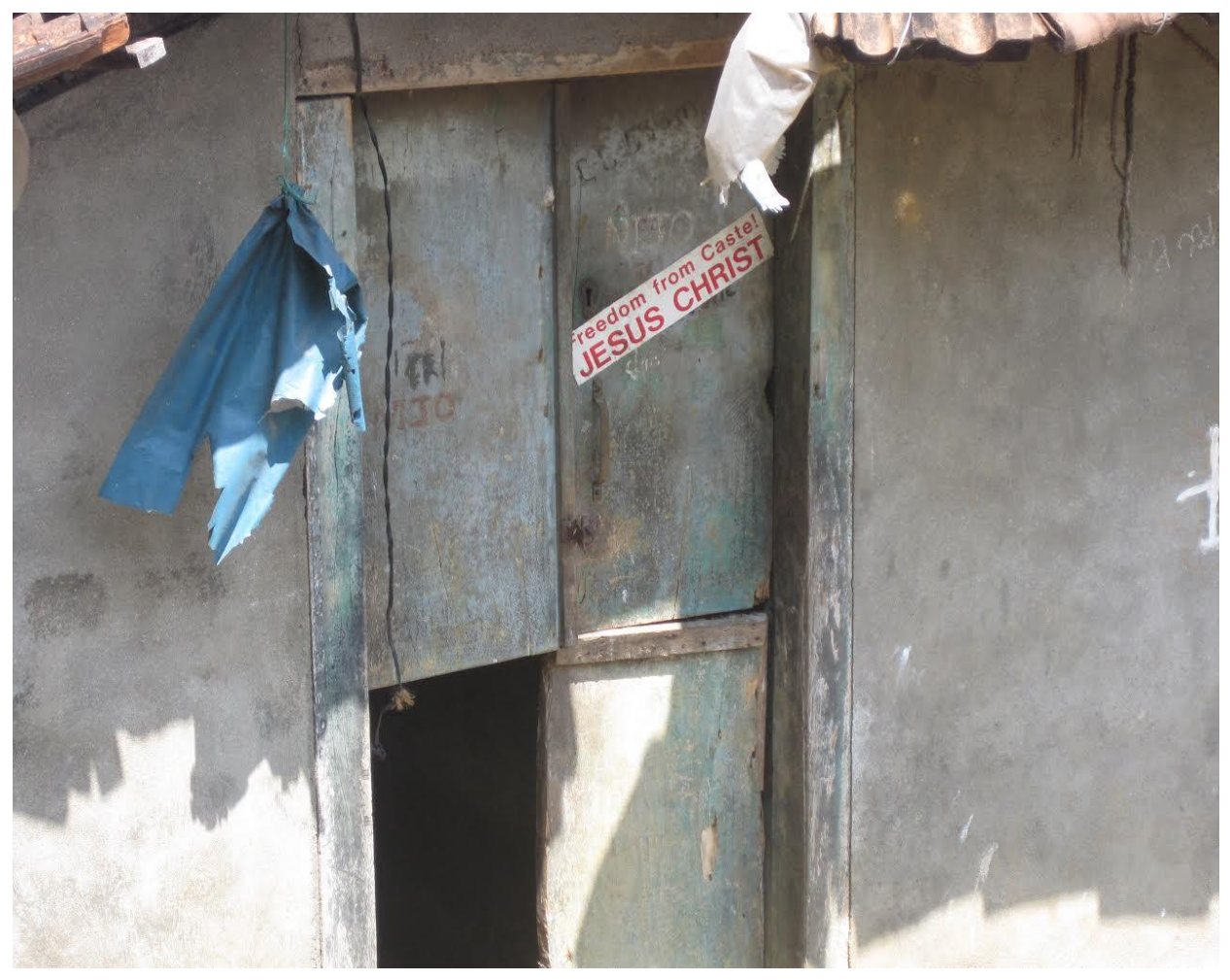

Figure 28: Sticker on door. Dalit Christian home in the colony. Personal photo.

Religious conversion ${ }^{66}$ among Dalits has also sparked the larger political debate about the entanglement of religion with affirmative action reservations in education and employment. The women often spoke of their consciousness of their caste and class when they addressed government reservations and constitutional guarantees. The Dalit Christians do not qualify for government reservations in terms of stipends, grants, reserved spots in educational institutions and employment while Dalit Hindus do qualify based on their religious affiliations. To

\footnotetext{
${ }^{66}$ Hindu Dalits are also often referred to as Scheduled Caste by the government, which serves as a government categorization, while converted Dalit in this study fall under the government category of OEC (Other Eligible Communities). Religious conversion to Christianity moved Cheramar Christian into the Other Eligible Communities category from the Scheduled Caste category government reservations. Being Hindu Cheramar places them in the Scheduled Caste category, which has, greater educational and job benefits from the government.
} 
understand why Hindus but not Christians receive reservations, we must return to the foundation of the caste system in India, which is a hierarchical Hindu structure. When Dalits convert from Hinduism to Christianity they are placed outside the caste system. Addressing the condition of converted Dalits, Thorat and Senapati (2007) of the Indian Institute of Dalit Studies state, "Though technically they are outside the matrix of the Hindu social caste system, they continue to suffer from caste-based discrimination in certain spheres and are known as the ex-untouchable castes" (p. 2).

The women often spoke of their consciousness of their caste and class when they addressed government reservations and constitutional guarantees. This is most evident in Uma's family (Mother, 45 years) who identifies as Pulaya Hindu. She spoke of how the family was deliberate about positioning themselves as Hindu to gain government reservations. Uma's husband's family converted to Christianity, however Uma continues to identify as Hindu. She openly acknowledged her navigation of the discourse of reservations to help her girls gain better access to education. This is indicative of the prevailing exclusionary government policies that are based on religious kinship versus an authentic acknowledgment of Dalit needs.

It was evident from the narratives in this study that the women who are often framed as passive welfare receivers are far from voiceless. They expressed their agency, power and resistance such as seen in Lila's (Mother, 38 years) case. Lila financially supports her family, pays their debts, and cares for her children and home in the face of extreme financial burdens. She often spoke of how she never shares her burden with anyone because that is what her mother taught her. Lila is unwavering in her determination to ensure that both her daughters study and are given the best opportunities to succeed. Lila, like Mala, Sonja, and Uma in this study, disrupts the gendered framing that places women in the domestic sphere and men as providers in 
Kerala. It is essential to understand Dalit women's work outside the home in the context of their financial duress that often forces women to work outside the home. Rinu and Suman do not work outside the home; this was seen primarily because their husbands make enough money to support their family.

Another essential factor that served to determine women's participation in work outside the home was their husbands' alcohol use. Men often squandered away their income to support their alcohol use, thus resulting in women working outside the home. Both Rinu's and Suman's husbands do not drink, resulting in greater financial stability for their families. This indicates the complex gendered landscape that Dalit women navigate in Kerala, a state that is often written about as experiencing a gender paradox with the lowest female labor force participation rates in the country (Devika \& Mukerjee, 2007; George, 2011; Hapke, 2013; Mukhopadhyay, 2007).

Furthermore, Dalit women are exposed to greater susceptibility to violence due to their social position as Dalit women (Irudayam, Mangubhai, \& Lee, 2011). Every woman and girl in this study spoke of violence in their homes and communities being a major concern. The domestic violence coupled with the alcohol use in their homes and communities makes Dalit women vulnerable but not passive. Many narratives in this study addressed how women resist and negotiate the violence in their lives. Priya (14 years, Suman's niece), for example, has an alcoholic father and a mother who left because of the violence. Priya cares for family, cooks, collects water, washed clothes and is completing her 9th class. Priya said she is tired all the time due to the burden of chores and the fighting that often keeps her up at night. She works hard at school, often studying between classes or during lunch breaks. With little choice in her life, Priya is a 14-year-old caught between the struggles of the home and the limitations placed on her as a 
Dalit girl. But Priya spoke assertively about her desire to complete school and her daily give and take of conformity and rebelliousness that helps her navigate her life.

In response to the violence that women in Kerala are exposed to, the state responds with a narrative of women's protection from violence instead of self-reflection into the patriarchal social order that supports violence against women. This narrative is framed in the context of restricted mobility and monitoring spaces that women can inhabit so they can be protected from violence. In the case of Dalit women, this monitoring has greater gendered consequences because they are already often restricted in spaces that they can inhabit due to their caste, class and religion. The women in this study spoke of self-monitoring mobility in public spaces, such as Uma who spoke about how she knows when she is not welcome somewhere because of her caste, she said that people don't say anything but she knows when they are thinking about her as lower caste and class. There was no mention of overt public discrimination by the women and girls, but there was a silent recognition of the social order that places Dalits at the bottom of Kerala society.

Dalit voices and bodies are silently monitored in Kerala in public spaces. Thus, the question that requires examination here is, "Are Dalit voices monitored in politics and policy?" Rekha Raj's (2013) work is essential to consider here. Raj explores Dalit women activists' experiences in Kerala and states, "Dalit women were part of most of the visible forms of "public action' (such as dharnas, mass demonstrations, strikes, and so on). But they remained invisible in both the discourses and the organizational structure of leftist politics at all levels" (p. 56). Raj asserts that the lack of political mobility in the Dalit movement comes down to the lack of bargaining power along with a deficiency of capital that would help visible public protests to translate to visible policy attention and representation. There is a need for greater Dalit 
representation in the politics in Kerala, which will ensure that Dalit agendas are heard and addressed.

Thus, the framing of Dalits in Kerala is a crucial starting point for how their inclusion and exclusion is delineated in Kerala's Model of Development. The Dalit struggle has been erased from both public and intellectual spaces (Dasan, 2012). This lack of critical consideration in government policies that takes into account caste, class, gender and religion has facilitated this erasure. As demonstrated in this study, public outcry, media attention and policy agendas cater to upper caste and middle class needs, not Dalit needs.

\section{Limiting and Controlling the Subaltern Subject}

In this discussion of limiting and controlling the subaltern subject, I address obstacles that Dalit communities face every day as a result of the state's disregard of Dalit rights as citizens in Kerala. These limitations impede the Dalit community's engagement with development and specifically with education. Dasan (2012) highlights the dark underbelly of Kerala's Model of Development by exposing how various major policies undertaken by the government were clearly anti-Dalit. He addresses these two specific bills as the "blind spots" in Kerala's development narrative as they strayed from their intended goals to address Dalit needs for land and education (Table 7). The goal of the Land Reform Bill (1969) was to provide land to the Dalit communities, but instead they were denied land ownership. The upper and middle caste communities were given land and the Dalits were turned into landless agricultural workers. Furthermore, the Education Bill (1959) ushered into Kerala a wave of greater privatization of education and ownership by upper caste communities. Greater privatization and ownership by upper caste communities resulted not only in rising costs but also a proliferation of policies that 
fail to account for the complexities of Dalit lives. The Education Bill subsequently negated room for Dalit knowledge and needs (Dasan, 2012).

Table 7

Major Reform Bills

\begin{tabular}{ccl}
\hline $\begin{array}{c}\text { Land Reform Bill } \\
\text { (1969) }\end{array}$ & $\begin{array}{l}\text { Aimed at providing access to } \\
\text { land. } \\
\end{array}$ & $\begin{array}{l}\text { Forced Dalits to become } \\
\text { landless and forced them into } \\
\text { colonies. }\end{array}$ \\
\hline The Education Bill & $\bullet$ & $\begin{array}{l}\text { Aimed at ensuring that } \\
\text { educational institutions were } \\
\text { beyond the control of private } \\
\text { management. }\end{array}$ \\
& $\bullet \begin{array}{l}\text { Failed to control private } \\
\text { management of education. }\end{array}$ \\
& $\begin{array}{l}\text { Excluded Dalits by creating } \\
\text { an educational environment } \\
\text { that was based on upper class } \\
\text { and caste needs. }\end{array}$ \\
\hline
\end{tabular}

Note: Adapted from Dasan (2012).

Thus, I draw attention to how these two policies have worked to limit the subaltern in Kerala. Firstly, consequences associated with the Land Bill are documented through narratives and photos about life in the Dalit colony. The colony was spoken about as a space of struggle but it was also spoken about as a space for collective identity. Women often spoke of how they would rather live in the colony than anywhere else, because they have friends, family and a sense of community that they do not have if they move out of the colony. They shared a strong awareness about their geographical and social segregation in the colony, which is often surrounded by bigger houses owned by higher caste and class families. On the other hand, life in the colony addressed themes around water, sanitation, access and electricity. The women spoke 
of their everyday struggles to access these resources and how the government has been unsuccessful in addressing their concerns. Lila's narrative about the water tank shared how the government tried to build a water tank to address the colony's water needs. But due to a lack of planning and improper execution of the project, it was abandoned. Similarly, the colonies did not have adequate sanitation and the people were often forced to use the surrounding wooded areas to urinate and defecate.

The gendered burden of this lack of amenities in homes and schools has been documented in Stromquist's (2001) work on girls' education and poverty in Latin America. She explores how poverty limits women's education and asserts that in communities without water, sanitation, and waste collection, women and girls take on these tasks, which takes women and girls away from time that they can spend on their education. This narrative was also frequently observed in this fieldwork when women and girls spoke of spending after school time doing domestic work, which often involved collecting water. Furthermore, insufficient electricity often hindered schoolwork completion, as seen with Kavita (Lila's daughter, 10 years). Kavita struggles with an optic nerve condition, which coupled with the dim electricity in the house makes doing school work in the evening difficult.

The Kerala Development Report (2008) draws attention to the plight of women across the state who live in communities without sanitation and privacy. This lack of privacy has severe gendered consequences. Open urination and defecation deprives women and girls of privacy and makes them vulnerable to violence (United Nations, 2014). Furthermore, in response to this sanitation deficit in Kerala, the Kerala State Women's Development Corporation ${ }^{67}$ (KSWDC)

${ }^{67}$ Kerala State Women's Development Corporation is part of the Department of Social Justice, Government of India. 
piloted twenty "women friendly electronic self-cleaning She-toilets" in Thiruvananthapuram, the State capital (Figure 29). They aim to install 200 additional She-toilets across the State in the coming years. Some of its features include an incinerator to burn napkins; a coin operated sanitary pad dispenser, flushing and security features. However, no Malayalam instructions are provided.

One of the interesting aspects of such highly publicized development projects is that they cater to middle class, English speaking women who shape the popular imagination about development in Kerala. KSWDC states that by promoting She-toilets they are working towards effectively ensuring the safety, privacy and dignity of women. Who is this woman they are ensuring has safety, privacy and dignity? It is evident that it is not a Dalit woman being protected or offered privacy, as indicated by the various narratives in this study.

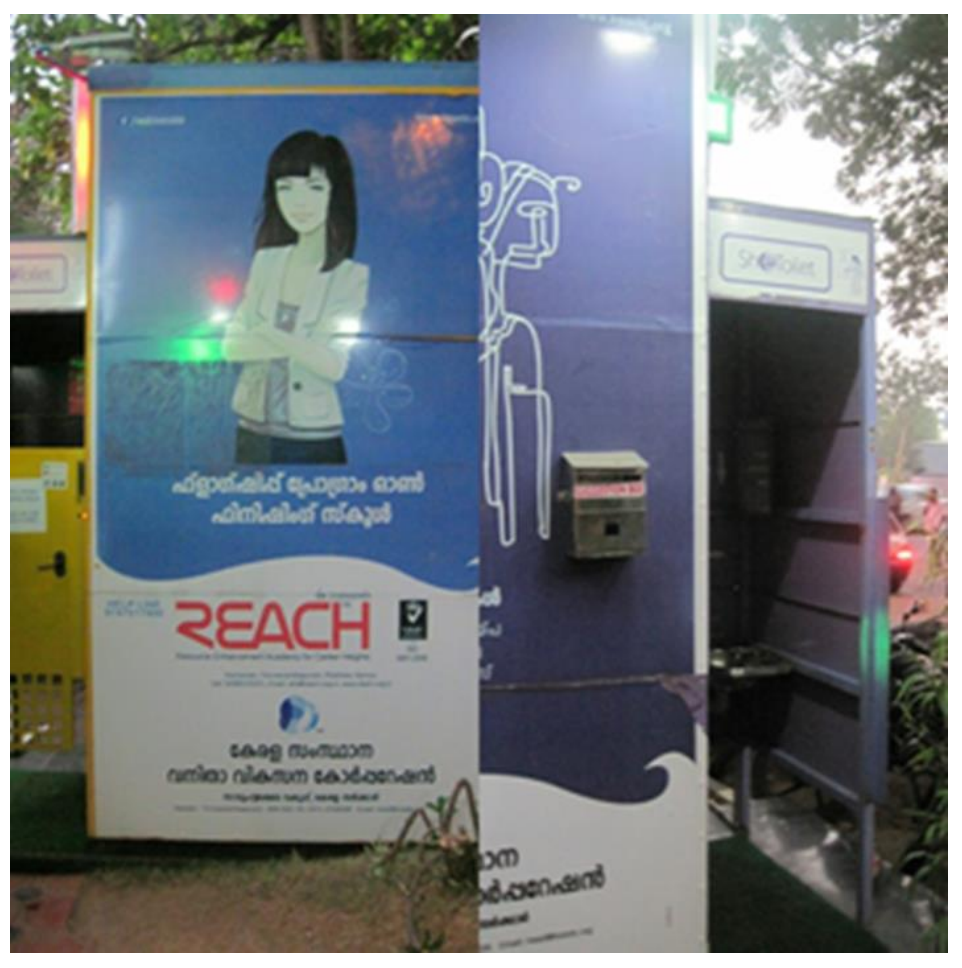

Figure 29. She toilets. Personal photo taken during fieldwork. 
Dalit women across three generations in some families have been denied this safety, privacy and dignity. A Dalit woman's experiences specifically cannot be generalized under the category of woman in Kerala, as it fails to enlist their specific historical experiences of the past that continue to shape their present. Raj (2013) draws on bell hooks' writing about Black women's erasure from public discourse in the United States where the term woman often denotes a White woman. Likewise, the term woman in Kerala often denotes an upper caste woman.

Secondly, the Education Bill was framed to manage privatization of education in Kerala and guarantee that all communities were able to access education. However, it failed to accomplish its intended goal for the Dalit community. In addressing how the Education Bill limited the Dalit community, Dasan (2012) states, “As a consequence, instead of being institutions of democratic diversity and plurality, these centers are reduced to institutions functioning within the management's ideological framework" (p. xxii). This elimination of democratic diversity that Dasan notes is seen as a result of the saturation of the educational system by the forces of privatization in Kerala.

The narratives in this study spoke to political and economic forces of neoliberalism in the following ways. Firstly, there is an unregulated rise in private management schools in Kerala. Government schools are failing in their constitutional obligation to provide education, which has resulted in Dalit communities going to private aided schools for education. These private aided schools are often managed and controlled by private organizations even though the government funds them. The problem lies in the fact that the government fails to offer any regulation in the running of these schools. For example, the Syrian Christian community in Kerala is seen as higher class and caste and their monopolizing of the educational system has resulted in little space for upper caste and class knowledge and no space for Dalit knowledge. Because there is no 
public oversight, the powerful communities limit subaltern communities in Kerala from owing and running schools and creating a curriculum that presents their history. Dalit communities tried to own and influence schools in Kerala, however, they could not contest the power of other communities such as the Syrian Christians in terms of investment and governmental support (Padmanadhan, 2010).

Secondly, private schools have selective discriminatory hiring policies for teachers, which favor higher caste and class communities. The lack of Dalit teachers in schools in Kerala results in greater social distance between the teachers and Dalit students in Kerala (Padmanadhan, 2010). This distance between the teachers and students was exposed in this dissertation. Mala (Mother, 40 years), for example, failed the same class twice. Mala asserted how the teachers failed to understand her life, the domestic violence, the household chores and her home environment and thus could not help her navigate. Mala also spoke of feeling that her daughter's teachers do not teach, thus resulting in her having to send her to private tuitions. Private tuitions are supplementary education outside the school system. , Families have to pay for private tuitions and they are expensive. The teachers are a protected group in Kerala that have strong unions and political power. This protection of teachers has resulted in better salaries and benefits for them. However, these protections offered to teachers in Kerala have also resulted in the protection of the agendas of powerful communities. Addressing this conundrum that the education system faces in Kerala, Padmanadhan (2010) asserts that there is a lack of regulation of teacher quality, along with a complete disregard for social distance between the teacher and student in the education system.

Thirdly, the governing educational rhetoric is one that seeks to prepare students in Kerala for the global market. The partiality for English medium schools was addressed as a way to 
prepare students for jobs. The mothers in this study often spoke about education as a means to jobs for their children. This focus on English in education prohibits Dalit girls from participation in public life, according to Dalit activist Seleena Prakkanam. She asserts that Dalit girls do begin their education, and particularly higher education, but often drop out because of a lack of English proficiency. Prakkanam in her interview with Malayali feminist Devika (2014), sharing her own story, states:

The family would want to send this child to college but would have no clue about choosing an appropriate stream, so the child would just accept whatever stream that was offered. Then would come the major challenge: lacking adequate language skills and having to sit in a classroom with others fluent in English. Teachers would pay no attention to you, either, and after a time, all you would want to do is run out for your life. It is hard to describe those feelings! This is not just my story it is the story of many, many Dalit girls who eagerly enter higher education but then leave it in grief. (p. 41)

Education as a step towards employment was a commonly heard narrative among the women when they explained why they wanted to educate their children. The older generations (mothers, grandmothers, mother-in-laws, and aunts) did not see much change in the jobs they have, their mothers often did domestic work and manual work, and they often continued doing the same. Caste-based occupational patterns were observed between generations of Dalit women. The younger girls spoke of greater support from their families in terms of their education. The girls in most cases have studied beyond what their mothers studied in terms of formal education but they are also facing a new set of limitations. Thus, a cycle of limitation is maintained by neoliberal forces, which forces families to pay extra fees to educate their children in English, with private tuitions and in private schools. 
Fourth, specific gendered repercussions of neoliberalism magnify the burden of rising costs for Dalit families. Mothers and grandmothers spoke about the importance of education for themselves and their daughters. Education was significant but marriage often was spoken of as being a defining force in a woman's life. Marriage is a major expenditure to families, who are often responsible for the wedding and dowry. It is evident that in a patriarchal system the undue burden of marriage expenses on a girl's family coupled with rising costs of education often limit how much a family can pay for a girl's education. It is a complex situation faced by Dalit families who have to navigate patriarchal forces to ensure their daughters' marriages and the neoliberal forces to ensure their educations. Kandyoti (1988) reminds us how women navigate patriarchy: "Different forms of patriarchy present women with distinct 'rules of the game' and call for different strategies to maximize security and optimize life options with varying potential for active or passive resistances in the face of oppression"(p. 274). It is crucial to reflect on how Dalit women in this study navigate the patriarchy by aligning themselves to the importance of marriage because they understand that a conjugal home presents them with greater protection as women (Rao, 2014; Still, 2011).

An interesting example of this was seen in Anama's case. She spoke of how she paid for her daughter's wedding in installments and took on debt. Her daughter did not complete school. Anama supervised her daughter's education but did not have the money to pay for tuitions. When I inquired if Anama would take on debt to pay for tuition, Anama said she would rather take on debt to pay for a wedding. She indicated that marriage would give her daughter more security. Anama clearly recognized the importance of education and marriage for her daughter, but her selection of marriage funding over educational funding is based on her conscious recognition of how patriarchy shapes women's lives in Kerala. Subrahmanian (2007) addresses how marriage 
and education are linked states, "The marriage market may not discourage education, and it may well shape what is considered to be appropriate and adequate education for girls (p. 45). Thus, this highlights how marriage continues to be a powerful force in women's lives.

In sum, it is evident that intergenerational Dalit families continue to grapple with exclusionary institutions and practices such as a lack of basic amenities, loss of land, unemployment, rising costs of education and debt. These, coupled with the gendered burden placed on women by public and private patriarchal forces, complicates women's engagement with education. Thus, this study exposes the liminal relationship that Dalit women have with state-sponsored neoliberal development, which seeks to create an illusion of freedom for Dalit lives in Kerala.

\section{Implications and Limitations}

The implications of this study are divided into three sections: policy, theory and methodology. The policy implications of this study concern loopholes in Kerala's policies that fail to account for Dalit needs and offer suggestions about ways to fill these gaps. The theoretical section addresses the significance of critical feminist thinking in both practice and policies, paying specific attention to the roles of patriarchal and neoliberal machinery in shaping women's lives. Finally, methodological insights from fieldwork include ethnographic data collection, analysis and ethical relations in this setting.

\section{Policy Implications}

This study examines various policy shortcomings in the context of Kerala's Model of Development and its limitations in catering to Dalit women's needs. It is essential to revisit how development as a whole is framed in Kerala in the context of women and more specifically in the 
context of Dalit women in order to expose and contextualize these shortcomings. I began this dissertation with Jeffery's (1987) work about the significant place that women held in early Kerala society along with their role in nation building that suggests that "literate men have literate sons, literate women have literate children in Kerala" (p. 462). The essential underpinning is that women are seen by the state as nation builders and change agents in Kerala society. Women are held accountable for shouldering the tasks for reproductive labor, domestic labor and the social responsibility of ensuring that Kerala's citizens are educated. Women's education is framed as emancipatory for women and society as a whole in Kerala. Thus, drawing from the development literature I assert that Kerala's educational policy framework leans more towards Women in Development (WID) and not in a Gender and Development (GAD) framework. In Table 8, Unterhalter (2005) lays out a clear distinction in the difference between WID and GAD policy frameworks.

Table 8

WID and GAD Frameworks

\begin{tabular}{llll}
\hline Policy Framework & $\begin{array}{l}\text { Understanding of } \\
\text { Gender }\end{array}$ & $\begin{array}{l}\text { Understanding of } \\
\text { Development }\end{array}$ & $\begin{array}{l}\text { Understandings of } \\
\text { Equity }\end{array}$ \\
\hline $\begin{array}{l}\text { Women In } \\
\text { Development }\end{array}$ & $\begin{array}{l}\text { Gender=Women, } \\
\text { Girls }\end{array}$ & $\begin{array}{l}\text { Growth, Efficacy, } \\
\text { Good Governance }\end{array}$ & Equality of Resources \\
\hline $\begin{array}{l}\text { Gender and } \\
\text { Development }\end{array}$ & $\begin{array}{l}\text { Constructed Social } \\
\text { Relations, Power }\end{array}$ & $\begin{array}{l}\text { Challenging Inequity } \\
\text { and Oppression }\end{array}$ & $\begin{array}{l}\text { Redistribution of } \\
\text { Power }\end{array}$ \\
\hline
\end{tabular}

Source: Unterhalter (2005), p.16.

In the context of education, WID policy focuses on increasing rates of school enrollment or literacy rates, but does not account for the hegemonic power structures that women work within/ against inside and outside the home. While in a GAD policy framework, Unterhalter 
(2005) asserts that policies are framed to address structural inequalities that impede and shape educational engagement and access. Thus, an essential consideration in GAD policy frameworks is catering to both practical gender needs and strategic gender interests (Molyneux, 1985; Moser, 1993). Practical gender needs focus on the material conditions of women such as water and food while strategic gender needs focus on issues of power, control, and the subordination of women that shape gender inequality and maintain inaccess (Molyneux, 1985; Moser, 1993). In Kerala, governmental policies about women often address and measure conventional indicators of development such as female literacy but fail to account for women's subjectivities associated with power, agency and control in a postcolonial patriarchal society (Devika \&Mukerjee, 2007; Mukhopadhyay, 2007; Rajan \& Sreerupa, 2007). Furthermore, social hierarchies are hidden in a neoliberal market driven economy. Hill and Kumar (2009), address the policy implications of neoliberalism in their outline of three essential areas that require deliberation: (1) loss of equity as well as economic and social justice, (2) loss of democracy and democratic accountability, and (3) loss of critical thought.

Thus, in the context of communities such as that of Dalit women, this form of critical consideration allowed by a GAD policy framework is imperative to expose why historically marginalized people continue to struggle. Nambissan (1996), explaining pitfalls in educational policies catering to Dalit communities, states, "the 'scheduled castes ${ }^{681}$ are treated as a homogeneous group without being sensitive to their varied historical experiences and presentday economic, social and educational situation" (p. 1021). I contend that this lack of critical consideration is reflected in women's development policies, which envision empowerment as a simple and universally uniform goal for all women in Kerala. The neoliberal climate in Kerala

\footnotetext{
${ }^{68}$ Government category for Dalits.
} 
has confused accountability for education between private and public, thus allowing the state to neglect its constitutional obligation to provide equity in and through education for all citizens.

To this end, I provide a list of policy gaps and corresponding suggestions to promote equity in education based on this study's findings. I argue that this list of gaps in policy, although it is not comprehensive, serves to highlight some of the issues that would help bridge the gap for Dalit women and girls in Kerala (Table 9).

Table 9

Policy Gaps

\section{Policy Gaps}

Non-responsive to Dalit needs
Suggestions Based on Study Findings

Address the diversity of Dalit experiences in Kerala society in policy framing using an intersectional lens that draws attention to the roles of caste, class and religion in creating social hierarchies that maintain a culture of inequality.

Failure to promote equity in and through education for Dalit communities
Understand home environments of students as an essential step towards creating effective educational interventions (burden of domestic labor, poverty, violence).

Reflect on how teaching practices are shaped by Kerala's social structure based on caste, class, religion and gender.

Consider how school amenities such as water, sanitation, electricity, and school meals affect vulnerable communities instead of focusing only on the needs of middle class students.

Consider how school practices such as corporal punishment affect students' educational engagement. Create greater 
teacher liability for using corporal punishment as a disciplinary practice.

Pay special attention to teacher evaluation in schools, both private and public. This includes creating a culture of accountability of both teachers and management.

Pay special attention to the lack of Dalit teachers and teachers from lower caste and class communities. Increase the number of Dalit teachers.

Account for institutional culture in educational institutions that supports gender inequalities and subordination.

Account for institutional and social culture that marginalizes lower caste and class students (language of instruction, rising cost, increasing privatization).

Thus, to address Dalit women's concerns about educational engagement, access and inclusion, Kerala's government will have to engage in some introspection into the goals and outcomes of their blanket policies about free and compulsory education and the constitutional protections it offers historically marginalized communities. Systematic problems that result from broader social structures like patriarchy, caste, class and religion are not solved by simple policy recommendations, however it is essential to unpack the processes and workings of these social structures to affect gender-responsive policy change.

\section{Theoretical Implications}

This section highlights the theoretical insights gleaned from this study's findings. I propose that integrating intersectionality (Collins, 1991) and postcolonial feminist concerns 
(Alexander \& Mohanty, 1997; Mohanty, 2003; Spivak, 1988) is crucial for exploring historicized and contextualized Dalit narratives. Narratives of Dalit abjection and suffering abound in civil and academic discourse, but using an intersectional lens coupled with postcolonial concerns reveals Dalit power, agency and resistance in those narratives. Thus, the findings of this study have theoretical implications for existing scholarship (Devika, 2010; Rao, 2003; Rao, 2014, Raj, 2013) that seeks to represent the complexities of Dalit women's experiences in India.

\section{More Than One Identity}

In order to correct the present development narrative for Dalit communities in Kerala, we must move beyond a myopic understanding of their contemporary realities in a postcolonial and neoliberal state. This myopic understanding of Dalit lives in Kerala is framed by social and governmental categories that serve to label Dalits as outliers, thus masking their historical location. Their subaltern location is framed by multiple relational identities that emerge from caste, gender, class and religion in Indian society. Using intersectionality to frame their identities helps to uncover how these said identities create opportunity and oppression (Zinn \& Dill, 2009).

In Gendering Caste through a Feminist Lens, Chakravorty (2006) draws attention to the centrality of caste in a Dalit woman's life. She states, "Caste ideologies denies subjectivity to the Dalits by depriving them of dignity and personhood" (p.7). Chakravorty further asserts that in present day India, "Struggles over resources for the Dalits are simultaneously struggles over socially constructed meanings, definitions and identities" (p.7). For example, the intergenerational narratives of women's lives in a Dalit colony without basic amenities speaks to how their identities are more than a singular identity defined by their abjection but instead are a confluence of caste, class and gender. By drawing attention to how Dalit spaces are created, 
denied and demarcated, the multiple historical and contemporary forces shaping subaltern marginality in Kerala are exposed. Thus, attending to their social positions brought about by their multiple intersecting/ interlocking hierarchies of identities (Collins, 1991) helps to draw attention to the complex histories that shape Dalit lives.

\section{Working Within/Against Many Systems}

Secondly, it is necessary to reflect on identities of caste, class, religion and gender as interlocking/intersecting systems of power as addressed by an intersectional analysis (Crenshaw, 1991; Collins 1991). In the context of these patriarchal forces, Rao (2003) challenges us to "disarticulate a unified and monolithic account of patriarchy in action" (p. 5). Attending to the multiplicity of patriarchal forces helps draw attention to diverse systems that Dalit women work within and against every day, which are often unaccounted for in policy narratives. For example, this study discusses the intergenerational narratives of how gendered labor coupled with domestic violence in Dalit households facing poverty and debt complicates Dalit women's educational engagement. There are myriad hegemonic structures and hierarchal systems that are at work in a Dalit woman's life.

The patriarchal forces shape labor and violence; neoliberalism coupled with the hegemony of caste maintains poverty with a lack of jobs and limited education. Furthermore, accounting for the multiplicity of systems allows us to fully understand and situate Dalit women's actions and resistance. Representation of women's issues draws attention to cultural or historic specificity (Narayan, 1998; Mohanty, 2003). The state in Kerala frames women as domestic workers and men as providers (Hapke, 1998). However, Dalit women problematize this binary with their labor both outside and inside the home to provide for their families because 
their husbands fail to provide for them. In doing so, they challenge the generalized gendered ideology of the region which the state supports and perpetuates through policy and practice. Additionally, Dalit women also enact conformity and resistance in the face of violence in exchange for conjugal protections. Such is seen in the narratives of Dalit women who stay in homes where they face violence every day because they know how Kerala society further oppresses and marginalizes a single Dalit woman and her children.

Accounting for Dalit women's multiple identities and the ensuing systems that result from those identities helps move the dialogue away from essentializing narratives that focus on "general" women's concerns to specific Dalit concerns. This is an important consideration that needs to be addressed while envisioning development strategies and initiatives for the region. It helps to include conversations about representation by raising the question about whose interests and mission the development initiatives truly represent. Likewise, Narayan (1998) reminds us that essentialist generalizations result in "theoretical perspectives and political agendas that efface the problems, perspectives, and political concerns of many women who are marginalized in terms of class, race, ethnicity and sexual orientation" (p. 86). These generalizations in Kerala's development policy narrative mask an accurate acknowledgment of Dalit needs. Such as seen in Kerala's private education sector which is managed by upper caste and class communities and has resulted in unmonitored equity issues, rising school costs and a deficiency in school amenities has educational consequences for Dalit girls.

Thus, by drawing on theoretical considerations inserted by postcolonial feminists and intersectionality, Dalit women's education can be seen as more than just data points that support the rhetoric about literacy rates but instead is systematically framed and shaped by complex power structures. 


\section{Methodological Implications}

This section discusses three methodological implications which serve as reminders of the ambivalence often encountered in the field. They attend to the power of language in interview questions, learning how to be comfortable with/ in silence, and negotiating safe spaces for research participants.

To begin with, I would like to address (re) framing questions during fieldwork. Talking with Lila helped me rethink and reframe interview questions. Both caste and religion are socially and politically charged issues in the Indian context. Thus, framing questions about caste and religion requires information about the social context of the region of fieldwork along with a need for reframing questions based on initial exploratory research. For example, my first interview was with Lila, who was asked to give feedback about the questions. When I asked her if she identified as Dalit, she said she was Cheramar Christian and not Dalit Christian, thus distancing herself from the term Dalit. One of my researcher journal jottings read, "From the first interview I sensed that using the term Dalit is problematic. Lila does not identify as Dalit. Need to be careful not to enforce identities... So maybe 'what is your Jati? How do I ask about caste?'” (Researcher memo, 11, February 2015).

It is important to inquire about participants' individual/communal caste identities and experiences while ensuring that the researcher is not reinforcing identities of marginalization on the participants. Chacko (2004) addresses how identity, knowledge and power are linked during fieldwork in her statement that, "Every label the researcher or informant adopts, or is given, produces specific discourses. In the process of knowledge creation and transfer, researchers will often find it useful to deconstruct elemental categories to understand the discourses they 
produce" (p. 58). Having a candid conversation about interview questions with Lila and subsequently reframing questions was very helpful, as she provided me with much insight about how interview questions shape discourses of power during the interview. Lila's feedback about interview questions addressing caste identity exposed the larger conversation of how communities reposition themselves and push back to distance themselves from their labels of marginalization. This draws attention to the larger conversation about the productive power that languages hold during feminist interviewing (DeVault \& Gross, 2012).

In this project, I was also challenged as a researcher to work with silences, pauses and unspoken narratives during interviews (DeVault, 1996; Luttrel, 1997). I attended to feminist activist Adrienne Rich's (1978) call to historicize silences in her poem Cartographies of Silence. She writes:

Silence can be a plan rigorously executed the blueprint to a life

It is a presence it has a history a form

Do not confuse it with any kind of absence (p.16)

I experienced silence not as just a pause in narrative, but as reflective of the relationship between silence and power. I witnessed silence during fieldwork in various forms when a conversation was suddenly stopped as another family member walked into the house, or as women and girls stopped speaking or paused when I inquired about violence in their homes. Such behavior was seen during Rinu's first interview when she spoke about how her husband and in-laws do not want her to work. When I inquired why they did not want her to work, she responded, "That is how it is, there is nothing to say," which was followed by a long silence. 
During this silence, Rinu and I just sat together in silent acquiescence of the patriarchal discourses that shape her life. One of my researcher journal jottings reflecting on that moment read, "Should I have said something, when Rinu and I were quiet? Rinu referred to the unspoken forces that shape her life, but she did not want to say anything more about it. What does her silence mean?" (Researcher memo, 1 March, 2015). There was an awareness in her tone and silence that spoke to the multiple patriarchies and gendered subjectivities that shaped her life. Thus, listening for subaltern silence and placing silence in the context of colonist discourses moves the responsibility for silencing to those with power (Rowe \& Malhotra, 2013).

Lastly, I would like to draw attention to considerations about probing painful memories. Before leaving for fieldwork, the IRB process made me think through some of the ethical considerations of fieldwork more deeply. The IRB required an oral consent for mothers and daughters along with a written parental consent and a minor asset form (Appendices D and E). Thinking through the consent and assent processes for potential adults and minors in research set the stage for some deeper introspection about consent in the field. Consent and asset in the field was not as linear and prescriptive as projected by institutional ethics. Burman, Batchelor, and Brown (2001) address the renegotiation of consent in their work with young girls facing violence. They state:

A key issue is the inherent tension set up between the aims of research (to 'elicit information') and ethical concerns (to 'protect' those taking part). Having given consent, participants should (in theory, anyway) be aware of the potential harm and consequences of disclosure, though it is still the responsibility of the researcher to renegotiate this consent throughout the research encounter and in doing so to minimize harm. (Burman, Batchelor, \& Brown, 2001, p. 449) 
This was an important consideration in my work, which included probing personal and potentially painful memories about rape, violence and disenfranchisement. An essential consideration was knowing when to stop an interview, take a break, or move to another issue during an interview while probing painful memories. One of my journal memos read:

Knowing when to stop has been important during interviews. So many painful memories. Lila started to cry during her interview talking about the burden of her life, so we stopped. She said she was fine, but I felt like we should stop. I asked if I could come back tomorrow. Lila asked me to come back on Monday. (Researcher Memo, March 1, 2015)

Lila's interview was one of many that addressed violence in their home. At the end of every interview, I spoke to them about community health workers and resources in their area that could support them and their families. The primary goal in all research situations of this study is the safety and the wellbeing of the women and girls. I always presented the option of meeting outside their home if they chose to, and some women came to my house for interviews. We met in a private closed room, which provided a more private space that offered support and enabled conversations. Those private conversations were often longer and deeper in the context of experiences and narrative. They often covered traditionally female centered conversations such as menstruation among school-going girls or the cost of sanitary pads. It is essential to provide survivors of domestic violence a safe space both as a physical and emotional space to share their stories (Campbell, Sefl, Wasco, \& Ahrens, 2004). Thus, fieldwork becomes a navigation of identities and positionalities that requires critical self-reflection and subsequent adaptation of questions, processes and schedules based on this reflection. 


\section{Limitations}

There are three specific limitations of this study that warrant attention, which primarily arose due to limited time and logistical concerns in the field.

Firstly, there is only one Hindu Dalit family (Uma's family) in this study. As Anzaldúa (1990) states, "The tensions between opposing theories and political stances vitalize the feminist dialogue" (p 224). In a study seeking to explore the diversity of Dalit women's experiences in the context of caste, class, religion, and greater Hindu representation would have been beneficial. The Christian Dalits in this study converted to Christianity, some of them over two generations ago. Dalit Christians do not qualify for reservations implemented by the Government of India, which is a major issue of contention between Hindu and Christian Dalits in the region. I was hoping to engage with more Hindu Dalit families through Uma, but I was unable to gain access due to scheduling concerns. Uma's narratives about caste and religious identity highlight how government reservations reinforce divisions and inequality in access by including Hindu Dalits and excluding Christians Dalits.

Secondly, this study could be broadened and deepened by including teachers' and educational management's perspectives, particularly in the context of the neoliberal forces shaping education in Kerala. There were many narratives about teachers, which included violence in the classroom, the dismal quality of teaching, and teacher apathy. However, as I was thinking through these narratives and writing up the findings, it became increasingly important to include teacher voices as a more multidimensional way towards understanding Kerala's educational system and policies. Some questions that require consideration in future work include: What kind of pressure are teachers facing from management? How do neoliberal forces 
shape teacher education? What are teachers' attitude and justifications for the use of corporal punishments? How are teachers' pedagogical practices shaped by their own training?

Thirdly, this study does not explore Dalit women's non-formal educational experiences in depth. Kerala has an extensive network of non-formal education in the form of adult literacy programs and income generating programs (Abraham, 2010). The women, except Mala, often disregarded possibilities or options to pursue non-formal education due to a lack of time or a lack of support from their conjugal home. It would be useful to conduct additional data collection to explore non-formal dimensions of Dalit education in Kerala. Many women in this study participate in state sponsored poverty alleviation schemes such as Kudumbashree, which provides training for women in skills building. It would be valuable to reflect on Dalit women's experience in the realm of non-formal education.

However, despite these limitations, this study does serve to fill a gap in the research on Dalit education in Kerala. There is a gap in in-depth qualitative research which includes Dalit women's voices in Kerala and this study is a seminal work towards addressing that void.

\section{Conclusions}

The failure to recognize the multiple patriarchies and gendered subjectivities that shape women's lives in Kerala has exacerbated the gender paradox in this region and further marginalizes the Dalit communities. I believe that the celebratory rhetoric about Kerala does muffle the voices of those who have been left out. Thus, this feminist qualitative inquiry is a step towards engaging with subaltern voices through their education narratives in an attempt to examine the disparities in Kerala's Model of Development. Furthermore, these conversations about marginality, neoliberalism and patriarchy are also a step towards ensuring that future 
generations of Dalit women are not marginalized by the confines of state initiated empowerment and narrow definitions of women's work and roles in society.

The main findings of this study are:

1) Dalit women and girls are lagging behind non Dalit communities in Kerala. This is attributed to the failure of the state to understand and cater to their social and material needs and locations. The deficit narrative that frames them as outliers in Kerala's development has fueled a policy framework that has further marginalized the Dalit community. This indicates that the state has often found quick-fix solutions for these communities and has failed to truly situate interventions and initiatives in deep understandings of their needs.

2) Dalit women and girls are struggling in a development climate that is defined by greater privatization and globalization. The modern state of Kerala is preoccupied with ensuring that Kerala's citizens are prepared for the global market. Dalit communities bear the brunt of this preoccupation with rising costs of education, a lack of Dalit voices in education and the promotion of English-based education. Kumar (2016) addressing the façade of a neoliberal system in Kerala operating under the guise of democracy states, "It gives us the illusion of being democratic by touting how well it represents diversity and difference in society" (p. 2). This illusion is maintained in Kerala through an educational narrative that celebrates high female literacy rates, school enrollment, and low dropout rates but fails to look at issues of equity, power, mobility and access.

3) Dalit women's educational narratives are shaped within and by institutional and societal structures in postcolonial Kerala. The intersecting/interlocking forces of caste, class and gender function collectively to maintain control over women's lives in a complex patriarchal 
system. However, women exercise strength and agency in the face of patriarchal control. This is seen in Dalit women's narratives about marriage and domestic violence, which are structures that are maintained by the larger patriarchal narrative of control and power in Kerala society.

In conclusion, this study presents an image of uneven development where the distance between the centers of power and the people at the margins continues to broaden in the context of access, equity and inclusion both in their homes and schools. The findings add to the current thinking and scholarship on Kerala's Model of Development by highlighting Dalit assertions and agency in the face of dominant neoliberal and colonial forces and their subsequent discursive and exclusionary practices. 


\section{References}

Adukia, A. (2014). Sanitation and education. Cambridge, MA: Harvard University.

Abraham, L. M. (2010). Role of public libraries in non-formal education in Kerala. Kelpro Bulletin, 14, 60-67.

Anzaldúa, G. (1990). Bridge, drawbridge, sandbar or island. In L. Albrecht and R. M. Brewer (Eds.), Bridges of power: Women's multicultural alliances (pp. 216-231). Philadelphia: New Society Publishers.

Alexander, K. C. (1968). Changing status of Pulaya Harijans of Kerala. Economic and Political Weekly, 1071-1074.

Alexander, M. J., \& Mohanty, C. T. (1997). Feminist genealogies, colonial legacies, democratic futures. New York: Routledge.

Aikman, S., \& Unterhalter, E. (Eds.) (2005). Beyond access: Transforming policy and practice for gender equality in education. Oxford, UK: Oxfam.

Appadurai, (2001). Deep democracy: Urban governmentality and the horizon of politics Environment and Urbanization, 13, 23-43.

Abraham, S. (2007). Identity, ethics, and nonviolence in postcolonial theory: A Rahnerian theological assessment. New York: Palgrave Macmillan.

Ardener, E. (1975). Belief and the problem of women. In S. Ardener (Ed.), Perceiving women. London: Wiley. 
Acker, J. (2004). Gender, capitalism and globalization. Critical Sociology, 30 (1), 17-41.

Agnes, F. (2015). Section 498A, marital rape and adverse propaganda. Economic \& Political Weekly, 50 (23), 13.

Bhavnani, K., \&Talcott, M. (2012). Interconnections and configurations: Toward a global feminist ethnography. In S. N. Hesse-Biber, C. Gilmartin, and R. Lydenberg (Eds.), Handbook of feminist research: Theory and praxis (pp. 135-153). Thousand Oaks, CA: Sage.

Brewster, M. M., Herrmann, T. M., Bleisch, B., \& Pearl, R. (2006). A gender perspective on water resources and sanitation. Wagadu, 3(1-16).

Brueck, L. (2012). At the intersection of gender and caste: Re-scripting rape in Dalit feminist narratives. In A. Loomba \& R. Lukose (Eds.), South Asian feminisms Durham, NC: Duke University Press. Retrieved from Amazon.com

Bajaj, M. (2011). Human rights education: Ideology, location, and approaches. Human Rights Quarterly, 33(2), 481-508.

Baxter, P., \& Jack, S. (2008). Qualitative case study methodology: Study design and implementation for novice researchers. The Qualitative Report, 13(4), 544-559.

Bilge, S. (2009). Smuggling intersectionality into the study of masculinity: Some methodological challenges. Paper presented at Feminist Research Methods: An International Conference, University of Stockholm, February 4-9, 2009. 
Balagopalan, S. S. (2003). Dalit and Adivasi children in schools: Some preliminary research themes and findings. IDS Bulletin, 34(1), 43-54.

Beneria, L., \& Sen, G. (1982). Class and gender inequalities and women's role in economic development—-theoretical and practical implications. Feminist Studies, 8(1), 157-178.

Bhaskaran, S. (2011). Informed by gender? Public policy in Kerala. Economic \& Political Weekly, 43, 75-84.

Burman, M. J., Batchelor, S. A., \& Brown, J. A. (2001). Researching girls and violence: Facing the dilemmas of fieldwork. British Journal of Criminology, 41(3), 443-459.

Chandra, U. (2015). Rethinking subaltern resistance. Journal of Contemporary Asia, 45(4), 563573.

Chatterjee, Partha. (2004). Politics of the governed. New Delhi: Permanent Black.

Comaroff, J., \& Comaroff, J. L. (1991). Of revelation and revolution, volume 1: Christianity, colonialism, and consciousness in South Africa. Chicago: University of Chicago Press.

Collins, P. H. (1990). Black feminist thought. Boston: Routledge.

Creswell, J. W. (2007). Qualitative inquiry and research design: Choosing among five traditions (2nd ed.). Thousand Oaks, CA: Sage.

Crenshaw, K. (1991). Mapping the margins: Intersectionality, identity politics, and violence against women of color. Stanford Law Review, 43(6), 1241-1299. 
Choo, H. Y., \& Ferree, M. M. (2010). Practicing intersectionality in sociological research: A critical analysis of inclusions, interactions, and institutions in the study of inequalities. Sociological Theory, 28(2), 129-149.

Coombs, P., Prosser, R.C., \& Ahmed, M. (1973). New path to learning: For rural children and youth. New York: International Council for Educational Development.

Campbell, R., Sefl, T., Wasco, S. M., \& Ahrens, C. E. (2004). Doing community research without a community: Creating a safe space for rape survivors. American Journal of Community Psychology, 33(3-4), 253-261.

Chacko, E. (2004). Positionality and praxis: fieldwork experiences in rural India. Singapore Journal of Tropical Geography, 25(1), 51-63.

Chakravarti, Uma. Gendering caste through a feminist lens. Calcutta: Stree.

Cole, E. R., \& Stewart, A. J. (2012). Narratives and numbers: feminist multiple methods research. In S. N. Hesse-Biber, C. Gilmartin, and R. Lydenberg (Eds.), Handbook of feminist research: Theory and praxis (pp. 368-387). Thousand Oaks, CA: Sage.

Das, V. (2007). Life and words: Violence and the descent into the ordinary. University of California Press.

Dasan, M., Pratibha, V., \& Pāmpirikunnà, P. (Eds.). (2012). The Oxford India anthology of Malayalam Dalit writing. New York: Oxford University Press.

DeVault, M. L. (1996). Talking back to sociology: Distinctive contributions of feminist methodology. Annual review of sociology, 22 (1), 29-50. 
DeVault, M. L., \& Gross, G. (2007). Feminist interviewing: Experience, talk and knowledge. In S. N. Hesse-Biber, C. Gilmartin, and R. Lydenberg (Ed.), Handbook of feminist research: Theory and praxis (pp. 173-198). Thousand Oaks, CA: Sage.

Dilip, T. R. (2011). On the diffusion of school educational attainment in Kerala State. Demography India, 40(1), 51-63.

Dowling, R. (2000). Power, ethics and subjectivity in qualitative research. In I. Hay (Ed.) Qualitative Methods in Human Geography (pp. 23-36). Melbourne: Oxford University Press.

Desai, M. (2005). Indirect British rule, state formation, and welfarism in Kerala, India, 18601957. Social Science History, 29(3), 457-488.

Devika, J. (2006). Negotiating women's social space: public debates on gender in early modern Kerala, India. Inter-Asia Cultural Studies, 7(1), 43-61.

Devika, J., \& Mukherjee, A. (2007). Re-forming women in Malayalee modernity: A historical overview. In S. Mukhopadhyay (Ed.), The Enigma of the Kerala Woman: A Failed Promise of Literacy (pp. 102-130). New Delhi: Social Science Press.

Devika, J. (2009). Bodies gone awry the abjection of sexuality in development discourse in contemporary Kerala. Indian Journal of Gender Studies, 16(1), 21-46.

Devika, J. (2010). Egalitarian developmentalism, communist mobilization, and the question of caste in Kerala state, India. The Journal of Asian Studies, 69(03), 799-820. 
Devika, J. (2014). Becoming society: An Interview with Seleena Prakkanam. Economic \& Political Weekly, 49(17), 40-44.

Devika, J., \& Mukherjee, A. (2007). Re-forming women in Malayalee modernity: A historical overview. In S. Mukhopadhyay (Ed.), The Enigma of the Kerala Woman: A Failed Promise of Literacy (pp. 102-130). New Delhi: Social Science Press.

Dreze, J., \& Sen, A. (2002) India: Development and Participation. New Delhi: Oxford University Press.

Dreze, J., \& Goyal, A. (2003). Future of mid-day meals. Economic and Political Weekly, 46734683.

Eapen, M. (2001). Women in informal sector in Kerala: Need for re-examination. Economic and Political Weekly, 2390-2392.

Eapen, M., \& Kodoth, P. (2003). Family structure, women's education and work: re-examining the 'high status' of women in Kerala. In S. Mukhopadyay and R. Surdarshan (Eds.), Tracking gender equity under the economic reforms (pp. 227-267). New Delhi: Kali for Women.

Escobar, A. (1988). Power and visibility: Development and the invention and management of the third world. Cultural Anthropology, 3(4), 428-443.

Escobar, A. (2001). Culture sits in places: Reflections on globalism and subaltern strategies of localization. Political Geography, 20(2), 139-174

England, K. (1994). Getting personal: Reflexivity, positionality, and feminist research. 
Professional Geographer, 46(1), 80-89

Feldman, S. (2010). Shame and honour: The violence of gendered norms under conditions of global crisis. Women's Studies International Forum, 33, 305-315.

Faust, D., \& Nagar, R. (2001). Politics of development in postcolonial India: English-medium education and social fracturing. Economic and Political Weekly, 36(30), 2878-2883.

Fine, M. (1994). Working the hyphens. In N. Denzin \& Y. Lincoln (Eds.). Handbook of qualitative research. Thousand Oaks, CA: Sage.

George, M. (2011). In the midst of a storm: distress of Kerala women. Affilia, 26(3), 304-313.

Grewal, I. (1996). Home and harem. Durham, NC: Duke University Press.

Grewal, I., \& Kaplan, C. (Eds.) (1994). Scattered hegemonies: Postmodernity and transnational feminist practices. Minneapolis: University of Minnesota Press.

Hill, D., \& Kumar, R. (Eds.). (2012). Global neoliberalism and education and its consequences. New York: Routledge.

Hapke, H. M. (2013). Theorizing patriarchy: Development paradoxes and the geography of gender in South Asia. Gender, Technology and Development, 17(1), 1-29.

Harding, S. (1987). Introduction: Is there a feminist method? In S. Harding (Ed.), Feminism and methodology (pp. 1-14). Bloomington, IN: Indiana University Press.

Haraway, D. (1988). Situated knowledges: the science question in feminism and the privilege of partial perspective. Feminist Studies, 14(3), 575-99. 
Hall, B. L. (1992). From margins to center? The development and purpose of Participatory research. The American Sociologist, 23(4), 15-28.

Haraway, D. (1988). Situated knowledges: The science question in feminism and the privilege of partial perspective. Feminist Studies, 14(3), 575-599.

Hunter. G (Ed.). (2014). Intersectionality-informed qualitative research: A primer. Vancouver, BC: Institute for Intersectionality Research and Policy, Simon Fraser University.

Hesse-Biber, S. N. Gilmartin, C., \& Lydenberg, R. (Eds.) (2007). Handbook of feminist research: Theory and praxis. Thousand Oaks, CA: Sage.

Hesse-Biber, S. N., \& Piatelli, D. (2007). From theory to method and back again: The synergistic praxis of theory and method. In S. N. Hesse-Biber, C. Gilmartin, and R. Lydenberg (Eds.), Handbook of feminist research: Theory and praxis (pp. 143-154). Thousand Oaks, CA: Sage.

Jeffrey, R. (1987). Governments and culture: How women made Kerala literate. Pacific Affairs, 447-472.

Jackson, P. (1985). Urban ethnography. Progress in Human Geography, 9,157-76.

Jeffrey, C., (2005). Dalit young men and formal education. In R. Chopra and P. Jeffrey (Eds.), Educational regimes in contemporary India. New Delhi: Sage.

Jeffrey, C., (2008). Degrees without freedom? Education, masculinities, and unemployment in North India. Stanford: Stanford University Press. 
Jaggar, A. M. (2001). Is globalization good for women? Comparative Literature, 53(4), 298-314.

Jefferey, P. (1979). Frogs in a well: Indian women in purdah. Chanakya: New Delhi.

Kapoor, D. (2007). Gendered-caste violations and the cultural politics of voice in rural Orissa, India. Gender, Place and Culture, 14(5), 609-616.

Karade, J. (2008). Development of scheduled castes and scheduled tribes in India. Cambridge, UK: Scholars Publishing.

Kumar, N. A., \& George, K. (2009). Kerala's education system: From inclusion to exclusion? Economic and Political Weekly, 44(41), 55-61.

Kurien, P. A. (2002). Kaleidoscopic ethnicity: International migration and the reconstruction of community identities in India. New Brunswick, NJ: Rutgers University Press.

Kurein, J. M (2008, July 21). With age no bar, non-formal education a hit in Kerala. The Hindustan Times. Retrieved March 20, 2016 from http://twocircles.net/2008jul20/age_no_bar_non_formal_education_hit_kerala.html\#.V LwqMEeDlBk.

Kandiyoti, D. (1988). Bargaining with patriarchy. Gender \& Society, 2(3), 274-290.

Khera, R. (2006). Mid-day meals in primary schools: Achievements and challenges. Economic and Political Weekly, 4742-4750.

Kim-Puri, H. J. (2005). Conceptualizing gender-sexuality-state-nation: An introduction. Gender\& Society, 19(2), 137-59. 
Kernic, M. A., Holt, V. L., Wolf, M. E., McKnight, B., Huebner, C. E., \& Rivara, F. P. (2002). Academic and school health issues among children exposed to maternal intimate partner abuse. Arch Pediatric Adolescent Med. 156(6), 549-555.

Kernic, M. A., Wolf, M. E., Holt, V. L., McKnight, B., Huebner, C. E., \& Rivara, F. P. (2003). Behavioral problems among children whose mothers are abused by an intimate partner. Child Abuse \& Neglect, 27(11), 1231-1246.

Lichterman, P. (2002). Seeing structure happen: Theory-driven participant observation. In B. Klandermans and S. Staggenborg (Eds.), Methods of social movement research (pp.118145). Minneapolis: University of Minnesota Press.

Lewis, R., \& Mills, S. (2003). Feminist postcolonial theory: A reader. New York, NY: Routledge.

Loomba, A. (1993). Dead women tell no tales: Issues of female subjectivity, subaltern agency and tradition in colonial and post-colonial writings on widow immolation in India. In History Workshop (pp. 209-227). New York: Oxford University Press.

Lewis, M. A. and Lockheed, M. E. (2006). Inexcusable Absence: Why 60 million girls still aren't in school and what to do about it. Washington D.C.: Center for Global Development.

Lindberg, A. (2001). Class, caste, and gender among cashew workers in the south Indian state of Kerala 1930 - 2000. International Review of Social History, 46(02), 155-184.

Lather, P. (1992) Critical frames in educational research: Feminist and poststructural perspectives. Theory into Practice, 31(2), 87-99. 
Lorde, A. (1984). Sister outsider. Freedom, CA: Crossing Press.

Lorde, A. (1981). An open letter to Mary Daly. In C. Moraga and G. Anzaldua (Eds.), This bridge called my back: Writings by radical women of color. New York: Kitchen Table Press.

Lorber, J. (2001). Gender inequality. Los Angeles: Roxbury.

Lukose, R. (2005). Consuming globalization: Youth and gender in Kerala, India. Journal of Social History, 38(4), 915-935.

Lukose, R. (2006). Re (casting) the Secular: Religion and Education in Kerala, India. Social Analysis, 50 (3). 38-60.

Louis, P. (2003). Scheduled castes and tribes: The reservation debate. Economic and Political Weekly, 38 (25). 2475-2478.

Luttrell, W. (1997). Schoolsmart and motherwise: Working-class women's identity and schooling. New York: Routledge.

Massey, D. (1994). Place, space and gender. Minneapolis: University of Minnesota Press.

Merriam, S. (1998). Qualitative research and case study applications in education. San Francisco: Jossey-Bass.

McCall, L. (2005). The complexity of intersectionality. Signs, 30(3), 1771-1800.

Mohanty, C.T. (2003). Feminism without borders: Decolonizing theory, practicing solidarity. Chapel Hill, NC: Duke University Press. 
Mukundan, M. V., \& Bray, M. (2006). The decentralisation of education in Kerala State, India: Rhetoric and reality. Netherlands: Springer.

McDowell, L. (1992b). Doing gender: feminism, feminists, and research methods in human geography. Transactions of the Institute of British Geographers, 17, 399-416.

Miles, M. B., \& Huberman, A. M. (1994). Qualitative data analysis: An expanded sourcebook. Thousand Oaks, CA: Sage.

Moffitt, P., \& Vollman, A. R. (2004). Photovoice: Picturing the health of Aboriginal women in a remote northern community. Canadian Journal of Nursing Research, 36(4), 189- 201.

Mies, M. (1982). The lace makers of Narsapur: Indian housewives produce for the world market. London: Zed Press.

Mies, M., Bennholdt-Thomsen, V., \& Von Werlhof, C. (1988). Women: The last colony. London: Zed.

Mohanty, C. T. (2003). Feminism without borders: Decolonizing theory, practicing solidarity. Chapel Hill, NC: Duke University Press.

Mohanty, C. (1999). Women workers and capitalist scripts: Ideologies of domination, common interests, and the politics of solidarity. In S. Hesse-Biber, C. Gilmartin, and R. Lydenberg (Eds.), Feminist approaches to theory and methodology (pp. 362-388). New York: Oxford University Press.

McEwan, C. (2001). Postcolonialism, feminism and development: Intersections and dilemmas. Progress in Development Studies, 1(2), 93-111. 
Majid, A. (2012). Future of Untouchables in India: A Case Study of Dalit. South Asian Studies, 27(1), 263-285.

Menon, A. S. (1990). Kerala history and its makers. Kottayam: DC Books.

Menon, N. (Ed.) (1999) Gender and politics in India. New Delhi: Oxford University Press

Morrell, R. (2001) Corporal punishment and masculinity in South African Schools. Men and Masculinities, 4, 140-156.

Mitra, A., \& Singh, P. (2007). Human capital attainment and gender empowerment: The Kerala paradox. Social Science Quarterly, 88(5), 1227-1242.

Minh-Ha, T. T. (1989). Woman, native, other. Bloomington, Indiana: Indiana University Press.

Mangubhai, J. P., \& Lee, J. G. (2012). Dalit women speak out: Caste, class and gender violence in India. New Delhi. Zubaan.

Molyneux, M. (1985) Mobilization without emancipation? Women's interests, state and revolution in Nicaragua. Feminist Studies, 11(2), 227-254

Moser, C. (1993) Gender planning and development: Theory, Practice and Training. New York: Routledge.

Mukhopadhyay, S. (2007). Understanding the enigma of women`s status in Kerala: Does high literacy necessarily translate into high status? In S. Mukhopadhyay (Ed.), The Enigma of the Kerala Woman: A failed promise of literacy (pp. 2-27). New Delhi: Social Science Press. 
Narayan, U. (1998). Essence of culture and a sense of history: A feminist critique of cultural essentialism. Hypatia, 13(2), 86-106.

Nambissan, G. B. (1996). Equity in education? Schooling of Dalit children in India. Economic and Political Weekly, 31 (16/17). 1011-1024.

Nampoothiri. S (2004). Costs of Schooling in Kerala: A study of private and institutional costs under different types of management. Discussion Paper No. 77, Centre for Development Studies Thiruvananthapuram.

Nagar, R., Lawson, V., McDowell, L., \& Hanson, S. (2002). Locating globalization: feminist (re) readings of the subjects and spaces of globalization. Economic Geography, 78(3), 257-284.

Oberhauser, A. (1997). The Home as 'field': Households and homework in rural Appalachia. In Jones et al., Threshold in feminist geography: Difference, methodology, representation (pp. x-x). Lanham, MD: Rowman \& Littlefield.

Osella, C., \& Osella, F. (1998). Friendship and flirting: micro-politics in Kerala, South India. Journal of the Royal Anthropological Institute, 4 (2).189-206.

Osella, F., \& Osella, C. (1996). Articulation of physical and social bodies in Kerala. Contributions to Indian Sociology, 30(1), 37-68.

Preissle, J. (2007). Feminist research ethics. In S. N. Hesse-Biber, C. Gilmartin, and R. Lydenberg (Ed.), Handbook of feminist research: Theory and praxis (pp. 515-534). Thousand Oaks, CA: Sage.

Planning Commission. (2008). Kerala development report. New Delhi: Academic Foundation. 
Patton, M. Q. (2001). Qualitative research and evaluation (3rd ed.). Thousand Oaks, CA: Sage.

Paik, S. (2009). Caste, Gender and Education in India: The Experience of Dalit Women. New Delhi: Routledge.

Planning Commission. (2008). Kerala development report. New Delhi: Academic Foundation.

Padmanabhan, R (2010). Learning to learn Dalit education in Kerala. In Raman, K. R. (Ed.), Development, democracy and the state: Critiquing the Kerala model of development (pp.102-118). New York: Routledge.

Panda (2004). Domestic violence against women in Kerala. Discussion Paper No. 86. Thiruvananthapuram: Kerala Research Programme on Local Level Development Centre for Development Studies.

Proctor, L. M. (2015). “Boys must be beaten”: Corporal punishment, gender, and age in New Delhi Schools. Landscapes of Violence, 3(3), 3.

Parpart, J. L. (1993). Who is the "other"?: A postmodern feminist critique of women and development theory and practice. Development and Change, 24(3), 439-464.

Pandey, A. (2004). Culture, gender, and identity in cross-cultural personals and matrimonials. World Englishes, 23(3), 403-427.

Ramasubramanian, S., \& Jain, P. (2009). Gender stereotypes and normative heterosexuality in matrimonial ads from globalizing India. Asian Journal of Communication, 19(3), 253269. 
Rich, A. C. (1996). Cartographies of silence. Arizona. Kore Press.

Riessman, C. K. (2000). Stigma and everyday resistance practices childless women in South India. Gender \& Society, 14(1), 111-135.

Rajan, S., Irudaya, I \& Sreerupa (2007). Gender disparity in Kerala: A critical reinterpretation. In S. Mukhopadhyay (Ed.), The enigma of Kerala Women: A failed promise of literacy (pp. 33-71). Delhi: Social Science Press.

Razavi, S. (1999). Seeing poverty through a gender lens. International Social Science Journal, 51(162), 473-482.

Robinson, R. (2014). Minority rights versus caste claims. Economic \& Political Weekly, 49(14), 83.

Radhakrishnan, M. G. (2013, December 20). Lessons well learnt in Kerala. Retrieved March 8, 2016 from http://indiatoday.intoday.in/story/kerala-best-state-in-the-field-ofeducation/1/332173.html.

Reinharz, S. (1992). Feminist methods in social research. New York: Oxford University Press.

Rossman, G. B., \& Rallis, S. F. (2003). Learning in the field: An introduction to qualitative research. Thousand Oaks, CA: Sage.

Rycroft, D. J., \& Dasgupta, S. (Eds.). (2011). The politics of belonging in India: Becoming Adivasi. Oxon. Routledge.

Raman, K. R. (Ed.). (2010). Development, democracy and the state: Critiquing the Kerala model of development. New York: Routledge. 
Rao, N. (2014). Marriage, violence and choice: Understanding Dalit women's agency in rural Tamil Nadu. Gender \& Society, 10, 6-24.

Rao, A. (2003). Gender and caste. New Delhi: Kali for Women.

Rammohan, K. T. (2008). Caste and landlessness in Kerala: Signals from chengara. Economic and Political Weekly, 7(1), 14-16.

Raj, R. (2013). Dalit women as political agents: A Kerala experience. Economic \& Political Weekly, 17(18), 56-63.

Retnakumar, J. N., \& Arokiasamy, P. (2006). Explaining school enrolment trends in Kerala, India. Journal of South Asian Development, 1(2), 231-248.

Rege, S. (1998). Dalit women talk differently: A critique of difference and towards a Dalit feminist standpoint position. Economic and Political Weekly, 33 (44), 39-46.

Runyan, A. S., \& Marchand, M. H. (2000). Conclusion: Feminist approaches to global restructuring. In A. S. Runyan and M. H. Marchand (Eds.), Global Restructuring: Sightings, sites and resistance (pp. 225-230). London: Routledge.

Reader, S. 2007. The other side of agency. Philosophy, 82, 579-604.

Sangari, K. (1993). Consent, agency and rhetorics of incitement. Economic and Political Weekly, 28 (18). 867-882.

Still, C. (2011). Spoiled brides and the fear of education: honour and social mobility among Dalits in South India. Modern Asian Studies, 45(5), 1119-1146. 
Subrahmanian, R. (2007). Gender in primary and secondary education: A handbook for policymakers and other stakeholders. London. Commonwealth Secretariat.

Sinha, K. (2003). Citizenship degraded: Indian women in a modern state and a pre-modern society. Gender \& Development, 11(3), 19-26.

Stromquist, N. (2001). What poverty does to girls' education: The intersection of class, gender, and ethnicity in Latin America. Compare, 31(1), 39-56.

Sreekumar, S. (2009). Scripting lives: Narratives of dominant women in Kerala. Hyderabad: Orient BlackSwan.

Sreerekha, M. S. (2012). Illegal land, illegal people. Economic \& Political Weekly, 47(30), 21.

Saradamoni, K. (1994). Women, Kerala and some development issues. Economic and Political Weekly,4(8), 501-509.

Sen, A. (2000). Development as freedom. New York: Anchor Books.

Still, C. (2008). Dalits in the social justice revolution in India. Public Policy Research, 15(2), 9396.

Sujatha, D. (2014). Redefining domestic violence. Economic \& Political Weekly, 49(47), 19.

Spivak, G. C. (1988). Can the subaltern speak? In C. Nelson and L. Grossberg (Eds.). Marxism and the Interpretation of Culture (pp. 271-308). Urbana: University of Illinois Press. 
Tichy, L.L., Becker, J.V. \& Sisco, M. M. (2009). "The downside of patriarchal benevolence: Ambivalence in addressing domestic violence and socio-economic considerations for women of Tamil Nadu, India. Journal of Family Violence, 24, 547-558.

Thorat, S., \& Newman, K. S. (2007). Caste and economic discrimination: causes, consequences and remedies. Economic and Political Weekly, 4121-4124.

Thorat, S., \& Neuman, K. S. (2012). Blocked by caste: economic discrimination in modern India. New York: Oxford University Press.

Thresia, C. (2014). Social inequities and exclusions in Kerala's' egalitarian development. Monthly Review, 65(9), 28-38.

Vasavi, A. R. (2003). Schooling for a new society? The social and political bases of education deprivation in India. IDS Bulletin, 34(1): 72-80.

Williams, P., Vira, B., \& Chopra, D. (2011). Marginality, agency and power: experiencing the state in contemporary India. Pacific Affairs, 84(1), 7-23.

Wang, C., \& Burris, M. A. (1997). Photovoice: Concept, methodology, and use for participatory needs assessment. Health Education \& Behavior, 24(3), 369-387.

Wang, C. C. (2006). Youth participation in photovoice as a strategy for community change. Journal of Community Practice, 14(1-2), 147-161.

Weber, L. (2009). Understanding race, class, gender and sexuality: A conceptual framework. New York: Oxford University Press.

Xaxa, V. (2001). Protective discrimination: why scheduled tribes lag behind scheduled 
castes. Economic and Political Weekly, 36 (29), 2765-2772.

Yuval-Davis, N. (2006). Intersectionality and feminist politics. European Journal of Women's Studies, 13(3), 193-209.

Yin, R. K. (1994). Case study research: Design and methods (3rd ed.). Thousand Oaks, CA: Sage.

Yadav, N. (2006). Gender, caste and class in India. New Delhi: Pragun Publications.

Zinn, M, B. \& Dill, B. T. (2003). Theorizing difference from multiracial feminism. In C. L. McCann and S. Kim (Eds.), The Feminist theory reader: Local and global perspectives (pp. 353-361). New York: Routledge. 
Appendix A

INTERVIEW GUIDE AND ORAL QUESTIONNAIRE (MOTHERS AND DAUGHTERS)

Mother

Introduction/ Explanation of the study/ IRB/ Confidentiality/ Choose pseudonym

Background

Information about participant

Name/ Chosen Pseudonym:

Caste:

Religion:

Age:

Education (Formal):

......Primary School

.......Lower Primary (Classes I - IV)

.......Upper Primary (Classes V - VII)

........Secondary School

.......Secondary (Classes VIII - X)

........Higher Secondary School

.Higher Secondary (Classes XI - XII)

Education (Non-formal):

\section{Employment}

......Farmer ......Self-employed.....Government Job.........Laborer ..Other (Describe) 
Family members (Total number of family members= $\quad$ )

\begin{tabular}{|l|l|l|l|l|}
\hline Member/Relationship & Age & Sex & Education & Employment \\
\hline & & & & \\
\hline & & & & \\
\hline & & & & \\
\hline & & & & \\
\hline & & & & \\
\hline & & & & \\
\hline
\end{tabular}

What is your family's monthly income?

What are some of your weekly expenses?

\begin{tabular}{|l|l|l|l|}
\hline Expense & $\begin{array}{l}\text { How much do you } \\
\text { spend }\end{array}$ & $\begin{array}{l}\text { Who pays for these } \\
\text { expenses? }\end{array}$ & $\begin{array}{l}\text { Who makes decisions } \\
\text { about these expenses? }\end{array}$ \\
\hline & & & \\
\hline & & & \\
\hline & & & \\
\hline & & & \\
\hline & & & \\
\hline
\end{tabular}

How long have you lived in this house?

Do you own land? Do you own your house? 


\section{Describe your water source?}

\section{Sanitation facilities}

Single toilet

..Common use toilet

.Other

\section{Household Appliances}

.......TV

Radio

..Telephone/ Cell phone

...Electricity

Other

\section{Mothers}

Semi-Structured Interview Questions

- Do you identify as Dalit?

- What does it mean to be a Dalit woman?

- What are your primary responsibilities in the house? Describe.

- What are some of decisions that you make in the house?

- What decisions are you not allowed to make?

- Can you travel far distances by yourself? Can you visit friends and family by yourself?

- Do you feel safe when you travel?

- What are some of the issues and concerns that women face in this community?

- What are some of the assets and strengths of your community?

- What do you consider as "education"? What comes to your mind? 
- Did your family want you to study?

- Do you have siblings? Did they study?

- How long did you study? Where? What kind?

- What are some of the reasons for continuing/discounting your formal education or nonformal education?

- Is education important in your family? What did your family say about the value of education?

- What are some of the government schools in the area?

- What kinds of government schools? How far are they?

- What do you think of these schools? Do you or your children go to these schools? If not why?

- What are the strengths of these schools?

- What are weaknesses of these schools? What are the problems at the schools? (Do they have toilets? Solid roofs? Condition of the building?)

- What kind of curriculum do they have? What is the language of instruction?

- How are the teachers?

- Do the schools provide mid-day meals or uniforms or books?

- What about non formal education initiatives?

- Who runs them? What kinds of training do they provide?

- What are some of the spaces that you consider welcoming in your community? Why?

- What are some of the spaces that you do not consider welcoming? Why?

- What can the government do to improve the education in your community? What is the government doing well?

- Plans for the future? What are some of your hopes for yourself and your family?

\section{Daughter}

- How old are you?

- How long have you lived in this hamlet?

- Do you identify as Dalit? What does Dalit mean to you? 
- What is like to be a young Dalit woman? What is expected from you?

- Tell me about your family?

- What are some of the issues and concerns that girls face in this community?

- What are some of the assets and strengths of your community?

- What are some of your hopes for yourself and your family?

- Did your family want you to study?

- Do you have siblings? Did they study?

- How long did you study? Where? What kind?

- How often do you miss school? What are some of the reasons you miss school?

- Tell me about your friends at school? What do you like to do with your friends? Games, etc.?

- What is your school like? Tell me about a day at school.

- How are your teachers? What is the language of instruction?

- What is your favorite subject?

- What do you love about school? Is there anything that you dislike about school?

- What are some of your responsibilities at home? Describe your day to me.

- What are some of the reasons for continuing/discontinuing your formal education or nonformal education?

- Is education important in your family? What did your family say about the value of education?

- What do you consider as "education"? What comes to your mind?

- What are some of the spaces that you consider welcoming in your community?

- What are some of the spaces that you do not consider welcoming? Why?

- Plans for the future? What do you want to be when you grow up? 


\section{APPENDIX B}

\section{MALAYALAM TRANSLATION FOR INTERVIEW PROTOCOL

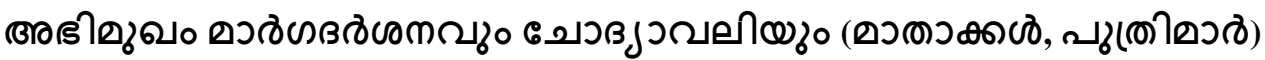

BDPO

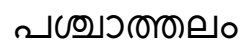

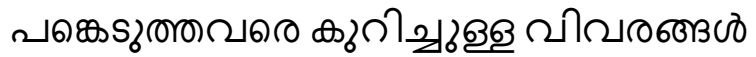

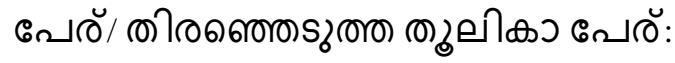

ஜวตา:

๑கை:

(๐)ツ०:

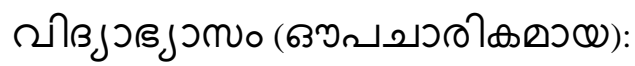

...... (ேวமவிக விв วอம。

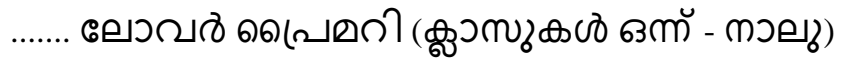

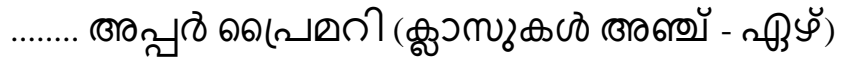

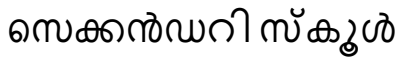

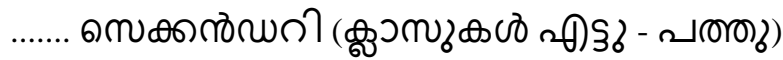

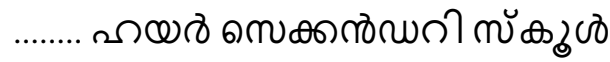

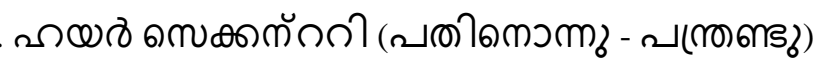

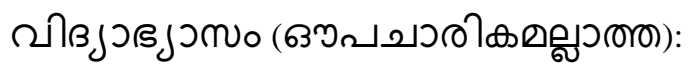

๑๐ைधीอ

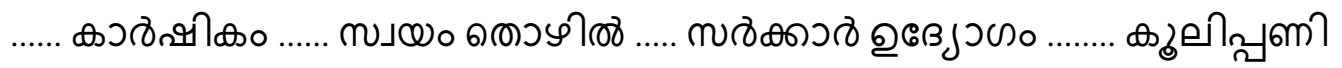

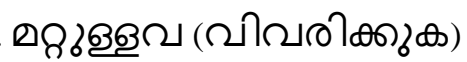

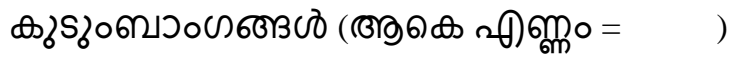




\begin{tabular}{|c|c|c|c|c|}
\hline 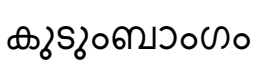 & (ـगळం & ৫ூளஸ̆/வேஸ̆ & 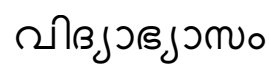 & கைசிக \\
\hline & & & & \\
\hline & & & & \\
\hline & & & & \\
\hline & & & & \\
\hline & & & & \\
\hline
\end{tabular}

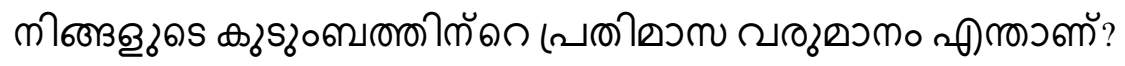

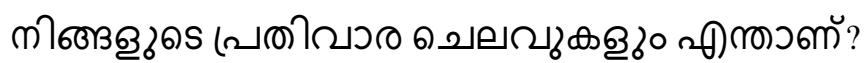

\begin{tabular}{|c|c|c|c|}
\hline 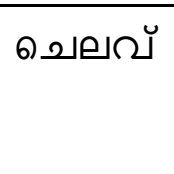 & 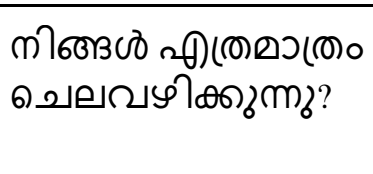 & 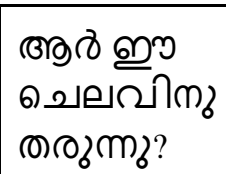 & 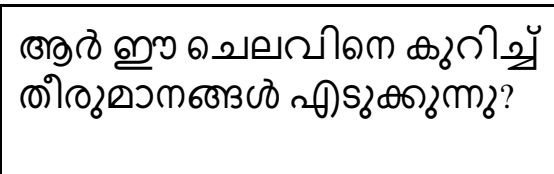 \\
\hline & & & \\
\hline & & & \\
\hline & & & \\
\hline & & & \\
\hline & & & \\
\hline
\end{tabular}

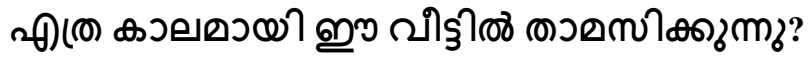




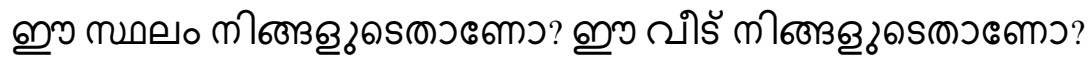

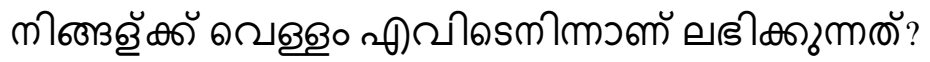

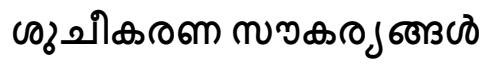

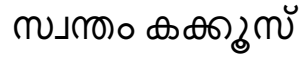

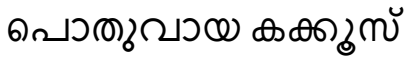

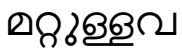

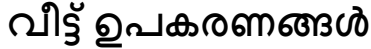

ડीกी

กேखीตே

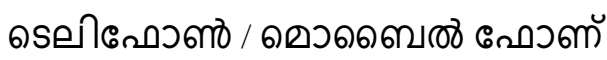

ถெณืรา

๑๐З६ญ

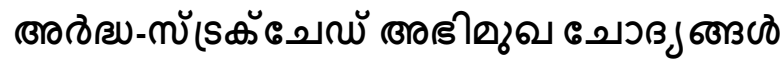

(৫)வ )

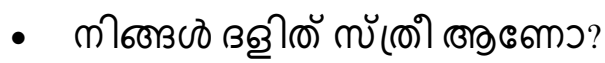

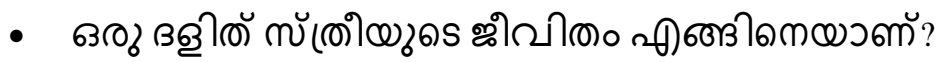

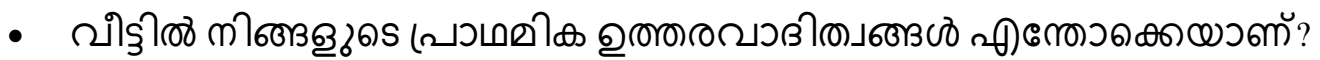
लीटणीक्ठक.

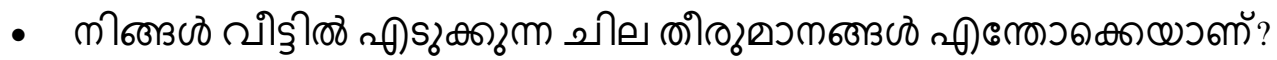

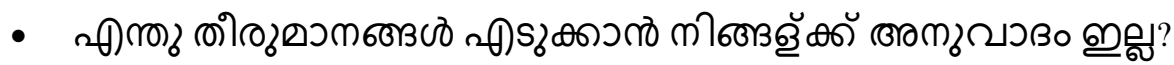

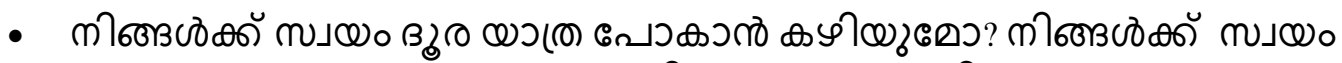

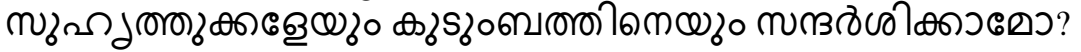

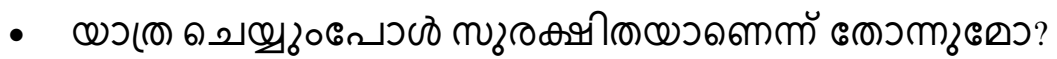

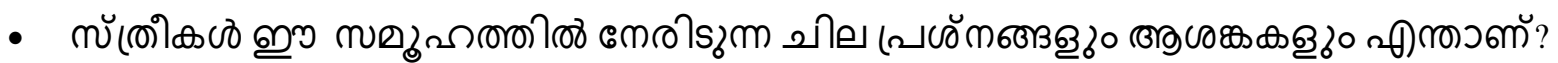




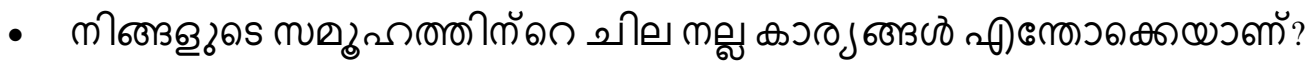

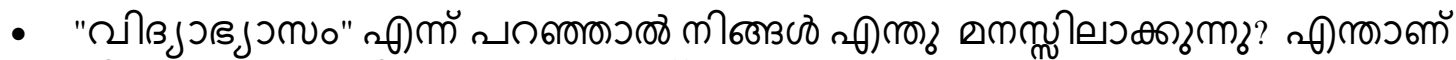

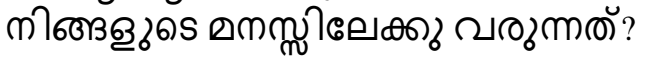

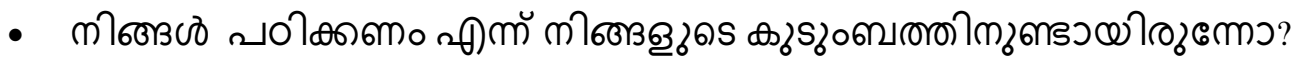

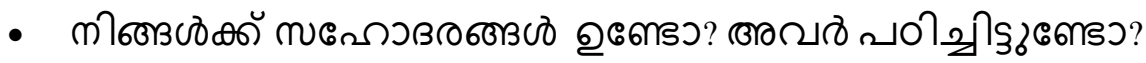

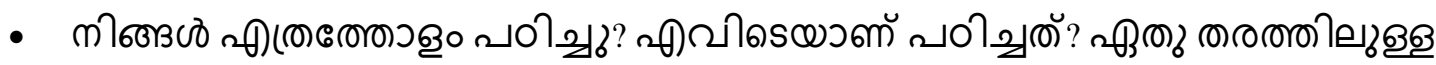
ऽOMo?

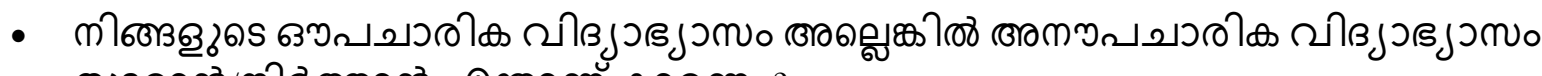
कुड

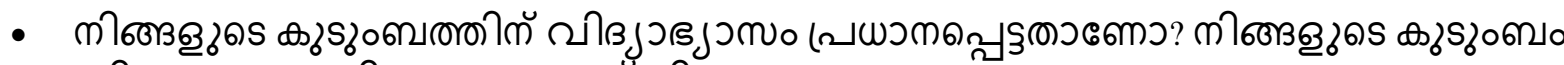

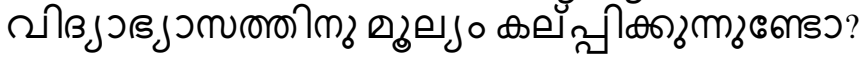

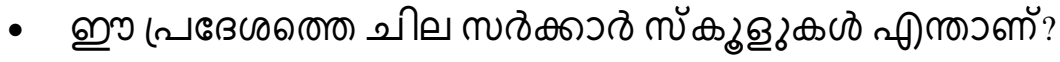

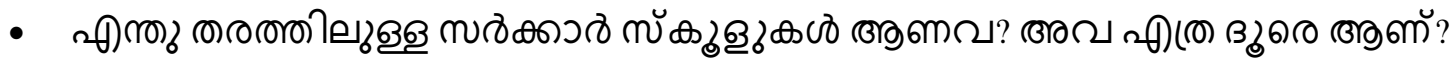

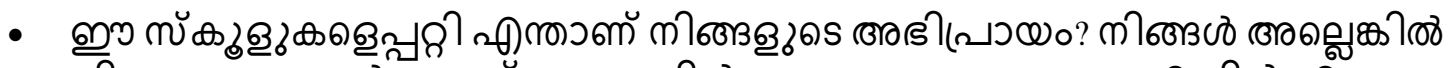

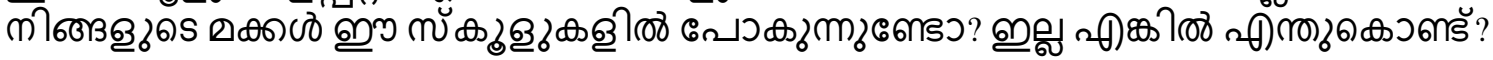

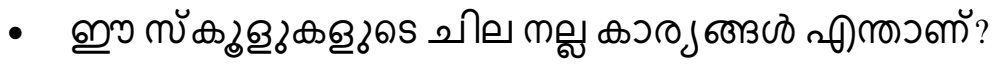

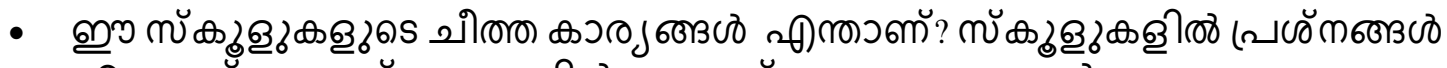

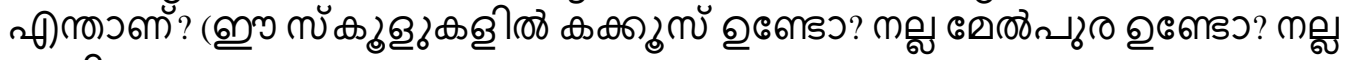

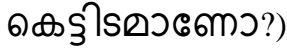

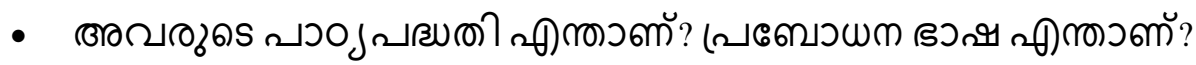

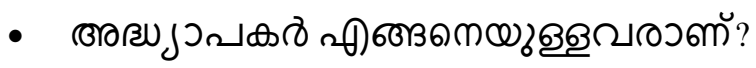

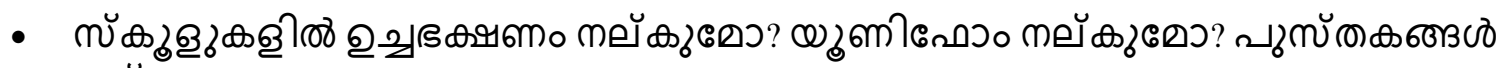

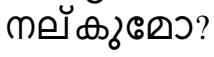

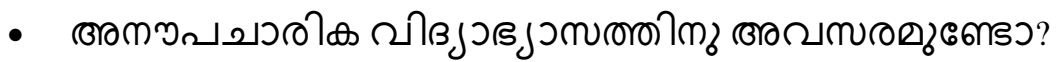

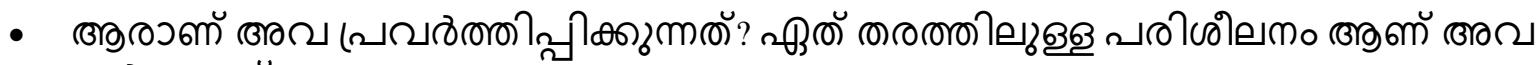

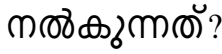

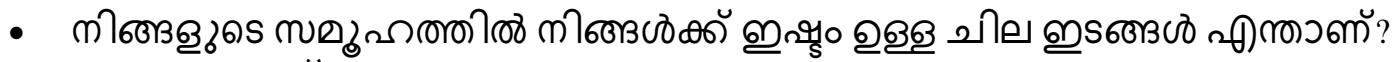

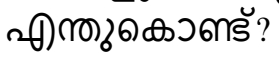

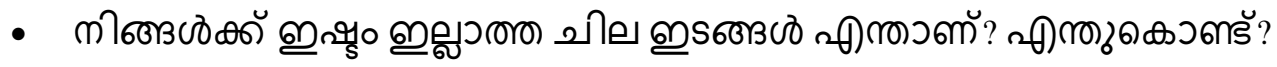

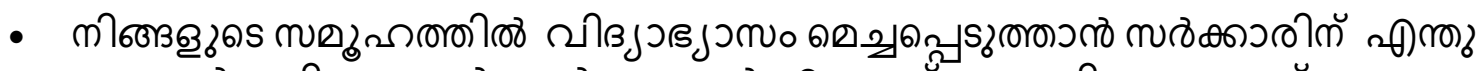

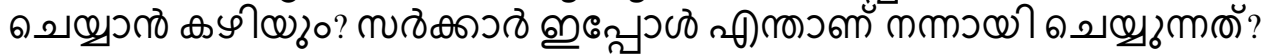




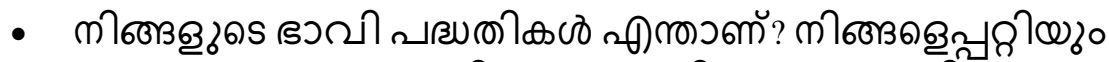

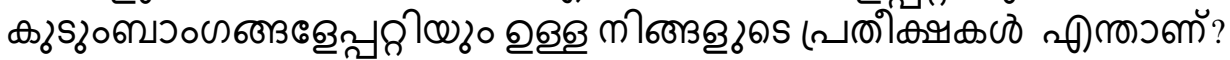

( - (ळ) $)$

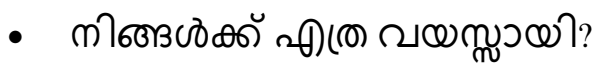

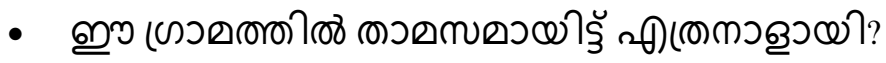

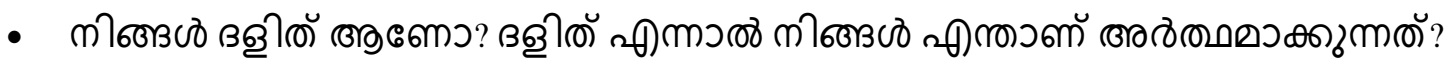

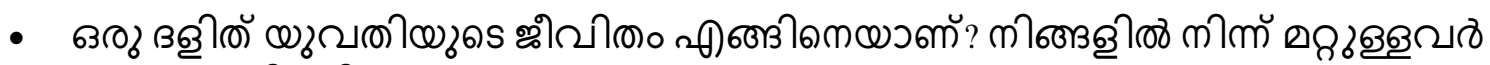

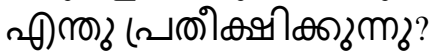

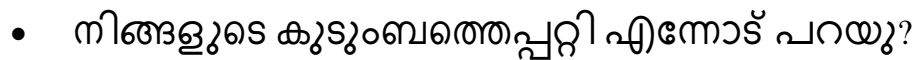

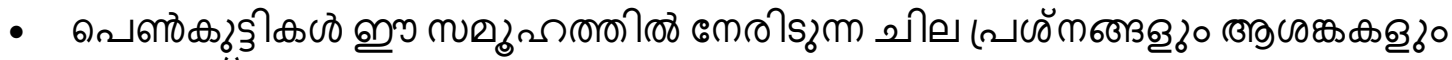

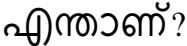

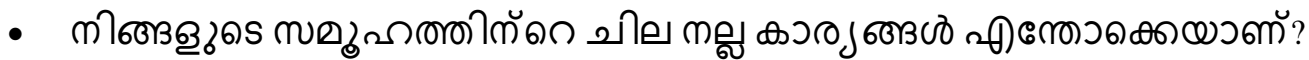

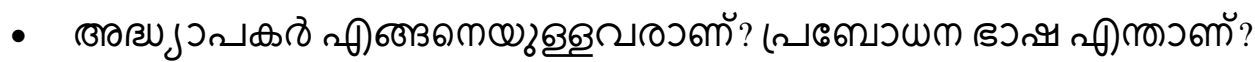

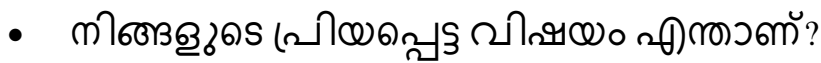

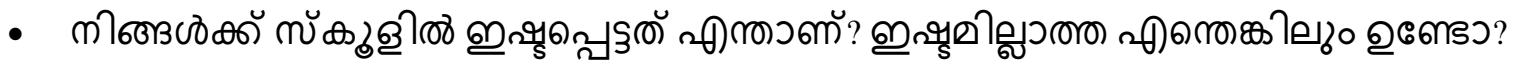

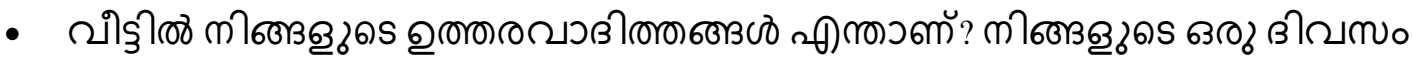

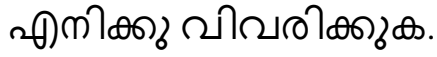

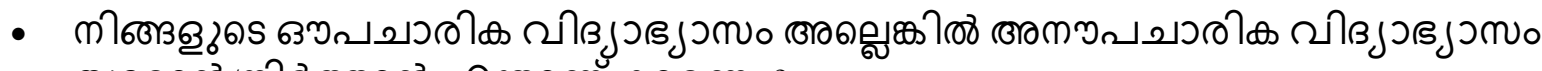

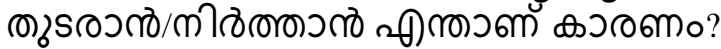

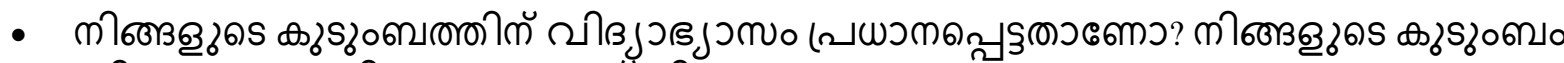

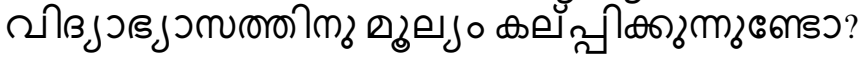

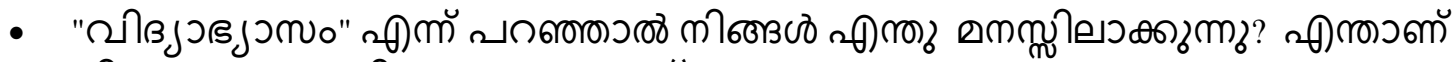

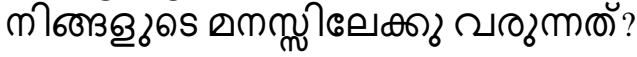

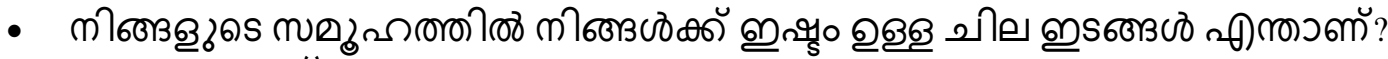

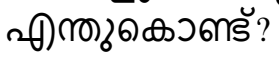

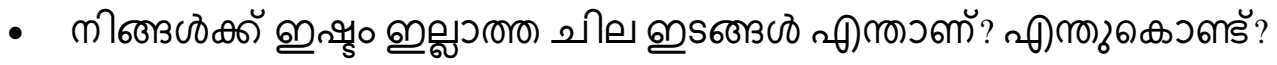

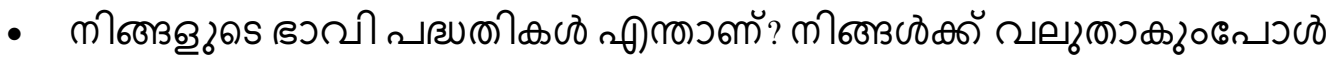

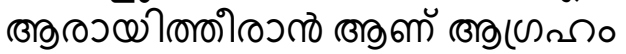




\section{APPENDIX C}

\section{PHOTOVOICE PROTOCOL}

Each participant will be trained in using the camera (turning it on, zooming, light) and camera ethics. Participation is voluntary and I will discuss risks/ benefits of participation and complete consent forms for participation and publish forms. These instructions have been adapted from (Wang, 2006; Wang \& Redwood-Jones, 2001).

This session will be begin with the following questions (Wang, 2006).

1. What is an acceptable way to approach someone to take their picture?

2. Whether you ought to take pictures of other people without their knowledge?

3. When would you not want to have your picture taken?

The following responsibilities of the participants will be discussed.

- Obtaining oral consent before taking photographs will be discussed. So when we're taking pictures you shouldn't take a picture of a person without their permission

- Informing participants about what can and cannot be photographed (difference between private and public) will be discussed.

Placing a person or place in a false light by twisting the truth to bring up ideas that are untrue about the person or place. (Wang \& Redwood-Jones, 2001). Thus, it is essential to be respectful and truthful about the photos you take. Telling true but embarrassing facts" (Wang \& RedwoodJones, 2001)

- Confidentiality must be maintained and respected.

Logistics of taking photos will be discussed:

- Initial ideas for photographs will be discussed. I will brainstorm initial themes.

- Time frame for taking photographs will be discussed

- Cameras will be distributed.

- At the end of the session, the participant will be asked to use the camera to document a response to the following question

What are the strengths and assets of your community?

Session \#2 after photographs are collected and printed. 
- Participants will select photographs that best address the question.

- Two sets of the photos will be made, one for the participants and one for the researcher, so participants have their own set of photos to keep if they choose to.

- Also if participants have some pictures but decide they don't want to show them for whatever reason they can always make that choice. There will be no negative consequences for them choosing not to show a photo

- Participants will contextualize photographs using the SHOWeD Method (Wang \& Burris, 1997; Wang, 2006).

$\checkmark$ What do you $\underline{\text { See here? }}$

$\checkmark$ What is Happening here?

$\checkmark$ How does this relate to our lives?

$\checkmark \quad$ Why does this situation, concern or strength exist?

$\checkmark$ What can we Do to improve the situation, or to enhance these strengths?

- Participants will code the themes that arise from the photograph 


\section{APPENDIX D \\ ORAL ASSENT FORM - CHILDREN}

\section{Advisor: Dr. Melissa Sherfinski \\ Student Researcher: Sera Mathew \\ Study Title: Dalit Women's Educational Experiences in Kerala, India}

Dear possible research participant,

My name is Sera Mathew. I am a post-graduate student at West Virginia University U.S.A. I specialize in women's education in Kerala, India, and as part of my work for a doctor of education degree, I am studying Dalit women and girls education in Kerala.

The purpose of this research project is to bring to light what Dalit women and girls think about their experiences in government run education programs. How does it meet your needs? What do they feel about it? I am asking that you to participate in this project because I believe you have a valuable perspective to offer.

The answers to these questions could be important for other Dalit women and girls in Kerala and around the country.

Your participation will entail interviews lasting about 60-90 minutes and will involve three interviews with me. Also, you will also be provided with a camera and will be requested to take photos of your community. You will be trained in using a camera by me and I will print the photos and bring them back for our interviews for us to discuss.

If you allow me to work with you, we will proceed under the following conditions:

- Interviews will be tape recorded so that nothing is missed and so words are not changed or misunderstood. You can turn off the tape recorder anytime you wish. You do not have to answer any questions that you don't want to answer and you may end the interview at any time you want

- The information from the research will be used in my research report, and publication. Your privacy and confidentiality will be protected and all identifying information will be 
removed. You should understand, however, that I will quote directly from our interviews but will not use your name in any part of the report.

- You will review the information I obtain so that you can discuss it with me and suggest modifications for accuracy, clarity, or new information. You will be active participants in the process of analyzing the information because I am interested in your perspective.

I appreciate your willingness to give your time to this project and helping me learn more about Dalit women's and girls' experiences of education in Kerala. If you agree to these guidelines and would like to participate in the research, please let me know.

Thank you for your consideration.

If you have any questions concerning your rights as a research subject, you may contact the West Virginia University Office of Research Integrity and Compliance

886 Chestnut Ridge Road

PO Box 6845

Morgantown, WV 26506-6845

Telephone: +1(304) 293-7073

E-Mail: Jonathan.Young@mail.wvu.edu 


\section{APPENDIX E}

\section{ORAL CONSENT FORM - ADULT DAUGHTERS AND MOTHERS}

\section{Advisor: Dr. Melissa Sherfinski \\ Student Researcher: Sera Mathew \\ Study Title: Dalit Women's Educational Experiences in Kerala, India}

Dear possible research participant,

My name is Sera Mathew. I am a post-graduate student at West Virginia University U.S.A. I specialize in women's education in Kerala, India, and as part of my work for a doctor of education degree, I am studying Dalit women and girls education in Kerala.

The purpose of this research project is to bring to light what Dalit women and girls think about their experiences in government run education programs. How does it meet your needs? What do they feel about it? I am asking that you to participate in this project because I believe you have a valuable perspective to offer. The answers to these questions could be important for other Dalit women and girls in Kerala and around the country.

Your participation will entail interviews lasting about 60-90 minutes and will involve three interviews. Also, you will also be provided with a camera and will be requested to take photos of your community. You will be trained in using a camera by me and I will print the photos and bring them back for our interview.

Your participation is voluntary. You do not have to answer any questions that you don't want to answer and you may end the interview at any time you want. The information that I 
gather from you will be presented in a report that describes Dalit women's educational experiences in Kerala and will be shared with others who are interested in knowing more about Dalit women's education. However, your answers will be completely confidential, which means your name will not be used and will never be used in connection with any of the information you tell me.

Pictures that are taken by you might also be used to help share these stories after the study is conducted. You will have the opportunity to state in another document whether you agree to include pictures taken by you in reports about Dalit women's education. You will review the information I obtain so that you can discuss it with me and suggest modifications for accuracy, clarity, or new information. You will be active participants in the process of analyzing the information because I am interested in your perspective.

I believe there are no known risks associated with this interview; however, a possible inconvenience may be the time it takes to complete the interview. If at any point you feel uncomfortable, they can let me know and we can end the session. I appreciate your willingness to give your time to this project and helping me learn more Dalit women's experiences of education. If you agree to these guidelines and would like to participate in the research, please let me know.

Thank you for your consideration.

If you have any questions concerning your rights as a research subject, you may contact the West Virginia University Office of Research Integrity and Compliance at (304) 293-7073 
886 Chestnut Ridge Road

PO Box 6845

Morgantown, WV 26506-6845

Telephone: +1(304) 293-7073

Fax: (304) 293-3098

E-Mail: Jonathan.Young@mail.wvu.edu 


\section{West VurginiaUniversity.}

Office of Reseurch Integrity and Compliance

\section{Approval Letter Expedited}

To

From

Action Date

Approval Period

Subject

Protocol Number

Title
Melissa Sherfincki

WVU Office of Research Integrity and Compliance

01/26/2015

01/26/2015 Expiration Date 01/25/2016

Protocol Approval Letter

1501534412

Dalit Women's Educational Experiences

The above-referenced research study was reviewed by the West Virginia University Institutional Review Board IRB and was approved in accordance with 46 CFR $46.101 b$.

It has been determined that this study is of minimal risk and meets the criteria as defined by the expedited categories listed below:

" Category 6. Collection of data from voice, video, digital, or image recordings made for research purposes.

" Category 7. Research on individual or group characteristics or behavior (inchuding, but not limited to, research on perception, cognition, motivation, identity, language, communication, cultural beliefs or practices, and social behavior) or research employing survey, interview, oral history, focus group, program evaluation, human factors evaluation, or quality assurance methodologies. [NOTE: Some research in this category may be exempt from the DHHS regulations for the protection of human subjects. See Exempt Categories and 45 CFR 46.101(b)(2) and (b)(3). This listing refers only to research that is not exempt]

Documents for use in this study are available in the WVUke system in the Notes and Attachments section of your protocol

The Office of Research Integrity and Compliance is here to provide assistance to you from the initial submission of an IRB protocol and all subsequent activity. Please feel free to contact us by phone at 304.293 .7073 with any question you may have. Thank you.

WVU Office of Research Integrity and Compliance

Date: 01/26/2015 